THE INTERNATIONAL

REVIIEW OF RESEARCH IN

OPEN AND DISTANCE LEARNING

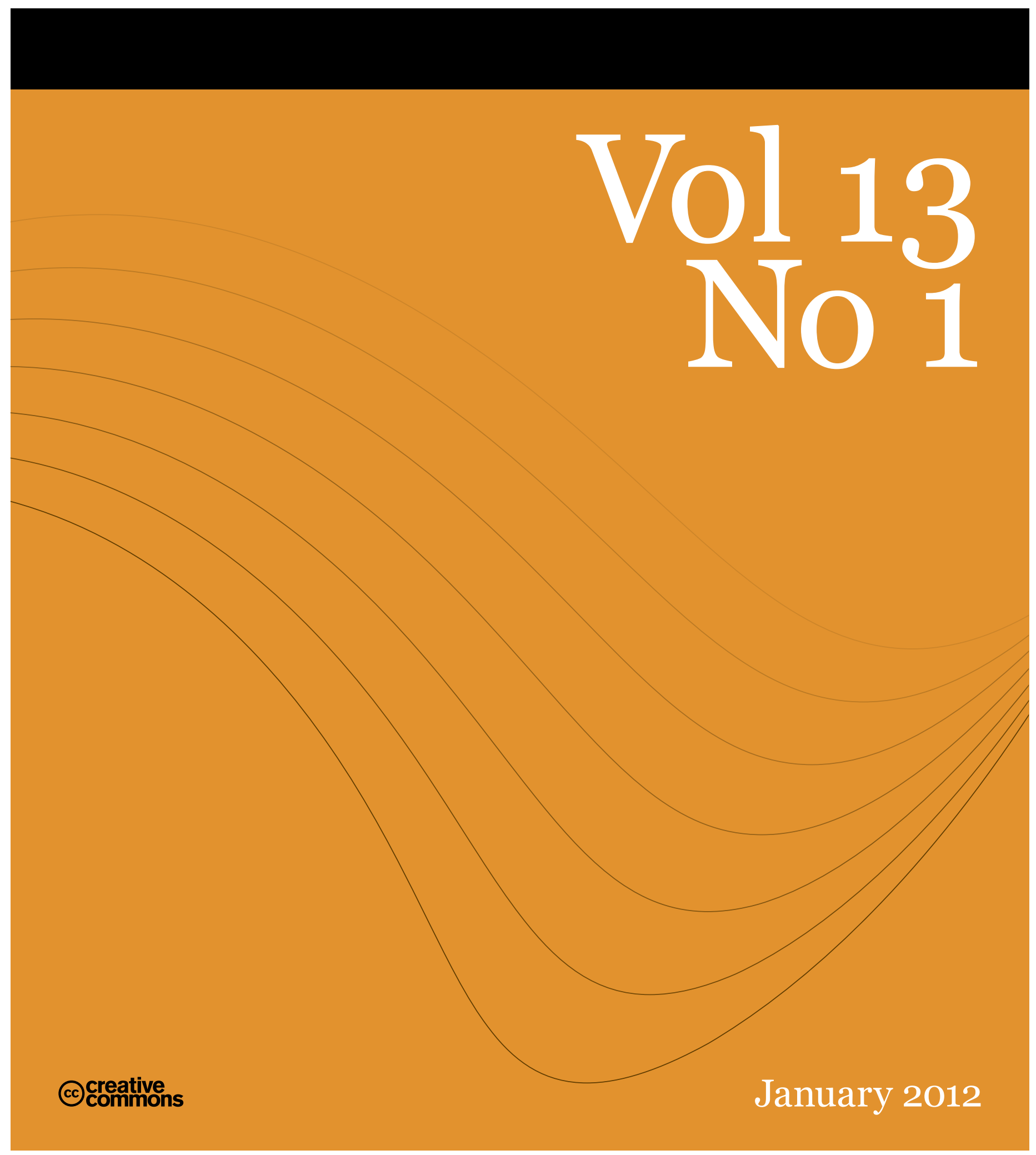


THE INTERNATIONAL

REVIEW OF RESEARCH IN

OPEN AND DISTANCE LEARNING

\section{Editorial - Volume 13, Issue Number 1}

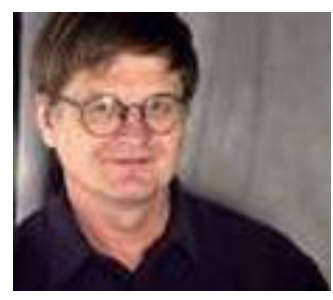

Terry Anderson Editor, IRRODL

Best wishes to all IRRODL readers, editors, reviewers, and authors. We are very pleased to start the new year off with a large IRRODL issue that contains 15 articles.

I want to do three things with this editorial. The first is to summarize IRRODL's position and influence with respect to the growing interest in, and use and adoption of, open scholarship. The second is to help clarify the different sections in IRRODL for the benefit of authors as well as readers. Finally, as usual, I offer a brief overview of the contents in this issue.

\section{Open Scholarship}

I have had the privilege of delivering a number of keynote talks on open scholarship (sample slides at http://www.slideshare.net/terrya/follow-the-sun-2011). I find that it takes more and more slides to even touch on all of the initiatives that are exploding under the general theme of open scholarship. But this is welcome news as each new open access development complements the others in a growing network of expertise and commitment to using, developing, and, of course, sharing open resources. I won't dwell more than in passing on open source software - the success stories of projects such as Moodle, Linux, or Apache, or the failed projects such as SourceForce that litter repositories. However, there is no doubt that open source software can be developed with both commercial and social success. There is certainly much to learn about leadership, networking, team building, and economics from these earliest open projects.

Of perhaps greatest interest to IRRODL readers are open educational resources (OERs). We continue to see developments in the repositories, in government and institutional policy, and in the quantity of both tools to create (for example, Apple's new iBooks Author) and to distribute open learning content. More recently, we are witnessing the development of programs from both existing institutions and completely new institutions that are de- 
signed to exploit OERs. You have likely heard the buzz from MIT with the addition of their credential-light tool set and the emergence of OERu consortium, which seeks to both create and credential learning achieved through use of OER content. The People's University, with the moniker "World's first Tuition-Free University," continues to expand its programming, while Khan Academy diversifies and adds staff from ad-generated revenue.

Open Access publishing thrives as demonstrated by the seven issues produced by IRRODL last year and the increasing number of open access journals listed on Directory of Open Access Journals (currently over 7,00o journals with 230 from Canada alone). We also note the continuing increase in the number of journals hosted using the open source Open Journal System, the platform used to manage and host IRRODL.

Open Science thrives as well, forecasting a future in which science is an activity not just for men in white lab coats, but one that engages and benefits a global population. Open data initiatives abound, allowing citizens access to government data and the capacity to manipulate, display, track, and mash data from a wide variety of public and private sources. Of course, open publication through blogs and wikis also thrives, bringing a voice to millions of Earth's guardians-as well as diverse political propagandists.

No doubt this list could and will be expanded as open initiatives continue to gather support and we get better at developing and managing open resources and communities. I won't suggest that we have solved the sustainability challenges associated with many open initiatives, but these initiatives prove that open access is critically important to a world that needs to act more intelligently, to create more equal opportunity, and to more equitably share our finite resources.

We are proud to be playing one small but active part in the Open Scholarship movement, and as a reader, author, editor, or reviewer for IRRODL, we hope you share this sense of contribution and community as well.

\section{Component Sections of IRRODL}

As an evolving open journal, IRRODL is regularly developing new sections in order to find an appropriate place and category for each of the diverse contributions submitted for publication. This can be a bit confusing, so I want to share our understanding of the various sections and invite your contributions to or comments on any of these.

Research Articles: Articles in this section have all been rigorously blind reviewed by at least two peer reviewers. These works must show high qualities of scholarship, rigour, and originality. Research articles usually contain new data, but occasionally exceptionally strong theoretical pieces and literature reviews are published in this section.

Research Notes: Sometimes we get submissions that will likely be of interest to the distance education community but that do not provide the rigour or completeness of a full research article. These may also be papers announcing new or ongoing research projects. Many of these articles are peer reviewed, but some are edited only by the editor and copy 
editors.

Field Notes: Similar to research notes, these submissions usually lack the literature review, theoretical grounding, or empirical results of a full research article, but they are likely of interest to our readers.

Technical Notes: Since distance education is, by definition, enmeshed in some type of communications technology, many of our readers appreciate being informed of developments in appropriate new technology. This section provides an outlet for such reviews. Many of these articles are written by graduate students, and they are usually edited by faculty members but are normally not subjected to blind peer review.

Article Notes: Scholarship is based on discussion and debate. Thus occasionally we get well-argued reactions to previously published research articles, which we print in this section. We occasionally ask for a response to the response from the authors of the original articles, but articles in this section are also not peer reviewed.

Book Notes: As is common in many journals, IRRODL publishes reviews of books that are particularly relevant to our field. Some of these are solicited by our Book Notes editor, but we also appreciate unsolicited reviews of recently published books that are relevant to open and distance learning.

\section{Issue 13(1)}

This is a general issue that contains 12 articles and three notes.

The first research article presents a case study of a set of content objects from one of the most successful open educational resource (OER) projects. "An Open Education Resource Supports a Diversity of Inquiry-Based Learning" documents the use and impact of music OERs from the Connexions repository. As the author notes, making OERs available is one thing, but understanding or even knowing about their use in different contexts is another challenge all together.

The next article is from faculty at the Open University of Israel and is entitled "Toward a CoI Population Parameter: The Impact of Unit (Sentence vs. Message) on the Results of Quantitative Content Analysis." This is a quantitative article that examines the impact of the unit of analysis on computer conference transcript analysis. This is an area dear to my heart as it reminds me of the challenges we faced with this issue when developing and validating the community of inquiry in the late 1990s. This issue is still not fully resolved, but is greatly informed by this article.

Every good teacher tries to match his or her instruction and learning activities with the capabilities and background of the learners. This is sometimes challenging at a distance where opportunities for informal assessment and feedback may be limited. Thus "Pretesting Mathematical Concepts with the Mobile Phone: Implications for Curriculum Design" is a useful guide and exploration of the challenges and benefits of assessing prior understand- 
ing by the use of mobile phones.

Heutagogy, along with connectivism and the pedagogy of nearness, was the first formal learning theory that was explicitly based on the affordances of a ubiquitous Internet. In "Heutagogy and Lifelong Learning: A Review of Heutagogical Practice and Self-Determined Learning," the author takes us back over the first decade since the development of heutagogy and revisits its potential to guide learning design and activities.

We present two articles that focus on an area of huge potential and many challenges-that of providing science teachers and professional development for them to schools in rural Zimbabwe. "Science Teacher Training Programme in Rural Schools: An ODL Lesson from Zimbabwe" reviews the challenges and innovations in bringing much-needed professional development to rural schools in Africa and suggests the need to train and recruit local teachers, rather than outsiders, for this important job. The second, "Challenges of Virtual and Open Distance Science Teacher Education in Zimbabwe," looks at similar challenges in a different province, this time dealing with practicing teachers. Together these articles paint a stark but promising picture of the importance of open and distance learning in a region facing many challenges and opportunities.

Despite the huge and growing influence on and time committed to social networking, these technologies are little used in distance- or campus-based formal education systems. This issue features two articles focusing on issues of adoption. "Investigating Instructional Strategies for Using Social Media in Formal and Informal Learning" illuminates the concerns, fears, and challenges of teachers as well as the potential of deeper integration of these media into formal education. "Online Social Networks as Formal Learning Environments: Learner Experiences and Activities" notes the attitudes of learners and reinforces the need to bring informal technologies into the formal assessment process if effective use is to be made by our often instrumental learners.

We also feature two articles focused on teachers in virtual schools. Loneliness is an experience of many distance learners, but distance teachers also need to overcome many professional, technical, and academic challenges. "Rapport in Distance Education" details the concerns, and strategies for alleviating such concerns, of a sample of Canadian distance education teachers. The second article, "An Investigation of Communication in Virtual High Schools," documents the efforts made by teachers to maintain interest and commitment of school-age distance learners.

In "Connectivism and Dimensions of Individual Experience," the authors examine behaviour and interactions in a massive open online course (MOOC). This recent evolution of distance learning allows scalability, yet relies on individual motivation and commitment to learn. The authors examine the dimensions of individual experience in connective environments and explore the meaning of autonomy, connectedness, diversity, and openness.

Despite the growth of global learning resources and the networks to distribute them, learning is always a localized experience. "The Implications of the Local Context in Global Vir- 
tual Education" provides a useful analysis and suggestions for exploiting, rather than ignoring, the cultural context within which all learning-even that developed elsewhere-must operate.

We present one note from the field exploring the challenges of moving to a new learning management system or virtual learning environment, "Learning Management System Migration: An Analysis of Stakeholder Perspectives." This study will be useful for any institution facing the challenges of changing the major platform for its distance or blended learning delivery.

The research note compares successful distance learners to those who did not qualify to write a final examination in a distance delivery engineering program in Sri Lanka. "Motivating Factors that Affect Enrolment and Student Performance in an ODL Engineering Programme" examines the prior experiences, attitudes, qualifications, and knowledge that were associated with positive and negative outcomes.

In the final section, Article Notes, the principal creator of the community of inquiry model, Randy Garrison, writes a response to "Social Presence within the Community of Inquiry Framework," an article by David Annand that was published in IRRODL, 12(5). Dr. Garrison, perhaps not surprisingly, is critical of Annand's analysis, largely because of differing epistemological assumptions of learning and knowledge construction. This is an old debate, but it is brought to light with the development of what Jon Dron and I (2011) referred to as three different generations of distance education pedagogy-all of which are thriving and have strong adherents within our scholarly and practitioner communities.

We hope you enjoy and learn from all of these contributions, and I invite you to share your responses and appreciation of these gifts with the authors.

\section{Athabasca University $\mathbf{A}$}

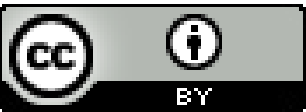


THE INTERNATIONAL

REVIEW OF RESEARCH IN

OPEN AND DISTANCE LEARNING

\section{An Open Educational Resource Supports a Diversity of Inquiry-Based Learning}

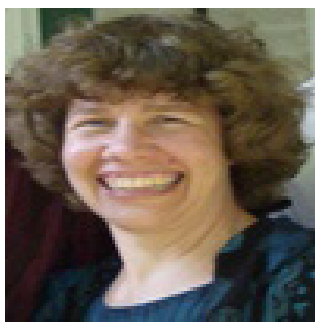

Catherine Anne Schmidt-Jones University of Illinois Urbana-Champagne, USA

\section{Abstract}

There have been numerous calls for research that demonstrates how open education resources (OERs) are actually being used. This case study sought to shed light on the users of a well-visited set of modular music-education materials published at Connexions. Respondents to a voluntary survey included teachers, students, self-directed learners, music ensemble participants, and casual learners. Most reported accessing individual modules on their own initiative, as part of a specific, immediate inquiry, rather than responding to institutional directives or following entire online courses. This was supported by computer-log records, which showed that most visitors to a module arrived from an Internet search for terms specific to that module. The study suggests that, for teachers and students as well as self-directed learners, one function of OERs is as a resource for just-in-time, inquiry-based learning.

Keywords: Open education resource; OER; learning objects; inquiry-based learning; justin-time learning; case study; survey; Connexions

\section{Introduction}

There have been numerous calls for research into the real-world effects of online openeducation resources (OERs) on teachers and learners. Walker (2008), for example, has noted that proponents of open education are increasingly being asked to provide evidence of concrete gains in meeting learning objectives. Kanwar et al. (2010) found:

....a dearth of systematic empirical data to help answer the following questions: Who uses OER and for what purpose? What is the impact of the OER? To what extent have OER engendered changes in teachers' professional 
practices? Have OER led to improvements in the quality of learning and learning outcomes? (p. 72)

Iiyoshi and Kumar (2008) have also called for research into the value and impact of open education, stating,

... one of open education's most critical questions - how can open educational tools, resources, and knowledge demonstrably improve educational quality? - is rarely mentioned or explored. Unfortunately, this omission from the conversation and action mirrors the education community's serious lack of engagement in investigating the transformative potential of open education. (p. 429)

The challenge of exploring real-world uses is complicated by the partial nature of the available data. Computer logs indicate numbers of visits to a resource, but not educational outcomes. Voluntary surveys can indicate educational benefits for respondents, but not whether respondents are typical of all visitors. Statistical studies yield persuasive data about the use of an OER by one population, but, as this case demonstrates, the very openness of an OER means that it may be affecting many different, widely dispersed populations. Also, data gathered about one OER cannot be assumed to be relevant to another. OERs can vary in a number of important ways as demonstrated by the contrast, outlined below, between just two of the wide variety of resources available. Numerous studies will be needed to provide enough "data points" to begin to develop a well-rounded understanding of the effects of OERs in the real world.

This case study is meant to be one such data point. I gathered both survey and computerlog data about a highly visited, modular, music-education resource. The results suggest that, although the modules were organized into online courses, most users were accessing modules individually through search engines. Even visitors who were formally teaching or studying the subject appeared to be using this OER as a resource for self-directed inquiry. From Dewey (1938) to Freire (1970) to Knowles (1984), many researchers and theorists have suggested that education organized around the learner's present problems and interests is highly motivating and effective. One powerful consequence of near-constant access to extensive online resources is the ability to easily conduct an extensive inquiry around nearly any problem or interest (Cope \& Kalantzis, 2009). Calls to assess the impact of OERs (such as those quoted above) often focus on use by educators, but educators are often reluctant to adopt technology. As Hennessy, Ruthven, and Brindley (2005) have shown, even teachers who are enthusiastic about adopting technology in the classroom experience significant barriers, including lack of access to equipment, reliability issues, lack of training and support, insufficient time for instruction in both subject matter and technology use, and policies that limit use of technology during testing and assessment. The results of this study suggest that the most significant educational effects of this set of materials may be due to informal rather than classroom-based use. Although these results are not generalizable, the widespread use of the Internet for informal inquiry-based learning, combined 
with current constraints on formal, classroom-based uses, suggests that it is possible that informal use may be a significant source of the educational impact created by many OERs.

\section{Method}

This case study focused on 103 music-education modules published at Connexions (see http://cnx.org/). Connexions is a large and fast-growing (Ochoa, 2010) online repository and management system for educational materials. It is supported by Rice University, but is freely available to any educator who wishes to publish or manage content at the site. Authors are encouraged to publish materials in short modules, and site-based tools and Creative Commons licensing ensure that modules can easily be viewed, downloaded, altered, rearranged and reused in new courses at the site, or republished elsewhere, as needed, by any educator or learner.

The Connexions modules that were part of this study varied in format (textbook, encyclopedia entry, and lesson plan), in content area (Western music theory and notation, acoustics, and ethnomusicology), and in content level (from music novice to specialist). They are published individually but are heavily interlinked and arranged into multiple overlapping courses.

Numbers from this study cannot be generalized to any population; instead, the implications of the case arise from the fact that a very large number of people who chose to look at a resource were offered an opportunity to comment, and a wide variety of users responded. During the six months that I collected computer-log data, a total of 627,521 visits were recorded for all modules. Modules varied greatly in popularity, ranging from over 3,000 visits per month for some of the basic music theory texts to fewer than 10 visits per month for some of the lesson plan modules. Because I was interested in visitors' reactions to the materials, the invitation to participate in the survey was at the end of each module, and so would only have been noticed by relatively engaged users who had at least skimmed through an entire module. The 488 respondents who completed the survey were less than a tenth of a percent of all visitors, but, as Fowler (1993) has explained, such non-statistical surveys can be useful for exploring the "range of ideas or opinions that people have or the way that variables seem to hang together" (p.10). I took this exploratory-case-study approach, searching for common patterns and issues. For the sake of clarity, the percentages reported below are percentages of all completed surveys $(N=488)$ or of all logged visits $(N$ $=627,521)$. When a number might be interesting either as a percentage of one category of respondents or as a percentage of all respondents, I report it as a number of respondents rather than a percentage.

The research question was: Who uses these materials, for what purposes? The survey was voluntary and anonymous. Available from March 2010 to March 2011 through a link (to Survey Monkey) at the end of each module, the survey gathered some demographic data (age, gender, and country of residence), but focused mainly on the respondents' music-education background, reason for accessing the materials, and opinions about the materials. 
(See survey instrument at http://cnx.org/content/m34234/latest/.) The survey was the focus of the study, but for 6 months during the survey (from mid-April to mid-November 2010), I also collected computer-log data about all visits, focusing on the number, source (for example, search term or referring site), and country of origin of visits to each module. I compared those results to the number and country of origin of survey responses for each module, looking for evidence of ways in which survey respondents did or did not appear to be representative of all visitors.

\section{Analysis}

\section{All Respondents}

Reported ages ranged from 11 to 87 years, with a mean of 37 (see Figure 1). The age distribution was somewhat skewed towards younger people, but interest among older learners was also strong. Respondents describing themselves as students ranged in age from 11 to 73 years (with a mean of 26), and those describing themselves as self-directed learners ranged from 12 to 87 years (with a mean of 38). The male-female ratio of respondents was $55 \%-45 \%$.

Figure 1. Age Distribution of Respondents

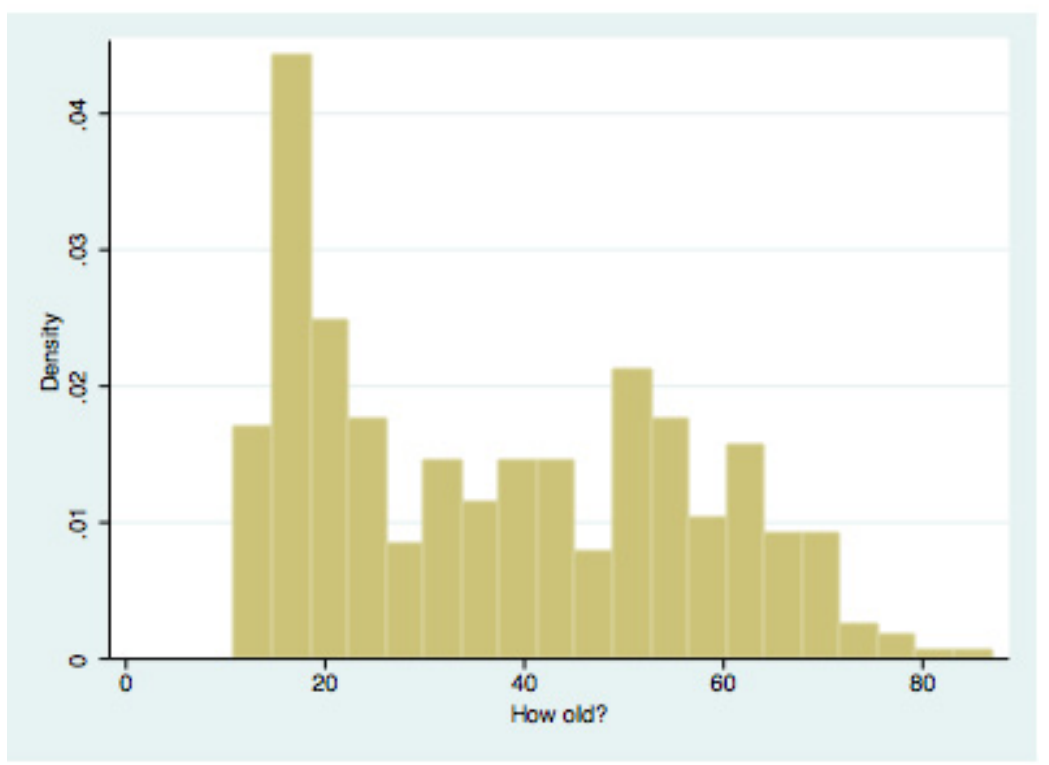

Visits from 117 countries were logged, and survey responses arrived from 41 of those countries. For the seven countries that generated large numbers of visits, the proportion of survey responses was similar to the proportion of all visits, with the exception of the Philippines, which generated a large percentage of visits but few survey responses (see Figure 2). 


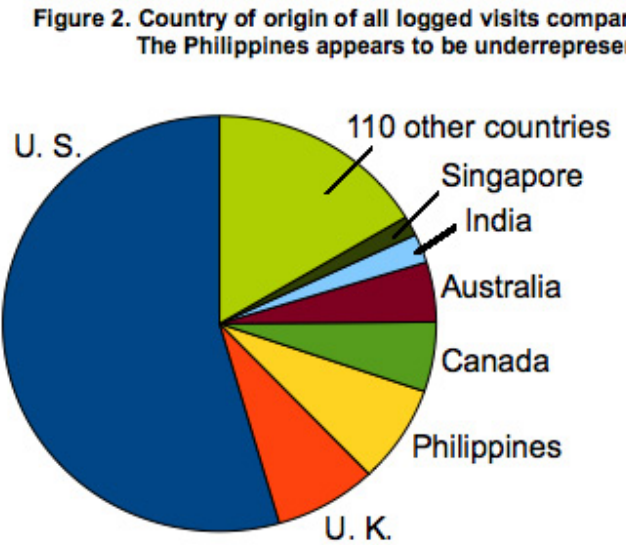

All Visits

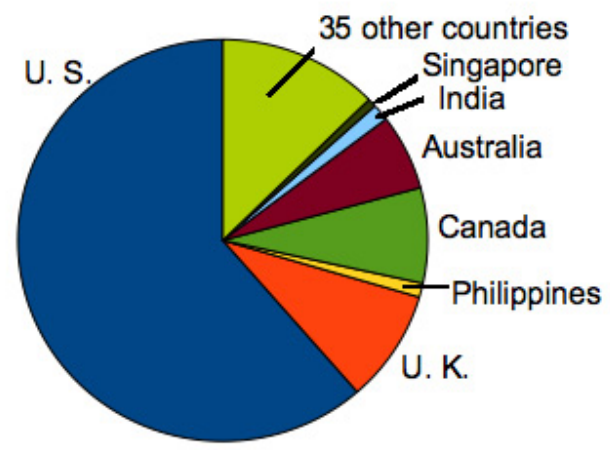

Survey Responses

Survey responses suggested that visitors came from a wide variety of educational situations. Music learning can take place in very different contexts. Music classes and lessons typically involve explicit instruction, similar to classes in other subject areas. However, many learners choose to study music primarily, or entirely, within the context of an ensemble. Ensemble is a general term referring to any group of musicians that play together, including school bands, youth orchestras, church choirs, and teen-organized "garage bands." As Wenger (1998) has described, learning often takes place within communities of practice, in which understanding is gained through a "process of being active participants in the practices of social communities and constructing identities in relation to these communities" (p. 4). Music ensembles often function as Wengerian communities of practice. Participants are mutually engaged in an endeavor, for example preparing to perform together, and teaching and learning take place as an integral part of that endeavor.

Finally, as evidenced by the many "Teach Yourself to Play..." books available, there are also music learners who are working on their own, without regular opportunities to learn directly from other musicians. The survey used the music-learning venue as a way of categorizing respondents under the assumption that such contexts probably have important effects on the users' music-education needs and goals. In a multiple choice question, respondents were asked to choose a self-description indicating their reason for looking at the materials. An open-ended question then requested details about the multiple-choice response (see Figure 3). 


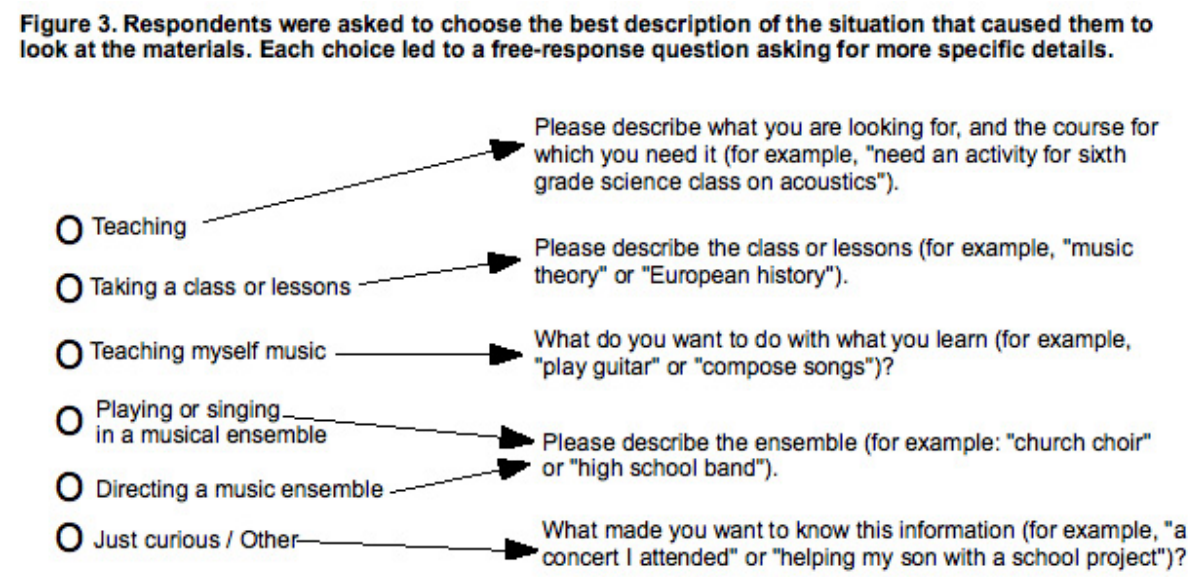

Reported benefits were spread fairly evenly among the respondent categories. The survey asked respondents to rate how helpful they had found the module, on a 5-point scale from "not at all" (=1) to "extremely" $(=5)$ helpful. The mean of 3.998 corresponded very closely with "very helpful" $(=4)$. Means within each category were close to the overall mean, ranging from 3.84 (among students) to 4.20 (among teachers).

\section{Self-Directed Learners}

Self-directed learners were the largest group of respondents (190, or $39.26 \%$ of respondents). This group also appeared to be the most deeply engaged with the materials; over $55 \%$ of the respondents who reported visiting the materials multiple times in the previous year were self-directed learners.

Common goals mentioned by self-directed learners included the following:

- improving performance skills (94 respondents);

- improving composition/arranging skills (36);

- improving both performance and composition skills (23);

Goal descriptions included the following:

- I'd like to analyse the works of the great and, probably, "different" composers, like Debussy, Wagner, Ravel and the works of the great jazz composers in order to compose and play new and somewhat "different" music myself. (age 17, Moldova)

- I play piano, want to learn to transpose on the fly. (age 51, U.S.)

- Arranging a piece, as a wood wind player, I am not familiar with ranges, and scoring techniques for brass. (age 17, U.S.) 


\section{Were Learners Self-Directing out of Choice or Need?}

"Teaching yourself," simply for enjoyment and self-improvement, is perhaps a more common pursuit in music than in other subjects, and $13 \%$ of self-directed learners reported that they were not interested in formal music classes or lessons. Comments included the following:

- I took one music theory class in high school but I prefer to learn and practice one thing at time, rather than being bombarded with too much information in too short of time. (age 22, U.S.)

- I got to a point where I decided I did not want any more classes, and was going to be self-taught (the Internet is great). If I have weird questions, I just ask somebody. (age 21, Colombia)

However, over half of the self-directed learners reported that they had not received as much formal music education as they would have liked. Money or cost was the most common reason given. Other circumstances that were cited as restricting access to music education included a lack of family support, geographic isolation, inflexibility in school schedules, and lack of access for those who are past "school age." Characteristic comments include:

- Piano lessons are too expensive. I'm trying to teach myself and my little boy through online material and so far so good! (age 40, England)

- I come from a country where music is not a part of formal education and getting a good teacher is next to impossible. (age 23, India)

- I grew up in a small town in the middle of nowhere in Australia, and ... no family members have any kind of music background. (age 39, Australia)

- I embraced music after the cut-off point where I had to specialise into what I wanted to learn. At the age of 16, it was too late to pick up a high school music course since I hadn't been interested beforehand, and so didn't have the prerequisites. The same applies now being the majority of the way through a Physics degree; there is little time for me to enrol in any formal classes. (age 21, Scotland)

- I'm a late bloomer.... There's a whole big group out there that's not having their questions being answered at their level of life. (age 62, U.S.)

\section{"Other" Non-Student Learners}

The inquiries of the 73 respondents (15.08\%) who chose "Just curious/other" described a very wide variety of goals, projects, and inquiries:

- An English musical word I was unsure at since English is not my mother tongue. (age 37, Sweden)

- Talking to a composer at a dinner party.... I did not realize how interesting and scien- 
tific it is. I am a scientist who is looking for intellectual stimulation (age 43, U.S.)

- Writing guitar help site on facebook (age 50, England)

- Helping my daughter with a school project. (age 23, England)

- I will be interviewing a tap dance teacher for local TV. (age 76, U.S.)

- I make Indian bamboo flutes as hobby. (age 51, India)

\section{Students}

The 109 respondents (22.52\%) who indicated they were using the online materials to supplement formal instruction included students in

- $\quad$ music theory courses (43),

- class or lessons focused on playing an instrument (26), and

- $\quad$ acoustics courses (7).

Some - particularly those in lessons - appeared to be satisfying personal curiosities raised by their studies, while others appeared to be working to meet course expectations:

- My homework project it's about Mauritius so I thought that I should write about Mauritius dancers and their dance steps. (age 12, U.K.)

- I'm Studying Sound Tech/Production, and I have a test coming up on sound waves theory. (age 17, Australia)

- Getting back into playing tenor trombone, learning tenor / alto clef, and alto trombone. (age 44, U.S.)

- I am the sort of [piano] student that needs to know "why" and this has filled in a lot of gaps in my understanding. (age 58 , U.K.)

\section{Ensemble Participants and Directors}

Eleven respondents (2.27\%) cited ensemble directing, and 38 respondents (10.12\%) participation in a musical ensemble, as their reason for looking at the materials. Respondents mentioned a wide variety of teaching, performing, and informal ensembles:

- High school marching band and high school choir (age 15, U.S.)

- $\quad$ Live classic rock cover band (tenor sax) (age 36, U.S.)

- Little orchestra playing folk music from different cultures (age 35, Germany)

- Our women's community choir has asked me to lead them, and I reluctantly said "yes". 
... This site was a great tutorial for me to brush up on conducting motions and teach myself to lead these ladies. (age 33, U.S.)

- Jazz Orchestra. ... I never learned what I need now. When they hand you music that has no notes and say "play" it, I sit and stare at it and laugh! Got to learn and keep learning! (age 69, U.S.)

- Ensemble of kantelet (traditional Finnish harp related to dulcimer) playing folk songs and church music. ... My musical ensemble plays some music written in some church modes and your explanations helped me with that (as well as appreciating modal music in jazz). (age 38, Canada)

\section{Teachers}

Comments from the 60 respondents $(12.4 \%)$ who identified themselves as teachers mentioned

- teaching children, elementary-school classes, or beginners (11 respondents),

- teaching secondary music courses (10),

- teaching instrumentalists or private music lessons (9),

- teaching a subject other than music (8),

- taking courses themselves or preparing for certification examinations (6).

They appeared to be conducting a wide variety of self-directed inquiries with the goal of improving their teaching practices:

- I'm teaching a college undergraduate Theory I course. The book does a terrible job of explaining chord symbols, and I am looking for an online resource to supplement that material. (age 25, U.S.)

- Need rhythm activities and ideas for kindergarten students. (age 39, Mali)

- I am looking for worksheets on half-steps and whole steps for 7th and 8th grade students. I'm specifically looking for Bass staff materials because there's so few out there. (age 41, U.S.)

- I teach [acoustics] at a university and am having a momentary frustration with my students because they are all speaking English as a second language, therefore, they do not respond well to technical and analytical terms. I searched and found your site in an effort to see how other people might be presenting it. (age 35, Czech Republic)

- I teach English at a middle school in South Korea.... I've been adapting material from your Basic Elements of Music course for roughly 3 months now in my after school middle school class on the American folk music tradition. Your discussion of non-western 
music is especially appreciated. (age not given, South Korea)

\section{The Modular Nature of the Materials}

The previous comment was the only survey response that named a specific course published at Connexions (Basic Elements of Music), and the context is in reference to adapting the materials in order to create another course (the American folk music tradition). In Hatakka's (2009) study, instructors reported problems with reusing open resources that were packaged in large chunks, such as entire lectures, because only portions of the lecture were relevant to their course:

So rather than using full lectures or courses in their content development they prefer to use smaller pieces of information that can be fitted into their content more easily. This means that the granularity of the objects is of importance and can be an inhibiting factor for reuse (p. 8, emphasis in the original).

It could be, then, that users who prefer entire online courses are choosing other resources, while the modular materials in this study are unusually attractive or helpful to those who prefer small pieces of information. The examples above suggest that these include not only teachers who want to customize their curriculum, but also students who need supplementary materials and independent learners pursuing inquiries not well-served by standard courses.

\section{The Distribution of Respondents}

As Stake (1995) explains, the emphasis in case study should be on understanding the object of study as a unique case, rather than on producing generalizations. It is perhaps better suited to raising questions and issues than to finding answers. One issue raised by this study concerns the distribution of the respondents in terms of educational situation. To date, there have been few attempts to characterize the distribution of users of an OER; the most visible is the evaluation of the Massachusetts Institute of Technology (MIT) OpenCourseWare (OCW). The distribution found by Carson (2006) for MIT's OCW was substantially similar to the distribution in the present study, which is interesting because the two resources are different in so many ways. Major differences include the following:

1. Subject area. OCW use was strongly centered on areas in which MIT is widely recognized for excellence, such as engineering and math; less than $1 \%$ of visits were related to music (Carson, 2006).

2. Level of materials. OCW publishes only materials from university courses. As indicated above, my acoustics and advanced music theory modules are sometimes used in college courses, but most of the modules are basic introductions to aspects of music theory, notation, and specific music traditions, content that is more typically associated with elementary and secondary education. 
3. Institutional use. The association with actual MIT courses provides OCW with support for content development and a community of users among the school's professors, students, and alumni, as well as "brand" recognition among outsiders. In contrast, the link between Connexions and its affiliated institution, Rice University, has been downplayed in favor of opening the site to any interested content developer. This provides a very useful publishing platform for a wide range of educators, but the relationship of the materials to the Web site and institution is different. As Atkins, Brown, \& Hammond (2007) have noted:

The Connexions Project complements the MIT project in that it provides not only a rapidly growing collection of free scholarly material but also a set of free software tools to help authors publish and collaborate; instructors build rapidly and share custom courses; and learners explore the links among concepts, courses, and disciplines. It focuses on building and supporting communities of digital object consumers and producers who credential material. (p. 15)

4. Courseware vs. learning objects. OCW emphasizes the MIT course as the context for the materials. Carson (2006) found that popular materials include course syllabi, lecture notes, and assignments; visits typically began at the OCW home page; and over $70 \%$ of visits were referred or direct traffic. In contrast, Connexions places emphasis on modules, published individually so that they may easily be used and reused in a variety of courses and contexts. According to Ochoa (2010), Connexions functions as a social learning object repository rather than as courseware, meaning that a module is created within a social milieu of author-educators, but it functions as an independent learning object for instructors and learners. Ochoa's model is supported by the present study. Computer log data showed that $65 \%$ of all visitors arrived at a module directly from an Internet search for key words (such as "circle of fifths" or "major scales"). Only $4 \%$ arrived through referrals from other sites, and 31\% visits were "direct." In other words, most OCW visitors appear to be focusing their search on MIT course materials, while most visitors to my materials appear to be focusing their search on the subject matter. This suggests that the typical use for the two resources may be quite different, with OCW users looking for information presented within the context of a course from a trusted source, and users of these music-education materials looking simply for specific information, with less regard for the context or source of the information. Data from the survey supports this as $82 \%$ of respondents reported either that it was their first time to visit the materials, or that they did not know whether they had visited them previously. Use of these materials as courses also appears to be much lower than use of individual modules, which may be one reason why searching at a specific, trusted site was less of an issue for users. Nearly all of the specific positive comments in the survey focused on clarity and ease of understanding the materials; it may be that for immediate, limited inquiries, many users judge that answers that are easy to find and 
understand have a "good-enough" trustworthiness.

5. Medium. Popular OCW materials also include videos of lectures (Carson, 2006). The materials under study here were text-oriented and did not include video lectures.

Figure 4. Comparison of educational role of users of MIT-OCW, as found by Carson (2006, p. 12), and users of this music-education resource
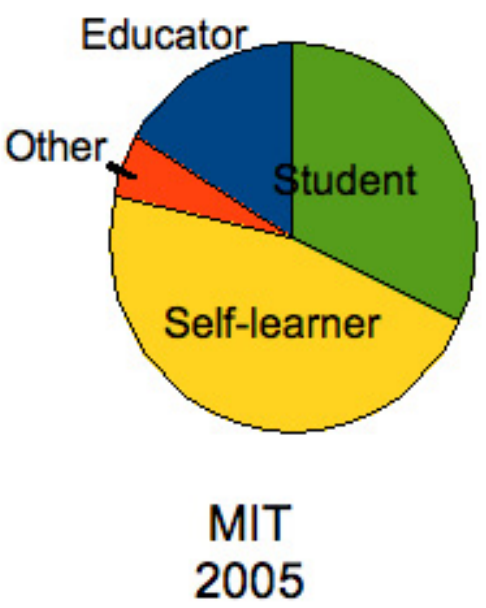

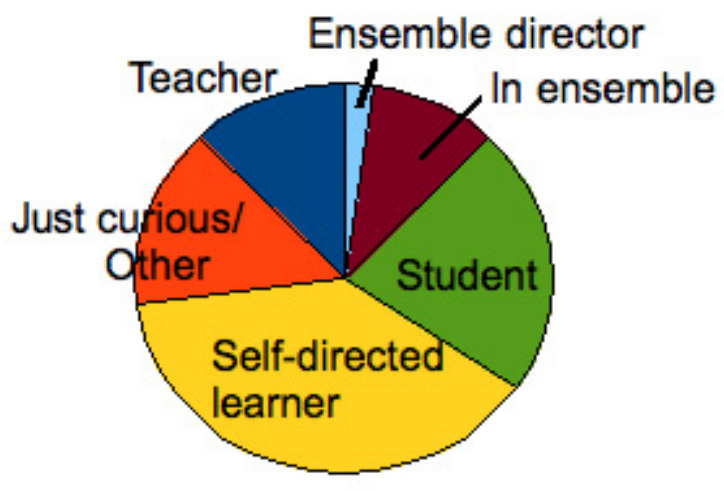

Music-education resource 2011

Given the differences between the two resources, a similarity in patterns of use becomes a point of interest. There appear to be similarities in the educational roles of survey respondents (see figure 4). Proportions of teachers and self-directed learners are similar for both resources. At first glance, the student proportions look very different because this study included categories not in the MIT study: ensemble participants and directors. As described above, ensembles often function as communities of practice in which learning about music is an integral aspect of the act of playing music with others. Although such learning is much less explicit than classroom-based learning, the role of music director in these music-making communities is in some ways parallel to that of the classroom teacher, and the role of the learning musician parallels that of the student.

Seen in this light, the proportions of students, teachers, and self-directed learners begin to look even more similar to those found for OCW. Because the two resources are so different, this similarity may reflect an underlying "distribution of typical OER users" more than it reflects the distribution of interest in a specific resource. If so, then the greatest educational effects of OERs may be due to direct, informal use by learners.

\section{Context and Limitations of this Study}

I chose to study this resource because I am the author of the modules; one goal of the study was to collect feedback that would help me improve the materials. My position as author 
gave me easy access to computer log and survey data. However, there is evidence that it also affected the survey responses. As Bergquist and Ljungberg (2001) explain, in the social calculus of Internet-based open-information communities, acceptance of a free gift of information may create a sense of moral obligation to pay back the giver in some way. In this case, the final survey question was an invitation to comment on the survey itself. Only 166 (34\%) responded to this question, and 80 of those comments were simply expressing appreciation or gratitude for the materials, with some explicitly linking their gratitude to their survey participation:

- To be honest, I was so happy to have found the answers to my questions on this site that the survey could have been idiotic and I still would have completed it without complaint. Thank you so much!

- Thanks for supplying this site, you deserve survey takers.

- I hope this survey helps you, because your site helped me.

The dynamics involved in this interaction - my personal interest in improving the materials, and the possibility that survey responses were colored by attitudes about me as provider of the materials - are part of the context for understanding this case.

\section{Conclusions}

This case demonstrates that one function of OERs is to serve as readily available resources for informal, inquiry-based learning. Of the users who were sufficiently engaged with the materials to respond to the survey, over $39 \%$ identified themselves as self-directed music learners, and a further $15 \%$ chose "just curious/other" to describe their visit. The remaining respondents reported involvement in music teaching or learning in a variety of settings; however, even for this group, the search for online information was typically self-chosen and self-directed, serving as an informal supplement to the formal curricula of classrooms and lessons, or the implicit, community-of-practice-style curricula of performing ensembles.

Satisfied users were very diverse in age, geographic location, previous experience in the subject, educational role, and goals. Most survey respondents were seeking specific knowledge to resolve an immediate question, problem, or curiosity. Evidence from computer logs supported this result; most visitors arrived at a module by searching the Internet for terms specific to that module.

The preference for seeking small portions of knowledge as needed, rather than entire courses, may have been partly due to specific characteristics of the OER, such as the subject area or publication format. However, for the question "who uses this OER," the results of this case were similar to the results found by Carson (2006) for MIT's OCW, a very different resource. The differences make a direct comparison problematic in large part because so many music learners are based in ensemble communities-of-practice rather than in class- 
rooms. Still, in both studies, the largest group of respondents categorized themselves as self-directed learners, with students the second largest group, and educators representing fewer than $20 \%$ of respondents. If ensemble-based learners can be considered "students" in the sense that, like students, they have regularly scheduled opportunities for face-to-face learning, then the proportions found in the two studies begin to look very similar. Do other OERs also attract more self-directed learners than students, and more students than educators? Citing the results of the MIT-OCW study, Kanwar et al. (2010) assert that the

... role of OER is increasingly changing from primarily a teaching to a learning resource. This reflects the wider change within education from a teacher-centered to a learner-centered model. Instead of teachers and educational institutions being the main users, it is students who now constitute the majority of users of OER. (p. 67)

Looking at a very different resource, the present case supports the conclusion that direct, informal use by both students and self-directed learners is the main use of OERs. Education researchers, policy-makers, and OER developers may want to consider the best ways to understand and support this type of use and take steps to make it truly available to all learners.

Further research could also clarify the extent to which OERs are being used, by both learners and educators, as resources for individualized, just-in-time inquiries. In particular, research that focuses on the user rather than the resource, seeking to understand the frequency, extent, and educational significance of informal online inquiries in the lives of various types of learners and educators, would help provide a better context for understanding the educational value of just-in-time OER use. Given that OERs appear to be empowering learners to direct their own learning activities in pursuit of their own learning purposes, a high educational value can reasonably be expected. As Dewey (1938) has stated:

There is, I think, no point in the philosophy of progressive education which is sounder than its emphasis upon the importance of the participation of the learner in the formation of the purposes which direct his activities in the learning process. (p. 67) 


\section{References}

Atkins, D. E., Brown, J. S., \& Hammond, A. L. (2007). A review of the open educational resources (OER) movement: Achievements, challenges, and opportunities (Report to the William and Flora Hewlett Foundation). Retrieved from http://www.oerderves. org/2007/o3/a-review-of-the-open-educational-resources-oer-movement/

Bergquist, M., \& Ljungberg, J. (2001). The power of gifts: Organizing social relationships in open source communities. Information Systems Journal, 11, 305-20.

Carson, S. (2006). 2005 Program evaluation findings report: MIT OpenCourseWare. Retrieved from http://ocw.mit.edu/about/site-statistics/

Cope, B., \& Kalantzis, M. (Eds.). (2009). Ubiquitous learning. Urbana: University of Illinois Press.

Dewey, J. (1938/1997). Experience \& education. New York: Touchstone.

Fowler, Floyd J. Jr. (1993). Survey research methods. Newbury Park: Sage Publications.

Freire, P. (1970). Pedagogy of the oppressed. New York: Continuum.

Hatakka, M. (2009). Build it and they will come? Inhibiting factors for reuse of open content in developing countries. The Electronic Journal on Information Systems in Developing Countries, 37(5), 1-16.

Hennessy, S., Ruthven, K., \& Brindley, S. (2005). Teacher perspectives on integrating ICT into subject teaching: commitment, constraints, caution, and change. Journal of Curriculum Studies 37(2), 155-192.

Iiyoshi, T., \& Kumar, M. S. V. (Eds.). (2008). Opening up education: The collective advancement of education through open technology, open content, and open knowledge. Cambridge, MA: The MIT Press.

Kanwar, A., Kodhandaraman, B., \& Umar, A. (2010). Toward sustainable open education resources: A perspective from the global south. The American Journal of Distance Education, 24(2), 65-80. DOI: 10.1080/08923641003696588

Knowles, M. (1984). Andragogy in action: Applying modern principles of adult learning. San Francisco and London: Jossey-Bass Inc.

Ochoa, X. (2010). Connexions: A social and successful anomaly among learning object repositories. Journal of Emerging Technologies in Web Intelligence, 2(1), 11-22.

Stake, R. (1995). The art of case study research. Thousand Oaks, CA: Sage Publications.

Walker, E. (2008). Evaluating the results of open education. In T. Iiyoshi \& M. S. V. Kumar (Eds.), Opening up education: The collective advancement of education through 
open technology, open content, and open knowledge. Cambridge, MA: The MIT Press.

Wenger, E. (1998). Communities of practice: Learning, meaning and identity. Cambridge: Cambridge University Press.

\section{Athabasca University}

(c) (†)


THE INTERNATIONAL

REVIEW OF RESEARCH IN

OPEN AND DISTANCE LEARNING

\section{Toward a CoI Population Parameter: The Impact of Unit (Sentence vs. Message) on the Results of Quantitative Content Analysis}
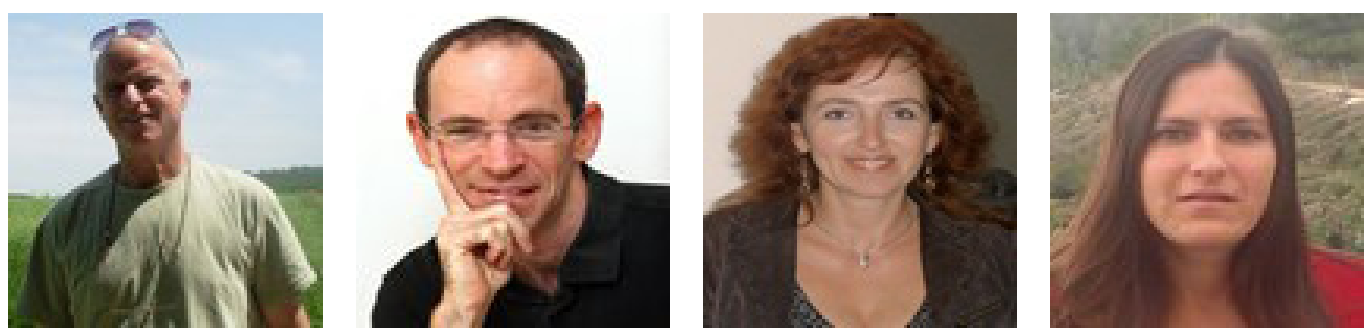

Paul Gorsky, Avner Caspi, Ina Blau, Yodfat Vine (not shown), and Amit Billet Open University of Israel

\section{Abstract}

The goal of this study is to further corroborate a hypothesized population parameter for the frequencies of social presence versus the sum of teaching presence and cognitive presence as defined by the community of inquiry model in higher education asynchronous course forums. This parameter has been found across five variables: academic institution (distance university vs. campus-based college), academic discipline (exact sciences vs. humanities), academic level (graduate vs. undergraduate), course level (introduction vs. regular vs. advanced), and course size (small vs. medium vs. large), that is, the number of students enrolled. To date, the quantitative content analyses have been carried out using the syntactic unit of message. In an attempt to further establish the parameter's goodness-of-fit, it is now tested across two different syntactic units, message versus sentence. To do so, the same three-week segments from 15 Open University undergraduate course forums (10 from humanities and five from exact sciences) were analyzed twice-once by the unit message and once by the unit sentence. We found that the hypothesized parameter remained viable when the unit of analysis is the sentence. We also found that the choice of syntactic unit is indeed a critical factor that determines the "content" of the transcript and its inferred meaning.

Keywords: Higher education; asynchronous forums; protocol analysis; community of inquiry model; quantitative content analysis; syntactic units 


\section{Introduction}

\section{Prelude}

We first present a brief overview of the research carried out. Concepts and variables mentioned here will be elaborated upon and placed in a more explicit perspective further below.

The community of inquiry framework has become an accepted and widely used model that describes teaching and learning in online and blended learning environments. The model assumes three dimensions or presences (social presence, teaching presence, and cognitive presence), through which dialogic behavior (verbal interactions) may be categorized. Considerable research has been conducted using the framework (Akyol et al., 2009). One particular line of inquiry, carried out by Gorsky and his colleagues (Gorsky, 2011; Gorsky \& Blau, 2009; Gorsky, Caspi, Antonovsky, Blau, \& Mansur, 2010; Gorsky, Caspi, \& Blau, 2011), has been the search for recurrent patterns in the frequencies of social presence, cognitive presence, and teaching presence in higher education, asynchronous course forums. To date, a ratio for the frequencies of "social presence" (the sum of its three categories) versus the sum of "teaching presence" and "cognitive presence" (the sum of their combined seven categories) has been calculated. This ratio (61.75\%:38.25\%) has been found stable across five variables: academic institution (distance university vs. campus-based college), academic discipline (exact sciences vs. humanities), academic level (graduate vs. undergraduate), course level (introduction vs. regular vs. advanced), and group size (small vs. medium vs. large), that is, the number of students enrolled. Given the recurrence of this ratio, we suggest that it may represent a population parameter that holds for higher education asynchronous course forums.

To date, the quantitative content analyses that established the parameter have been carried out using the syntactic unit of a message. The first objective of this investigation is to further corroborate the parameter's viability, that is, its goodness-of-fit, across two different units of analysis, message and sentence. To do so, we analyze the same 15 forums twice, first by message then by sentence.

The second objective of this investigation is to document similarities and differences that emerge from using two different analytic procedures on the same protocols. Although the importance of selecting an appropriate unit of analysis has been noted (Rourke, Anderson, Garrison, \& Archer, 2001), to the best of our knowledge, no research has been carried out which shows the explicit costs and benefits associated with each procedure in the manner we propose. Furthermore, De Wever, Schellens, Valcke, and Van Keer (2006, p. 19) criticized current reporting practices, noting that "most authors do not mention arguments for selecting or determining the unit of analysis." We hope to provide criteria for selecting either sentences or messages as the unit of analysis.

In the following two sections, we summarize the research that led to the discovery of the hypothesized parameter and the research into the impact of unit of analysis on the outcomes of content analysis. We will not discuss the community of inquiry model. Readers unfamil- 
iar with the model are referred to the Web site (http://www.communitiesofinquiry.com).

\section{Toward a Population Parameter}

A parameter is a number (or set of numbers) that describes a particular characteristic of a given population. The population under question in this ongoing research project is the set of all higher education asynchronous course forums, university and college, both distance and campus-based. The characteristic being investigated is the ratio of "social presence" versus the sum of "teaching presence" and "cognitive presence."

We believe that this particular ratio is meaningful for two reasons. First, whatever the setting (e.g., institution type, academic discipline, course level, etc.), rates of social presence (calculated from different samples) distribute closely around a hypothesized parameter. Second, although individual rates of teaching presence and cognitive presence vary within different settings, their sum also distributes closely around a hypothesized parameter.

The hypothesized population parameter emerged from a study (Gorsky et al., 2010) that analyzed three-week segments from 50 undergraduate course forums, 25 from exact sciences and 25 from humanities, at the Open University of Israel using the quantitative content analysis technique (Rourke et al., 2001) derived from the community of inquiry model (Garrison, Anderson, \& Archer, 2000). The initial goal of that study was to determine the impact of academic discipline (exact science vs. humanities) on dialogic behavior in course forums. For both disciplines, frequencies of teaching presence, cognitive presence, and social presence were calculated. Findings pointed toward two distinct distributions, one for each discipline. The individual frequencies, as well as their mean frequency, are shown in Table 1.

Table 1

Frequencies from Open University Asynchronous Course Forums and from a College Course Forum Based on Academic Discipline

\begin{tabular}{|l|l|c|c|c|c|}
\hline Institution & Parameter or course & $\begin{array}{c}\text { Social } \\
\text { presence }\end{array}$ & Teaching & Cognitive & Totals \\
& presence & presence & \\
\hline \multirow{2}{*}{$\begin{array}{l}\text { Open Uni- } \\
\text { versity }\end{array}$} & Humanities parameter & $65.87 \%$ & $18.98 \%$ & $15.15 \%$ & $100 \%$ \\
\cline { 2 - 6 } & Sciences parameter & $57.63 \%$ & $18.27 \%$ & $24.09 \%$ & $100 \%$ \\
\hline \multicolumn{7}{|l|}{} & $61.75 \%$ & $18.63 \%$ & $19.62 \%$ & $100 \%$ \\
\hline College & Humanities course & $63.72 \%$ & $31.18 \%$ & $5.10 \%$ & $100 \%$ \\
\hline
\end{tabular}

Further analysis (Gorsky et al., 2010) showed that, in addition to academic discipline, the mean frequencies were constant across the variables course level (introductory, regular, advanced), academic level (undergraduate and graduate courses), and group size (small, 
medium, large), that is, the number of students enrolled. At this point, it was proposed that these three frequencies might represent actual population parameters.

An additional study (Gorsky et al., 2011) was carried out to corroborate the existence of these frequencies at a different kind of institution for higher education, namely a campusbased college which also routinely used asynchronous course forums as an instructional resource. We carried out quantitative content analysis on an entire year-long, two-semester humanities course. We compared these frequencies with those obtained from the Open University. Findings (Table 1) showed that the frequencies for each of the three presences differed significantly at each institution (for in-depth statistical analyses and for an explanation as to how and why rates of cognitive presence and teaching presence differed, see Gorsky et al., 2011). However, the similar rates of social presence for the forums in both institutions (Table 1) are striking.

Table 2 shows an alternate representation of the data shown in Table 1. In this format, there is no significant difference between the frequencies from the campus-based college course forum and the frequencies from the Open University humanities forums and the frequencies for the mean parameter (the proposed population parameter). It was also noted by Gorsky (2011) that the proposed population parameter (61.75:38.25) approximates the Golden Ratio with $99.75 \%$ precision.

Table 2

Distributions for Social Presence versus the Sum of Teaching and Cognitive Presence

\begin{tabular}{|l|l|c|c|c|}
\hline Institution & Parameter or course & Social & Teaching + & Totals \\
& presence & cognitive presence & \\
\hline \multirow{2}{*}{ Open University } & $\begin{array}{l}\text { Humanities param- } \\
\text { eter }\end{array}$ & $65.87 \%$ & $34.13 \%$ & $100 \%$ \\
\cline { 2 - 5 } & Mean parameter * & $61.75 \%$ & $38.25 \%$ & $100 \%$ \\
\hline College & Humanities course & $63.72 \%$ & $36.28 \%$ & $100 \%$ \\
\hline
\end{tabular}

* Proposed population parameter

\section{The Impact of Unit of Analysis on the Results of Content Analy- sis}

Content analysis has been defined as "any technique for making inferences by objectively and systematically identifying specified characteristics of messages" (Holsti, 1969, p. 14). To date, content analysis is characterized by two separate but complementary methodologies, quantitative and qualitative. Quantitative methodologies generally code and summarize communications. Frequencies, which serve as a basis for comparison and statistical analysis, are often calculated. Qualitative methodologies are generally grounded in interpretive paradigms that attempt to identify major themes or categories within a transcript 
or protocol and to describe the social reality derived from those themes or categories in a particular setting.

A great deal of research in protocol analysis, both within and outside the community of inquiry model, has been carried out using different units of analysis. Associated with qualitative content analysis, Henri (1992) used a thematic unit. Murphy and Ciszewska-Carr (2005) pointed out that Henri's thematic unit was later adopted in a number of other studies (they cited Aviv, 2001; Gunawardena, Lowe, \& Anderson, 1997; Howell-Richardson \& Mellar, 1996; Jeong, 2003; McDonald, 1998; Newman, Webb, \& Cochrane, 1995; Turcotte \& Laferrière, 2004). Associated with quantitative content analysis, Hara, Bonk, and Angeli (2000) used a paragraph; Aviv, Erlich, Ravid, and Geva (2003) and Gorsky (2011) and Gorsky and colleagues $(2009,2010,2011)$ used the entire message; Fahy $(2001,2002)$ and Poscente and Fahy (2003) chose the sentence.

These researchers chose units of analysis in accord with their research objectives. For example, Poscente and Fahy (2003) sought to identify strategic initial sentences (triggers) in computer conferencing transcripts. In line with this objective, the sentence is obviously the best unit of analysis. Aviv et al. (2003) analyzed transcripts by message in an attempt to understand the collaborative process in asynchronous course forums. They innovatively assigned more than one code to a message if it included more than one type of behavior. Gorsky (2011) and his colleagues (2009; 2010; 2011), in their search for recurrent patterns in the frequencies of social presence, cognitive presence, and teaching presence, chose the message unit since it combines a high-level overview of the dialogic behavior in course forums with very high rates of inter-rater reliability. They also assigned more than one category to an entire message.

When selecting syntactic message units, Rourke et al. (2001) cited four important criteria that should be taken into account. First, the unit must be "objectively identifiable"; that is, different raters can agree consistently on the total number of cases and who posted each case. The ability to identify units reliably increases with the size of the syntactic unit. Given the nature of archived transcripts, a message can be identified as such with $100 \%$ reliability. Identifying a paragraph or sentence may be problematic. For example, Rourke et al. (2001, p. 16) noted difficulty in identifying sentences. The syntax in the conferences they studied "combined a telegraphic writing style with the informality of oral conversation." An example from their paper follows:

Certain subjects could be called training subjects . . i.e. How to apply artificial respiration. . . . as in first aid ... and though you may want to be a guide on the side. ... one must know the correct procedures in order to teach competency ... other subjects lead themselves very well to exploration and comment/research ...

Second, the unit should generate "a manageable set of cases." Murphy and Ciszewska-Carr (2005, p. 549) noted that "the choice of a sentence as a unit of analysis may prove problem- 
atic with long and multiple transcripts." Rourke et al. (2001) reported that participants in their study wrote more than 2,00o sentences during a 13-week discussion. They deemed this "an enormous amount of cases."

Third, the unit should yield relatively high rates of "inter-rater reliability." More than 30 years ago, Saris-Gallhofer, Saris, and Morton (1978) found that shorter coding units, such as words, yielded higher reliability than longer units, such as sentences or paragraphs. On the other hand, Insch, Moore, and Murphy (1997) noted that choosing too small a unit may result in obscuring subtle interpretations of statements in context.

Fourth, the unit should possess "discriminant capability"; that is, the structure of the unit should enable the researcher to discriminate between the different constructs being observed. Rourke et al. (2001, p. 11) noted that fixed syntactic units "do not always properly encompass the construct under investigation."

Using these four criteria, we attempt to determine the impact of unit of analysis on the results of content analysis, that is, on the frequencies measured by each.

The Current Study: Rationale, Research Questions, and Hypotheses

As noted, the goals of this study are twofold: (a) to validate the hypothesized population parameters by using an alternative analytic procedure; and (b) to investigate the impact of unit of analysis (message vs. sentence) on the results of content analysis, that is, the frequencies of the different presences. If the parameter is not viable (i.e., low goodness-of-fit as determined by chi square statistics) for the same forums analyzed twice, once by message and a second time by sentence, then it is an artifact of a very specific analytic procedure and its significance is limited, at best, and meaningless, at worst. If the hypothesized parameter holds (that is, there is no significant difference between the frequencies for social presence and the sum of teaching presence and cognitive presence) across academic discipline, academic institution, academic level, course level, group size (the number of students enrolled), and syntactic unit, then this study is another small, but possibly meaningful step toward finding a population parameter for higher education asynchronous course forums. Such a parameter might be named the community of inquiry constant or CoI constant.

Rourke et al. (2001) noted the importance of selecting the unit of analysis when doing content analysis of this particular type. Almost every research paper that uses the quantitative content analysis procedure to study communities of inquiry cites this reference; however, to the best of our knowledge, no findings have been reported as to the actual differences obtained when the two procedures are applied to the same forum or forums. The operational research questions being asked are framed in the criteria suggested by Rourke et al. (2001). When comparing content analyses carried out on the same transcripts with two different units of analysis, sentence versus message:

1. To what extent are sentences "objectively identifiable" as such? 
2. Does analysis by sentence generate "a manageable set of cases"; that is, what is the overall ratio of sentences to messages?

3. What is the impact of unit of analysis on "inter-rater reliability"?

4. How does the unit of analysis affect "discriminant capability"; that is, what information is gained or lost? Specifically,

a. What are the overall distributions of "social presence," "teaching presence," and "cognitive presence" and what are the distributions across different disciplines? In other words, will these two distributions differ significantly when analyzed by sen tence and message?

b. What are the distributions of "social presence," "teaching presence," and "cognitive presence" for instructors and for students, both overall and across different disci plines?

Finally, regarding the hypothesized parameters, we ask:

1. What are the overall distributions of "social presence" versus the sum of "teaching presence” and "cognitive presence," and

2. What are the distributions across different disciplines?

In other words, will these distributions differ significantly from the hypothesized (two-dimensional) population parameter and humanities parameter?

\section{Methodology}

\section{Background}

The Open University of Israel is a distance education university that offers undergraduate and graduate studies to students throughout Israel. The learning environment is blended: The University offers a learning method based on printed textbooks, face-to-face tutorials, and an online learning content management system (LCMS) wherein each course has its own Web site. Course sites simplify organizational procedures and enrich students' learning opportunities and experiences. Web site use is optional, non-mandatory so that equality among students is preserved. It does not replace textbooks or face-to-face tutorials, which are the pedagogical foundations of the Open University. The Web site provides forums for asynchronous instructor-student and student-student interactions. Each course has a coordinator, who is responsible for all administrative and academic activities, and instructors, who lead tutorials. Instructors and coordinators are available for telephone consultations at specified days and times.

\section{Participants (Course Forums)}

We analyzed three-week segments from 15 undergraduate Open University course forums, 
10 from the humanities and five from the exact sciences. The trial period began one month after the start of the semester in order to insure that opening messages and initial enthusiasm had waned and that the final exam was still far distant. Participation in all forums was non-obligatory; no grades or bonuses were linked to student participation. Courses are shown in Table 3.

Table 3

Open University Course Forums: Discipline, Academic Level, and Group Size (Number of Students Enrolled)

\begin{tabular}{|l|l|l|c|}
\hline & Discipline & Academic & Group \\
size*
\end{tabular}

* Number of students enrolled in the course

\section{Instruments and Procedure}

The quantitative content analysis technique was used to code and analyze transcriptions from the forum. This technique has been widely used; when used properly, it is reliable and valid (Garrison \& Arbaugh, 2007). We will discuss here both the technique and the technicians (those who carried out the content analyses). Regarding the technique, several issues must be dealt with.

The first issue is the unit of analysis. In this study, two different syntactical units of analysis were used, message and sentence. Indeed, it is the outcomes of this distinction that are be- 
ing investigated.

A second issue is the level of coding (e.g., indicator vs. category). Content analysis, as described by Rourke and Anderson (2004), is time-consuming, and coding at the indicator level is difficult, often yielding poor reliability (Murphy \& Ciszewska-Carr, 2005). In this study, as in the previous ones (Gorsky, 2011, Gorsky \& Blau, 2009; Gorsky et al., 2010, Gorsky et al., 2011), coding was at the category level in order to obtain a reliable, high-level overview of dialogic behavior.

A third issue is scoring. As in the previous studies cited above, we analyzed each unit, message or sentence, and scored each of the 10 categories as either present or not present (1 or o). In other words, if a category occurred more than once in a given message or a given sentence (say, two distinct occurrences of "open communication"), we recorded present only once. We did not count multiple recurrences of a category within the same message or sentence. Codes were recorded in a spreadsheet. Each row is a syntactic unit, either message or sentence, all of which were numbered. Table 4 shows a typical layout.

Table 4

A Typical Layout for Scoring Protocols

\begin{tabular}{|c|c|c|c|c|c|c|c|c|c|}
\hline \multicolumn{2}{|c|}{ Social presence } & \multicolumn{3}{c|}{ Teaching presence } & \multicolumn{3}{c|}{ Cognitive presence } \\
\hline Affective & $\begin{array}{c}\text { Open } \\
\text { com. }\end{array}$ & Cohesion & Design & Discourse & Instruction & Trigger & Exploration & Integration & Resolution \\
\hline & & & & & & & & & \\
\hline
\end{tabular}

The rationale for this scoring method is simple: When analyzing a message, it is taken in its entirety; for example, either the category "cohesion" is present or not. If it is present more than once, then it is present in an additional sentence. In other words, such analysis would be taking place at the level of sentence, not message. In a similar manner, when analyzing a sentence, it too is taken in its entirety; either the category "cohesion" is present or not. If it is present more than once, then it is present in an additional clause, either dependent or independent. In other words, such analysis would be taking place at the level of sentence clauses, or even words, not sentences.

Regarding the technicians, those who analyzed and coded the transcripts, we describe briefly how they were selected and prepared for the task at hand. Four different raters took part in this study: Rater A (third author) is a senior faculty member at the Open University of Israel and an expert in the field of quantitative content analysis. She trained raters B, C (fourth author), and D (fifth author), who were graduate students working toward their degrees in educational technology. Training included participation in a three-hour workshop that dealt with the theoretical basis of the CoI model and with the practical applications of quantitative content analysis. After the seminar, the trainees analyzed transcripts until they reached high inter-rater agreement with the instructor, Rater A. 
Raters A and B analyzed messages in a study whose findings were reported by Gorsky et al. (2010); these findings had no relationship at all with the findings presented here. Raters C and $\mathrm{D}$ analyzed the same protocols, by sentence. They were aware that their findings would be compared with those obtained from analysis by message. Given the very large number of sentences analyzed, such awareness could have no possible impact on their coding.

\section{Findings}

Impact of Unit of Analysis on the Frequencies of the Different Presences

Three-week segments from 15 Open University undergraduate course forums (10 from humanities and five from exact sciences), were analyzed twice, once by message, once by sentence. The 15 forums included 664 messages composed of 3,243 sentences. Findings are presented in accord with the research questions asked.

1. To what extent are sentences "objectively identifiable" as such?

In order to overcome any potential difficulties involved with identifying sentences, two raters worked together as suggested by Rourke et al. (2001). They agreed upon the syntactical structure of the entire transcript prior to the content analysis and reliability check. They did so based on the following guidelines, which we defined:

- A text segment enclosed in parentheses, within a sentence, was viewed as an independent sentence if the text segment was an independent clause;

- A text segment delineated by two dashes was viewed as an independent sentence if the text segment was an independent clause;

- A sentence with a semicolon that united two independent clauses was dismantled and each independent clause was counted as an independent sentence;

- A run-on sentence, where two independent clauses (each a complete sentence) are joined with no conjunction or punctuation, was dismantled and each independent clause was counted as an independent sentence.

Given these guidelines, close to full agreement was achieved. For about 30 sentences (about $1 \%$ of the total), discussion resolved any lack of agreement.

2. What is the ratio of sentences to messages?

The ratio of sentences to messages is 4.88:1. In other words, content analysis by sentence requires about five times the effort needed to analyze the identical transcripts by message. Messages in the humanities had $23.50 \%$ more sentences than their counterparts in the exact sciences. This does not necessarily indicate greater verbosity (words were not counted), 
only that humanities students wrote more sentences, whatever their length.

3. What is the impact on "inter-rater reliability"?

Twenty-five percent of postings were randomly chosen and re-estimated by a second rater. Ninety-two percent agreement was recorded (Cohen's $\kappa=0.89$ ) for the 15 forums analyzed by message; $95 \%$ agreement was recorded (Cohen's $\kappa=0.91$ ) for the 15 forums analyzed by sentence.

4a. What are the overall distributions of "social presence," "teaching presence," and "cognitive presence" and what are the distributions across different disciplines? In other words, how does the unit of analysis affect "discriminant capability"? Table 5 presents these findings.

Table 5

Frequencies for Social Presence, Teaching Presence, and Cognitive Presence: Sentence versus Message, All Posts

\begin{tabular}{|c|c|c|c|c|c|c|c|}
\hline & \multicolumn{2}{|c|}{$\begin{array}{l}\text { Social } \\
\text { presence }\end{array}$} & \multicolumn{2}{|c|}{$\begin{array}{l}\text { Teaching } \\
\text { presence }\end{array}$} & \multicolumn{2}{|c|}{$\begin{array}{l}\text { Cognitive } \\
\text { presence }\end{array}$} & $\begin{array}{l}\text { Chi } \\
\text { Square }\end{array}$ \\
\hline All forums & \# & $\%$ & \# & $\%$ & $\#$ & $\%$ & \\
\hline Sentence & 3255 & $55.02 \%$ & 753 & $12.73 \%$ & 1908 & $32.25 \%$ & \\
\hline Message & 1121 & $61.53 \%$ & 324 & $17.78 \%$ & 377 & $20.69 \%$ & $\chi^{2(2)}=8.58, \quad p<.05$ \\
\hline Humanities & $\#$ & $\%$ & \# & $\%$ & $\#$ & $\%$ & \\
\hline Sentence & 1369 & $55.67 \%$ & 419 & $17.04 \%$ & 671 & $27.29 \%$ & \\
\hline Message & 417 & $66.51 \%$ & 104 & $16.59 \%$ & 106 & $16.91 \%$ & $\chi 2(2)=8.17, p<.05$ \\
\hline Science & $\#$ & $\%$ & $\#$ & $\%$ & $\#$ & $\%$ & \\
\hline Sentence & 1886 & $54.56 \%$ & 334 & $9.66 \%$ & 1237 & $35.78 \%$ & \\
\hline Message & 704 & $58.91 \%$ & 220 & $18.41 \%$ & 271 & $22.68 \%$ & $\chi^{2(2)}=12.05, p<.01$ \\
\hline
\end{tabular}

As seen from the data in Table 5, there were statistically significant differences between each of the distributions. In other words, different analytic procedures, based on the unit of analysis, yielded different results. When analyzed by sentence, as opposed to message, forums in the humanities were characterized by increased cognitive presence and reduced social presence. Forums in the sciences were characterized by increased cognitive presence and reduced teaching presence. 
4b. What are the distributions of "social presence," "teaching presence," and "cognitive presence" for instructors and for students, both overall and across different disciplines? These findings also reflect the "discriminant capability" of each unit of analysis. Data based on postings made by instructors only are presented in Table 6 .

Table 6

Frequencies: Sentence versus Message (Instructors Only)

\begin{tabular}{|c|c|c|c|c|c|c|c|}
\hline & \multicolumn{2}{|c|}{$\begin{array}{l}\text { Social } \\
\text { presence }\end{array}$} & \multicolumn{2}{|c|}{$\begin{array}{l}\text { Teaching } \\
\text { presence }\end{array}$} & \multicolumn{2}{|c|}{$\begin{array}{l}\text { Cognitive } \\
\text { presence }\end{array}$} & $\begin{array}{l}\text { Chi } \\
\text { Square }\end{array}$ \\
\hline All forums & $\#$ & $\%$ & $\#$ & $\%$ & $\#$ & $\%$ & \\
\hline Sentence & 1349 & $56.59 \%$ & 398 & $16.69 \%$ & 637 & $26.72 \%$ & \\
\hline Message & 378 & $47.25 \%$ & 277 & $34.63 \%$ & 145 & $18.12 \%$ & $\chi 2(2)=15.22, p=.001$ \\
\hline Humanities & $\#$ & $\%$ & $\#$ & $\%$ & $\#$ & $\%$ & \\
\hline Sentence & 536 & $58.39 \%$ & 210 & $22.87 \%$ & 172 & $18.74 \%$ & \\
\hline Message & 150 & $50.68 \%$ & 104 & $35.14 \%$ & 42 & $14.19 \%$ & $\chi 2(2)=6.92, p<.05$ \\
\hline Science & $\#$ & $\%$ & $\#$ & $\%$ & $\#$ & $\%$ & \\
\hline Sentence & 813 & $55.46 \%$ & 188 & $12.82 \%$ & 465 & $31.72 \%$ & \\
\hline Message & 228 & $45.24 \%$ & 173 & $34.33 \%$ & 103 & $20.44 \%$ & $\chi^{2}(2)=22.02, p<.001$ \\
\hline
\end{tabular}

As seen from the data in Table 6, the distributions differ significantly. When analyzed by sentence, as opposed to message, the dialogic behavior of instructors in the humanities and sciences was similar: reduced teaching presence and increased cognitive presence and social presence.

Next, we analyzed the distributions based on postings made by students only. Findings are shown in Table 7. 
Table 7

Frequencies: Sentence versus Message (Students Only)

\begin{tabular}{|c|c|c|c|c|c|c|c|}
\hline \multirow[b]{2}{*}{ All forums } & \multicolumn{2}{|c|}{$\begin{array}{l}\text { Social } \\
\text { presence }\end{array}$} & \multicolumn{2}{|c|}{$\begin{array}{l}\text { Teaching } \\
\text { presence }\end{array}$} & \multicolumn{2}{|c|}{$\begin{array}{l}\text { Cognitive } \\
\text { presence }\end{array}$} & \multirow[t]{2}{*}{$\begin{array}{l}\text { Chi } \\
\text { Square }\end{array}$} \\
\hline & \# & $\%$ & $\#$ & $\%$ & $\#$ & $\%$ & \\
\hline Sentence & 1906 & $53.96 \%$ & 355 & $10.05 \%$ & 1271 & $35.99 \%$ & \multirow[b]{2}{*}{$\chi^{2}(2)=19.07, p<.001$} \\
\hline Message & 743 & $72.70 \%$ & 47 & $4.60 \%$ & 232 & $22.70 \%$ & \\
\hline Humanities & $\#$ & $\%$ & $\#$ & $\%$ & $\#$ & $\%$ & \\
\hline Sentence & 833 & $54.06 \%$ & 209 & $13.56 \%$ & 499 & $32.38 \%$ & \multirow[b]{2}{*}{$\chi 2(2) \infty, p<.001$} \\
\hline Message & 267 & $80.66 \%$ & o & $0.00 \%$ & 64 & $19.34 \%$ & \\
\hline Science & $\#$ & $\%$ & $\#$ & $\%$ & $\#$ & $\%$ & \\
\hline Sentence & 1073 & $53.90 \%$ & 146 & $7 \cdot 33 \%$ & 772 & $38.77 \%$ & \multirow[b]{2}{*}{$\chi 2(2)=11.09, p=.01$} \\
\hline Message & 476 & $68.89 \%$ & 47 & $6.80 \%$ & 168 & $24.31 \%$ & \\
\hline
\end{tabular}

Again, as seen from the data in Table 7, there are highly significant statistical differences between each of the distributions. When analyzed by sentence, as opposed to message, the dialogic behavior of students in the humanities was characterized by highly reduced social presence and increased cognitive presence and teaching presence. Students' dialogic behavior in the sciences was characterized by reduced social presence and increased cognitive presence. Teaching presence remained about the same.

One specific finding in Table 7 is highly anomalous, namely no recorded incidents of students' teaching presence in the humanities were recorded when the protocols were analyzed by message. When the same protocols were analyzed by sentence, 209 incidents were recorded. This anomaly will be addressed below in the Discussion section.

\section{Validating the Hypothesized Population Parameters}

Finally, in order to corroborate the three hypothesized parameters (population parameter, humanities parameter, and science parameter) across units of analysis, we calculated the overall distributions of "social presence" versus the sum of "teaching presence" and "cognitive presence" for the same forums, analyzed first by message and then by sentence. Table 8 presents these findings. 
Table 8

Frequencies for Social Presence versus the Sum of Teaching and Cognitive Presence

\begin{tabular}{|l|l|c|c|}
\hline & Unit of & Social & Teaching + \\
& analysis & presence & cognitive presence \\
\hline 1. Hypothesized population parameter & Message & $61.75 \%$ & $38.25 \%$ \\
\hline 2. Hypothesized humanities parameter & Message & $65.87 \%$ & $34.13 \%$ \\
\hline 3. Hypothesized science parameter & Message & $57.63 \%$ & $42.37 \%$ \\
\hline 4. All 15 forums & Sentence & $55.02 \%$ & $44.98 \%$ \\
\hline 5. Ten humanities forums & Sentence & $55.67 \%$ & $44.33 \%$ \\
\hline 6. Five science forums & Sentence & $54.56 \%$ & $45.44 \%$ \\
\hline
\end{tabular}

No significant differences were found for the following parameters (analyzed by message) and the following forums (analyzed by sentence):

1. Hypothesized population parameter vs. all 15 forums: $\chi 2(1)=1.57, p=.21$

2. Hypothesized population parameter vs. 10 humanities forums: $\chi 2(1)=1.26, p=.26$

3. Hypothesized population parameter vs. 5 science forums: $\chi 2(1)=1.80, p=.18$

4. Hypothesized science parameter vs. 5 science forums: $\chi 2(1)=0.27, p=.60$

Borderline difference between the hypothesized humanities parameter and the 10 humanities forums was noted $\left(\chi^{2}(1)=3.81, p=.05\right)$.

In other words, the hypothesized population parameter (calculated by analyzing messages) is viable or compatible with the same ratios obtained from forums calculated by analyzing sentences.

\section{Discussion}

We asked two broad research questions. First, do the hypothesized parameters for the frequencies of "social presence" versus the sum of "cognitive presence" and "teaching presence" in higher education asynchronous forums remain viable when different units of analysis are used? Second, what is the impact of unit (sentence vs. message) on the results of quantitative content analysis; that is, what similarities and differences emerge when the same forum is analyzed using different units of analysis, message and sentence? We begin with the latter issue. 


\section{The Impact of Unit (Sentence vs. Message) on the Results of Quantitative Content Analysis}

We will discuss the outcomes of the content analyses in terms of the four criteria noted by Rourke et al. (2001).

1. Both procedures yielded "objectively identifiable" units. Although messages are automatically identified as such, sentences were also relatively easily identified and mutually agreed upon by the raters before the start of the analyses. For whatever reasons, students generally wrote sentence-based text and did not use a telegraphic writing style associated with the informality of oral conversation as reported by Rourke et al. (2001). This criterion, therefore, need not be an obstacle that prevents the use of the sentence as a reliable and valid unit of analysis.

2. High rates of "inter-rater reliability" were achieved in both analyses, by sentence ( $95 \%$ agreement) and by message (92\% agreement). Again, this is not a restrictive factor.

At this point, we will discuss the anomalous findings noted in Table 7. (No recorded incidents of students' teaching presence in the humanities were recorded when the protocols were analyzed by message. When the same protocols were analyzed by sentence, 209 incidents were recorded.) We suggest that these findings are related to inter-rater reliability and that they do not change the findings reported here in any statistically significant way. We now review the process of content analysis and its accompanying inter-rater reliability test.

As noted above, four raters were employed. Rater B analyzed the protocols by message; Rater A re-estimated $25 \%$ of postings that were randomly chosen. Ninety-two percent agreement was recorded (Cohen's $\kappa=0.89$ ). Rater $\mathrm{C}$ analyzed the protocols by sentence; Rater D re-estimated $25 \%$ of postings that were randomly chosen. Ninety-five percent agreement was recorded (Cohen's $\kappa=0.91)$.

We suggest two possible explanations for the apparent discrepancies. First, high rates of agreement were scored between raters $\mathrm{A}$ and $\mathrm{B}$ and between raters $\mathrm{C}$ and $\mathrm{D}$. No such reliability tests were carried out between raters A and C. In retrospect, it may have been preferable to have used one pair of raters only for both content analyses (sentence and message). This would have assured a uniformly high rate of inter-rater reliability. The downside of this procedure, however, would be in the creation of a potential prejudicial cross-over problem since the raters would be rescoring the same texts they had already reviewed.

Second, to account for the "disappearance" of incidents of teaching presence from the messages of humanities students, we reviewed the reliability check between raters A and B. We found a total of 44 instances of inter-rater disagreement between cognitive presence and teaching presence that occurred in the same message. Such disagreement means that a type 1 error and a type 2 error occurred in the same message. To illustrate, Table 9 shows two disagreements between raters A and B in the same message. 
Table 9

Inter-Rater Disagreement with a Type 1 Error and a Type 2 error

\begin{tabular}{|l|l|l|l|}
\hline & Social & Teaching & Cognitive \\
Rater & presence & presence & presence \\
\hline A & 1 & 1 & O \\
\hline B & 1 & O & 1 \\
\hline
\end{tabular}

In retrospect, had rater A performed the entire content analysis and rater B the reliability test, 13 incidents of students' teaching presence would have been noted (as opposed to the current value of zero). Statistically, whether there are 13 incidents of students' teaching presence or zero incidents, the difference is insignificant and can be attributed to reasonable fluctuations in inter-rater agreement and disagreement.

3. There were nearly five sentences per message (4.88:1). Is this "a manageable set of cases"? There should be very compelling reasons to invest nearly five times the time, effort, and cost to analyze by sentence.

4. Such reasons may be found in terms of the criterion "discriminant capability" (Rourke et al., 2001). Tables 6 and 7 show the frequencies of the three presences for instructors and for students. For instructors in the humanities, when analyzed by sentence as opposed to message, their transcripts indicate about a 35\% decrease in teaching presence. In a similar manner, for instructors in the sciences, when analyzed by sentence, their transcripts indicate about a $63 \%$ decrease in teaching presence. For researchers investigating the perceived or "objective" impact that results from instructors' teaching presence on the dialogic behavior of course forums, these findings appear to be especially meaningful. These findings will be noticeable if and only if the unit of analysis is the sentence where the resolution is five times greater than that of the message. Clearly, given the scoring procedure based on present/not present, additional categories are revealed when forums are analyzed sentence by sentence.

For instructors in the sciences, when analyzed by sentence, their transcripts indicate about a 55\% increase in cognitive presence. Again, this finding seems straightforward: Messages from instructors may often include many different ideas expressed in multiple sentences. For researchers investigating the factors associated with the extent and nature of instructors' cognitive presence in communities of inquiry, these findings may be especially meaningful. Rates of cognitive presence for instructors in the humanities were similar for both units of analysis. These low rates of cognitive presence in humanities forums were described by Gorsky et al. (2010).

For students in both disciplines, social presence was diminished when protocols were analyzed by sentence. Social presence for science students was about $22 \%$ less and for humanities students about one third less. This makes sense since social presence is often laconic 
(e.g., "Hi, all," "I was thinking the same thing," etc.) and at higher resolutions, sentence by sentence, is diminished. Again, for researchers investigating the nature of students' social presence and its relationship to other presences as well as to "perceived learning," these findings appear to be especially meaningful.

For students in both disciplines, cognitive presence increased by about $50 \%$ when protocols were analyzed by sentence. This finding reflects the notion that ideas are often expressed in multiple sentences. Furthermore, it hints at collaborative learning where students aid and abet their fellow students. Such collaborative behavior has been reported by Caspi and Gorsky (2006), Gorsky, Caspi, and Trumper (2004, 2006), and Gorsky, Caspi, and TuviArad (2004).

In summation, it would seem that researchers seeking causal relationships among the three presences have exceptionally good reasons to analyze by sentence despite the additional burden in time and cost. A large amount of useful data, unobservable when transcripts are analyzed by message, suddenly becomes available.

\section{Corroborating the Hypothesized Two-Dimensional Population Parameters}

The two-dimensional ratio (61.75:38.25), the hypothesized population parameter, was found viable for both units of analysis, message and sentence. This is truly surprising given the kinds of changes in dialogic behavior exhibited by instructors (Table 6) and students (Table 7) when analyzed by the different units of analysis. In the wake of this study, this parameter has been found to be constant across six variables: academic institution (distance university vs. campus-based college), academic discipline (exact sciences vs. humanities), academic level (graduate vs. undergraduate), course level (introduction vs. regular vs. advanced), group size (small vs. medium vs. large), that is, the number of students enrolled, and unit of analysis (sentence vs. message). In order to approach some understanding as to what a population parameter means in the framework of this research, we return to some first premises and look again at the nature of content analysis itself.

To begin, we reiterate the obvious, namely, that the results of any content analysis, or any scientific inquiry whatever the discipline, are dependent upon its theoretical base and the selected methodology that includes a particular unit of analysis. Clearly, findings are the outcome of particular decisions that determined the questions asked and the analytical tools used. This was noted by Heisenberg (1958), one of the founders of quantum theory: "We have to remember that what we observe is not nature herself, but nature exposed to our method of questioning."

Thus said, the hypothesized parameters are relevant only for the given theoretical base (community of inquiry model, Garrison et al., 2000) and for the given methodology (quantitative content analysis, Rourke et al., 2001) that encompasses two units of analysis, message and sentence. Within these restraints, the hypothesized population parameter may be named the community of inquiry constant or the CoI constant. 
Once again, before continuing on, we wish to emphasize that the parameters and/or CoI constant and/or symmetry inferred from these and previous findings are, at best, extremely tentative. In order to more fully support the parameter, first and foremost, corroborative research needs to be carried out. In addition, research needs to be carried out in a wider context that may include different learning environments, different coding processes, and different coders not trained by the third author. We have, however, pointed to the intriguing possibility that such a parameter may exist.

To conclude, we will momentarily suspend disbelief and attempt to assign meaning to this parameter, as if it does indeed exist. First and foremost, any parameter, constant, or symmetry in the behavioral sciences is rare. This hypothesized parameter describes symmetry between social presence and the sum of cognitive and teaching presence in certain kinds of communities of inquiry. Regarding behaviors associated with teaching and learning, we are social beings, and this essence is expressed in the parameter: Our social nature ("social presence") is in a fixed proportion with the nature of teaching and learning ("teaching presence" and "cognitive presence"). And ... social presence outweighs the sum of teaching presence and cognitive presence. 


\section{References}

Akyol, Z., Arbaugh, J. B., Cleveland-Innes, M., Garrison, D. R., Ice, P., Richardson, J. C., \& Swan, K. (2009). A response to the review of the community of inquiry framework. Journal of Distance Education, 23, 123-136.

Aviv, R. (2001). Educational performance of ALN via content analysis. Journal of Asynchronous Learning Networks, 4, 53-72.

Aviv, R., Erlich, Z., Ravid, G., \& Geva, A. (2003). Network analysis of knowledge construction in asynchronous learning networks. Journal of Asynchronous Learning Networks, 7, 1-23.

Caspi, A., \& Gorsky, P. (2006). Open University students' use of dialogue. Studies in Higher Education, 31(6), 735-752.

De Wever, B., Schellens, T., Valcke, M., \& Van Keer, H. (2006). Content analysis schemes to analyze transcripts of online asynchronous discussion groups: A review. Computers and Education, 46, 6-28.

Fahy, P. J. (2001). Addressing some common problems in transcript analysis. International Review of Research in Open and Distance Learning, 1. Retrieved from http:// www.irrodl.org/index.php/irrodl/article/view/321/530

Fahy, P. J. (2002). Epistolary and expository interaction patterns in a computer conference transcript. Journal of Distance Education, 17, 20-35.

Garrison, D. R., Anderson, T., \& Archer, W. (2000). Critical inquiry in a text-based environment: Computer conferencing in higher education. The Internet and Higher Education, 2, 87-105.

Garrison, D. R., \& Arbaugh, J. B. (2007). Researching the community of inquiry framework: Review, issues, and future directions. The Internet and Higher Education, $10,157-172$.

Gorsky, P. (2011). Hidden structures in asynchronous course forums: Toward a golden ratio population parameter. In Proceedings of Ninth International Conference on Computer Supported Collaborative Learning: Connecting Computer Supported Collaborative Learning to Policy and Practice. Center for Information Technology in Education, University of Hong Kong.

Gorsky, P., \& Blau, I. (2009). Effective online teaching: A tale of two instructors. International Review of Research on Distance Learning, 10(3). Retrieved from http:// www.irrodl.org/index.php/irrodl/article/view/712/1270

Gorsky, P., Caspi, A., Antonovsky, A., Blau, I., \& Mansur, A. (2010). The relationship between academic discipline and dialogic behavior in Open University course fo- 
rums. International Review of Research on Distance Learning, 11(2). Retrieved from http://www.irrodl.org/index.php/irrodl/article/view/820/1546

Gorsky, P., Caspi, A., \& Blau, I. (2011). Communities of inquiry in higher education asynchronous course forums: Toward a population parameter. Manuscript submitted for publication.

Gorsky, P., Caspi, A., \& Trumper, R. (2004). Dialogue in a distance education physics course. Open Learning: The Journal of Open and Distance Learning, 19(3), 265-277.

Gorsky, P., Caspi, A., \& Trumper, R. (2006). Campus-based university students' use of dialogue. Studies in Higher Education, 31(1), 71-87.

Gorsky, P., Caspi, A., \& Tuvi-Arad, I. (2004). Use of instructional dialogue by university students in a distance education chemistry course. Journal of Distance Education, 19(1), 1-19.

Gunawardena, C., Lowe, C. A., \& Anderson, T. (1997). Analysis of a global online debate and the development of an interaction analysis model for examining social construction of knowledge in computer conferencing. Journal of Educational Computing Research, 17, 397-431.

Hara, N., Bonk, C. J., \& Angeli, C. (2000). Content analyses of on-line discussion in an applied educational psychology course. Instructional Science, 28, 115-152.

Heisenberg, W. (1958). Physics and philosophy: The revolution in modern science. Lectures delivered at University of St. Andrews, Scotland, Winter, 1955-56. New York: Harper and Row.

Henri, F. (1992). Computer conferencing and content analysis. In A. R. Kaye (Ed.), Collaborative learning through computer conferencing (pp. 117-136). Berlin: Springer Verlag.

Holsti, O. R. (1969). Content analysis for the social sciences and humanities. Reading, MA: Addison-Wesley.

Howell-Richardson, C., \& Mellar, H. (1996). A methodology for the analysis of patterns of interactions of participation within computer mediated communication courses. Instructional Science, 24, 47-69.

Insch, G., Moore, J. E., \& Murphy, L. D. (1997). Content analysis in leadership research: Examples, procedures, and suggestions for future use. Leadership Quarterly, 8, $1-25$.

Jeong, A. C. (2003). The sequential analysis of group interaction and critical thinking in online threaded discussions. American Journal of Distance Education, 17, 25-43. 
McDonald, J. (1998). Interpersonal group dynamics and development in computer conferencing: The rest of the story. In Proceedings of the 14th conference on distance teaching and learning. Madison, WI: Continuing and Vocational Education, University of Wisconsin-Madison.

Murphy, E., \& Ciszewska-Carr, J. (2005). Contrasting syntactic and semantic units in the analysis of online discussions. Australasian Journal of Educational Technology, $21,546-566$.

Newman, D. R., Webb, B., \& Cochrane, C. (1995). A content analysis method to measure critical thinking in face-to-face and computer supported group learning. Interpersonal Computing and Technology Journal, 3, 56-77.

Poscente, K. R., \& Fahy, P. J. (2003). Investigating triggers in CMC text transcripts. International Review of Research in Open and Distance Learning, 4(2). Retrieved from http://www.irrodl.org/content/v4.2/poscente fahy.html

Rourke, L., \& Anderson, T. (2004). Validity issues in quantitative computer conference transcript analysis. Educational Technology Research and Development, 52, 5-18.

Rourke, L., Anderson, T., Garrison, D. R., \& Archer, W. (2001). Methodological issues in the content analysis of computer conference transcripts. International Journal of Artificial Intelligence in Education, 12, 8-22.

Saris-Gallhofer, I. N., Saris, W. E., \& Morton, E. L. (1978). A validation study of Holsti”s content analysis procedure. Quality and Quantity, 12, 131-145.

Turcotte, S., \& Laferrière, T. (2004). Integration of an online discussion forum in a campusbased undergraduate biology class. Canadian Journal of Learning and Technology, 3o, 73-92.

\section{Athabasca University $\mathbf{C}$}

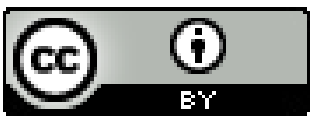


THE INTERNATIONAL

REVIEW OF RESEARCH IN

OPEN AND DISTANCE LEARNING

\section{Pretesting Mathematical Concepts with the Mobile Phone: Implications for Curriculum Design}

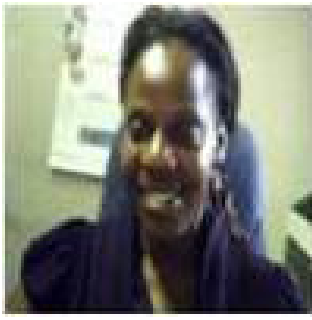

Rita Ndagire Kizito

University of South Africa (UNISA)

\section{Abstract}

One of the neglected elements when teaching at a distance is establishing what learners already know at the beginning of the course or module. Unlike the face-to-face environment, in distance learning there is no opportunity for administering diagnostic activities just before the onset of instruction. This means that both the weak and more advanced students receive the same level of support since there is no mechanism for differentiating their learning needs. This paper describes the characteristics of a diagnostic test aimed at determining student understanding of the basic calculus concepts of the derivative and the integral, using the mobile phone as the method of delivery. As a proof-of-concept exercise, 10 questions designed to test concept attributes and procedural knowledge involving the two basic calculus concepts were given to a sample of 30 students at the beginning of the course. The implications for curriculum design were then analysed in terms of the didactical functionalities and the communication strategy that could be developed with reference to the mobile phone.

Keywords: Prediagnostic testing; mobile phone; distance learning; undergraduate calculus teaching; Realistic Mathematics Education; didactic functionalities

\section{Introduction}

Imagine the following scenario:

You are a student wanting to take a distance calculus course, but you aren't sure that you are really up to it. It has been a while since you did your high school mathematics. You quickly access the UNISA Web site via your phone for the pretest they offer and take it. The results indicate the 
areas you need to revise before joining the course. You contact a social network friend who has been in a similar situation. He or she immediately texts back a message attaching an online calculus manual that you need to go through. Once home, you continue your preparations for the next pretest on your computer.

The scenario is based on the observation that mobile learning is an emerging and rapidly expanding field that provides new opportunities for learning improvement. Strictly speaking, mobile learning is a very broad term that is used in different contexts and that involves a number of mobile devices such as mobile phones, personal digital assistants (PDAs), various forms of handheld devices, and even notebooks. For the purposes of this article, I am using the term mobile learning to refer to handheld pocketsize technologies that can be put in your pocket at the point of learning. In the South African distance education environment, where the majority of students simply cannot afford access to web-based learning, the use of a mobile learning strategy seems to be a viable and rational alternative for providing instructional support.

Previously, the adoption of mobile learning was constrained by slow networks, limited services, and hesitancy on the part of organisations to invest in devices whose shelf life was too short. Mobile phone penetration and adoption were not really matched by a parallel uptake of mobile learning, despite predictions of a possible mobile learning revolution (Wagner, 2005). Reasons posited for the delay in adoption included limited and non-standardised broadband distribution capacity (Wagner, 2005), device attributes such as screen size, battery life, and security (all of which hinder learning), limited resources, and a lack of organisational acceptance (Brown, Metcalf, \& Christian, 2008).

The limitation of mobile content development and distribution is slowly changing as demonstrations of the potential and actual roles of mobile technologies increase. Consumers (including distance students) who are apt mobile users have established a demand for mobile technology use. According to Traxler (2007), mobile devices are creating a new "mobile conception of society in which we are beginning to look at new ways of creating and accessing knowledge, performance, art forms, and even new economic activities" (p. 4). However, not enough research has been conducted to identify the actual functionalities that should be targeted when designing instruction using the mobile device in teaching.

Within the context of distance teaching, a neglected element is the establishment of learners' prior knowledge at the beginning of the course or module with a view to offering the learner appropriate support. This type of diagnostic testing, prior to the onset of a learning unit or module, is slightly different from the pre-enrolment tests offered via paper (postal system), by telephone, or through prerequisite courses. While pre-enrolment testing establishes learner readiness for participating in a course, the precourse diagnostic testing is conducted to determine the amount and level of support a learner will require to advance successfully within the course. Unlike the face-to-face environment, in which a teacher has the time to briefly find out where the learners are before the course begins, in distance 
learning there are few opportunities for administering diagnostic activities once students have enrolled for each course or module. This means that both weak and more advanced students receive the same level of support since there is no quick mechanism for responding to individual learning needs (as would be the case in a traditional classroom). The problem is exacerbated by the large number of students enrolled in any distance learning module.

This paper describes the characteristics of a precourse diagnostic test aimed at determining initial student understanding of the basic calculus concepts of the derivative and the integral, using the mobile phone as the method of delivery. The aim of the project was to try to find out what the didactic functionalities of a simple mobile phone were and how these could be exploited to inform supporting learning mathematics at a distance. The questions posed were as follows:

- Can we use the mobile phone to facilitate the administration of diagnostic activities quickly?

- If we are going to use the mobile phone, what are its didactic functionalities?

- How can these functionalities be exploited in order to inform teaching and learning as well as curriculum design in distance education?

\section{The Role of the Mobile Phone in Providing Learning Support}

There have been a number of examples of successful mobile learning interventions. For instance, Wei and Chen's (2006) e-book interface design allowed students to enter queries on the text which were transferred to a discussion forum accessible through the mobile phone. Hartnell-Young and Vetere (2008) personalised learning by letting students capture everyday aspects of their lives in order to reconstruct their lived narratives within a classroom environment. Kinsella (2009) built a mobile application which allowed students to anonymously post questions to the teacher, who was then able to give summarised feedback to all participating students in real time. The reports from South Africa have been predominantly around the SMS "short message system" usage. These include Viljoen and Carlcook's (2005) exploration of the experiences of adult learners' use of SMS as a support tool while enrolled in the University of Pretoria's distance education unit and Van Rooyen's (2010) investigation of student responses to the integration of SMS as support tool systems in an accounting module at UNISA.

The current smart phones have multimedia conduits which, if exploited, are potentially useful for teaching and learning in many subjects. Students can collect evidence and data via audio and video recordings and by taking photographs. Students can send short text messages between mobile telephone devices or even send messages that include multimedia objects (e.g., video images and audio recordings). All these features can make a difference to the way in which students build new knowledge (Daher, 2010).

\section{Mobile Phone Use in Supporting Mathematics Learning}

Mobile phone usage in mathematics learning is slowly increasing. For example, in their 
research, Yerushalmy and Ben-Zaken (2004) established that the mobile phone was a tool capable of opening up fascinating opportunities for learning because of its mobility, availability, and flexibility. Professor Yerushalmy and her team at the University of Haifa developed Java-based mathematical applications that can be installed on most mobile phones. The devices operate as minicomputers and are used for constructing graphs, solving equations, and sketching functions. Their Math4Mobile phone applications for learning algebra, geometry, and calculus can be accessed from the Web at www.math4mobile.com. This team has developed activities for elementary, middle, and high school students. Dynamic lessons where students explore mathematical concepts can be accessed from mobile phones. This means that students who have no access to classroom computers are not excluded from these learning opportunities.

On the basis of their research study, Roschelle, Patton, and Tatar (2007) claim that using mobile devices transforms the mathematics classroom into a student, assessment, knowledge, and community-centred entity. Genossar, Botzer, and Yerushalmy (2008) analysed the learning processes and experiences that occurred within a mobile phone learning environment. They found that, apart from making the dynamic mathematical applications more accessible, the mobile phone enabled students to engage in real, authentic tasks. For instance, students could record simple dynamic events with their cell phones' video cameras and later convert the video clips into mathematical models using the mathematics applications. The mobile phone learning environment also allowed the students to work collaboratively by sharing graphs and formulae and solving problems collectively. This helped establish a community of mathematics learners. In a recent study (2010), Daher confirmed the formation of collaborative communities of budding young mathematicians. Preservice teachers collected data that supported the finding that middle school student knowledge building could be fostered through learning mathematics in a mobile phone environment. Students jointly engaged in and solved authentic mathematical problems with the help of mobile phones.

In South Africa, the Meraka Institute (a research institute) has been at the forefront of the innovative use of mobile/cell phone technology to support the teaching and learning of mathematics. The Institute has been able to develop a mobile tutoring system, Doctor Maths, which runs on the MXit platform. MXit is a very popular instant-messaging service that is accessible via cell phones and that has over three million school-age subscribers. Volunteers from the Department of Engineering at the University of Pretoria offer real-time mathematical support to the high school students using the MXit chat facility on students' cell phones at reduced rates. From an initial enrolment of just 20 students, to date the service has grown to support over 1,000 students (Van Rooyen, 2010). However, even with this evidence, it is still difficult to clearly isolate the actual functionalities that should be targeted when designing instruction using the mobile phone in teaching.

\section{Diagnostic Testing in Distance Education}

The aim of the precourse diagnostic testing carried out in this project was to determine, as quickly as possible, students' prior knowledge of the subject at the beginning of an in- 
troductory distance calculus course. The type of pre-testing administered in this project is slightly different from the multiple-choice computerised diagnostic testing administered to determine students' mathematical skill competencies with a view to suggesting remedial strategies (Appleby, Samuels, \& Treasure-Jones, 1997). Prior research done at the undergraduate level consistently reveals that students start calculus courses with a limited view and understanding of the functional concept (Tall, 1996; Ferrini-Mundy \& Lauten, 1993). In addition to this, students often exhibit cognitive difficulties when interpreting the functional concept using algebraic and graphical representations (Schnepp \& Nemirvosky, 2001). The aim of this project was to ascertain if the students who enrolled for the calculus course at UNISA had an understanding of the two basic calculus concepts, the derivative and the integral, and to subsequently build on that knowledge to inform future instructional design decisions.

The use of precourse diagnostic testing in order to support student learning is not a new idea. Over the years, the recognition that students' initial beliefs and ideas about particular phenomena form the basis of their future learning was used to design and develop diagnostic instruments to test and support student learning (Halloun \& Hestenes, 1985). Currently, there are many examples of computer-assisted tutoring and testing systems (Chiou, Hwang, \& Tseng, 2009; Springer \& Pear, 2008). The advent of web technology has also provided us with a platform on which web-based diagnostic systems can be accessed by face-to-face and distance students alike (Bälter, 2009).

For this study, it was important to identify, as a proof-of-concept exercise, how the mobile phone could be used to enhance the learner's experience in a way that current distance learning provision was failing to do. The main aim of the study was to establish what the didactic functionalities of a mobile phone were and how they could be exploited to inform prediagnostic testing design at a distance.

\section{Theoretical Framework of the Study}

The learning transaction between teacher and student in a distance learning environment cannot occur without some form of technological mediation. The theoretical framework used in this study therefore includes ideas borrowed from two parent frameworks, an instructional design (or teaching and learning framework) together with a framework for analysing the role played by technology. The next sections are elaborations of these two frameworks; note that these two frameworks were combined for the final analysis of the project outcomes.

\section{The Instructional Design Framework}

The prediagnostic testing in this project is part of a larger project that examines the developmental efforts required to adapt the instructional design perspective of Realistic Mathematics Education (RME) to the teaching and learning of calculus via distance education. RME was first introduced at the Freudenthal Institute in the Netherlands in the 1970s in response to a call for reform in mathematics education. RME is based on Freudenthal's 
(1973; 1991) belief that mathematics education should take its point of departure in mathematics as a human activity, rather than mathematics as some sort of ready-made system. The fundamental idea is that by designing instruction in which both everyday situations and mathematical activities are mathematised, students can be helped to reinvent mathematics and (as a result) attain a better understanding of the subject.

The approach capitalises on mathematising (regarding or treating a subject or problem in mathematical terms) as a central learning activity together with guided reinvention and emergent modelling as central processes within the learning experience (Gravemeijer, 1994; Bakker, 2004; Zulkardi, 1999).

- Guided reinvention involves reconstructing "a natural way of developing a mathematical concept from a given problem situation” (Bakker, Dorman, \& Drijvers, 2003).

- Emergent models are models that initially represent problem situations, but later on develop into models of abstract mathematical objects and relations (Bakker, Dorman, \& Drijvers, 2003).

From a design perspective, the teacher needs to have some idea about where his/her students are in terms of the projected learning in order to design appropriate learning activities based on ideas that are less sophisticated than the mathematical concepts being developed. This is why the diagnostic test needed to be administered quickly. In this case, the diagnostic test was directed to getting a sense of students' initial knowledge of the concepts of derivative and integral at the beginning of the course.

\section{Framework for Analysing the Role Played by the Technology}

Since the transaction between teacher and student in a distance learning environment cannot occur without some form of technological mediation, a type of construct was required to analyse the role played by the technology. Cerulli, Pedemonte, and Robotti's (2005) perspective of didactical functionalities fit well with this requirement. Cerulli et al. (2005) regard didactical functionalities as those properties (or characteristics) of a given information and communication technology (ICT) and its modalities of employment which may favour or enhance teaching and learning processes in reaction to a specific education goal.

Another construct borrowed from Cerulli et al.'s (2005) approach was the education experiment cycle (EEC) model. This was used to identify the critical phases within the project. The EEC model has three main phases: (a) the planning phase involving the setting up and sequencing of activities; (b) the putting into practice phase, in which the planned activity is implemented; and (c) the diagnostic phase, which involves evaluating the actors (teachers and students) involved. A tool's modality of employment can be analysed in any (or only one) of the three phases, depending on the educational goal.

In order to illustrate the universality of their theory, Cerulli et al. (2005) demonstrated how the perspective of didactic functionalities could be combined with different teaching and learning theoretical frameworks in order to delineate the didactical purposes of the tech- 
nological tools employed in the course of teaching and learning. Examples of the teaching and learning frameworks examined were Brousseau's theory of didactic situations, Nardi's version of activity theory (concentrating on computer-mediated learning), and the theory of instruments of semiotic mediation.

- Brousseau's (1997) theory of didactic situations organises the teaching process into three parts: (a) the non-didactical, which is not specifically organised to allow for learning; (b) the didactical, in which the teachers explicitly organise tasks to teach students forms of knowledge in a specific manner; and (c) the adidactical. The adidactical refers to the process of channelling students into solving problems that are designed to provoke students into finding their own solutions. As a result, students acquire the desired forms of knowledge and reasoning for understanding given concepts. At the heart of Brousseau's theory is the milieu, which describes the middle ground of the teaching and learning cognitive space in which the teacher, the learner, and all the facets of the teaching/learning environment interact. The basis for this theory is a Piagetian view of learning, where the learner goes through the universal processes of assimilation and adaptation in well-defined stages of learning development until he or she reaches the complete adidactical situation of taking full responsibility for his or her learning. Analysis of tool use in this case focuses on interactions and retroactions or feedback. The modality of employment involves situations where the learners interact with a tool and receive feedback. This can be achieved in either the planning or implementation phases. The didactical functionalities are defined in terms of the user's retroactions.

- Activity theory is a research framework entrenched in a set of viewpoints derived from the work of the Russian psychologists Vygotsky, Leont'ev, and others in the 1920 s (Nardi, 1996; Engeström, 1999). Activity theorists seek to understand and scientifically explore individual consciousness (cognitive acts) rooted in everyday practice and embedded in social mediums composed of people and artefacts (Nardi, 1996). Artefacts here may be either tools or symbol systems (e.g., languages). In this project, the point of reference is Nardi's version of activity theory as applied to human computer interaction (HCI) research. Consequently, the examination of tool use in this context shifts to the structuring of activities. The modalities of employment are geared toward creating activities designed to encourage the engagement of all participants. In this case, the didactical functionalities are defined in terms of how the tools are used to structure the activities.

- The last example Cerulli et al. (2005) refer to is one using the theory of instruments of semiotic mediation. This approach is derived from a Vygotskian social cultural theoretical view of learning, in which the development of meaning is based on a phenomenological experience of the learner with other members of the society, with the help of an artefact or tool. According to Mariotti (2002), the artefact serves as a semiotic mediator because it is used by the teacher to help the learner construct meaning. For the learner, meanings emerge as he or she participates in an activity involving the artefact. Here, the modalities of employing the tool require setting up activities involving the tool as well as orchestrating discussions using signs developed by the tool to assist 
meaning making.

\section{The Combined Framework}

For this project, Cerulli et al.'s (2005) perspective of didactic functionalities and the RME approach to instructional design were combined to create a framework for designing and evaluating the precourse assessment activities. The RME framework was used to guide the design of the preassessment activities. The resulting theoretical framework, consisting of a combination of RME and the perspective of didactic functionalities, is shown in Figure 1. In terms of the perspective of didactic functionalities, the tool being considered in this research was the mobile phone within the mobile learning platform. The goal was to establish the tool's didactic functionality. The didactic functionalities of the mobile phone were analysed in only one modality of employment, that of diagnostic testing.

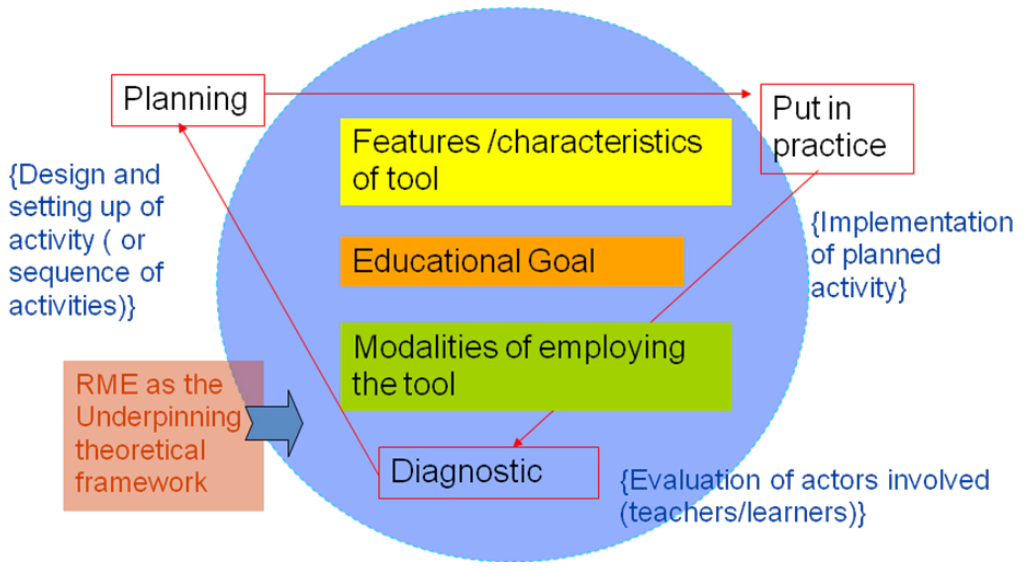

Figure 1. RME and the perspective of didactic functionalities in prediagnostic testing design using the mobile phone as a didactic support tool (diagram developed by the author).

\section{Method}

A prediagnostic test aimed at determining initial student understanding of basic calculus concepts (the derivative and integral) was delivered using both print and the mobile phone. Thirty volunteer students took a 10-item prediagnostic test that was delivered using both print and the mobile phone. The students were UNISA students who had completed their first semester in a first-year calculus course. The researcher for the study was the curriculum designer, who also played an instructor role in this pilot study.

The questions were designed to gauge the students' understanding of functions, their interpretation of graphs, and their understanding of the terms the derivative and the integral (see Appendix). Questions 1 and 2 were designed to test students' understanding of the function and its graphical representation. Questions 3 to 7 tested students' understanding of the derivative, including personal definitions, graphical interpretation of the concept, and use of simple formulae. Questions 8 to 9 tested students' personal definitions of the integral and included one typical integral evaluation problem. Question 10 was designed to check the students' understanding and graphical interpretation of both the derivative and 
integral concepts in relation to the average velocity and total distance covered by a moving object.

\section{The Creation of the Content}

OutStart-Hot Lava Mobile, available at http://www.outstart.com/about-hot-lava-mobile. $\underline{\mathrm{htm}}$, was used as the learning development and management platform. Figures 2 and 3 are representations of two question items ( 1 and 4 ) as they appeared in the normal text version and the mobile phone version.

\section{Normal text version}

Q1 Let $f$ be a function defined by $2 \sin (x+3)$ and let $g$ be the function defined by $\boldsymbol{g}(\boldsymbol{u})=\boldsymbol{s i n u}+\boldsymbol{c o s} \boldsymbol{u}$ $2 \sin (u+3)$ for all real numbers $x$ and $u$, then,

A $\quad f$ and $g$ are exactly the same functions B $\quad f$ and $g$ are different functions if $x$ and $u$ are different numbers

$\mathrm{C}$ not enough information is given to determine if $f$ and $g$ are the same functions
Mobile phone version
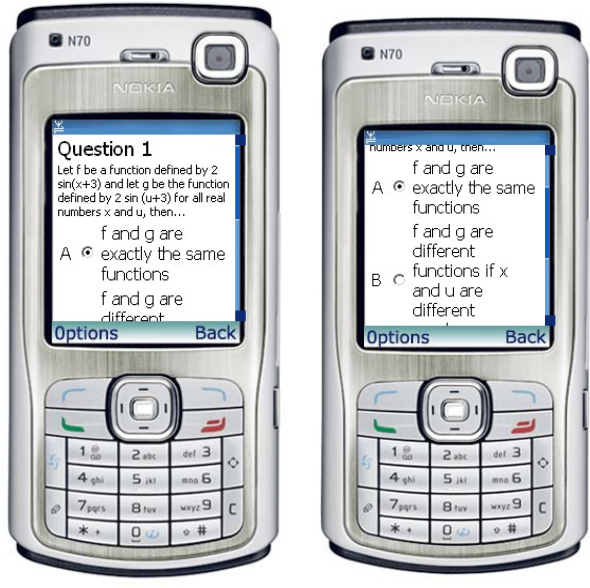

Figure 2. Representation of question 1 in the normal and the mobile phone versions.

\section{Normal text version}

Q4 Interpret from the graph what the quotient

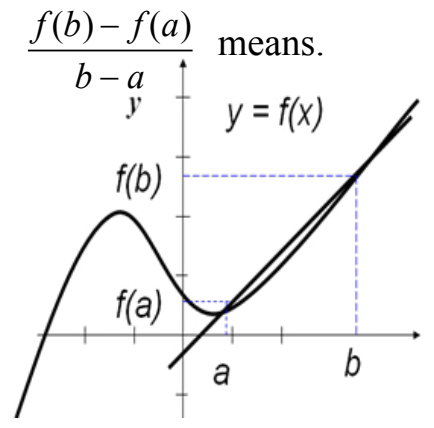

\section{Mobile phone version}

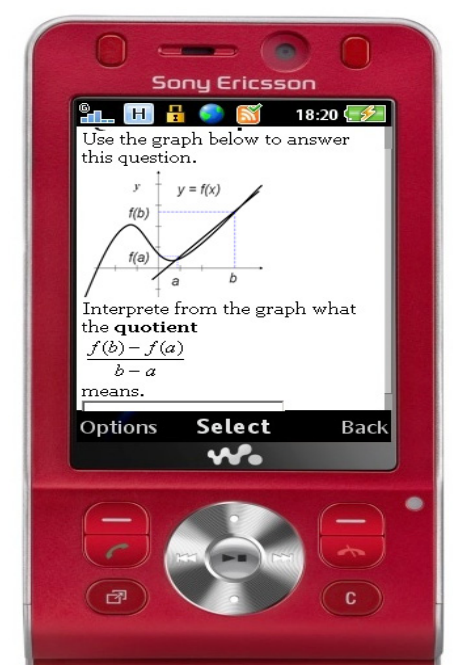

Figure 3. Representation of question 4 in the normal and the mobile phone versions. 
The Hot Lava software integrated an authoring system with a mobile delivery and tracking system. The integrated system of components provided a fast and efficient way of designing, creating, editing, deploying, and tracking content that could be delivered to different mobile phone models. One advantage of Hot Lava was that the content could be delivered on a variety of mobile phones. The other main advantage was its ability to track and see which students were logged in and when they registered. On individual screens, the instructor could see the order in which students attempted the questions and the number of attempts at each question before a final answer was submitted. I could also see how much time students spent on the test.

\section{Results}

Only nine students (30\%) of the group preferred to take the test on the mobile phone. Those who declined to take the test on the phone felt that they were more comfortable working with mathematics on paper. However, all of the students who took the test on the mobile indicated that they enjoyed it. There were no notable differences in terms of overall student performance on tasks. There were a few differences in terms of the number of questions completed (due to input issues), the turnaround time for receiving the answers, and the availability or nonavailability of a system for tracking student responses. Table 1 is a comparative summary of some of the findings.

Table 1

Comparison of Students who took the Print and Mobile Versions of the Test

\begin{tabular}{|c|c|c|}
\hline & Print version & Mobile version \\
\hline $\begin{array}{l}\text { Number of participants in- } \\
\text { volved }\end{array}$ & 21 & 9 \\
\hline Number of completed tests & 17 & 9 \\
\hline Time taken to complete test & Not available & 7 minutes and 45 seconds \\
\hline Time spent on each question & Not available & $46.5 \mathrm{sec}$ \\
\hline Questions not completed & None & $\begin{array}{l}\text { Q5 and Q8 (which required written } \\
\text { inputs) }\end{array}$ \\
\hline $\begin{array}{l}\text { Discernible difference in per- } \\
\text { formance on questions }\end{array}$ & None & None \\
\hline
\end{tabular}

Tracking information from the Hot Lava tracking system revealed that the average time spent on the mobile test was 7 minutes and 45 seconds.

\section{Responses}

The test sought initial student interpretations of the function, the difference quotient, and the concepts of derivative and integral. The following questions were used to guide the inquiry in terms of the four constructs. 
- Could students recognise that a function represented a relationship between the variation of one quantity (input) with the variation of another quantity (output)?

- Were students aware that the difference quotient $\frac{f(b)-f(a)}{b-a}$ represented a ratio between a change in output and a change in the input quantities?

- Did students associate the derivative with a rate of change of a quantity at a specific instant?

- Could students link the integral to an accumulated area under a curve?

\section{Responses from the Printed Version of the Test}

From the printed version of the test, only $17 \%$ of all participating students provided an acceptable interpretation of the concept of function.

The responses related to the difference quotient revealed that the majority of students had not yet developed a satisfactory interpretation of the difference quotient $\frac{f(b)-f(a)}{b-a}$ For example, one student referred to the quotient as the "gradient of the tangent to curve," even though the line drawn connecting the two points, $(a, f(a))$ and $(b, f(b))$, was not a tangent line. Another student defined the quotient as "the region between the graph $\mathrm{y}(f(\mathrm{x}))$ and the line." No respondent mentioned anything about the average rate of change of a function, which was what the quotient represented. A number of students said that the value of the quotient increased or the gradient became steeper as b moved close to a. The respondent who defined the quotient in terms of area said that "the area covered by the curve and the line as b moved closer to a." One student correctly stated that "as b moves nearer to a, the gradient of the chord approaches the gradient of the curve at point (a, $f(a))$.”

The general descriptions of the derivative given by the students depicted the derivative as an entity resulting from mathematical manipulations. Below are three examples of derivative definitions:

A derivative is a task that gets an expression out of a function and makes that found expression be a function on its own;

A derivative is a function or constant obtained from differentiating a previous function one or more times;

... a derivative is a mathematical equation or constant obtained after def.

All the students using the print version were able to interpret the integral sign $\int^{b} f(x) d x$ correctly. Responses included descriptions such as "... this is integration of the function (x) with respect to $\mathrm{x}$ between limits a and b" and "the term that means the total area between 
the $\mathrm{f}(\mathrm{x})$ and the $\mathrm{x}$-axis within the limits $\mathrm{b}$ (which is the upper limit) and a (which is the lower limit) on the x-axis." There was also a computational or procedural definition: "to integrate means to raise the power of the function $\mathrm{f}(\mathrm{x})$ by 1 and divide the top function by what you get after raising the function." The majority of students carried out the graphical evaluations of integrals correctly.

\section{Responses from the Mobile Version of the Test}

Responses from students using the mobile version were similar to those who used the print version. Students still confused the difference quotient and the derivative. One respondent defined the difference quotient as "the gradient of the curve found from first principles, an approximate value of its gradient." Students gave the correct interpretation of the integral and acceptable responses to Q9 and Q10, which involved graphical interpretations. The multiple question items on the mobile phone were all completed, but some of the items that required filling in were not completed. In contrast, all students completed all 10 items when using the print-based format.

\section{Conclusion and Future Directions}

Even though the sample size was quite small, one can deduce that the important didactic feature of the tool (the mobile phone) was mainly the speed and ease of tracking and analysing student responses. From this preliminary study, it was clear that the utility of the mobile phone for pre-enrolment diagnostic testing in distance learning could be enhanced if the phone was used in conjunction with a mobile phone platform such as Hot Lava. As far as the adoption of an RME perspective in the design of instruction is concerned, the phone would be useful in quickly determining a student's starting point before embarking on any form of learning. Simple diagnostics tests could also be interjected at different teaching points during the course of learning to check student progress. In terms of student precourse testing, it seemed that the most prominent didactic functionality of the mobile phone was the speed and ease of tracking and analysing student responses.

One of the limitations of the mobile device was the students' difficulty in handling questions that required manipulating symbols and equations. The mobile phone interfaces of the smart phones used were unable to handle this effectively. Another drawback to using the Hot Lava platform was that this platform is too expensive to maintain in a developing world context. For example, the cost for the initial testing was US $\$ 1,000$ for the 30 students, and this fee did not include the additional charges required for each student registering on the Outstart-Hot Lava Web site.

Taking into account the limitations of this study (e.g., small sample size), one can draw the following conclusions:

- The mobile phone (embedded within a mobile phone platform such as Hot Lava mobile) can be used for precourse testing in a distance teaching and learning environment.

- The modality of employment for the tool in this project was as a diagnostic tool. The 
tool's didactic functionality was positively influenced by the speed and ease of tracking and analysing student responses but negatively affected by issues of availability (related to cost) and ease of use (linked to the difficulty of manipulating symbols and equations).

- For effective delivery and acceptance by users, one would need to find a way of using mobile devices where issues of affordability and ease of usage are adequately addressed.

Tim O’Reilly (2008) projects similar futuristic design ideas when he imagines future mobiles that have sensor-rich interfaces (having features such as a microphone, a camera, a touch screen, an accelerometer). These devices are also able to link to an array of cloud services that support data recognition and retrieval in order to contain assets such as voice recognition and location sensors (GPS or cell triangulation). The technology is certainly advancing very quickly, and it is therefore possible that in the near future devices and affordable systems allowing easy manipulation of symbols and more opportunities for quality student-teacher interactions will be within reach of the majority of students. For now, it becomes more efficient to make instruction design decisions based on the required human functions and make adjustments as the technology progresses.

While it is essential to understand the strengths and weaknesses of a particular technology such as the mobile phone and use this information to deploy good pedagogical practices to achieve specific learning goals, we should-as do Jay Cross, Tony O'Driscoll, and Eilif Trondsen (2007)-ask the question: "What can this technology do that will enhance the learner's experience that my current learning provision does not?” For example, precourse assessment provision could be leveraged by organising it around a functional set of student needs, such as flexibility of symbol manipulation and affordability. One would then be able to examine the affordances the mobile device allows and map it onto students' ease of use and course instructors' priorities to develop relevant precourse assessment content.

In general, students preferred the paper-based tests, although they welcomed the increased opportunities for communicating with their tutor. Interviews would have to be integrated into future studies to explore in-depth perceptions of student experiences of mobile phone use. The results from this proof-of-concept project can inform the design of projects involving precourse assessment with a larger number of students. More focused research is still required to determine how best to turn the capabilities of the mobile phone into a leading component of the testing environment in distance education. 


\section{References}

Appleby, J., Samuels, P., \& Treasure-Jones, T. (1997). Diagnosys - A knowledge-based diagnostic test of basic mathematical skills. Computers and Education, 28(12), $113-131$.

Bakker, A. (2004). Design research in statistics education: On symbolizing and computer tools. Utrecht: CD- $\beta$ Press.

Bakker, A., Doorman, M., \& Drijvers, P. (2003). Design research on how IT may support the development of symbols and meaning in mathematics education. Retrieved from http://www.fi.uu.nl/publicaties/literatuur/5896.pdf

Bälter, O. (2009, November). Diagnostic web-based monitoring in CS1. Paper presented at the Ninth Koli Calling International Conference on Computing Education Research, Koli National Park, Finland. Retrieved from http://arachne.it.uu.se/research/publications/reports/2010-027/2010-027.pdf\#page $=67$

Brown, J. D. M., Metcalf, D., \& Christian, R. (2008, Summer). Mobile learning update. The Learning Consortium Perspective. Retrieved from http://www.masie.com/

Brousseau, G. (1997). Theory of didactical situations in mathematics (N. Balacheff, M. Cooper, R. Sutherland and V. Warfield, trans.), Kluwer, Dordrecht.

Cerulli, M., Pedemonte, B., \& Robotti, E. (2005). An integrated perspective to approach technology in mathematics education. Paper presented at the CERME 4, Sant Feliu de Guíxols, Spain, 1389-1399. Retrieved from http://telearn.noe-kaleidoscope. org/warehouse/Cerulli-M-Pedemonte-P-Robotti-E-2006.pdf

Chiou, C. K., Hwang, G. J., \& Tseng, J. C. R. (2009). An auto-scoring mechanism for evaluating problem-solving ability in a web-based learning environment. Computers \& Education, 53(2), 261-272.

Cross, J., O’Driscoll, T., \& Trondsen, E. (2007). Another life: Virtual worlds as tools for learning. Paper presented at eLearn 2007. Retrieved from http://www.reviews.

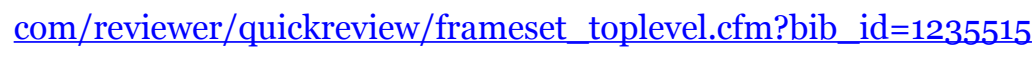

Daher, W. (2010). Building mathematical knowledge in an authentic mobile phone environment. Australasian Journal of Educational Technology, 26(1), 85-104.

Engeström, Y. (1999). Expansive visibilization of work: An activity-theoretical perspective. Computer Supported Cooperative Work, 8(1-2), 63-93.

Ferrini-Mundy, J., \& Lauten, D. (1993). Teaching and learning calculus. In P. Wilson \& S. Wagner (Eds), Research ideas for the classroom: High school mathematics (pp. 117-139). New York: MacMillan. 
Freudenthal, H. (1973). Mathematics as an educational task. Dordrecht: Kluwer Academic Publishers.

Freudenthal, H. (1991). Revisiting mathematics education - China lectures. Dordrecht: Kluwer Academic Publishers.

Genossar, S., Botzer, G., \& Yerushalmy, M. (2008). Learning with mobile technology: A case study with students in mathematics education. International Journal of Emerging Technologies in Learning, 4(1), 23-28.

Gravemeijer, K. P. E. (1994). Educational development and educational research. Journal for Research In Mathematics Education, 25(5), 443-471.

Halloun, I., \& Hestenes, D. Common sense concepts about motion. American Journal of Physics, 53, 1056-1065.

Hartnell-Young, E., \& Vetere, F. (2008). A means of personalizing learning: Incorporating old and new literacies in the curriculum with mobile phones. Curriculum Journal, 19(4), 283-292.

Kinsella, S. (2009). Many to one: Using the mobile phone to interact with large classes. British Journal of Educational Technology, 4O(5), 956-958.

Mariotti, M. A. (2002). Influence of technologies advances on students' mathematical learning. In L. English, D. Tirosh, \& M. Bartolini Bussi (Eds.), Handbook of international research in mathematics education (pp.73-87). LEA.

Nardi, B. A. (1996). Activity theory and human-computer interaction. In B. A. Nardi (Ed.), Context and consciousness: Activity theory and human-computer interaction (pp. 69-103). Cambridge: MIT Press.

O’Reilly, T. (2008). Voice in Google mobile app: A tipping point for the web? Retrieved from $\quad$ http://radar.oreilly.com/2008/11/voice-in-google-mobile-app-tippingpoint.html

Roschelle, J., Patton, C., \& Tatar, D. (2007). Designing networked handheld devices to enhance school learning. Advances in Computers, 7o, 1-60.

Schnepp, M., \& Nemirvosky, R. (2001). Constructing a foundation for the fundamental theorem of calculus. In A. Cuoco \& F. Curcio (Eds.), The role of representation in school mathematics. Reston, VA: NCTM.

Springer, C. R., \& Pear, J. J. (2008). Performance measures in courses using computeraided personalized system of instruction. Computers \& Education, 51(2), 829-835.

Tall, D. (1996). Functions and calculus. In A. Bishop, K. Clements, C. Keitel, J. Kirkpatrick, \& C. Laborde (Eds), The International handbook of mathematics education: Part 
$I$ (pp. 289-325) . Dordrecht: Kluwer Academic Publishers.

Traxler, J. (2007). Defining, discussing and evaluating mobile learning: The moving finger writes and having writ. International Review of Research in Open and Distance Learning, 8(2). Retrieved from http://www.irrodl.org/index.php/irrodl/article/ viewArticle/346

Van Rooyen, A. A. (2010). Effective integration of SMS communication into a distance education accounting module. Meditari: Research Journal of the School of Accounting Sciences, 18(1), 47-57.

Viljoen, J. D., \& Carlcook, A. (2005). The case for using SMS technologies to support distance education students in South Africa: Conversations. Perspectives in Education: Research on ICTs and Education in South Africa, Special Issue, 4(23), 115122.

Wagner, E. D. (2005). Enabling mobile learning. EDUCAUSE Review, 4O(3), 40-53.

Wei , F.-S., \& Chen, G.-D. (2006). Collaborative mentor support in a learning context using a ubiquitous discussion forum to facilitate knowledge sharing for lifelong learning. British Journal of Educational Technology, 37(6), 917-935.

Yerushalmy, M., \& Ben-Zaken, O. (2004). Mobile phones in education: The case forMathematics. Haifa. Retrieved from http://construct.haifa.ac.il/ michalyr/celular\%20 report.pdf

Zulkardi. (1999). How to design mathematics lessons based on the realistic approach. Literature Study. University of Twente. Retrieved from http://www.geocities.com/ ratuilma/rme.html 


\section{Appendix}

TASK 1 - THE PRE-TEST

INSTRUCTIONS: Attempt all questions.

Do not panic if you cannot answer all the questions - we we can support you better!

Mobile phone
activity I

Questions 1-10 can be completed on your mobile phone or printed and faxed to your tutor.

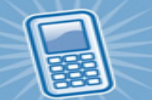

Q1 Let $f$ be a function defined by $2 \sin (x+3)$ and let $g$ be the function defined by $2 \sin (u+3)$ for all real numbers $x$ and $u$ then

A $\quad f$ and $g$ are exactly the same functions

$f$ and $g$ are different functions if $x$ and $u$ are

C nifferent numbers

formation is given to determine if $f$
Q2

The graph of $f$ is shown below:

$x$

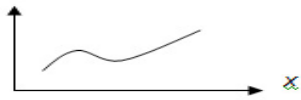

The statement, " $f$ is a function of $x "$ is ....
A
true
false

Q3 Explain in your own words what the "derivative" is $\left[\begin{array}{c}n \\ \end{array}\right.$

Q4 Interpret from the graph what the quotient $\frac{f(b)-j}{b-c}$ means.

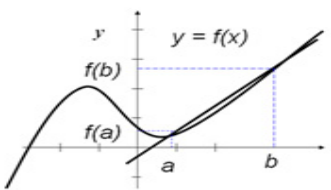

Q5 Interpret from the graph what happens to $\frac{f(b)-f(a)}{b-a}$ when b moves closer to $a$
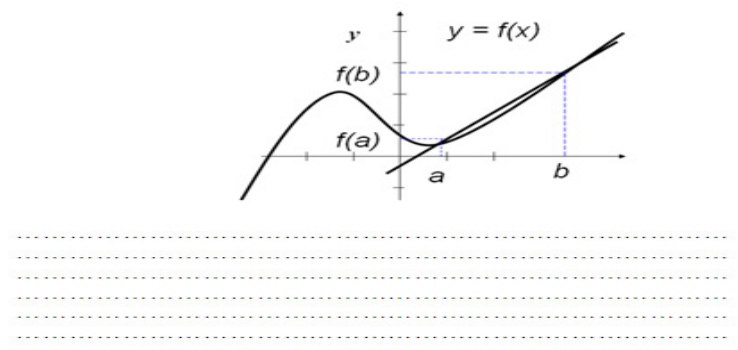

Q6 $\frac{d}{d x}\left(x^{2}+3\right)=$

Q8 How do you explain to a fellow classmate the meani $\int_{a}^{b} f(x) d x$ ?

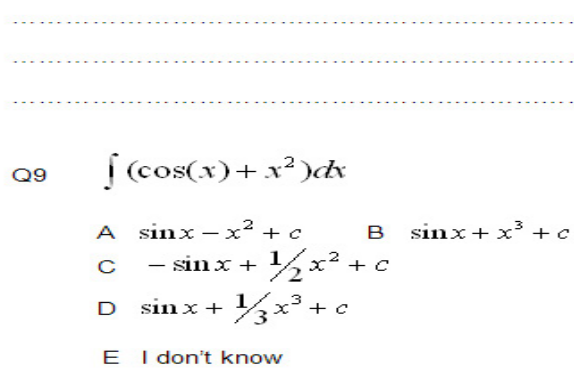

A $2 x+3 \quad$ B $2 x \quad$ C $x^{2} \quad$ D 2 Enl don't know

Q7 $\frac{d}{d x}(4 \cos (3 x))=$

Q10 Use the graph below to answer questions 10(a) and $10(b)$

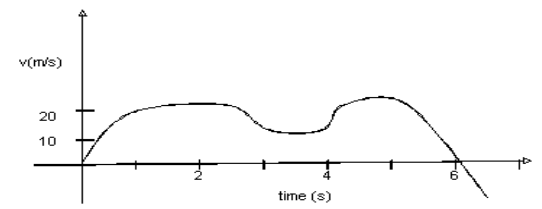

(a) Interpret from the graph what the average Interpret from the
velocity might be

A $\quad 5 \mathrm{~m} / \mathrm{s}$

B $15 \mathrm{~m} / \mathrm{s}$

E I don't know

C $25 \mathrm{~m} / \mathrm{s}$

(b) Interpret from the graph what the total distance covered by the car in $6 \mathrm{~s}$ is:

A $\quad 10 \mathrm{~m}$ B $50 \mathrm{~m}$

C $90 \mathrm{~m}$

D $120 \mathrm{~m}$ 


\section{Athabasca University $\mathbf{z}$}

(c) (†) 
THE INTERNATIONAL

REVIEW OF RESEARCH IN

OPEN AND DISTANCE LEARNING

\section{Heutagogy and Lifelong Learning: A Review of} Heutagogical Practice and Self-Determined Learning

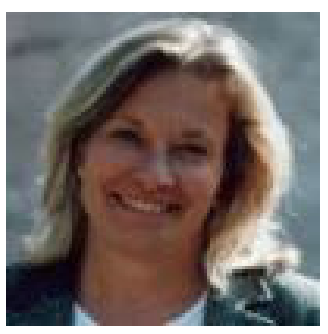

Lisa Marie Blaschke

Oldenburg University and University of Maryland University College (UMUC)

\section{Abstract}

Heutagogy, a form of self-determined learning with practices and principles rooted in andragogy, has recently resurfaced as a learning approach after a decade of limited attention. In a heutagogical approach to teaching and learning, learners are highly autonomous and self-determined and emphasis is placed on development of learner capacity and capability with the goal of producing learners who are well-prepared for the complexities of today's workplace. The approach has been proposed as a theory for applying to emerging technologies in distance education and for guiding distance education practice and the ways in which distance educators develop and deliver instruction using newer technologies such as social media. The renewed interest in heutagogy is partially due to the ubiquitousness of Web 2.o, and the affordances provided by the technology. With its learner-centered design, Web 2.0 offers an environment that supports a heutagogical approach, most importantly by supporting development of learner-generated content and learner self-directedness in information discovery and in defining the learning path. Based on an extensive review of the current literature and research, this article defines and discusses the concepts of andragogy and heutagogy and describes the role of Web 2.0 in supporting a heutagogical learning approach. Examples of institutional programs that have incorporated heutagogical approaches are also presented; based on these examples and research results, course design elements that are characteristic of heutagogy are identified. The article provides a basis for discussion and research into heutagogy as a theory for guiding the use of new technologies in distance education.

Keywords: Lifelong learning; heutagogy; self-determined learning; andragogy; self-directed learning; social media; capability; competency; double-loop learning; reflection 


\section{Introduction}

Educators today are tasked with developing lifelong learners who can survive and thrive in a global knowledge economy - learners who have the capability to effectively and creatively apply skills and competencies to new situations in an ever-changing, complex world (The World Bank, 2003; Kuit \& Fell, 2010). Pedagogical, even andragogical, educational methods are no longer fully sufficient in preparing learners for thriving in the workplace, and a more self-directed and self-determined approach is needed, one in which the learner reflects upon what is learned and how it is learned and in which educators teach learners how to teach themselves (Peters, 2001, 2004; Kamenetz, 2010). New technologies have also created a need for considering new pedagogical approaches, with andragogy falling out of favor with some educators, seemingly "outmoded in the light of recent rapid development in new teaching methods, learning resources, and digital media” (Wheeler, 2011 para. 1).

The concept of heutagogy offers certain principles and practices that could be considered as a response to these developments within higher education. A heutagogical learning environment facilitates development of capable learners and emphasizes both the development of learner competencies as well as development of the learner's capability and capacity to learn (Ashton \& Newman, 2006; Bhoryrub, Hurley, Neilson, Ramsay, \& Smith, 2010; Hase \& Kenyon, 2000). A renewed interest in heutagogy has also been generated by Web 2.0 as a result of the affordances of social media that complement and support this learning approach. Heutagogy has been called a "net-centric" theory that takes advantage of the key affordances of the Internet; it is also a pedagogical approach that could be applied to emerging technologies in distance education, as well as serve as a framework for digital age teaching and learning (Anderson, 2010, p. 33; Wheeler, 2011).

Heutagogy is of special interest to distance education, which shares with heutagogy certain key attributes, such as learner autonomy and self-directedness, and has pedagogical roots in adult teaching and learning. Self-determined learning, characteristic of distance education formats such as contract learning and prior learning assessment, is also an attribute of distance education. Distance education and heutagogy also have in common the same audience: mature adult learners. Specifically, heutagogy has the potential to become a theory of distance education, in part due to the ways in which heutagogy further extends the andragogical approach and also due to the affordances it offers when applied to emerging technologies in distance education (such as Web 2.0).

\section{Research Method}

This article provides an extensive review of the past and current research available on heutagogical practice and approaches. In approaching the research, the author sought to establish a basic understanding of the concept of heutagogy (for example, by relating the concept to andragogy) and how it has been applied within education environments. The review of the literature first presents definitions of andragogy and heutagogy, describing heutagogy in relation to established educational concepts of pedagogy and andragogy. The review incorporates discussion on the reasons for the re-emergence of heutagogy and spe- 
cifically considers the role of social media in supporting heutagogical practice. Examples of instructional design elements and social media that support heutagogical practice are also included. The article provides a basis for further discussion and research into heutagogy as a theory for emerging technologies in distance education and for exploring the feasibility of adopting heutagogy within distance education practice.

\section{Andragogy (Self-Directed Learning)}

Knowles (1978, as cited in Moore \& Kearsley, 2012) defined andragogy in the 1970 's as specific to adult education and characterized by learner control and self-responsibility in learning, learner definition of learning objectives in relation to their relevance to the learner, a problem-solving approach to learning, self-directedness in how to learn, intrinsic learner motivation, and incorporation of the learner experience. In an andragogical approach to teaching and learning, learners are actively involved in identifying their needs and planning on how those needs will be met (McAuliffe, Hargreaves, Winter, \& Chadwick, 2008; Rachal, 2002). A key attribute of andragogy is self-directed learning, defined by Knowles (1975) as

a process in which individuals take the initiative, with or without the help of others, in diagnosing their learning needs, formulating learning goals, identifying human and material resources for learning, choosing and implementing appropriate learning strategies, and evaluating learning outcomes (p. 18)

The goals of self-directed learning include helping learners develop the capacity for selfdirection, supporting transformational learning, and promoting "emancipatory learning and social action" (Merriam, 2001, p. 9). Within transformational learning, learning occurs along a self-directed path; as the learner matures and reflects on life experiences in relation to his or her self-perception, beliefs, and lifestyle, the learner perspective is adjusted and transformative learning can occur (Mezirow, 1997).

The role of the educator in an andragogical approach is that of tutor and mentor, with the instructor supporting the learner in developing the capacity to become more self-directed in his or her learning. The instructor shows learners how to find information, relates information to the learner experience, and places a focus on problem-solving within real-world situations (McAuliffe et al., 2008). Instructors establish objectives and curriculum based on learner input and guide students along the learner path, while the responsibility for learning lies with the learner.

\section{Heutagogy (Self-Determined Learning)}

Heutagogy (based on the Greek for "self") was defined by Hase and Kenyon in 2000 as the study of self-determined learning. Heutagogy applies a holistic approach to developing learner capabilities, with learning as an active and proactive process, and learners serving 
as "the major agent in their own learning, which occurs as a result of personal experiences" (Hase \& Kenyon, 2007, p. 112). As in an andragogical approach, in heutagogy the instructor also facilitates the learning process by providing guidance and resources, but fully relinquishes ownership of the learning path and process to the learner, who negotiates learning and determines what will be learned and how it will be learned (Hase \& Kenyon, 2000; Eberle, 2009).

A key concept in heutagogy is that of double-loop learning and self-reflection (Argyris \& Schön, 1996, as cited in Hase \& Kenyon, 2000). In double-loop learning, learners consider the problem and the resulting action and outcomes, in addition to reflecting upon the problem-solving process and how it influences the learner's own beliefs and actions (see Figure 1). Double-loop learning occurs when learners "question and test one's personal values and assumptions as being central to enhancing learning how to learn” (Argyris \& Schön, 1978, as cited in Hase, 2009, pp. 45-46).

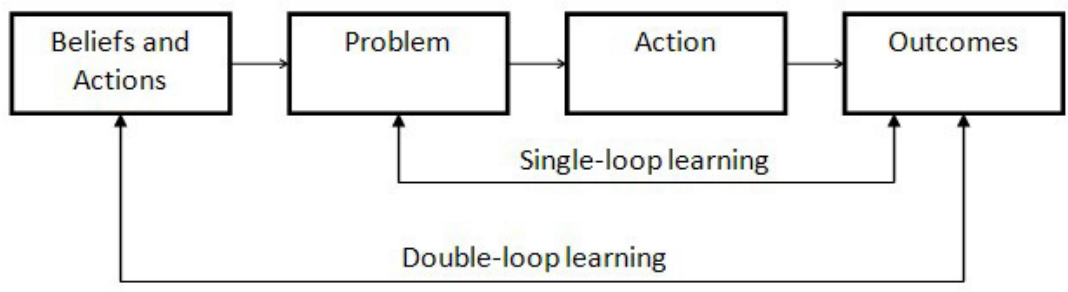

Figure 1. Double-loop learning (Eberle \& Childress, 2005, as shown in Eberle, 2009, p. 183).

In self-determined learning, it is important that learners acquire both competencies and capabilities (Stephenson, 1994 as cited in McAuliffe et al., 2008, p. 3; Hase \& Kenyon, 2000, 2007). Competency can be understood as proven ability in acquiring knowledge and skills, while capability is characterized by learner confidence in his or her competency and, as a result, the ability "to take appropriate and effective action to formulate and solve problems in both familiar and unfamiliar and changing settings" (Cairns, 2000, p. 1, as cited in Gardner, Hase, Gardner, Dunn, \& Carryer, 2007, p. 252). Capable people exhibit the following traits:

- $\quad$ self-efficacy, in knowing how to learn and continuously reflect on the learning process;

- communication and teamwork skills, working well with others and being openly communicative;

- creativity, particularly in applying competencies to new and unfamiliar situations and by being adaptable and flexible in approach;

- positive values (Hase \& Kenyon, 2000; Kenyon \& Hase, 2010; Gardner et al., 2007). 
When learners are competent, they demonstrate the acquisition of knowledge and skills; skills can be repeated and knowledge retrieved. When learners are capable, skills and knowledge can be reproduced in unfamiliar situations. Capability is then the extension of one's own competence, and without competency there cannot be capability. Through the process of double-looping, learners become more aware of their preferred learning style and can easily adapt new learning situations to their learning styles, thus making them more capable learners. With its dual focus on competencies and capability, heutagogy moves educators a step closer toward better addressing the needs of adult learners in complex and changing work environments (Bhoryrub et al., 2010).

\section{Heutagogy as an Extension of Andragogy}

The heutagogical approach can be viewed as a progression from pedagogy to andragogy to heutagogy, with learners likewise progressing in maturity and autonomy (Canning, 2010, see Figure 2). More mature learners require less instructor control and course structure and can be more self-directed in their learning, while less mature learners require more instructor guidance and course scaffolding (Canning \& Callan, 2010; Kenyon \& Hase, 2010). Cognitive development of learners, a requirement for critical reflection and discourse to occur, could also be integrated into this pyramid, with cognitive development progressing in parallel with learner maturity and autonomy (Mezirow, 1997).

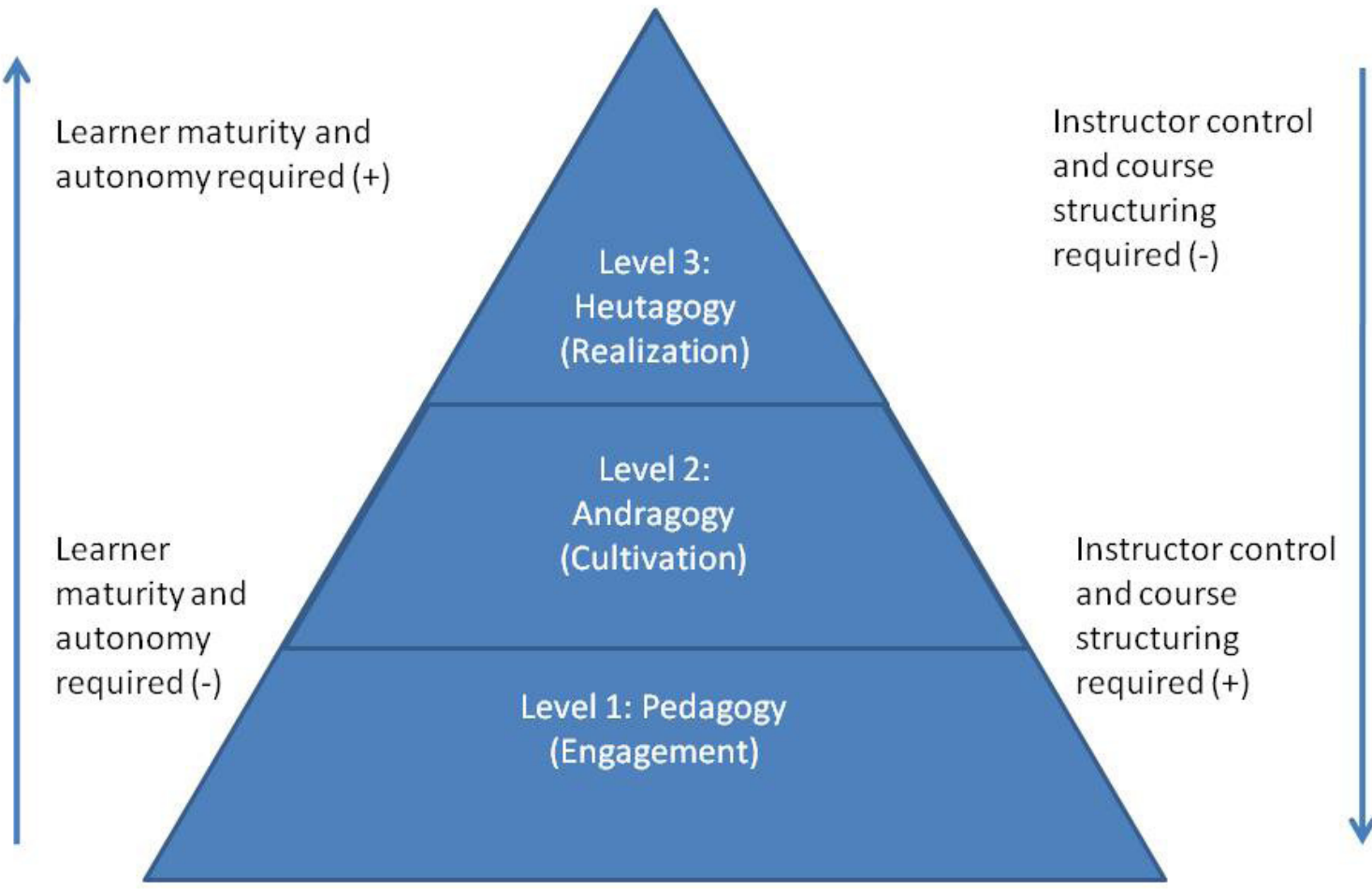

Figure 2. Progression from pedagogy to andragogy then to heutagogy (based on Canning, 2010, p. 63). 
With its basis in andragogy, heutagogy further extends the andragogical approach and can be understood as a continuum of andragogy (Table 1). In andragogy, curriculum, questions, discussions, and assessment are designed by the instructor according to the learner needs; in heutagogy, the learner sets the learning course, designing and developing the map of learning, from curriculum to assessment (Hase, 2009). Heutagogy emphasizes development of capabilities in addition to competencies (andragogy). Table 1 provides an overview of traits that help demonstrate ways in which heutagogy builds upon and extends andragogy.

Table 1

Heutagogy as a Continuum of Andragogy

\begin{tabular}{l|l|l}
\hline Andragogy (Self-directed) & & Heutagogy (Self-determined) \\
\hline Single-loop learning & & Double-loop learning \\
\hline Competency development & - & Capability development \\
\hline $\begin{array}{l}\text { Linear design and learning ap- } \\
\text { proach }\end{array}$ & $\checkmark$ & Non-linear design and learning approach \\
\hline Instructor-learner directed & - & Learner-directed \\
\hline Getting students to learn (content) & $\triangleright$ & $\begin{array}{l}\text { Getting students to understand how they learn } \\
\text { (process) }\end{array}$ \\
\hline
\end{tabular}

These traits and the continuum from andragogy to heutagogy require further consideration and definition. What can be derived from this comparison, however, is that heutagogy is an approach founded in andragogy and can be considered an expansion of the existing concept.

\section{Relevance to Distance Education}

Distance education is in a unique position for creating learning environments for supporting a heutagogical teaching and learning approach, as well as for contributing to further research into heutagogy. Specific characteristics of distance education that align themselves with heutagogy include:

- Technology: Technology's symbiotic relationship with distance education requires that, with each emerging technology, distance educators consider the implications of the technology on distance education theory and practice. Heutagogy has been identified as a potential theory for applying to emerging technologies in distance education (Anderson, 2010; Wheeler, 2011), although additional research and discussion is necessary in order to determine the credibility of heutagogy as a theory of distance education.

- Profile of the distance education learner: Traditionally, distance education has been designed, developed, delivered, and targeted to the adult learner, usually working 
adults with extensive life experience and more maturity than campus-based students (Holmberg, 2005; Peters, 2001; Moore \& Kearsley, 2012; Richardson, Morgan, \& Woodley, 1999). Distance education practice has historically been strongly influenced by Knowles' andragogical theory of teaching and learning, and as an extension of andragogy, heutagogy could be considered as a relevant theory for adult distance education.

- Learner autonomy: Distance education, as a distinct form of education, both requires and promotes autonomy, a learner skill that is central to a heutagogical teaching and learning approach (Peters, 2001). Because learner autonomy is characteristic of and promoted in distance education learning environments, distance education inherently supports heutagogical practice.

\section{How Web 2.0 and Social Media Enable Heutagogy}

Web 2.0 and social media has played an important role in generating new discussions about heutagogy within higher education. Web 2.0 design supports a heutagogical approach by allowing learners to direct and determine their learning path and by enabling them to take an active rather than passive role in their individual learning experiences. Key affordances of social media - connectivity with others, information discovery and sharing (individually and as a group), and personal collection and adaptation of information as required - are also affordances that support self-determined learning activities (McLoughlin \& Lee, 2007, p. 667). In addition, Web 2.0 encourages interaction, reflection in dialogue, collaboration, and information sharing, as well as promotes autonomy and supports creation of learnergenerated content (Lee \& McLoughlin, 2007; McLoughlin \& Lee, 2008, 2010). With Web 2.0 as its supporting technological framework, heutagogy can now be seen as further developing pedagogy 2.0 (as defined by McLoughlin \& Lee, 2007): learners are self-directed to continue to learn on their own and "can personalize their learning paths in the way they desire" (Kuit \& Fell, 2010, p. 320).

Recent research also indicates that the use of social media can support self-determined learning.

- Mobile learning: Cochrane and Bateman's (2010) research showed that mobile learning supports collaboration, data and resource capturing and sharing, and reflective practice. Use of mobile learning was also found to increase learner-learner and learnerexternal interaction, as well as reflective practice (learning journals).

- Virtual Philosopher: Hornsby and Maki (2008) report on an asynchronous learning tool meant to build learners' skills in developing, reflecting upon, and transforming thinking processes and logic. The online tool provides active learning activities built around various scenarios that the learner works through in a process of self-discovery. Through these scenarios and the responses provided by students, the Virtual Philosopher identifies flaws in the learner's thought processes, forcing the learner to evaluate and re-evaluate why she or he thinks in a certain way. According to Hornsby and Maki 
(2008), the asynchronous environment "seemed to reinforce deeper learning" and promotes problem solving and critical analysis (para. 30).

- Twitter: A recent study by Junco, Heiberger, and Loken (2010) showed that students who used Twitter (as compared to those who did not) were more actively engaged in their learning processes and had higher GPAs. Junco et al. (2010) also found that the use of Twitter boosted student-student and student-instructor interaction, as well as promoted active learning.

- Learner-generated content (active media use): Active use of social media in creating learner-generated content seems to contribute to development of skills of self-directedness. Initial research findings by Blaschke, Porto, and Kurtz (2010) indicate that active use of social media, for example, development of learner-generated content, supports cognitive and metacognitive skill development, whereas passive use (consumption) is less effective in supporting development of these skills.

These examples illustrate how social media has the potential to support elements of a heutagogical approach, such as creation of learner-generated content, active engagement in the learning process and with instructors and other learners, group collaboration, and reflective practice through double-loop learning. Research on the use of social media and its role in supporting heutagogy is limited, however, indicating that this is an area for further investigation.

\section{Heutagogy in Practice}

The higher education response to heutagogy so far has been one of reluctance, which could be due to the impracticality of implementing a full-blown educational framework of heutagogy. While acknowledging the need for pedagogy and andragogy, McAuliffe et al. (2008) argue that "the removal of the educator makes the concept of heutagogy impractical in a credentialing institution" and that it is not possible or even reasonable to implement heutagogy's trademark of learner-guided assessment (p. 4). Despite this, educators in the nursing, engineering, and education professions have found heutagogy to be a credible response to the critical issues that their learners are faced with in the workplace and have designed their learning environments based on the approach (Bhoryrub et al., 2010; Ashton \& Newman, 2006; Gardner et al., 2007). For example, within the nursing profession, Bhoyrub et al. (2010) report that heutagogy provides a learning framework that addresses needs of nursing students, who must learn in an ever-changing environment that is both complex and unpredictable; a heutagogical approach to learning helps them to become lifelong learners, as well as "makes sense of the necessary uncertainties that defines nursing" (p. 326).

University of Western Sydney in New South Wales, Australia, is an example of one institution that has implemented a heutagogical approach in its teacher education program by redesigning programs to integrate learner-directedness through blended learning. The approach has been integrated into course design, development, and delivery, however not in 
the area of summative assessment. Through the use of this approach, the university has identified the following benefits: improved teacher outcomes, more capable teachers (learners) who are better-prepared for the complexities of the learning environment, increased learner confidence in perceptions, engaged learners in communities of practice, learner scaffolding of peers' learning processes, improved ability of the learner to investigate ideas, and further development of the learner's ability "to question interpretations of reality from their position of competence" (Ashton \& Newman, 2006, p. 829; Ashton \& Elliott, 2008).

Canning and Callan (2010) report on three higher education institutions in the UK that have used a heutagogical approach. Findings from their research show that the approach supports learner control of learning, collaborative reflection, learner's self-perception and professional development, and critical thinking and reflection. Reflective practice was found to help learners gain more control over learning, as well as comprehend and apply what they have learned in practical situations. Reflecting on the learning experiences and relating these experiences to professional practice helped keep learners motivated to learn, to connect with other learners, and to continue on with the reflective process (Canning \& Callan, 2010; Canning, 2010). Learners demonstrated both competency and capability through self-awareness, articulation of "feelings, experiences, and ideas," engagement in group discussion, self-directed investigation in developing independent ideas, and selfconfidence (Canning \& Callan, 2010, p. 80).

\section{Design Elements of a Heutagogical Approach}

When designing a self-determined learner experience, certain considerations should be made. A heutagogical approach to learning and teaching is characterized first and foremost by learner-centeredness in terms of both learner-generated contexts and content. Course design elements that support learner-centeredness in a heutagogical approach are presented below.

- Learner-defined learning contracts: Learning contracts support students in defining and determining their individual learning paths. These individualized contracts, such as those used at distance education institution Empire State College (see www.esc. edu), define what will be learned (e.g., scope), how it will be learned (e.g., teaching and learning approaches, learning activities), and what will be assessed and how it will be assessed (Kenyon \& Hase, 2010; Gilbert, 1975; Cristiano, 1993).

- Flexible curriculum: In a self-determined learning environment, the learner is the driver in creating flexible curriculum, which is defined by the student: learners create the learning map, and instructors serve as the compass (Hase \& Kenyon, 2007; Hase, 2009). Flexible curriculum in this sense is negotiated action learning, which adapts and evolves according to learner needs (Hase, 2009; Hase \& Kenyon, 2007). Learners negotiate "how, when, where and to what upper (rather than minimal) level they want to take their learning" (Hase, 2009, p. 47).

- Learner-directed questions: Learner-directed questions and the discussion that re- 
sults from these questions are what guide learners and serve as mechanisms for helping learners make sense of course content, bring clarity to ideas, and promote individual and group reflection (Kenyon \& Hase, 2001; Eberle, 2009). Guiding learners to define self-directed questions is one of the biggest challenges facing developers of heutagogical courses, as designers must be "creative enough to have learners ask questions about the universe they inhabit” (Kenyon \& Hase, 2001, para. 29).

- Flexible and negotiated assessment: In heutagogy, the learner is involved in designing his or her assessment. Negotiated and learner-defined assessment has been shown to improve the motivation of learners and their involvement in the learning process, as well as make learners feel less threatened by instructor control of their learning process (Hase \& Kenyon, 2007, p. 115; Hase, 2009; Ashton \& Elliott, 2007; Canning, 2010). One way of incorporating negotiation into the assessment process is through the use of learning contracts (Hase, 2009). The assessment should include measurable forms of assessing understanding of content, including whether the learner has achieved the competencies desired. Rubrics can also be used effectively in guiding learners in their self-assessment process, for example by assessing "discussion skills, quality of work, outcomes, collaboration, academic soundness and knowledge of material" (Eberle, 2008, p. 186).

Another dually important characteristic of heutagogy is that of reflective practice, "a critical learning skill associated with knowing how to learn" (Hase, 2009, p. 49). According to Schön (1983), reflective practice supports learners in becoming lifelong learners, as "when a practitioner becomes a researcher into his own practice, he engages in a continuing process of self-education" (p. 299). Heutagogy's holistic approach takes into account the learner's prior learning experiences and the way in which these influence how she or he learns; by considering these past experiences and the learner's current experience and reflecting upon these, the learner moves into a growth process that has the potential to lead to transformative learning - a process described by Canning and Callan (2010) as "spirals of reflection" (p. 71). The following course design elements can be incorporated to support reflective practice.

- Learning journals: Reflective learning journals can be used for learners to document their learning journey, reflect upon the course content and discussions, and explore new ideas. Learning journals have also been found to support students in developing cognitive and metacognitive skills, as well as help establish an ongoing practice of reflection (Blaschke \& Brindley, in press).

- Action research: Another form of reflective practice, which can be done individually or as a group, is action research. Action research gives learners an opportunity to experiment with real-world scenarios, which can help prepare them for the professional workplace (Hase \& Kenyon, 2007, p. 113).

- Formative and summative assessment: Ongoing, personalized assessment and feedback support the learner in developing his or her reflective practice. Canning and Cal- 
lan (2010) recommend that as part of the formative assessment, instructors should recognize and reinforce examples of reflective practice demonstrated by learners.

Collaborative learning is also a critical component of the heutagogical classroom. When learning collaboratively, learners work together in a collaborative space to create shared meaning and to reflect and think about how they learned and how to apply it in practice (Canning \& Callan, 2010). Kenyon and Hase (2001) and Hase (2009) recommend teambased approaches to learning such as communities of practice, where the focus of learning is primarily on the learning process and how learners learn. Knowledge sharing should be strongly encouraged and can be achieved by encouraging learners to share resources and information (Ashton \& Newman, 2006).

To implement a self-determined learning environment, instructors need to alter their teaching approach, primarily by placing value on learner self-direction of the learning process. Such a shift would require minimal change within distance education environments as distance education teaching methods support self-directed learning and the instructor role is already one of guide-on-the-side. They would also need to accept the heutagogical approach as one that is unconventional, where the instructor becomes a facilitator in the learning students' learning process (Cristiano, 1993). Instructors not only must change their approach to teaching and learning, but also ensure that they explain this type of learning to their students from the very start of class. As in a distance learning environment, students also need to understand that a heutagogical learning environment is quite different from the traditional learning experience with which they are familiar. Instructor expectations of learners should be clearly stated: learners are responsible for knowledge creation and deciding upon the learning path (Ashton \& Newman, 2006; Schwier, Morrison, \& Daniel, 2009). Empathy helps create a comfortable learning environment for learners unaccustomed to self-determined learning, and, as with self-directed learning, it is important to create a climate of mutual trust and respect with a clear delineation of instructor and learner roles and one that supports dialogue (Knowles, 1975). Ongoing guidance and feedback, as well as sharing of resources, support students along their learning journey, and learners will require ongoing instructor guidance and support throughout the learning process if they are to develop the capability of self-direction (Collis and Moonen, 2001, as cited in Ashton \& Newman, 2006).

\section{Further Research}

When considering emerging technologies in distance education, Veletsianos (2010) calls for additional inquiry and research into the relationship of technology, pedagogy, and the Web, and for further research and discussion into new pedagogies for emerging technologies. The literature review conducted here indicates that there is substantial work to be done in researching heutagogy within this research construct, for example examination of the means in which Web 2.0 and social media support a self-determined teaching and learning approach, and investigation of the effectiveness of the approach in higher education and in creating lifelong learners able to effectively and successfully translate compe- 
tencies into capability in complex, real-world situations. Another area of research includes defining and testing criteria for heutagogy as a framework for teaching and learning.

\section{Conclusion}

Since its beginnings in Australia in 2000, heutagogy has been presented as an extension of andragogy, but has received limited attention from higher education and from researchers. Challenges of adopting a heutagogical approach are many, such as academic resistance to change and a "fear of relinquishing power" (from instructor to student), increased financial and learning pressure on students due to new technology requirements, and a continued student focus on assessment and grades rather than the learning process (Ashton \& Newman, 2006, p. 832; Lee \& McLoughlin, 2007; McAuliffe et al., 2008). While higher education is more accepting of pedagogical and andragogical approaches within the institutional framework, it views heutagogy with more wariness, as heutagogy places full control of all aspects of learning into the hands of the student, from curriculum development and instructional format to assessment. A lack of student preparedness and acceptance would require a shift in learner attitude and a greater emphasis on scaffolding within the course design process and on the development of learner autonomy skills.

Creating competent and capable learners is "critical to life in the rapidly changing economy and cultures that characterize postmodern times" (Anderson, 2010, p. 33). By incorporating heutagogical practice, educators have the opportunity to better prepare students for the workplace and for becoming lifelong learners, as well as to foster student motivation by cultivating students who "are fully engaged in the topic they are studying because they are making choices that are most relevant or interesting to them" (Kenyon \& Hase, 2010, p. 170). Distance education has a particular affinity to the heutagogical approach, due to distance education's inherent characteristics of requiring and promoting learner autonomy, its traditional focus on adult learners, and its evolutionary and symbiotic relationship with technology - all characteristics shared with this emerging theory. Because of this affinity, distance education is in a unique position to provide a sustainable environment for studying and researching this teaching and learning method - and for assessing and evaluating the theory's appropriateness as a theory of distance education. 


\section{References}

Anderson, T. (2010). Theories for learning with emerging technologies. In G. Veletsianos (Ed.), Emerging technologies in distance education. Edmonton: Athabasca University Press. Retrieved from http://www.aupress.ca/books/120177/ebook/o2 Veletsianos 2010-Emerging Technologies in Distance Education.pdf

Ashton, J., \& Elliott, R. (2007). Juggling the balls - study, work, family and play: Student perspectives on flexible and blended heutagogy. European Early Childhood Education Research Journal, 15(2), 167-181.

Ashton, J., \& Newman, L. (2006). An unfinished symphony: 21st century teacher education using knowledge creating heutagogies. British Journal of Educational Technology, 37(6) 825-840. DOI: 10.1111/j.1467-8535.2006.00662.x.

Bhoryrub, J., Hurley, J., Neilson, G.R., Ramsay, M., \& Smith, M. (2010). Heutagogy: An alternative practice based learning approach. Nurse Education in Practice, 10(6), 322-326.

Blaschke, L.M., \& Brindley, J. (2011). Establishing a foundation for reflective practice: A case study of learning journal use. European Journal of Open, Distance, and ELearning (EURODL), Special Issue. Retrieved from http://www.eurodl.org/materials/special/2011/Blaschke_Brindley.pdf

Blaschke, L.M., Porto, S., \& Kurtz, G. (2010). Assessing the added value of Web 2.0 tools for e-learning: The MDE experience. In Proceedings of the European Distance and Elearning Network (EDEN) Research Workshop, October 25-27, 2010. Budapest, Hungary.

Canning, N. (2010). Playing with heutagogy: Exploring strategies to empower mature learners in higher education. Journal of Further and Higher Education, 34(1), 59-71.

Canning, N. \& Callan, S. (2010). Heutagogy: Spirals of reflection to empower learners in higher education. Reflective Practice, 11(1), 71-82.

Cochrane, T., \& Bateman, R. (2010). Smartphones give you wings: Pedagogical affordances of mobile Web 2.o. Australasian Journal of Educational Technology, 26(1), 1-14.

Cristiano, M.J. (1993). I want to learn what I want to learn in the way I choose to learn it: Using learning contracts. Paper presented at the Western States Communication Association Great Ideas for Teaching Speech (GIFTS), Community College Interest Group, February 14, 1993.

Eberle, J. (2009). Heutagogy: What your mother didn't tell you about pedagogy and the conceptual age. In Proceedings from the $8^{\text {th }}$ Annual European Conference on eLearning, October 29-30, 2009. Bari, Italy. 
Gardner, A., Hase, S., Gardner, G., Dunn, S.V., \& Carryer, J. (2008). From competence to capability: A study of nurse practitioners in clinical practice. Journal of Clinical Nursing, 17(2), 250-258. DOI: 10.1111/j.1365-2702.206.0188.x

Gilbert, J. (1975). Contract learning. Paper presented at the Annual Meeting of the American Society for Engineering Education, June 16-19, 1975. Ft. Collins, Colorado.

Hase, S. (2009). Heutagogy and e-learning in the workplace: Some challenges and opportunities. Impact: Journal of Applied Research in Workplace E-learning, 1(1), 43-52. DOI: $10.5043 /$ impact.13

Hase, S. \& Kenyon, C. (2007). Heutagogy: A child of complexity theory. Complicity: An International Journal of Complexity and Education, 4(1), 111-119.

Hase, S., \& Kenyon, C. (2000). From andragogy to heutagogy. In UltiBase Articles. Retrieved from http://ultibase.rmit.edu.au/Articles/decoo/hase2.htm

Holmberg, B. (2005). The evolution, principles, and practices of distance education. Oldenburg, Germany: BIS - Bibliotheks- und Informationssystem der Univesität Oldenburg.

Hornsby, K.L., \& Maki, W.M. (2008). The virtual philosopher: Designing Socratic method learning objects for online philosophy courses. Journal of Online Learning and Teaching, 4(3). Retrieved from http://jolt.merlot.org/vol4no3/hornsby_o9o8. htm

Junco, R., Heiberger, G., \& Loken, E. (2010). The effect of Twitter on college student engagement and grades. Journal of Computer Assisted Learning. DOI: 10.1111/j.13652729.2010.00387.x

Kamenetz, A. (2010). Edupunks, edupreneurs, and the coming transformation of higher education. Canada: Chelsea Green Publishing Company.

Kenyon, C., \& Hase, S. (2010). Andragogy and heutagogy in postgraduate work. In T. Kerry (Ed.), Meeting the challenges of change in postgraduate education. London: Continuum Press.

Kenyon, C., \& Hase, S. (2001). Moving from andragogy to heutagogy in vocational education. Retrieved from http://www.avetra.org.au/abstracts and papers 2001/ Hase-Kenyon full.pdf

Knowles, M. (1975). Self-directed learning: A guide for learners and teachers. United States of America: Cambridge Adult Education.

Kuit, J.A., \& Fell, A. (2010). Web 2.0 to pedagogy 2.0: A social-constructivist approach to learning enhanced by technology. In Critical design and effective tools for $e^{-}$ 
learning in higher education: Theory into practice (pp. 310-325). United States: IGI Global.

Lee, M.J.W., \& McLoughlin, C. (2007). Teaching and learning in the Web 2.0 era: Empowering students through learner-generated content. Instructional Technology and Distance Learning, 4(10). Retrieved from: http://itdl.org/Journal/Oct 07/ articleo2.htm

McAuliffe, M., Hargreaves, D., Winter, A., \& Chadwick, G. (2008). Does pedagogy still rule? In Proceedings of the 2008 AAEE Conference, December 7-10, 2008. Yeppoon, Queensland. Retrieved from: http://www.engineersmedia.com.au/journals/aaee/ pdf/AJEE 15_1_McAuliffe\%20F2.pdf

McLoughlin, C. \& Lee, M.J.W. (2007). Social software and participatory learning: Pedagogical choices with technology affordances in the Web 2.0 era. In Proceedings from ascilite, December 2-5, 2007. Singapore. Retrieved from http://www.ascilite. org.au/conferences/singaporeo7/procs/mcloughlin.pdf

McLoughlin, C., \& Lee, M.J.W. (2008). Mapping the digital terrain: New media and social software as catalysts for pedagogical change. In Proceedings ascilite, November 30, December 3, 2008. Melbourne, Australia. Retrieved from http://www.ascilite. org.au/conferences/melbourneo8/procs/mcloughlin.pdf

McLoughlin, C., \& Lee, M.J.W. (2010). Personalised and self regulated learning in the Web 2.o era: International exemplars of innovative pedagogy using social software. Australasian Journal of Educational Technology, 26(1), 28-43. Retrieved from http://www.ascilite.org.au/ajet/ajet26/mcloughlin.pdf

Merriam, S.B. (2001). Andragogy and self-directed learning: Pillars of adult learning theory. New Directions for Adult and Continuing Education, 89, 3-13. San Francisco, CA: Jossey-Bass.

Mezirow, J. (1997). Transformative learning: Theory to practice. New Directions for Adult and Continuing Education, 74, 5-12. United States: Jossey-Bass Publishers.

Moore, M. G., \& Kearsley, G. (2012). Distance education: A systems view of online learning (3rd ed.). Belmont, CA: Wadsworth.

Peters, O. (2004). Distance education in transition - New trends and challenges (4th ed., Volume 5). Oldenburg, Germany: Bibliotheks- und Informationssystem der Universität Oldenburg.

Peters, O. (2001). Learning and teaching in distance education: Analyses and interpretations from an international perspective (2nd ed.). London: Kogan Page.

Rachal, J.R. (2002). Andragogy's detectives: A critique of the present and proposal for the 
future. Adult Education Quarterly, 52(3), 210-227.

Richardson, J. T.E., Morgan, A., \& Woodley, A. (1999). Approaches to studying distance education. Higher Education, 37, 23-55. Netherlands: Kluwer Academic Publishers.

Schön, D.A. (1983). The reflective practitioner: How professionals think in action. United States: Basic Books, Inc.

Schwier, R.A., Morrison, D., \& Daniel, B. (2009). A preliminary investigation of self-directed learning activities in a non-formal blended learning environment. Online Submission. Retrieved from EBSCO host.

Veletsianos, G.(2010). Emerging technologies in distance education. Canada: Athabasca University Press. Retrieved from http://www.aupress.ca/books/120177/ ebook/99A_Veletsianos_2010-Emerging_Technologies_in_Distance_Education. pdf

Wheeler, S. (2011, July 8). Learning with e's: Digital age learning. [Blog post.] Retrieved from http://steve-wheeler.blogspot.com/2011/o7/digital-age-learning.html

The World Bank. (2003). Lifelong learning in the global knowledge economy: Challenges for developing countries. Washington, D.C.: The World Bank. Retrieved from http://siteresources.worldbank.org/INTLL/Resources/Lifelong-Learning-in-theGlobal-Knowledge-Economy/lifelonglearning_GKE.pdf

\section{Athabasca University $\mathbf{A}$}


THE INTERNATIONAL

REVIEW OF RESEARCH IN

OPEN AND DISTANCE LEARNING

\section{Science Teacher Training Programme in Rural Schools: An ODL Lesson from Zimbabwe}
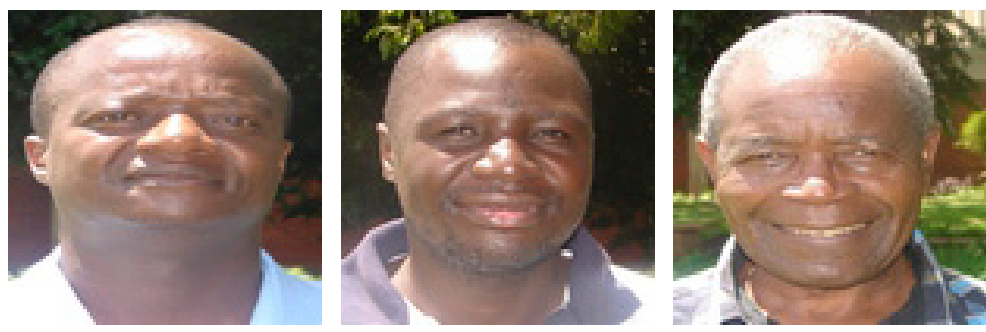

Misheck Mhishi, Crispen Erinos Bhukuvhani, and Abel Farikai Sana

Bindura University of Science Education, Zimbabwe

\section{Abstract}

This case study looked at 76 randomly selected preservice science teachers from Mbire and Guruve districts who were learning at the Mushumbi Centre in Zimbabwe and assessed their motivations for enrolling under the Bindura University of Science Education (BUSE)'s Virtual and Open Distance Learning (VODL) programme. It also looked at the challenges they faced, their views on how instruction under the programme can be improved, and their deployment preferences after graduation. The districts are located in the remote Zambezi Valley, which is characterized by poor infrastructure, pests and diseases, frequent attacks by wild animals on people, domestic animals, and crops, harsh climatic conditions, and seasonal floods, which make it very difficult to attract and retain qualified teachers. Through targeted recruitment, BUSE's VODL programme sought to train relief teachers already serving in the area in the hope that personal history and family connections would entice them to continue teaching in these areas after attaining their teacher certification. Data was collected using a questionnaire with closed and open-ended questions. Results obtained indicate that despite a lack of funding, a shortage of reading materials, and the nonavailability of e-learning facilities, the students were motivated to join the programme for personal and professional motives and that the students, the majority of whom had taught for two or more years in the districts, would prefer deployments in the area after graduation. The study therefore recommends that deliberate efforts be directed toward the targeted recruitment of school leavers and relief teachers from disadvantaged rural areas who possess the requisite minimum entry qualifications to train as science teachers in order to improve teacher retention in remote areas. Further research into the intrinsic problems in BUSE's VODL programme and a close scrutiny of its course development techniques are also encouraged in order to overcome some of the problems encountered by both the students and the institution. 
Keywords: Distance learning; skills retention; rural schools; targeted recruitment

\section{Background to the Study}

Since regaining independence in 1980, Zimbabwe has made substantial progress toward widening access to primary and secondary education. This has necessitated a proportional increase in the number of trained teachers. The number of teachers' colleges increased significantly during the first decade so as to supply a sufficient number of trained teachers to service the expanding system. Innovative approaches to the training of primary school teachers were adopted to augment teacher supplies from the conventional colleges. Preservice teacher training in four of the ten colleges that trained primary teachers combined short residential training (a duration of about one year) with extended teaching practice in the schools (a total duration of about three years). This approach to teacher education was called the Zimbabwe Integrated Teacher Education Course (ZINTEC) (UNESCO, 2000).

However, in the decade from 2000-2010, Zimbabwean schools have been hard hit by shortages of trained science teachers as a result of low enrollments at teacher training colleges, brain drain, and economic challenges faced by the country (Chetsanga, 2000). For example, the current staffing situation in Mashonaland Central Province, which has the lowest provincial literacy rate of $75 \%$ compared to the national rate of $96 \%$ (UNESCO, 2000), is critical in the sense that the majority of science teachers in the rural areas are relief teachers. Reportedly, over $80 \%$ of the science teachers in the Mbire and Muzarabani districts were either unqualified or required upgrading of their qualifications (interview with Mashonaland Central Provincial Education Director, 28 April, 2010). The current conventional science teacher education delivery system cannot totally cater to the local demand for science educators.

It was the demand for large numbers of science teachers within a short timeframe in Zimbabwe's rural schools that gave birth to the BUSE VODL programme. The programme is an in-service one that recruits untrained teachers who are working as science teachers. The programme is a concurrent model where academic subjects and professional studies are jointly offered. This is in contrast to the consecutive model where professional studies follow on a previous programme of academic studies ((Robinson \& Latchem, 2003). Currently, four centres in Mashonaland Central Province are operational: Mbire and Guruve districts at Mushumbi High School, Muzarabani district at St. Albert's Mission, Mount Darwin district at Chindunduma High 1, and Bindura-Mazoe districts at Bradley High School. The programme has since gone national with the opening of two learning centres in the Matebeleland provinces and another one in Mutare. Learning centres were established at secondary schools in the remote districts of the provinces. These centres serve as resource centres that ideally should have access to the Internet and offer minilibrary facilities. However, in reality, some of these centres have very limited resources. Print technology with face-to-face meetings and written feedback on students' assignments is predominantly used. Print was chosen because it is accessible, affordable, and familiar, and because it provides a permanent resource that student teachers can use (UNESCO, 2001). 
It was envisaged that the VODL programme would provide an opportunity for the university to train science educators in the comfort of their workplaces and homes during school holidays at an affordable cost. A major handicap to teacher supply is that once qualified, teachers may shun working in rural areas (Hedges, 2000; Akyeampong \& Lewin, 2002). The BUSE strategy was to embark on targeted recruitment, that is, to seek to recruit student teachers from the relief teachers already serving in the district in the hope that personal history and family connections would entice them to continue teaching in these areas after their graduation as qualified teachers.

There is some evidence from research and from the UK Open University's PGCE programme that twice as many teachers trained through ODL stay in the profession longer than those trained in conventional courses. This means that while intakes in ODL courses may be relatively smaller in some countries, its impact may be larger in the longer term in light of its contribution to teacher retention rates (Walker, 2001).

The interest that the relief teachers in the Mbire and Guruve districts have shown toward the BUSE VODL programme has triggered the present investigation into their motives to train as science teachers. Research has shown that knowledge about student characteristics and motivators helps with understanding who is likely to participate in and to complete a course in distance education. Similarly, such knowledge is vital since the motivators of adult distance students are often different from those of conventional students; therefore, knowing students' personal characteristics and motivations is important in planning and formulating policies for ODL programmes (Galusha, 1997).

Apart from that, a desire to document problems that may be faced by VODL students and to learn their views on how these difficulties could be curtailed also prompted this study. A need to predict the possible deployment trends of the same student teachers after graduation, that is, whether they would remain in the district, move into other, better perceived schools, or urban areas, was another push behind this study. Conclusions will be drawn from the responses of a questionnaire applied to 76 randomly sampled student teachers under the BUSE VODL programme in April-May of the 2011 teaching block session at Mushumbi High School in Mbire, Mashonaland Central Province of Zimbabwe. With these preoccupations in mind, the study sought to answer the following research questions:

1. What were the preservice teachers' motivations for training as science teachers under the VODL programme?

2. What problems did the student teachers encounter during their studies under the VODL science teacher training programme?

3. How best could BUSE conduct its ODL programme in order to improve teaching and learning?

4. What are the deployment preferences of preservice teachers in Mbire and Guruve districts after graduating as qualified teachers? 


\section{Theoretical Framework}

According to a 2001 UNESCO report, the world needs more well-trained educators in order to meet the target of Education for All by 2015. This came after the realisation that too many practicing teachers are still untrained and unqualified. Such urgent need for large numbers of additional teachers has focussed increased attention on the potential of distance education. Distance education can be a viable option for preservice, in-service, and continuing professional development for teachers (Robinson \& Latchem, 2003). It is accepted the world over that the teaching profession can be strengthened through the use of distance education or open and distance learning (UNESCO, 2001).

This realisation culminated in the launch of the BUSE VODL programme as an institutionally borne strategy to satisfy the training needs of prospective science educators who are already employed or wish to be employed by the Zimbabwean Ministry of Education, Sport, Arts, and Culture. The programme runs on a special kind of delivery strategy that merges Block Release and ODL methodologies. Lectures are conducted at the learning centres during one month long school holidays, while examinations are taken at the university's main campus in Bindura at the end of each semester. Two school holidays and the period in between constitute a VODL semester.

The success of ODL programmes hinges on individual, national, and institutional structures, as well as on students' willingness to undertake courses under this mode of education (UNESCO, 2001). This is so because the motives behind students' wishes to obtain a higher qualification may be diverse. For some, it may be for personal actualisation, and for others it may be for professional fulfilment. According to Azam (2001) and Hedges (2002), a teaching qualification may mean job security for some students from poor backgrounds, a chance for social mobility for others, or a passport to move to a "better" location, such as an urban area, or even to seek "greener pastures" outside the country.

However, undertaking courses under open distance learning programmes may have its own challenges. In many developing countries, the nonavailability of a reliable telecommunication network in remote districts, coupled with the cost of providing such technologies, as well as the low levels of penetration of the personal computer, have meant that e-learning, an inseparable component of distance education, cannot be easily implemented (Chikuya, 2007). The absence of e-learning facilities in rural areas has tended to worsen the shortages of reading materials faced by students.

The flexibility inherent in ODL and the fact that it can be undertaken concurrently with a full-time job makes it very convenient for student teachers as it allows them to study at an "affordable" cost and in the comfort of their homes and workplaces during school holidays. Furthermore, ODL courses and qualifications have the same value as those offered under conventional courses (Daniel, 2001). To this end, ODL has been adopted in different contexts in initial teacher training and in teacher skills upgrading programmes in such places as the National Teachers' Institute (Nigeria) and the China Television Teachers' College (China), as well as in India, Chile, the United Kingdom, Brazil, and South Africa (Pot- 
ter, 2001; Cerda, Leon, \& Ropoll, 2001; Mehrotra, 2001; Ederinoye, 2001; Walker, 2001; Oliveira, 2001; Zhang \& Jian, 2001; Robinson, 1997; Robinson \& Latchem, 2003).

The supply of teachers is adversely affected in many countries where retention rates are low for newly trained teachers or where significant numbers of teachers are being lost through HIV-AIDS, and in rural areas that have difficulty recruiting and retaining teachers (Daniel, 2001). Many countries report that teachers express a strong preference for urban postings. For example, in Ghana, over $80 \%$ of teachers said they preferred to teach in urban schools (Akyeampong \& Lewin, 2002). There are a number of rational reasons why teachers may prefer urban postings. One of the concerns about working in rural areas is that the quality of life may not be as good, and teachers have expressed concerns about the quality of accommodations (Akyeampong \& Stephens, 2002), classroom facilities, school resources, and access to leisure activities (Towse, Kent, Osaki, \& Kirua, 2002). Health concerns are also a major issue. According to Akyeampong and Stephens (2002), teachers may perceive that living in rural areas involves a greater risk of diseases and pests. Similarly, in the districts of Mbire and Guruve in Mashonaland Central under this study, poor infrastructure, very high climatic temperatures and low rainfall, perennial flooding, frequent attacks by wild animals on people, domestic animals, and crops, the high risk of contracting malaria and cholera, and the infestation of the tsetse fly are real, worrisome problems.

Teachers may also see rural areas as offering fewer opportunities for professional growth, while urban areas offer easier access to further educational development (Hedges, 2000). Teachers in rural areas may even find it more difficult to get their salaries on time, sometimes to the extent of having to put up with various frustrations such as political mistrust, corruption by officials, and the late submission of relevant papers to higher offices, resulting in late payments (Mulkeen, 2005).

In Zimbabwe, nearly all teachers are civil servants. Their deployment and distribution to meet the demand in the various regions, districts, and types of schools (regardless of ownership) is the responsibility of the government. Such a centralised deployment system has the advantage of distance from local pressures and can be more easily made fair and transparent. However, all these characteristics are dependent on the quality of information the government receives from the schools. According to Gottelmann-Duret and Hogan (1998) and Rust and Dalin (1990), centralised deployment is prone to congested decision-making and lacks attention to the individual needs of the teachers. Another weakness is that, practically, it is undermined by an inability to implement rational deployment (Hedges, 2000), that is, once the teachers are deployed, they may request transfers to more desirable areas. Although long delays may be experienced before teachers can transfer, many eventually get to move to where they want. For female teachers, transfers may be requested on the basis of marriage. In Malawi, there were some reports of women faking marriages in order to get transfers (Mulkeen, 2005). Teacher illness is another major justification for movement, and some teachers have circumvented the Ministry's posting policy by claiming fictitious health problems. All of this has resulted in disparities in teacher supply between rural areas and urban areas with more than 95\% of teachers in Zimbabwe teaching in urban schools as qualified teachers, while rural schools recorded the least number of qualified teachers 
(UNESCO, 2000).

As a result, rural schools have been poorly staffed or have longer delays in filling posts. Even if posts are filled, the rural schools may have fewer qualified teachers than their urban counterparts. Sometimes rural schools have less experienced teachers as the more experienced teachers find ways to move to urban schools or to the more desired schools of the district (Mulkeen, 2005). Teachers in rural schools may teach less than their counterparts in urban areas as any trip away from the area to visit a doctor, to collect pay, to engage in in-service training, or to visit family may involve long journeys and losses in man-hours. In addition, where teachers walk long distances to school, they may arrive at their workstations late and leave early. Furthermore, transport difficulties due to poor roads often make supervision visits from inspectors less frequent in many schools of the Mbire and Guruve districts, especially those in isolated parts where access is by four-wheel drive vehicles, which the Ministry of Education, Sports, Arts, and Culture cannot afford. Because the area is in the northern part of the country in the Zambezi Valley, the situation is exacerbated by seasonal floods. Even when teachers are teaching in remote districts, the quality of their work may be lower. This is partly because rural teachers often have less access to support services than their urban counterparts and fewer opportunities to attend in-service courses (Mulkeen, 2005).

The problem of teacher shortages in rural areas is often regarded as a problem of teacher numbers. However, the present pattern of high numbers of teachers in urban areas and severe shortages in the rural areas is strong evidence that the problem will not be solved simply by providing more teachers (Mulkeen, 2005; Daniel, 2001). Craig, Kraft, and du Plessis (1998) suggest that one possible solution to the shortage of qualified teachers and their retention in rural areas is to engage teachers who are "indigenous" to those rural places or to train relief teachers already serving in those areas through ODL. The presumption is that those individuals will have family roots in these areas and/or some economic interest (e.g., agricultural activity such as cotton growing in the Zambezi Valley), and so they may be more willing to train and remain in these rural settings. To justify this approach, it is believed that if teachers become established within their own community or home district, they may gain extra benefits from the proximity of relatives, which may help to ensure longterm stability. Working close to one's extended family may provide some level of moral as well as financial support and subsidy (Black, Esanu, Mugambe, Namwadda, \& Walugembe, 1993). Moreover, research studies in many countries have shown that twice as many teachers trained through ODL stay in the profession longer than those trained in conventional courses (Walker, 2001; UNESCO, 2001).

It should, however, be noted that the assumption that teachers recruited from a certain rural area would want to return to their own communities has been challenged by a number of researchers as educated members of a disadvantaged group may view their education as a means of social mobility and may have no desire to remain in the community once they are qualified (Azam, 2001; Rust \& Dalin, 1990). It is therefore presumed that the results from this research will offer insights into the possible deployment inclinations of the preservice teachers in the Mbire and Guruve districts. 


\section{Methodology}

The present research is a case study in which 76 preservice science teachers (42 males and 34 females) under the BUSE VODL teacher education programme at Mushumbi Centre (Mbire and Guruve districts) in Zimbabwe participated. These were randomly selected from a total population of 141 student teachers. The present sample constitutes $53.9 \%$ of the total population, and in coming up with the gender ratios, the researchers were guided by the programme's 1: 2.1 female to male ratio. However, a lower ratio of 1:1.2 was achieved due to the nonreturn of some questionnaires whose overall return rate stood at $66.1 \%$ despite repeated efforts to recover a larger number.

The results discussed in this paper come from a questionnaire that included a combination of open-ended and closed questions. The questionnaire items underwent pilot testing on BUSE's conventional students. The data from the pilot test were then analysed by three experienced lecturers in order to determine the efficacy of the next step of the research. The closed questions were processed through tables of frequencies and cross-tabulations obtained by using SPSS Version 17. Open-ended ones were analysed qualitatively. Qualitative analyses of statements and comments were preferred because they allow students' views on the various aspects of their learning under the VODL programme to be assessed (Cohen\& Manion, 1994; Patton, 2002).

Answers to the research questions show students' motivations for training as science teachers under the BUSE VODL programme (question 4); the problems they faced as VODL students (question 5); how, in their view, these problems may be solved (questions 6 and 7); and their willingness to undertake further professional development studies under VODL programmes (question 9). Their deployment preferences after graduation were captured by analysing the answers to question 8 of the questionnaire.

\section{Results and Discussion}

A description and an interpretation of each of the research questions are presented here.

\section{The Student Teachers' Motivations}

The majority of the participants (92.1\%) were motivated to attend the BUSE VODL teacher education programme for professional development reasons. They wanted to acquire a professional qualification to improve their teaching of science subjects in secondary schools. The following statement divulges one preservice teacher's motivations for training under the VODL programme: "to obtain a diploma in sciences so that I will be a qualified teacher with better knowledge and teaching knowledge [sic]."

Such sentiments reveal the personal and professional motivations that impel students to enroll under the BUSE VODL teacher education programme. Student motivation has a powerful effect on attrition and completion rates of ODL programmes, regardless of the challenges that may be encountered during studies (Galusha, 1997; Walker, 2001). The need to obtain a diploma in education in order to improve on the teaching and learning of 
science in schools was the major motivation for the participants. The acquisition of a higher educational qualification is both a personal and a professional motivation because it equips the students with new knowledge and confidence in science teaching, as well as a sense of self-actualisation and achievement.

A significant number of the participants (68.8\%) joined the programme because it is cheap and flexible. One male respondent had the following to say:

Obtaining a diploma in science education is a dream for everyone. My parents are poor such that they failed to meet fees [sic] for me to pursue further education. This programme is my last option because I will work at the same time [as] learning.

The desire to obtain a diploma that would enable the teacher to move to a better school also featured prominently (34.2\%). However, a minority of the preservice teachers (5.3\%) wanted the diploma in order to get access to leave the country.

By expressing that the programme is affordable, flexible, and allows them to obtain a diploma and move to a better school, the students manifested personal motivations. This notion concurs with findings by Azam (2001), whose research revealed that higher educational qualifications in remote districts offer students an opportunity for social mobility. Such qualifications would enable them to move to the more desired schools of the country.

\section{Problems Students Faced and Possible Solutions}

The shortage of reading materials during their studies, notably of textbooks, modules, and other reference books, as well as the shortage of library facilities, was identified as the major handicap by $68.4 \%$ of the preservice teachers. One student observed, "There is a problem of books. If you allow me to say SCRAMBLE for library books [sic] is a major problem." And another one complained of "inadequate learning materials (e.g., reference books, and no laboratory equipments for experiments).”

As the pioneers of the BUSE VODL programme, the students were confronted with a host of teething problems that impacted their learning experiences. These problems were both institutional and personal. For BUSE, which has traditionally offered conventional courses, ODL is a new adventure with its own idiosyncrasies and philosophy. Challenges encountered by the college include the provision of e-learning facilities and properly equipped libraries, among others. The provision of modules and handouts for sale in the library, more reference books, as well as improvements in laboratory facilities through mobile laboratories, were suggested by 54 of the participants $(71.1 \%)$ as possible solutions to this problem. Watson (2000) encourages institutions that provide ODL programmes to play a supportive and facilitative role in order to ensure that learners have access to quality library and information services to support their learning. In the case of BUSE, 10.5\% of the learners suggested that this could be achieved through the speedy introduction of virtual learning facilities at the learning centres. The nonavailability of enough ODL student support materials 
is a major weakness of the programme, especially because researchers in ODL programmes view these as crucial (Chikuya, 2007).

Although a shortage of learning materials was the major problem faced by the students, a sizeable proportion (52.6\%) identified financial problems as another obstacle affecting their studies. A small number (5.3\%) of the preservice teachers felt that some of the lecturers in the programme were incompetent and inexperienced. Galusha (1997) highlighted this possible pitfall and observed that in distance learning, students and teachers will find themselves playing different roles than is the norm in traditional education, hence they need to adapt to their new roles. In distance learning, the teacher is no longer the sole source of knowledge but a facilitator to support student learning, while the student actively participates in what and how knowledge is imparted. More than any other teaching methodology, distance learning requires a collaborative effort between student and teacher, unbounded by the traditional limits of time and single-instructor effort.

In order to alleviate the financial difficulties they face, $10.5 \%$ of the students urged the government to extend grants to fund their studies. The university is also encouraged by $53 \%$ of the students to consider ferrying them to the main campus for examinations or, better still, to conduct these examinations at the learning centres in order to reduce the costs incurred by the students in travelling to Bindura for examination sessions. Through these measures, it is hoped that a more conducive environment would be created for the students to undertake courses under open distance learning programmes.

\section{Students' Willingness to Undertake Further Studies under VODL}

Notwithstanding the above impediments, the majority of the participants endorsed the essence of the programme and hailed it as a noble initiative. Because of the competing priorities of work, home, and school, the structure of ODL programmes gives the student teachers a high degree of flexibility in that they have the greatest possible control over the time, place, and pace of their education (Galusha, 1997). In support of this assumption, the preservice teachers manifested a strong willingness to consider undertaking further educational courses through VODL programmes. Sixty-eight preservice teachers (89.5\%) said that they were willing to further their studies through a similar programme. Only $7.9 \%$ thought that studying under VODL was not an attractive option. Such a sentiment is summarised by the following student's comment: "No, because the course takes a lot of time to complete."

\section{Students' district of origin and their deployment preferences.}

A total of 76 participants took part in this study, [42 males (55.3\%) and 34 females (44.7\%)]. The majority of these participants (62, or $81.6 \%$ ) cited Mashonaland Central as their province of origin, and of these, $56(75.7 \%)$ come from Mbire and Guruve, which are the districts under study.

The majority of the preservice teachers (73.6\%) chose Mashonaland Central Province as 
their first-choice preference for deployment after graduation. Of these, $44.7 \%$ wanted to remain and teach in the rural areas of Mashonaland Central Province where the Mbire and Guruve districts are located. The results show a close relationship between area of origin and deployment desires, where the majority of those born in Mbire and Guruve wish to gain teacher certification and continue working in their district of origin. This is true for $62 \%$ of the respondents.

\section{Length of period taught in the district and students' deployment preferences.}

The majority of these preservice teachers (92.1\%) have been practising as relief teachers in the districts for two or more years. Those students who had been working in these districts for less than one year constitute $33 \%$ of those who prefer to continue teaching in these districts after graduation. Students who had spent between two and three years in Mbire and Guruve showed the highest preference (62.5\%) of continuing to teach in the districts. This is followed by those who had taught for more than three years. Of this group, $44 \%$ showed a willingness to teach in Mbire and Guruve. Cross-tabulated results manifest a relationship between the period of stay in the area and the deployment inclinations of the students, that is, the longer the period of stay in the districts (even for those who are not originally from Mbire and Guruve), the higher the preference by the students to remain and teach there after their teacher certification.

This result gives more credence to the presumption by Craig, Kraft, and du Plessis (1998) and UNESCO (2001) that these teachers may have family roots in these rural areas and are thus more willing to remain in these settings. However, the other $28.9 \%$ of the participants would want to teach in the urban areas of the same province. The urban schools of Mashonaland West and Harare attracted a combined $15.8 \%$ of the teachers' first-choice preferences.

As second choices, Mashonaland Central Province's urban areas were chosen by the highest total (23.7\%), while Mashonaland West urban (21.1\%) and Harare urban (10.5\%) occupied the second and third places respectively. A desire to move from this remote area to urban areas concurs with research findings made in Lesotho and Ghana, where recently qualified teachers preferred moving out of the rural postings to urban areas as quickly as possible (Rust \& Dalin, 1990; Azam, 2001).

As first- and second-choice preferences made by the teachers, Mashonaland Central rural province was the most popular choice, with $62.6 \%$. The provinces of Mashonaland East rural (18.4\%), Masvingo urban (10.4\%), and Harare urban (15.8\%) occupied the top three of the third- preference choices made by the preservice science teachers in the study.

None chose the same province as a third preference. The results manifest a strong preference by the preservice teachers to work in their home province but not necessarily in their home village or district. Such students may want to avoid the many demands made on them by family if they worked near their villages, as Mulkeen (2005) found out. This outcome 
opens a window of hope for the supply of teachers to rural schools in Africa.

\section{Conclusions and Recommendations}

Despite numerous difficulties encountered by the ODL preservice teachers in Mbire and Guruve districts, which included financial problems and a shortage of reading materials, the preservice teachers have shown a keen interest to train as science teachers. Motivations for enrolling in the training programme are both professional and personal. A study of the student motivators will help ODL institutions to develop appropriate course materials and techniques. While for many of the students, obtaining a diploma in science education equips them with the necessary content and methodology to be better science educators, others view the qualification as a chance for personal social mobility, which permits them to move to a better school or to teach in urban areas. The majority of the student teachers positively embrace the training programme and are willing to undertake further studies under the VODL programme. This is because of the advantages that are derived from obtaining an educational qualification through a flexible platform that allows them to work while learning at their "doorsteps" during school holidays.

In an endeavour to solve the problems faced in their studies, the students suggested several measures. They implored the government to look into the possibility of providing grants to finance their studies and also the Bindura University of Science Education to provide transport to ferry them to examination sessions, to provide better-equipped mobile libraries, and to introduce virtual learning facilities at the various learning centres. However, a close scrutiny of the intrinsic problems in distance education will help overcome some of the problems encountered by both the students and the institutions. There is also a need for research into course development techniques, which will enable institutions to identify the methods best suited to any ODL programmes they wish to undertake.

Targeted recruitment of relief teachers already working in the remote districts of Mbire and Guruve, done by BUSE, holds promise for their retention in that area after they graduate as qualified teachers. This study has shown that $92.1 \%$ of the preservice teachers had worked in the Mbire and Guruve districts as relief teachers for two or more years and that the majority (44.7\%) are willing to continue teaching in the same area after graduation. There is an assumption that during this period, many of them had established socioeconomic interests that would entice them to remain working in the district even after graduating as qualified science teachers (Craig, Kraft, \& du Plessis, 1998). This is a positive trend, especially in view of the fact that in many African countries rural areas have fewer qualified science teachers than urban areas due to poor working conditions. Centralised deployment of teachers has not been successful as teachers would still move out, especially science teachers, who are in great demand in the region as well as internationally, thereby fuelling brain drain (Chetsanga, 2000). It is, therefore, an encouraging signal that the ODL student teachers already working in these rural areas show a preference to continue teaching there even after graduation. Deliberate efforts should therefore be directed toward the recruitment of school leavers and relief teachers from disadvantaged rural areas who possess the requisite minimum 
entry qualifications to train as science teachers. 


\section{References}

Akyeampong, K., \& Lewin, K. (2002). From student teachers to newly qualified teachers in Ghana: Insights into becoming a teacher. International Journal of Educational Development, 22, 339-352.

Akyeampong, K., \& Stephens, D. (2002). Exploring the backgrounds and shaping of beginning student teachers in Ghana: Toward greater contextualisation of teacher education. International Journal of Educational Development, 22(3/4), 262-274.

Azam, J. P. (2001). The redistributive state and conflicts in Africa. Journal of Peace Research, 38(4), 429-444.

Black, T. R., Esanu, C., Mugambe, J., Namwadda, R., \& Walugembe, E. (1993). School improvement in the developing world: An evaluation of the Aga Khan Foundation programme. Retrieved from ERIC database. (ED 363930).

Cerda, C., Leon, M., \& Ropoll, M. (2001). Teachers learning to use information technology, Chile. In UNESCO (Ed.), Teacher education through distance learning pp. 11-12). Retrieved from http://unescodoc.unesco.org/images/0012/001242/124208e.pdf

Chetsanga, C. J. (2000). An analysis of the cause and effect of the brain drain in Zimbabwe. Harare: SIRDC. Retrieved from http://acpeu.euforic.org/civsoc/by_place/ zw.htm

Chikuya, H. H. (2007). Teacher education within the context of open and distance learning in Zimbabwe: A case study (Unpublished doctoral dissertation). University of South Africa.

Cohen, L., \& Manion, L. (1994). Research methods in education (4 ${ }^{\text {th }}$ Ed.). London: Routledge Falmer.

Craig, H. J., Kraft, R. J., \& du Plessis, J. (1998). Teacher development: Making an impact. Washington, D.C.:U.S. Agency for International Development.

Daniel, J.(2001). Preface. In UNESCO(Ed.)Teachereducationthrough distancelearning (p. iv). Retrieved from http://unescodoc.unesco.org/images/o012/001242/124208e. pdf

Ederinoye, R. (2001). An alternative route to primary teacher qualifications, Nigeria. In UNESCO (Ed.), Teacher education through distance learning (pp. 19- 20). Retrieved from http://unescodoc.unesco.org/images/o012/001242/124208e.pdf

Galusha, J. M. (1997). Barriers to learning in distance education. Interpersonal Computing and Technology, 5(3/4), 6-14.

Gottelmann-Duret, G., \& Hogan, J. (1998). The utilisation, deployment, and management 
of teachers in Botswana, Malawi, South Africa, and Uganda. Paris: UNESCO.

Hedges, J. (2000). The importance of posting in becoming a teacher in Ghana. University of Sussex Centre for International Education MUSTER Discussion Paper 13. Retrieved from http://www.sussex.ac.uk/usie/muster/reports/MDP\%2013-1102. doc

Hedges, J. (2002).The importance of posting and interaction with the education bureaucracy in becoming a teacher in Ghana. International Journal of Educational Development, 22, 353-366.

Mehrotra, R. N. (2001). Developing primary teachers' knowledge and skills in child guidance, India. In UNESCO (Ed.).Teacher education through distance learning (pp. 15-16). Retrieved from http://unescodoc.unesco.org/images/o012/001242/124208e.pdf

Mulkeen, A. (2005). Teachers for rural schools: A challenge for Africa. Paper presented at the Ministerial Seminar on Education for Rural People in Africa: Policy Lessons, Options, and Priorities. Addis Ababa: FAO, UNESCO, and the Association for the Development of Education in Africa.

Oliveira, J. B. (2001).Television-Plus: Journalism in the service of teacher development, Brazil. In UNESCO (Ed.), Teacher education through distance learning(pp. 7-8). Retrieved from http://unescodoc.unesco.org/images/o012/001242/124208e.pdf

Patton, M. (2002). Qualitative research and evaluation methods ( $3^{\text {rd }}$ ed.). Thousand Oaks, CA: Sage Publications.

Potter, C. (2001). New routes to teacher education degrees, South Africa. In UNESCO (Ed.), Teacher education through distance learning. (p. 23). Retrieved from http:// unescodoc.unesco.org/images/0012/001242/124208e.pdf

Robinson, B. (1997). Distance education for primary teacher training in developing countries. In J. Lynch,C. Modgil,\&S. Modgil (Eds.) Education and development: Tradition and Innovation, Volume 3: Innovations in delivering primary education. London: Cassell Educational Press.

Robinson, B., \& Latchem, B. (Eds).(2003). Teacher education through open and distance learning: World review of distance education and open learning, Volume 3. London: Routledge Falmer.

Rust, V., \& Dalin, P. (Eds.). (1990). Teachers and teaching in the developing world. New York: Garland.

Towse, P., Kent, D., Osaki, F., \& Kirua, N. (2002). Non-graduate teacher recruitment and retention: Some factors affecting teacher effectiveness in Tanzania. Teaching and Teacher Education 18, 637-652. 
UNESCO. (2000). The EFA 2000 assessment: Country reports, Zimbabwe. Retrieved from http://www.unesco.org/education/wef/countryreports/zimbabwe/rapport o.html

UNESCO. (2001). Teacher education through distance learning. Retrieved from http:// unescodoc.unesco.org/images/o012/001242/124208e.pdf

Walker, R. (2001). Using ICT to support school-based initial teacher education, UK. In UNESCO (Ed.), Teacher education through distance learning (pp. 25-27). Retrieved from http://unescodoc.unesco.org/images/o012/o01242/124208e.pdf

Watson, E. F. (2000). Library services to distance learners: The new professional paradigms. Retrieved from http://www.col.org/forum/pcfpapers/watson.pdf

Zhang,W.Y. \& Jian, N. (2001). Reaching teachers through television, China. In UNESCO (2001).Teacher education through distance learning (pp. 13-14). Retrieved from http://unescodoc.unesco.org/images/o012/001242/124208e.pdf

\section{Athabasca University $\mathbf{A}$}

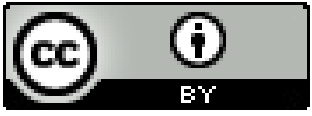


THE INTERNATIONAL

REVIEW OF RESEARCH IN

OPEN AND DISTANCE LEARNING

\section{Investigating Instructional Strategies for Using Social Media in Formal and Informal Learning}
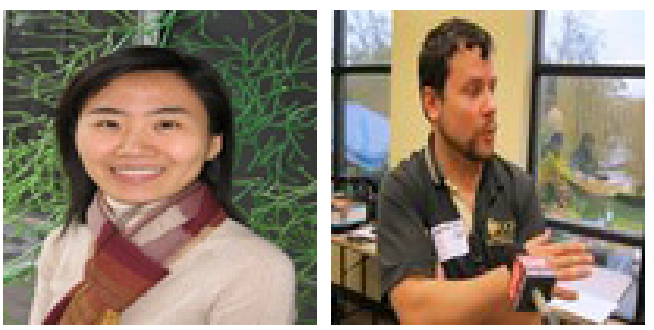

Baiyun Chen and Thomas Bryer University of Central Florida, USA

\section{Abstract}

Despite the high popularity of personal use of online social media, a low percentage of students and instructors use them for educational purposes. This qualitative study explores the use of social media among faculty in the discipline of public administration in the United States. Eight instructors participated in telephone interviews about their experiences and perceptions of using social media for teaching and learning. Instructors perceive that informal learning using social media could be facilitated by instructors and integrated into formal learning environments for enriched discussions, increased engagement, and broad connections. This study provides qualitative empirical support for social learning theories while offering strategies for and examples of how social media can be used to connect formal and informal learning.

Keywords: Social media; qualitative study; public administration; instructional strategy; formal learning; informal learning; social networking

\section{Introduction}

The use of social media has surged globally in recent years. Based on individual companies' statistics in July 2011, Facebook passed 750 million users (2011); LinkedIn had over 100 million members (2011); Twitter hit over 177 million tweets per day (2011); YouTube reached three billion views every day (2011). Social media are infiltrating the educational arena. The online social networks are increasingly being used not only by college students, but also by instructors for different reasons (Mazer, Murphy, \& Simonds, 2007; 2009). Hence, understanding the way individuals behave on such sites is a potentially valuable source of information for educators and researchers. 
Social media has been defined in different ways. For this study, we use the definition advanced by Bryer and Zavatarro (2011, p. 327): "Social media are technologies that facilitate social interaction, make possible collaboration, and enable deliberation across stakeholders. These technologies include blogs, wikis, media (audio, photo, video, text) sharing tools, networking platforms (including Facebook), and virtual worlds." The technologies of particular interest in this study are those that are web-mediated, thus falling within the realm of read/write collaborative Web 2.0 tools (Bryer \& Zavatarro, 2011). These contrast with media tools that have social features, but which may not connect individuals or groups through the Internet (e.g., response system technology, Rishel 2011).

The present study investigates how educators use social media to connect formal and informal learning and allow students to connect in new and meaningful ways. Our research focuses on understanding the use of social media tools among higher education faculty, strategies they use to integrate social media in formal learning, concerns they have, and their strategies to mitigate those concerns. The findings of this study will expand our knowledge about the use of social media and offer strategies for and examples of how these technologies can be used to connect formal and informal learning.

\section{Literature Review}

Two streams of literature are considered here. First is the history and development of social learning theories. Second is the distinction between formal and informal learning and the potential role of social media to connect both learning environments. Existing research and commentary regarding the efficacy of social media for education is also discussed below.

\section{Social Learning Theories}

The notion of social learning can be traced back to the theory of social constructivism in the 1960s (Vygotsky, 1978). The basic principle is that students learn most effectively by engaging in carefully selected collaborative problem-solving activities, under the close supervision of instructors (Vygotsky, 1978). Collaboration is the most important characteristic of social learning. While instructors help to facilitate group interactions, students have the autonomy to self-select what they need to learn to gain a better understanding of the problem.

A large body of critical analyses and research later concurred that learning is not an individual acquisition activity, but a social discourse (Hanson \& Sinclair, 2008; Jonassen, Howland, Moore, \& Marra, 2003; Lave \& Wenger, 1991). Many studies strongly suggest that collaborative learning has proven to be more effective than individualistic learning in contributing to motivation, in raising achievement, and in producing positive social outcomes ( Johnson, Johnson, \& Stanne, 2000; Slavin, 1995; Snowman, McCown, \& Biehler, 2009).

In the new digital age, Siemens $(2004 ; 2005)$ and Downes (2007) proposed the connectivism theory, where social learning is integrated with social media technologies. In the world of social media proliferation, learning is not an internal, individualistic activity. Rather, learners gather information from connecting to others' knowledge using Wikipedia, Twit- 
ter, RSS, and other similar platforms. One of the principles of connectivism is that capacity to learn is more critical than what is currently known (Siemens, 2004). The responsibility of a teacher is not just to define, generate, or assign content, but it is to help learners build learning paths and make connections with existing and new knowledge resources (Anderson \& Dron, 2011). Social learning theories, especially connectivism, provide insights on the roles of educators in this social networked environment.

\section{Formal and informal learning.}

Banks and his research team (2007) studied learning in formal and informal environments. Their findings indicate that formal learning is only a small fraction of the lifelong experience of human learning: The role of formal learning is about $19 \%$ in the first through twelfth grades, and the percentage is reduced to $8 \%$ in undergraduate years and $5 \%$ in graduate years. As students progress from high school to college and graduate schools, the role of informal learning becomes more and more important because learning can happen anywhere at any time. Learners acquire knowledge as a function of interactions between connected partners. The interactions allow learners to raise their connections with content and peernetworks. Social connections and networks are changing the ways we think about knowledge and learning and the ways we organize work and ideas.

Unfortunately, social networks have little or no integration into formal learning environments. The course management system (CMS), such as Blackboard, Sakai, and Moodle, is the most widely used learning technology in traditional higher educational settings. The conventional CMS environment provides limited opportunities for online learners to participate in online interactions, such as discussions and chats. These interaction activities are normally restricted to one class in one semester. Despite the fact that some social media features have begun to be integrated into newer versions of CMS, these features still cannot be fully implemented due to security or privacy restrictions. For example, CMS wikis cannot be shared with viewers outside of the institutions; learning portfolios cannot be maintained over multiple semesters. The connectivity and openness are lost in the present formal learning environment given the lack of access to external social opportunities.

Uses of social media as learning tools could possibly connect informal learning to the formal learning environment. For instance, third-party social media tools, such as WordPress, Wikipedia, and LinkedIn, can include members outside the class beyond the one-semester time duration and connect learners with communities, experts in the field, and peers across the world. It also provides engaging channels to facilitate student-student, studentinstructor, and student-content interactions in multimedia formats. This environment of involvement and creation potentially allows users to become more engaged in the learning process, and it entices users to collaborate on projects in real-world situations. Social media technologies that allow students to connect to educational contexts in new and meaningful ways beyond the traditional classroom environment have the potential to blur the line between formal and informal learning. The goal of this article is to investigate how educators can make this change happen. 


\section{Existing Research}

As social media is becoming increasingly ubiquitous to millennium learners, educators see the potential benefits of using these tools for academic purposes (Hughes, 2009; Nellison, 2007). Unfortunately, there is limited research on how social media impacts students and, in particular, how it influences students' learning experience (Hew, 2011; Mix, 2010). One of the common themes in previous research is that students use social media for personal reasons, but rarely for educational or learning purposes (Hew, 2011). Based on the 2009 and 2010 data from the EDUCAUSE Center for Applied Research (Caruso, Smith, \& Salaway, 2009; Smith \& Borreson, 2010), over 90\% of students responded that they used social networking services, such as Facebook, MySpace, Bebo, and LinkedIn. However, less than $30 \%$ of the participants reported using them in a course during the quarter or semester of the annual surveys. Uses of other social media sites, such as video sharing, blogs and wikis, follow the same pattern. EDUCAUSE (Smith \& Borreson, 2010) reported that only about $30 \%$ of their surveyed students used web-based word processor, spreadsheet, presentation, and wiki tools in courses. Even fewer students reported using technologies, such as video/photo-sharing sites, calendars, citation tools, blogs, social bookmarking tools, and online virtual worlds for classes. The limited education-related activities on social media platforms include creating study groups and other interactions with classmates without the knowledge of the instructor, "post-hoc" critiquing of learning experiences and events, reading web resources with little evidence of critical inquiry or analytical awareness, and file sharing, gaming, and brief communicating (Selwyn, 2009).

The use of social media in teaching by instructors is even scarcer. The Faculty Survey of Student Engagement (FSSE, 2010) surveyed 4,600 faculty members from 50 U.S. colleges and universities in 2009 and found that over $80 \%$ of the surveyed faculty did not know or never used social media technologies such as blogs, wikis, Google docs, video conferencing, video games, or virtual worlds. The only technology FSSE reported that faculty use extensively was the CMS. The national survey findings (2010) suggested that most instructors continue to teach using traditional lecture-based instruction. Empirical research is lacking in terms of what strategies instructors used for teaching with social media.

Despite the limited usage of social media in the academic world, research has supported connectivism theory and found benefits in using social media by instructors if the technology is adopted for teaching ( Mazer et al., 2007; 2009). Mazer et al. examined the effects of an instructor's self-disclosure via Facebook on her credibility as perceived by undergraduate students. Results showed that students tend to attribute higher perceived levels of instructor credibility to an instructor who willingly disclosed more information on Facebook than one who did not. More research needs to be conducted on instructor presence and social media strategies.

The literature identified concerns for using social media as a teaching and learning tool, such as its negative effects on academic performance. One study addressed the relationship between social media usage and academic performance (Kirschner \& Karpinski, 2010). The researchers surveyed 219 university students and found that Facebook users had signifi- 
cantly lower GPAs compared to non-users. This study did not infer a direct causal relationship and asked researchers to conduct further research on the impacts of social media on academic performance. The question is, if more instructors could facilitate social media activities based on the connectivist pedagogy to alter how the technologies are used, could social media be a beneficial learning tool? The gap between the theory and the lack of research to support students' networked learning indicates that researchers should consider how students and instructors can be encouraged to use these technologies and how to infuse social practices into learning activities using sound pedagogical practices.

There are discussions in the literature around the ethical issues of using social media in academic environments. Students' privacy and security issues are the primary concern (Foulger, Ewbank, Kay, Popp, \& Carter, 2009). The Family Educational Rights \& Privacy Act (FERPA) requires that student education records be protected. However, a class discussion on social media might reveal students' identification to the public. Moreover, some students are not aware that their posted information on social media is publicly available. A piece of personal information or a picture on the Web might lead to issues of identity theft or prevent them from future career opportunities. This study investigates this issue further.

\section{Research Questions}

This paper examines the pedagogical practices of using social media for teaching and learning based on qualitative data gathered from semistructured interviews with public administration faculty from institutions in the United States, who have already integrated social media in their class. The guiding questions for this study are as follows:

- RQ I: What social media tools do public administration faculty use and why?

- RQ II: What instructional strategies do public administration faculty use to integrate social media in formal learning?

- RQ III: What concerns do faculty have regarding the use of social media for teaching and what strategies do they have for mitigating these concerns?

\section{Population}

The study was designed as an exploratory analysis of current practices, concerns, and perceptions of public administration faculty regarding the use of social media in teaching. The social and multidisciplinary characteristics of social media are the reason to focus on the field of public administration. Public administration can be defined as "the intersection of multiple disciplines and sub-disciplines, joined together in the common interest of supporting or developing community, region, state, country, or world" (Bryer \& Chen, 2010, p. 241). Increasingly, public administration is recognized as a field well suited to forge collaboration across businesses, nonprofit organizations, government agencies, faith organizations, and active citizens. 


\section{Methods}

Given that there is relatively limited research on pedagogies of using social media, we used qualitative methods to explore the research questions through rich descriptions and explanations. The qualitative data reported in this article were collected as part of a larger research project, which surveyed a national sample of public administration faculty $(N=$ 57 ) to investigate the educational use of social media technology. The survey covered preliminary data on the types of social media sites, features of sites used, the interaction activities and assessment strategies used, motivation and concerns for faculty, and demographic questions. The survey findings were reported in Bryer and Chen (2010).

Interviews were semistructured to ensure that all participants were asked questions regarding their interaction and assessment strategies and motivations and concerns and to encourage them to raise other issues they felt relevant to the research. The interview questions are included in the Appendix.

\section{Data Collection}

Requests for participation in the study were emailed to the chairs/directors of all public administration departments or degree programs at institutions with accredited Masters in Public Administration (MPA) degrees in September 2009. A total of 57 faculty members from 28 universities across the United States voluntarily completed the initial survey.

Additionally, eight interviews were conducted by telephone in March 2010, averaging 30 minutes. Based on the theoretical sampling method (Glaser \& Strauss, 1967), we chose to interview participants to ensure a good mix of each of our theoretical categories: school location, ranking, and types of social media used. The interviewees are from five universities and one college, which are located in the north, east, south, and central United States. They hold six academic rankings, including department chair (tenured associate or full professor), professor, associate professor, assistant professor, and instructor. The interview questions focus on social media strategies in classes, especially strategies to engage students, assessment strategies, and measures to mitigate general concerns about using social media.

\section{Data Analysis}

All phone interviews were audio-recorded, transcribed, and checked for accuracy by the researchers. Google Doc spreadsheet tables were used for coding between the two researchers. The transcripts were analyzed and coded, and statements were classified into themes to answer the research questions. The constant comparison technique was used as the coding method (Glaser \& Strauss, 1967). All qualitative data were reviewed multiple times and open-coded to produce an initial code list until analysis reached theoretical saturation. Using this initial code list, the data were then selectively coded in terms of categories, identified with the initial code list directly related to social media tools, activities, assessments, benefits, concerns, and best practices. A total of 114 codes were generated based on the interview transcripts. One coder conducted the full analysis; a random selection of statements was later re-coded by a second coder, which produced full agreement on category 
assignments.

\section{Results}

\section{RQ I: What Social Media Tools do Public Administration Fac- ulty Use and Why?}

All interviewees used social media, either for personal, academic, research, or professional purposes. The most popular services were Facebook and LinkedIn. The majority of them used Facebook for personal communication and LinkedIn for professional connections. Some other services mentioned in the interviews include course management systems (CMS) (e.g., Blackboard), blog services (e.g., Blogger.com), wiki services (e.g., PBWorks), audio/video conferencing tools (e.g., Elluminate), virtual world services (e.g., Second Life), and screencast tools (e.g., Jing). Among all tools, CMSs were the most frequently used tool for teaching.

All of them used social media for personal benefits "at leisure" because the technologies are user-friendly. Their attitudes towards using social media for teaching were mixed. Some individuals did not see any academic benefits at all or considered social media to only be relevant to "lower-level undergraduate classes."

Most participants, however, saw added learning advantages and strongly encouraged students to participate for the benefit of creativity and social connections. Seven out of eight participants discussed the benefits. Ease of use is at the top of the list. Participants perceived students to be familiar with social media technologies. Faculty perceived that checking out Facebook and reading blogs were part of students' daily life. Social media were also perceived to provide added learning benefits. For instance, faculty believed that students could exercise their creativity with images, audios, and video mashups. One respondent observed that using multiple tools in an integrated fashion can help students firm up their understanding, noting that he promoted "writing analytical blogs, publishing informed and thoughtful commentary on blog assignments and posing new questions in various threads to help integrate material/concepts/etc."

Additionally, a number of participants discussed the relevance of using social media in the field of public administration. In terms of course content, they used these technologies to demonstrate concepts of "information transparency" and "citizen participation" in the public policy arena. Some instructors used online videos from YouTube and case studies from wiki pages to discuss change theory and convey concepts about information policy. One participant offered that "in my Public Information Management course, I cover the topic of social networking and how it is being used by government and non-profits." Thus, using the networking tools directly serve as an experiential exercise.

More importantly, students could benefit from internship and job opportunities through social networks. One instructor mentioned that 25 to $30 \%$ of their graduates were on Face- 
book and LinkedIn, and most of them were working in the local government. She is not alone in helping students take advantage of social capital. Five other interviewees strongly encouraged their students to establish social connections with alumni and community professionals via LinkedIn or other networking platforms. One participant cited the use of Ning by the MPA student association for promoting job opportunities.

\section{RQ II: What Instructional Strategies do Public Administration Faculty Use to Integrate Social Media in Formal Learning?}

\section{Instructional activities.}

Discussions and collaborations were the strategies that most participants mentioned. These participants took advantage of the Web 2.0 technologies to interact with students, help them with job seeking, facilitate group projects, organize student association networks, and promote their courses, programs, and conferences. They facilitated a strong sense of community and encouraged collective intelligence by creating social networks around academic topics or connecting students with alumni, outside communities, and experts around the world. For example, one participant advised students to join professional organizations on social media, such as the LinkedIn group of the National Academy of Public Administration. Some participants believed that social media is the extended classroom for students where they can learn from real-life events and professionals in the field.

Moreover, online social networks are convenient ways for faculty and students to keep up with their professional connections. Five out of eight interviewees maintained an active LinkedIn profile to connect with friends and former students in the profession, discuss career development, maintain their professional organization membership, and expand their consulting businesses. They also encouraged their students to do the same.

Participants successfully integrated social media, such as videos and case study materials, as part of their instruction in classes. However, the interaction features were not fully taken advantage of by our participants. Most of them heavily relied on the discussion and chat tools inside the CMS for student-student, student-content, and student-instructor interactions.

Our participants were interested in using social media in teaching. Unfortunately, not everybody was successful. One interviewee tried to use a class blog to engage students for one semester. The blog activity was optional and all postings needed to be approved by the instructor before publishing. Such strict requirements resulted in poor student participation. The instructor decided to give up the blog activity for the next semester. This case indicates that social media participation is informal and unstructured, which contradicts the orderly and organized flow of regular classroom teaching.

Another interviewee shared her success stories with us. She integrated LinkedIn in her class. This was a required assignment but students were not graded directly based on their activities on LinkedIn. Instead, they were graded on their critical reflections from their 
discussions with alumni. In this case, students were provided with a learning goal, but their interactions on LinkedIn were largely based on their own interests instead of the instructor's requirements.

Interviewees also had success with social media activities outside of class. For instance, they maintained and shared learning content, such as just-in-time news articles and videos, and facilitated noncredit, extracurricular discussions amongst students and a network of friends, associates, and colleagues. One common theme is that the focus of these activities is learners' personal interests and preferences, rather than institutional or instructors' requirements. Our participants' experience indicates that the key to successfully using social media for teaching is trying not to reshape the informal interactions but to "democratize" the classroom by empowering students to choose how and with whom to forge relationships. Their experience suggests that learning on social media is informal, conversational, and driven by users' interests.

\section{Assessments.}

The interviewees were probed about their assessment strategies regarding their social media activities. Most participants did not have an assessment strategy specifically designed for using social media. They felt that social learning should be optional, not required in classes. If some students chose not to complete the activities on social media due to personal reasons, they should not be punished for nonparticipation.

Among all the interviewees, two listed their social media activity in the course syllabi as a required assignment. Students were informed in the syllabi that they would need to use blogs, wikis, or online social networks in the classes as part of the course assignments. Both participants reviewed students' postings. One interviewee awarded participation credits based on students' blog postings. The other interviewee, as described above, required students to summarize and reflect on their assigned LinkedIn activities and then post their reflections as discussion postings inside their university CMS. She did not grade students' social media activities directly due to FERPA requirements and school policies, which do not allow any grading outside university systems. Instead, she graded students' reflections on their LinkedIn activities in the CMS using an online discussion rubric. The rubric criteria included clarity, comprehension, original thinking, and writing. None of the criteria were designed to directly guide students on their LinkedIn activities.

Activities on social media are largely informal, open, and self-regulated, at least as reported by our interviewees. Integrating informal learning on social media into formal educational environments brings a challenge to evaluation. What is the best way in which to evaluate students' network building and self-exploration on social media? Our participants indirectly evaluated students' social learning activities. They did not use the conventional fixed-criteria assessments, such as tests or quizzes. Instead, they integrated social media to supplement and reinforce classroom teaching using formative assessment strategies, such as rubrics, portfolios, and reflections. According to the U.S. Department of Education (2010), formative assessment is normally carried out by either the instructor or the 
students throughout the learning process to diagnose and aid the condition of learning and instruction in the form of feedback and reflection. It is generally conducted to facilitate learning, not necessarily for grading purposes. For example, a student can post questions on personal career goals in the discussions area on LinkedIn. He might get feedback from not just the instructor, but also peers, alumni, and professionals in the community. The feedback information is not evaluative, but diagnostic. It might augment, concur, or conflict with the student's ideas and facilitate his or her subsequent learning. Eventually, instructors could evaluate students' learning progress by reviewing his or her reflections on what they have gained through networked learning.

\section{RQ III: What Concerns do Faculty have Regarding the Use of Social Media for Teaching and What Strategies do They Have for Mitigating these Concerns?}

The top-rated concerns are cyber-security and privacy issues. Faculty were concerned about their professional identity. Two participants mentioned RateMyProfessor.com in the interviews and feared that their presence on the Web might damage their professional reputation. The Internet is such an open environment that nobody can control what others might post. Besides, participants were also concerned about students posting inappropriate content online that might pose a danger to their own future career development. One respondent observed that "students do not perceive these as learning tools, therefore, they do not approach them or use them in a way that will facilitate learning." The tools themselves may be more identified with personal entertainment or interaction, and, thus, not be used appropriately for learning.

Ethical issues are the next concern for our participants, especially for those who are not in a leadership position. Such issues include cyberbullying, marginalizing students, and being unfair because of befriending one student over another. A number of the interviewees claimed that to avoid potential student-instructor relationship issues, they did not friend their students until they graduated. One respondent went further than that, indicating that "many of us have grave concerns about security and identity theft associated with social networking sites. I have removed my personal profile from Facebook, and use LinkedIn only with trusted adult business contacts."

Student and faculty support is the key to success using social media for education, according to our interviewees. One participant stated that all students in her program joined LinkedIn. Her students benefited enormously from social networking activities. Her program provided students with strong support services, such as free training sessions from the IT unit, library, and digital media specialists. The IT staff coached students if they had any difficulties using technologies for learning. The librarians also regularly delivered sessions on what should or should not be revealed on social media. Since students were using online social networks extensively in their program, other instructors in the program started to adopt this technology more willingly. The other participants also mentioned the importance of student training. Not all students are comfortable with new technologies. 
Even if they know how to use technologies for entertainment, the majority of them still need guidance on how these technologies could assist their learning process. Additionally, one respondent was concerned about distractions present through social media, observing that "the information that would come from social networking has a poor signal to noise ratio. It's easier to control through traditional assignments (readings, etc.) the feed of information I want students to have."

Time constraints and technology barriers are big concerns among senior faculty. Junior faculty were interested in learning new technologies, but workload and productivity also prevented them from exploring new tools for teaching. Our interviewees expressed a strong need for faculty support in terms of adopting new technologies. Five participants pointed out that they could not download or install any new software on their work computers. They heavily relied on the technical staff, and their university policies did not appreciate innovations. They would like to have access to new technologies and learn more about innovative ways of using them, such as best practices and pitfalls. They looked forward to their institutions embracing innovations. Our participants perceived that there was a need for crafting and implementing clearly stated institutional policies on the use of social media. Only one out of eight participants was aware of a social media policy in their institution. More instructors would be willing to try to integrate new technologies in teaching but only if they knew that they were supported and their rights were protected by their institutions.

\section{Discussion}

This study indicates that educators utilize social media as an instructional medium to blend informal learning into formal learning environments within the public administration discipline. Social media provides them with the ability to break the limitation of course management systems, enables innovative and collaborative interactions, connects textbook knowledge to real-world problems, and facilitates personalized constructive learning. However, respondents also observed pitfalls or challenges, such as privacy concerns for faculty and students and helping students use the tools for learning, rather than entertainment or personal interactions. This discussion section uses the observations from study participants and expands further to suggest areas for future development and research.

Social media and networking technologies have significant potential to recreate the learning environment between student and teacher. Learning can be experienced as a uniquely social enterprise; course content can be co-created by a community of learners, where the instructor is a learner along with students. The role of instructor might then transform to become as much facilitator as subject matter expert. As one respondent noted, such role transformation can allow greater interaction across the teacher-student divide: "Students are more engaged with the professor...thus, appear to be more engaged with the materials."

These technologies, however, may not be implemented in their most pure form to take advantage of their full potential. The concerns expressed by faculty-namely concerns of privacy and student-teacher relationships-may alter the social landscape to prevent possible 
desired learning outcomes from being achieved. This dynamic can be understood through Fountain's (2001) technology enactment framework. Writing about how government agencies adopt and adapt e-technologies, Fountain observed that there is an important distinction between objective and enacted technologies. Objective technologies are the tools available that might directly be applied in the practice of teaching and learning (e.g., Facebook, Wikispace, YouTube, Ning). Enacted technologies are the same tools altered, based on institutional rules and organizational culture. What is enacted, thus, may be less than what is possible given the optimum or full use of the technologies. Learning outcomes that are possible in social environments may not be realized if the social dimensions of the objective technologies are not fully enacted.

Continuing development of social networking and other collaborative tools and increased opportunities for interaction will require new ways to measure academic progress in real time. Using traditional formal learning assessments to evaluate the social learning process is difficult, especially if the learning happens outside the classroom in an informal learning environment. If educators make use of the informal learning that occurs on social media and networking services, it is possible that the achievement gap between marginalized students and mainstream students can be reduced. Conversely, as study respondents observed, using these social tools in the learning process may lead to more distractions, and, thus, reduce student achievement. Further testing is needed on this important question of impacts of social media on academic performance. Future research can also explore the effects of using rubrics for social media use on learning outcomes and can include experiments to determine the best facilitation and assessment strategies for social learning.

The cultural norms that create a separation between teacher and student represent one filter that can drive a wedge between objective and enacted social media and networking technologies. Teachers, who have reservations about sharing their full "personal" selves, may disadvantage their students by diminishing the roots of their passions in the subject matter being taught (Palmer, 2007). Faculty who address this cultural norm by creating separate social media identities for their students than those for friends and family fall into this trap, as do faculty who refuse to "friend" current students at all. Some respondents in this study participated in both activities. Splitting oneself into personal, professional, and other categories diminishes the full social potential of technologies that thrive based on a willingness to be transparent about one's whole self. The enacted technology, then, is less than social and, thus, less likely to generate desired learning outcomes.

To achieve possible learning outcomes, capacity building and training is necessary for faculty, so that they can understand the theory behind social learning and the limitations that are created through the erection of a wall between teacher and students. Similarly, university rules that permit or do not permit the use of social media for teaching need to be examined to ensure such rules are not artificially constraining the pure adoption of objective social technologies. This call for institutional support is consistent with findings from this study. Interviewees expressed a strong need for faculty support in terms of adopting new technologies. They would like to have access to technologies and learn more about new ways of using them, such as best practices and pitfalls. They looked forward to their institutions 
embracing innovations. There is, ultimately, a need for crafting and implementing clearly stated institutional policies on the use of social media in the educational environment.

\section{Limitations}

There are several limitations that should be acknowledged in this qualitative research method and sample. One major limitation is the self-selection bias as participants volunteered for the study. Even though our participants come from a variety of academic positions and locations in the U.S., those that volunteered might be biased toward a more positive outlook. Also, the data only include faculty members in departments of public administration in the United States. The findings shed light on usage of social media in teaching in one discipline but cannot be generalized to other areas of higher education. Future research could focus on educators in other disciplines and possibly from other countries.

\section{Conclusion}

One of the central questions of interest in this study is how to use social media to facilitate student learning. The experience of the participants suggests strategies to integrate these technologies, not just in formal in-class environments, but, more importantly, to encourage social and active learning that is learner-centered and informal. If informal social networks are facilitated and agenda-driven, learning can be achieved. Is the learning superior to traditional content-centered education? Future research needs to be conducted on this question. It seems safe to suggest, though, that the publicly open social media sites provide students with access to more information and experiences than they would get in a closed environment alone. If properly facilitated and framed, such expanded exposures can benefit student learning by creating more connections across boundaries and over time. Though social media are informal and open, it is possible to learn what works from current practices in designing social media spaces for learning. Each of these practices can be established through experimental or other research design to gain better understanding of what works and in what contexts. The following are some of the current practices drawn from this study:

- Use social media as tools to facilitate informal discussions and collaborations with clear instructional goals.

- Understand that the focus of social media activity for some faculty is learners' personal interests and preferences, rather than institutional or instructors' requirements, evidenced by faculty, who reported both opportunities and concerns regarding their perceived obstacles to students using social media for learning purposes.

- Evaluate students' reflections on their learning via social media in the form of formative assessment.

- Use social media as an optional tool inside and outside classes. Provide students with alternative assignments if they choose not to participate.

- Educate students about the security and privacy issues of posting personal information 
online.

- Implement institutional policies on the use of social media in the educational environment in light of security/privacy issues, as well as faculty and student support.

- The use of social media in higher education teaching is an emergent area for study.

As discussed in the literature review, much scholarly research needs to be conducted, and, perhaps more importantly, individual experimentation is needed to understand what works, how, and in what circumstances. We close, then, with a call to the public administration discipline, but also to other areas, for study and experimentation. Importantly, we call for institutional changes that can facilitate and indeed encourage experimentation by faculty members, who wish to determine the efficacy of social media tools for teaching. Institutional changes might include resources for training and for technology acquisition. They might include opportunities for controlled experimental research to test different tools and technologies and their efficacy in teaching and learning. Last, they might include the granting of flexibility to faculty members, who wish to test new tools and technologies on their office computers and for interacting with students in new, boundary-spanning ways. This is an exciting time to be an educator; our task is to take advantage of opportunities without remaining frozen, given fears and concerns. 


\section{References}

Anderson, T., \& Dron, J. (2011). Three generations of distance education pedagogy. The International Review of Research in Open and Distance Learning, 12(3), 80-97. Retrieved from http://www.irrodl.org/index.php/irrodl/article/view/89o

Banks, J., Au, K., Ball, A., Bell, P., Gordon, E., Gutierrez, K., Heath, S., et al. (2007). Learning in and out of school in diverse environments (Consensus Report). Learning in Informal and Formal Environment (LIFE) Center. Retrieved from http://www. life-slc.org/knowledge-base/report-learning-in-and-out-of-school-in-diverse-environments

Bryer, T. A., \& Chen, B. (2010). Using social networks in teaching public administration. In C. Wankel, (Ed.), Cutting-edge social media approaches to business education: Teaching with LinkedIn, Facebook, Twitter, Second Life, and Blogs (pp. 241-268). Charlotte, NC: Information Age Publishing.

Bryer, T. A. \& Zavattaro, S. (2011). Social media and public administration: Theoretical dimensions and introduction to symposium. Administrative Theory \& Praxis, 33(3).

Caruso, J., Smith, S., \& Salaway, G. (2009). The ECAR study of undergraduate students and information technology (Research Study). Boulder, CO: EDUCAUSE Center for Applied Research. Retrieved from http://www.educause.edu/erso9o6

Downes, S. (2007). An introduction to connective knowledge. Presented at the International Conference on Media, Knowledge \& Education-Exploring New Spaces, Relations and Dynamics in Digital Media Ecologies. Retrieved from http://www. downes.ca/post/33034

Facebook. (2011). Facebook statistics. Facebook. Retrieved July 22, 2011, from http:// www.facebook.com/press/info.php?statistics

Foulger, T. S., Ewbank, A. D., Kay, A., Popp, S. O., \& Carter, H. L. (2009). Moral spaces in MySpace: Preservice teachers' perspectives about ethical Issues in social networking. Journal of Research on Technology in Education, 42(1), 1-28. Retrieved from http://ezproxy.lib.ucf.edu/login?URL=http://search.ebscohost.com/login.aspx?d irect $=$ true\&db=eric\&AN=EJ856930\&site=ehost-live

Fountain, J. E. (2001). Building the virtual state: Information technology and institutional change. Washington, DC: Brookings Institution Press.

FSSE. (2010, July 25). Professors' use of technology in teaching. The Chronicle of Higher Education. Retrieved from http://chronicle.com/article/Professors-Useof $/ 123682 /$ ?sid=wc\&utm_source=wc\&utm_medium=en

Glaser, B., \& Strauss, A. (1967). The discovery of grounded theory: Strategies for qualita- 
tive research. Chicago, IL.: Aldine Publishing.

Hanson, J. M., \& Sinclair, K. E. (2008). Social constructivist teaching Methods in Australian universities-- Reported uptake and perceived learning effects: A survey of lecturers. Higher Education Research and Development, 27(3), 169-186. Retrieved from http://ezproxy.lib.ucf.edu/login?URL=http://search.ebscohost.com/login. aspx?direct $=$ true\&db=eric\&AN=EJ803291\&site $=$ ehost-live

Hew, K. F. (2011). Students' and teachers' use of Facebook. Computers in Human Behavior, 27(2), 662-676. doi:16/j.chb.2010.11.020

Hughes, G. (2009). Social software: New opportunities for challenging social inequalities in learning? Learning, Media and Technology, 34(4), 291-305. Retrieved from http://ezproxy.lib.ucf.edu/login?URL=http://search.ebscohost.com/login.aspx?d irect $=$ true $\& \mathrm{db}=$ eric\&AN=EJ870729\&site=ehost-live

Johnson, D. W., Johnson, R. T., \& Stanne, M. B. (2000, May). Cooperative learning methods: A meta-analysis. http://www.tablelearning.com. Retrieved from http:// www.tablelearning.com/uploads/File/EXHIBIT-B.pdf

Jonassen, D. H., Howland, J. L., Moore, J. L., \& Marra, R. M. (2003). Learning to solve problems with technology: A constructivist perspective. Upper Saddle Rover, NJ: Merrill Prentice Hall.

Kirschner, P. A., \& Karpinski, A. C. (2010). Facebook® and academic performance. Computers in Human Behavior, 26(6), 1237-1245. doi:16/j.chb.2010.03.024

Lave, J., \& Wenger, E. (1991). Situated learning: Legitimate peripheral participation. Cambridge University Press.

LinkedIn. (2011). LinkedIn about us. LinkedIn. Retrieved July 22, 2011, from http://press. linkedin.com/about/

Mazer, J. P, Murphy, R. E, \& Simonds, C. J. (2007). I'll see you on "Facebook": The effects of computer-mediated teacher self-disclosure on student motivation, affective learning, and classroom climate. Communication Education, 56(1).

Mazer, J. P., Murphy, Richard E., \& Simonds, Cheri J. (2009). The effects of teacher selfdisclosure via Facebook on teacher credibility. Learning, Media \& Technology, 34(2), 175-183.

Mix, K. K. (2010). Online social networking: Exploring the relationship between use of Web-based social technologies and community college student engagement. ProQuest, UMI Dissertations Publishing. Retrieved from http://ezproxy.lib.ucf.edu/ login?url=http://search.proquest.com/docview/847401829?accountid=10003 
Nellison. (2007, December 11). ECAR: Facebook as a teaching tool? Blog. Retrieved March 18, 2010, from http://nellison.blogspot.com/2007/12/ecar-facebook-as-teachingtool.html

Palmer, P. (2007). The courage to teach: Exploring the inner landscape of a teacher's life. San Francisco, CA: Jossey-Bass.

Rishel, N. (2011). Digitizing deliberation: Normative concerns for the use of social media in deliberative democracy. Administrative Theory \& Praxis, 33(3), 411-432.

Selwyn, N. (2009). Faceworking: Exploring students' education-related use of "Facebook." Learning, Media and Technology, 34(2), 157-174. Retrieved from http://ezproxy. lib.ucf.edu/login?URL=http://search.ebscohost.com/login.aspx?direct=true\&db $=$ eric $\& \mathrm{AN}=\mathrm{EJ} 856841 \&$ site $=$ ehost-live

Siemens, G. (2004). Connectivism: A learning theory for the digital age. elearnspace. Retrieved from http://www.elearnspace.org/Articles/connectivism.htm

Siemens, G. (2005). Connectivism: Learning as network-creation. elearnspace. Retrieved from http://www.elearnspace.org/Articles/networks.htm

Slavin, R. E. (1995). Cooperative learning: Theory, research, and practice (2nd ed.). Boston, MA: Allyn \& Bacon.

Smith, S., \& Borreson, J. (2010). ECAR study of undergraduate students and information technology (Research Study, Vol. 6). Boulder, CO: EDUCAUSE Center for Applied Research. Retrieved from http://www.educause.edu/Resources/ECARStudyofUndergraduateStuden/217333

Snowman, J., McCown, R., \& Biehler, F. (2009). Psychology applied to teaching. Boston, MA: Houghton Mifflin Co. Retrieved from http://www.worldcat.org/title/psychology-applied-to-teaching/oclc/228007807?page=citation

Twitter. (2011, March 14). Twitter blog: numbers. Retrieved July 22, 2011, from http:// blog.twitter.com/2011/03/numbers.html

U.S. Department of Education. (2010, March 5). National education technology plan 2010. U.S. Department of Education Website. Retrieved from http://www.ed.gov/technology/netp-2010/executive-summary

Vygotsky, L. S. (1978). Mind in society: The development of higher psychological processes. Harvard University Press.

YouTube. (2011). YouTube - broadcast yourself. Retrieved July 22, 2011, from http://www. youtube.com/t/press_statistics 


\section{Appendix}

\section{Interview Protocol}

1. What social media tools have you used in your classes?

2. What activities did you use with the social media tools?

3. What assessment strategies have you used to evluate theses activities?

4. What benefits do you perceive of using these social media tools in your classes?

5. What concerns do you perceive of using these social media tools in your classes?

6. Do you see any impacts of using social media on students' learning outcomes? Why?

7. What technologies do you see that instructors can use in teaching and learning in the future?

8. Do you have any suggestions regarding the issue of using social media for teach ing?

\section{Athabasca University}

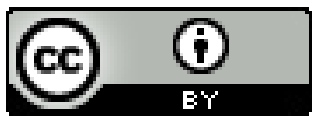


THE INTERNATIONAL

REVIEW OF RESEARCH IN

OPEN AND DISTANCE LEARNING

\section{An Investigation of Communication in Virtual High Schools}

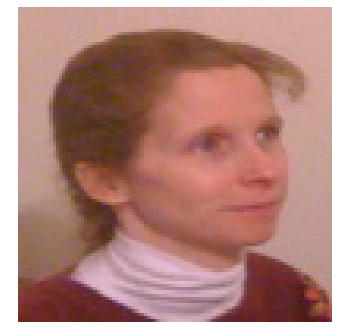

Marley Belair

USA

\section{Abstract}

Virtual schooling is an increasing trend for secondary education. Research of the communication practices in virtual schools has provided a myriad of suggestions for virtual school policies. The purpose of this qualitative study was to investigate the activities and processes involved in the daily rituals of virtual school teachers and learners with the goal of determining how regular phone calls by teachers contributed to the work habits of students. Eight virtual teachers were observed attempting to contact more than 60 struggling learners. Phone conversations with 12 of these learners showed that teachers repeatedly attempted to help them. Eleven students were interviewed and indicated preferences for written communications. Ten additional teachers who were interviewed emphasized the difficulty they had in reaching students by phone and the lack of student responses to phone-call attempts. The teachers in the study provided additional data regarding their regular communication patterns. Archival records from more than 100 contact attempts showed that approximately $20 \%$ of the students responded to teacher phone calls and less than half of these students completed the work requested. The interview data revealed that teachers believe written communications or multiple forms of communication may be more effective than regular phone calls. Future research should extend current research by expanding on sample size and investigating alternate methods of communication. Further investigation of learner responses to phone calls and of nonresponsive students could add to this data.

Keywords: Distance education; virtual school, communication

\section{Introduction}

Virtual schools have begun to overtake other forms of charter schools in many of the states in which charters are permitted (Kanna, Gillis, \& Culver, 2009; Peterson, 2010). The last decade has seen a plethora of virtual schools, from those that are state chartered to those 
run by management corporations, offering individual courses, credit recovery, and full high-school diplomas (Barbour \& Reeves, 2009). Research has shown that teacher practices and policies play the most important roles in student success in virtual schools (Oliver, Osborne, \& Brady, 2009; Weiner, 2003).

Teacher communications may be vital factors for virtual school success (Dennen, Darabi, \& Smith, 2007; Greenway \& Vanourek, 2006; Oliver et al., 2009; Weiner, 2003). The history of virtual schooling and virtual school studies are important facets for understanding virtual school communications. In order to understand the best practices for communication, qualitative analysis must be used to evaluate the nature of a variety of communication practices. The establishment of best practices for virtual communications is essential due to the rapid growth of virtual programs (Watson, 2007). Without uniform standards for communications and other aspects of educational effectiveness, virtual schools will not be able to conform to the expectations that parents and school administrators have established (Ferdig, Cavanaugh, DiPietro, Black, \& Dawson, 2009; U.S. Department of Education, 2008). The dearth of reliable qualitative data for assessing the effectiveness of virtual school communications could become a threat to the significance of the virtual school movement as a whole (Watson, 2007). There is limited research investigating online virtual K-12 school practices (Means, Toyama, Murphy, Bakia, \& Jones, 2009).

Research on communication practices and transactional distance is important for evaluating virtual school programs (Moore \& Kearsley, 1996). Communication is just one facet of transactional distance. However, any program in which the major forms of communication must be carried out through electronic media generally involves a higher degree of transactional distance (Moore, 2007). The degree and effectiveness of the various communication practices for a given program also affect the level of transactional distance (Anderson, 2007; Saba, 2007). Virtual schools must use effective communications to decrease the transactional distance and to ensure that participants do not feel constrained by differences in location (Lowry, Roberts, Romano, Cheney, \& Hightower, 2006). The results of some studies have indicated that the form of communication is less important than the personal factors involved in ensuring successful communication practices in virtual schooling (Harms, Niederhauser, Davis, Roblyer, \& Gilbert, 2006; Means et al., 2009).

The theory of transactional distance has been updated, tested, and reworked since it was first established (Moore, 2007). One premise for the continual investigation into the theory is that effective virtual school research requires investigating policies and practices from previous studies (Saba, 2007). This research was aligned with the review of recent literature on virtual school and communication studies. A qualitative approach for evaluating the communication practices for various schools was important because comprehensive, qualitative data lends itself to informing a cohesive picture of the school practices (Armstrong, 2006). The results of communications between students and teachers in this study were evaluated through the observations and interviews of participants within several virtual schools. It has been suggested that teacher and student interactions should be measured in qualitative ways to obtain a true representation of the effectiveness of the communications (Moore \& Kearsley, 1996; Shearer, 2007). 


\section{Method}

The research methods involved observations, interviews, and investigation of archival data from four virtual schools in North America. Personal observations and one-on-one interviews were vital in order to evaluate the methods of communication within the virtual school systems and to understand how the participants experience the system itself (Moustakas, 1994). Eight teachers were observed in their natural school environments and provided personal perceptions through follow-up interviews in order to shed light on various aspects of their communications with students within the virtual school. Although student observation was not possible, 11 students were interviewed. Further interviews with teachers who were not associated with field observations served to substantiate the research data. A total of 18 teachers and 11 students were interviewed in order to provide a wealth of qualitative data.

\section{Participants}

Participants included 18 teachers and 11 students from select virtual schools in North America. The teacher participants for observations included eight teachers from two different Midwestern virtual schools. There were also five teachers from these schools, two teachers from the largest virtual state charter school in the Southwestern United States, two teachers from another Midwestern virtual school, and one from a private virtual school who participated in interviews. A range of teaching experience and education was represented by these teachers. Demographics about age, nationality, and teaching experience were not specifically noted for these participants unless the data was forthcoming because the goal of the study was to focus on communications. This sample size was appropriate for a qualitative study because the general nature of qualitative research is to examine a small sample in order to explore an idea or phenomenon in detail (Patton, 2002; Shank, 2006).

\section{Procedures}

This qualitative investigation used a nested case-study approach to determine how daily phone calls by teachers influenced students and contributed to the work habits of learners involved in four virtual high schools. The nested case-study format included observations of eight virtual school teachers in the natural surroundings of their daily school practices, combined with interviews of teachers and learners and follow-up data (Patton, 2002). Teacher observations were vital to this study because communication can only be evaluated within the natural surroundings of the participants in order to investigate the normal practices of the individuals (Harms et al., 2006). Interviews were also used to obtain inferences and perceptions from teachers and students involved in virtual schools (Yin, 2009). This combination of teacher observations and participant interviews within a case-study design allowed investigation of the personal components of teacher and student communications (Patton, 2002). Archival data such as written communications, student submissions, phone logs, and teacher notes was provided by 10 of the 18 teacher participants. The teacher observations, participant interviews, and archival data created a triangulation of sources to strengthen the study evidence (Patton, 2002; Yin, 2011). 
The naturalistic inquiry and field-study observations involved eight virtual school teachers. These teachers were observed while they attempted to contact students by phone. All phone conversations, teacher notes, and messages left during more than 60 contact attempts during these observation periods were recorded as direct study data. These teachers were also interviewed after the observation periods. Interview-only data included 10 other teachers and 11 students directly involved in four online schools in North America. The teachers and students were interviewed in order to provide substantiation to the observation data. These interviews proceeded according to the protocol provided in the appendixes. The individuals were asked directly about their personal communications within their virtual school environments. The teachers also provided archival data such as phone logs and the results of attempted communications to further triangulate the data provided through observations and interviews.

Although this was a qualitative study, an additional note-taker was suggested by the sponsoring organization in order to add credibility to the data. Having a note-taker was also important because the teachers and students within the study worked from their homes, and ethical concerns were more easily addressed through this procedure. The notes were compared in order to ensure that the true observations and substance of each interview or observation period were presented as accurate data.

The initial field observations included a pilot study with the investigation of a teacher with whom the researcher has worked previously in order to overcome researcher-presence obstacles that could prevent accurate data collection. These notes were analyzed for possible patterns and ideas for subsequent observations. Notes taken during this data collection included direct quotes from voice messages or conversations and the results or summaries of the communications, along with any notes the teacher may have made about the communications. This initial observation was considered a pilot case and allowed the researcher to determine that the study should proceed to the formal observation stage (Yin, 1984). In order to follow the exact structure of the research data, the observed teacher was asked to recommend a student for a pilot interview. This student was one with whom the observed teacher had communicated and the researcher had previously established a professional relationship (Johnson, 2001; Wengraf, 2001). These criteria were important for ensuring the success of the interview as a pilot for subsequent student interviews. Upon completion of the pilot study, it was determined that a laptop computer was the least intrusive way of taking notes since most participants were accustomed to this process. The data from the pilot observation and interviews was analyzed in order to determine the efficacy of the next step of the research.

After the initial review and comparison of the pilot study, field observations with eight other teachers commenced once the observation and interview protocol were established. During this time, four teachers who were recommended by the school administrators and who had agreed to participate were observed for approximately two hours each. During each observation, the researcher and note-taker recorded the communication factors and made notes about any follow-up that was needed to obtain student work samples or questions that needed addressed. The notes included records of all the actions made by each 
teacher, including direct quotes from each phone conversation or phone message. An interview followed each observation in order to obtain teacher perceptions and recommendations. These open-ended interviews used a notes template, which was the interview guide that was piloted with the original participant and which is included in Appendix A. Each participant was asked to fill in gaps in the notes or to respond to inquiries from the researcher during the follow-up interview. These interviews served to clarify any issues from the observations and allowed the researcher to glean the participants' perspectives on the observed events (Yin, 2011). The participants were also asked to recommend students for subsequent interviews described in this article. This method of snowball sampling helped to ensure that the students who were interviewed had been previously contacted by the teachers during the observations.

This phase continued with a similar pattern of alternating observations of four additional teachers and interviews with three students in order to build on previously collected data (Merriam \& Associates, 2002). Two of these observations occurred via webcam. One benefit of the teacher observation periods is that they were scheduled for times when teachers were planning to perform specific communication duties. Each teacher was asked to schedule the observation for a period of two hours in which they would normally make routine phone calls to students. Notes were taken for all observed communications with students. These communications were often in the form of voice messages and follow-up K-mails. (Kmails are the closed and internal communications used by many schools as alternatives to e-mails.) Verbal and nonverbal observations were also noted for each communication incident. Detailed field notes included direct quotes, communication summaries, and observer perceptions of the communication processes that transpired. Supporting documentation, such as student submissions or records of previous teacher communications and attempts, were obtained during the observation period or noted for the researcher to acquire at a later time. Many teachers provided background about each call during the observation periods. The researcher notes included detailed information about any follow-up documentation that needed to be obtained to substantiate the observations (Patton, 2002).

The researcher was able to interview only 5 of the 12 students with whom the observed teachers had communicated. These interviews were linked to the observation data because the knowledge gained from each interview was contextual (Kvale \& Brinkmann, 2009). Therefore, the interviews that aligned with previous observations may have provided a more accurate picture of virtual school communication practices than the observation alone. It was important to perform these interviews as soon as possible after the teacher observation to keep the information clear and relevant (Yin, 2011). The researcher asked students to reflect on the recent communications they had had with their teachers. This open-ended approach allowed the students to express personal beliefs that were not influenced by researcher promptings (Yin, 2011). Four out of five of these students cited the communication incident that was witnessed by the researcher in response to this question. These interview responses helped to provide triangulation by giving another perspective in order to represent the students' perceptions of the communication experiences (Johnson, 2001). These perceptions also provided a more accurate analysis of the transaction distance 
within these communication incidents.

It was important to compare the interview responses from the teachers who were observed and the students with whom they communicated. Teacher interviews that followed field observations each began with open-ended invitations for the teachers to comment on the activities of the observation periods. The supporting questions included asking the teachers to provide advice for effective phone communications with virtual students. Teachers were asked to explain their expectations for student participation in and responses to phone calls. Teachers were also asked to explain their rationale for phone-call selections. Students were asked to reflect on their expectations for teacher-initiated communications. They were also asked to reflect on their perceptions of specific phone calls that had recently been initiated by their teachers. All interviews concluded with the researcher summarizing the main points of the interview and asking the participants to verify these summaries (Kvale, 2007). The notes from these interviews included a series of direct quotes and note-taker observations written or typed directly on the interview guides as found in the appendixes. Some interview participants also provided documents to support the data from the interview. For example, one teacher showed her Dropbox entries for two students who had resubmitted the same work after teacher communications. Another teacher shared and explained her communication notes from the entire semester. The researcher summarized these documents in the interview notes or obtained electronic copies of the items when it was feasible. These documents also included records of previous communications or results of written communications and student submissions.

The interviews that were not linked to previous observations were conducted in a similar manner as outlined above. Interviews with 10 additional teachers and 6 students who were not involved in teacher observations provided additional perspectives about virtual school communications. Perspectives from the personal observations of people who could not participate in researcher observations due to privacy issues, geographical distance, or concern for human subjects helped to strengthen the triangulation of data. The researcher relied heavily on direct quotes and interview shells that provided initial interview questions and necessary background information for the participants to ensure effective data for these interviews.

The researcher began each interview by asking participants to reflect on recent phone-call communications and the roles these may have had in their virtual schooling practices. The participants were then asked to give and explain their beliefs about the importance of regular phone communication between students and teachers in the virtual school. The presentation of these questions varied based on the subject, as seen in the interview guides found in the appendixes, and helped to establish the communication patterns that emerged within the various virtual school platforms. Participants were also asked if they had specific examples they were willing to share regarding the effects of communication on student work habits. Follow-up or probing questions required listening to and analyzing the participants' initial answers in order to ascertain the best direction for each interview (Kvale \& Brinkmann, 2009). Participants were asked to substantiate their responses with school records or documents. Three teachers provided detailed documentation of communication 
attempts. This data helped generalize about the results of phone calls and written communications within virtual schools.

The analysis of the data included correlating the observation, interview, and archival data. The observation data was analyzed and coded for patterns such as repeating themes, words, or word fragments. Repeating phrases or condensed meanings within the direct quotes of teacher phone calls made during the eight observation periods were noted and tracked for 47 voice messages, 11 conversations with learning coaches, and conversations with 12 students. Procedures that may have reflected the reason for communications or the results of communications were also analyzed for patterns and noted. The data for interviews was analyzed using inductive analysis and a continuation of the coding scheme for direct quotes and condensed meanings.

\section{Results}

The teacher observations revealed similarities in communication styles. Every observed teacher started the observation period by looking through his or her grade book. Six of the eight teachers who were observed sent written communications to most of the students with whom they communicated or attempted contact. All eight teachers consulted previous notes of some form and contacted only those students who were not passing the course. Three of the teachers spoke with students and explained how to earn enough points to pass an assignment or the course. Communication practices such as increased volume or the use of repetition for emphasis were noted for at least two teachers. The results of these observations included details and direct quotes from 47 voice messages, 11 conversations with learning coaches, and interactions with 12 students. Interviews with five of the students with whom the observed teachers communicated provided secondhand evidence and another perspective to enrich the study data for these communication instances (Gubrium \& Holstein, 2001; Yin, 2011).

\section{Teacher Interviews}

A total of 10 teachers were interviewed over a three-week period. The teacher interviews varied in length from less than 30 minutes to more than 75 minutes. All but two teacher interviews began with the teachers sharing specific positive stories regarding recent communications with students. One teacher did not feel that he had experienced a recent enough conversation to comment on the first interview question. Another teacher summarized the various forms and reasons for her communications. All 10 of the teachers agreed that the rationale for phone calls was to reach students who would be able to pass by completing work in response to the phone call. Four teachers referred to a "bubble" as the demarcation line between failing and being able to pull up grades through intervention. It was important to note that the expectations for teacher communications may have varied for these interview participants because they represented four different virtual schools.

The 10 stand-alone teacher interviews and the 8 teacher interviews that followed observations were coded and categorized separately but the data was analyzed together. These 
teacher interview responses were copied and coded with a coding scheme similar to the observation coding described above. Inductive analysis was used to begin to code data as the interviews progressed and to add new categories as necessary (Neuendorf, 2002). The interviews were also analyzed with specific coding to distinguish direct quotes and condensed meanings (Kvale, 2007). The categories were related to the interview questions.

The direct quotes that were used for coding included the terms (a) prioritize, (b) make it personal, (c) communication is key, (d) immediate feedback, and (e) students do not return calls. The condensed meanings were used across several answers. These included (f) prefer written communication, (g) be yourself, (h) autonomy, (i) grades/percentages, (j) multiple/alternate forms of communication, (k) show concern, and (l) do not expect response. Frequency totals for the codes from teacher interviews are included in Table 1. The category for preferred written communications was used for teachers who responded that they or their students preferred e-mails or K-mails, or who used the words written communications. This code was marked 24 times in the data for all 18 interviews. There were 15 responses that included the fact that students do not return phone calls. Prioritize was used in response to several interview questions and appeared as a direct quote 13 times across 9 different interviews.

All of the teachers were asked what advice regarding communications they would give to a fellow virtual teacher. Of the 18 teachers, 7 responded that teachers should personalize their communication attempts and let the students know they care. Although their explanations varied, 7 out of 18 teachers advised that written communications should be used as the primary means for contacting students. One teacher explained, "My advice would be to encourage e-mail. Students have no patience. They will call you before they make sure they really need you... It can be never-ending." Another teacher recommended that teachers should use every free moment to make phone calls. She suggested that if a teacher is sitting at her desk waiting for a meeting to begin, she should pick up the phone and attempt to contact a student. Out of 18 teachers, 2 recommended that teachers call as early as possible when they see signs of trouble for a particular student. One teacher advised, "Don't wait... As soon as they miss one assignment, try to get them on the phone." Three teachers mentioned giving detailed feedback on assignments so students feel connected. Several teachers were asked what makes students work in response to their phone calls. Of the 18 teachers who were asked, 3 believed that making the calls personal and showing concern were the best ways to entice students to work in response to teacher phone calls. Five teachers provided follow-up data within one month of the interviews, which was considered archival data. These teachers included the results of various communication attempts, including phone calls and written communications. One teacher provided a comprehensive log detailing the results of attempted contact with 37 students over a one-week period. Another teacher sent regular updates when a student with whom she had attempted contact submitted work. Another teacher provided one-note files regarding the calls she made over a two-week period.

\section{Student Interviews}

Eleven students participated in telephone, computer, or face-to-face interviews. The re- 
sponses to interview questions were recorded as direct quotes and summaries of answers. The use of inductive analysis mandated that the codes from previous interviews be used where applicable before introducing new codes (Merriam \& Associates, 2002; Neuendorf, 2002). The codes from teacher interviews that carried over to student interviews included (d) immediate feedback, (f) prefer written communication, (h) autonomy, (j) alternate forms of communication, and (k) show concern. New categories that were added included (m) focus on larger/important assignments, (n) positive experiences, (o) reasons for not answering phone, (p) submitted requested work, and (q) explanations for work not submitted. The frequency totals for these codes are included in Table 1. Due to limited data, it was not possible to align the teacher actions from observation data with the resultant student behaviors in student interview data.

There were several comments made during both the observations and teacher interviews indicating that teachers had reason to believe that most students avoided teacher phone calls. One observation participant indicated that she believed "some of the kids will K-mail me back like 10 minutes after I have left the message... They are there but don't want to talk to you." Three teachers included comments about students who were unable to talk on the phone because they had to leave for appointments. Two teachers indicated that they have used alternate phone numbers as well as caller ID blocking in attempts to prevent students from avoiding phone calls. This aligned with the student interview data where 8 out of 11 students indicated that they do not always answer the phone when they know a teacher is calling. 
Table 1

Response Frequencies for Interviews

Data Source

Teacher interviews

Student interviews
Key Responses

Prefer written communication $\quad 24$

Students do not return calls 15

Multiple forms of communication $\quad 15$

Grades/percentages 13

Prioritize 13

Autonomy 12

Students don't want phone calls $\quad 12$

Do not expect response 10

Make it personal 7

Communication is key 8

Immediate feedback 8

Be yourself 6

Alternate communications 6

Referenced bubble students $\quad 4$

Prefer written communication $\quad 11$

Submitted requested work 11

Examples of work they would not 9

submit when requested

Liked to contact teacher by phone 9

Do not always answer the phone 8

Immediate feedback 6

Alternate forms of communication 5

Show concern 5

Focus on larger/important assignments 5

Contact teachers with questions 4

Grateful 4

Positive experiences 3

Did not like teachers calling parents 3

Reasons for not answering the phone 3

4

2

0

8

8

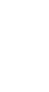

1

11

umber of 
were asked attributed the need for these repeat phone calls to the fact that the students do not tend to work in response to teacher-initiated phone calls. Of the 11 students who were interviewed, 9 indicated that there were specific assignments they would not complete even if a teacher contacted them by phone.

\section{Discussion}

Although teacher communications are vital in virtual schools (LaPointe \& Reisetter, 2008), the ways in which teachers choose to communicate vary based on the objectives of the communication. Transactional distance was not easily analyzed within the context of the results because the expectations and objectives of the various participants were not analyzed. Although the teachers in this study used personal phone calls to make contact with struggling learners in order to discover issues that may have been preventing success for these learners, the transactional distance varied within each situation. Teachers reported using K-mail and recorded phone calls much more frequently in order to address the majority of their students more quickly and to encourage students in good academic standing to maintain their academic progress.

A recent study found that virtual learners and teachers tend to prefer written communications for a variety of reasons (Watts, 2010). This information was supported by the results from most of the interview data from this study. Regular written communications and availability may be more important than teacher-initiated phone communications for virtual learners. Many students expect teachers to be available via e-mail, IM, or other digital formats for regular communications during school hours (Dennen et al., 2007; Grassian \& Kaplowitz, 2009). Out of 11 students, 8 indicated that they preferred to be K-mailed or contacted in writing by their teachers. Nine of these students held definite beliefs about when teachers should call and when they should use written forms of communication. Of the 11 students who were interviewed, 2 clearly stated that they prefer teachers not call them at all. Both of these students indicated that they would prefer written communications. Other research has indicated that students prefer communication methods that better align with the digital technology they use in their everyday personal lives (Baldarrain, 2006; Shearer, 2007; Young, Birtolo, \& McElman, 2009). These findings were reinforced by many of the students and teachers who were interviewed. Of the 11 students, 5 indicated that they liked the accessibility of their teachers who were available for instant messaging (IM). Three teachers also expressed that they had more success when they used text messaging to try and reach students. One teacher explained that she started to text message students when other teachers could not reach them. She stated, "I have really had success... They will gladly text back." This suggested that the transactional distance was not dictated by the school or location, but rather by the actions and perceptions of the students and teachers involved in the communication practices.

Observations and interviews included data which suggested that, for the most part, the students did not respond to phone calls. Five of the 18 teachers and 4 of the 11 students suggested that students do not often answer the phone when teachers call. Of the more than 60 
phone-call attempts, observed teachers spoke with only 12 students. During each observation period, the teacher called at least five students who had been contacted previously for missing assignments. Teachers did not reach any students during two of the eight observations. One teacher was able to reach 3 students with the 12 attempts she made during the observation period. The teacher notes used as archival data showed that the observed teachers, as well as other teachers, had repeatedly attempted to contact most of the students involved due to missing assignments. One teacher interview participant sent the researcher data which indicated that she had called 37 students she had previously attempted to contact via K-mail and phone calls. Fewer than $20 \%$ of those phone calls were answered. She did not receive return calls from any of the 12 families for which she left messages.

Although 8 of the 10 teacher interviews that were not associated with an observation began with the teacher sharing a success story, the overall conclusions were not altered by the interview data. All 18 teachers who were interviewed indicated that they expected very little results from their phone calls. Similarly, every teacher indicated that the number of contacts made with students compared with the number of attempts was very low. Three of these teachers agreed that "fewer than 30\%" of their phone calls resulted in actually speaking to a student. One respondent indicated that "the students who need the phone calls are going to be the ones who won't answer their phones... They are hiding." One participant indicated that he has a small group of students each year who will not respond at all to phone calls. This teacher indicated that he might make seven calls in one day to the same student in order to "try different times of day." He indicated that he was frustrated with this small portion of nonresponsive kids because he is "not able to help [any] kid if [he] can't talk to them [sic]."

This study showed that teachers did not find phone calls to be effective means of communication for learners. The results of the observations, teacher interviews, and archival documents showed some evidence of student work submitted in response to teacher-initiated phone calls. Future research on virtual school communications should include investigations regarding text messaging, instant messaging, and other social media in which teenagers often participate (Baldarrain, 2006; Shearer, 2007). 


\section{References}

Anderson, B. (2007). Independent learning. In M. Moore (Ed.), Handbook of distance education (pp. 109-122). Mahwah, NJ: Lawrence Erlbaum Associates.

Armstrong, T. (2006). The best schools. Alexandria, VA: Association for Supervision and Curriculum Development.

Baldarrain, Y. (2006). Distance education trends: Integrating new technologies to foster student interaction and collaboration. Distance Education, 27(2), 139-153.

Barbour, M., \& Reeves, T. (2009). The reality of virtual schools: A review of the literature. ScienceDirect, Computers and Education, 52(2), 402-416.

Dennen, V., Darabi, A., \& Smith, L. (2007). Instructor-learner interaction in online courses: The relative perceived importance of particular instructor actions on performance and satisfaction. Distance Education, 28(1), 65-79. doi:10.1080/01587910701305319

Ferdig, R., Cavanaugh, C., DiPietro, M., Black, E., \& Dawson, K. (2009). Virtual schooling standards and best practices for teacher education. Journal of Technology and Teacher Education, 17(4), 479-503.

Grassian, E., \& Kaplowitz, J. (Eds.). (2009). Information literacy instruction: Theory and practice $\left(2^{\text {nd }}\right.$ ed.). New York: Neal-Schuman Publishers.

Greenway, R., \& Vanourek, G. (2006). The virtual revolution: Understanding online schools. Education Next, 6(2), 34-41.

Gubrium, J., \& Holstein, J. (2001). From the individual interview to the interview society. In J. Gubrium \& J. Holstein (Eds.), Handbook of interview research: Context and method (pp. 1-32). Thousand Oaks, CA: Sage Publications.

Harms, C., Niederhauser, D., Davis, N., Roblyer, M., \& Gilbert, S. (2006). Educating educators for virtual schooling: Communicating roles and responsibilities. Electronic Journal of Communication, 16(1/2), 17-24.

Johnson, J. (2001). In-depth interviewing. In J. Gubrium \& J. Holstein (Eds.), Handbook of interview research: Context and method (pp. 103-120). Thousand Oaks, CA: Sage Publications.

Kanna, E., Gillis, L., \& Culver, C. (2009). Virtual schooling: A guide to optimizing your child's education. New York, NY: Palgrave MacMillan.

Kvale, S. (2007). Doing interviews. Los Angeles, CA: Sage Publications.

Kvale, S., \& Brinkmann, S. (2009). Interviews: Learning the craft of qualitative research interviewing ( $2^{\text {nd }}$ ed.). Los Angeles, CA: Sage Publications. 
LaPointe, L., \& Reisetter, M. (2008). Belonging online: Students' perceptions of the value and efficacy of an online learning community. International Journal on E-Learning, 7(4), 641-665. doi:1580113151

Lowry, P., Roberts, T., Romano, N., Jr., Cheney, P., \& Hightower, R. (2006). The impact of group size and social presence on small-group communication. Small Group Research, 37(6), 631-661.

Means, B., Toyama, Y., Murphy, R., Bakia, M., \& Jones, K. (2009). Evaluation of evidencebased practices in online learning: A meta-analysis and review of online learning studies. Washington, D.C.: U.S. Department of Education.

Merriam, S., \& Associates (Eds.). (2002). Qualitative research in practice: Examples for discussion and analysis. San Francisco, CA: Jossey-Bass.

Moore, M. (2007). The theory of transactional distance. In M. Moore (Ed.), Handbook of distance education (pp. 89-105). Mahwah, NJ: Lawrence Erlbaum Associates.

Moore, M., \& Kearsley, G. (1996). Distance education: A systems view. Cincinnati, OH: Wadsworth Publishing Company.

Moustakas, C. (1994). Phenomenological research methods. Thousand Oaks, CA: Sage Publications.

Neuendorf, K. (2002). The content analysis guidebook. Thousand Oaks, CA: Sage Publications.

Oliver, K., Osborne, J., \& Brady, K. (2009). What are secondary students' expectations for teachers in virtual school environments? Distance Education, 30(1), 23-45.

Patton, M. (2002). Qualitative research \& evaluation methods ( $3^{\text {rd }}$ ed.). Thousand Oaks, CA: Sage Publications.

Peterson, P. (2010). Saving schools: From Horace Mann to virtual learning. Cambridge, MA: Belknap Press.

Saba, F. (2007). A systems approach in theory building. In M. Moore (Ed.), Handbook of distance education (pp. 43-55). Mahway, NJ: Lawrence Erlbaum Associates.

Shank, G. (2006). Qualitative research: A personal skills approach ( $2^{\text {nd }}$ ed.). Columbus, OH: Pearson.

Shearer, R. (2007). Instructional design and the technologies: An overview. In M. Moore (Ed.), Handbook of distance education (pp. 219-232). Mahway, NJ: Lawrence Erlbaum Associates.

U.S. Department of Education. (2008). Lead and manage my school: Evaluating online 
learning: Challenges and strategies for success. Retrieved April 21, 2009, from http://www.ed.gov/admins/lead/academic/evalonline/report pg6.html\#sect6.

Watson, J. (2007). A national primer on K-12 online learning. Washington, D.C.: North American Council for Online Learning.

Watts, L. (2010). The role of dialogue in distance education: A qualitative study (Doctoral dissertation). Retrieved from ProQuest Dissertations and Theses Database. (AAT339457, ED515027).

Weiner, C. (2003). Key ingredients to online learning: Adolescent students study in cyberspace. International Journal on e-Learning, 2(3), 44-50.

Wengraf, T. (2001). Qualitative research interviewing: Biographic narrative and semistructured method. Los Angeles, CA: Sage Publications.

Yin, R. (1984). Case study research: Design and methods. Beverly Hills, CA: Sage Publications.

Yin, R. (2009). Case study research: Design and methods ( ${ }^{\text {th }}$ ed.). Thousand Oaks, CA: Sage Publications.

Yin, R. (2011). Qualitative research from start from finish. New York: Guilford Press.

Young, J., Birtolo, P., \& McElman, R. (2009). Virtual success: Transforming education through online learning. Learning and Leading with Technology, 36(5), 12-17. 


\section{Appendix A}

Interview Protocol-Interviews Following Teacher Observations

Thank you for taking additional time to clarify the observations and any questions I may have. I will start this interview by asking for your feedback on the observation period. I will then ask you to help clarify any gaps in my notes or to ensure the accuracy of specific notes. I will ask you a few questions regarding communication with students. Finally, I will ask you to recommend a few students with whom you communicated who may be interested in a follow-up interview with me. [Briefly summarize the purpose of the study, review IRB guidelines, and ask for consent.]

Q1. Can you share any thoughts or comments on the observation period? Please be as descriptive as you can be.

Q2. I would now like to ask you specific questions about what I just observed. [I will ask for clarification and share my initial analyses.] [I may ask for rationales for specific interactions or student work samples that relate to the observation period.]

Q3. How do you plan to follow up on these communications? [I may get specific for given observations.]

Q4. What is your rationale for how to follow up on specific phone calls?

Q5. If one of your colleagues asked you for advice on communicating with students, what might you tell him/her?

Q6. Is it OK to check back with you on [here cite specific students]?

Q7. Would you be willing to track the submissions for [here cite specific students]?

Q8. As discussed with your school administration, I would like to follow up with an interview with one or more of the students with whom you just communicated. Do you have recommendations for this process?

[Summarize the notes and ask for verification.] Thank you so much for taking the time today. I plan to analyze and summarize these notes. 


\section{Appendix B}

Interview Guide and Protocol-Interview-Only Teacher Participants

Do you have any questions about this interview or the research project?

Once we get started, I will ask you a series of questions and I will take notes on your answers. You do not have to answer any question and you may stop the interview at any time.

Q1. Can you describe a recent phone communication with a specific student or students? Please be as descriptive as possible.

Q1B. [may be needed if they describe only a limited example] Is this typical of your recent communications? Explain.

Q2. Can you provide any examples of recent communications and resultant student submissions? [may need further probes] [may use information from Q1]

Q3. What is your rationale for student communication? How do you decide whom to contact? [to be asked singularly] [may probe further on specifics from Q1 and Q2]

Q4. How do you use phone communications for students who are not struggling? How do you communicate with students who are not struggling? [These questions will be asked in one or both forms.]

Q5. What advice regarding contacting students would you give to a colleague who is new to virtual schools?

Q6. Do you have anything else you would like to share regarding student and teacher communications?

[Summarize notes and ask for verification.] Thank you so much for agreeing to this interview. I plan to analyze and summarize these notes. 


\section{Appendix C}

Interview Guide-Interview-Only Teacher Participants Needing Frequent Probes

I would like to review the informed consent and ask you to sign it. [Review the forms.]

Do you have any questions about this interview or the research project?

Once we get started, I will ask you a series of questions and I will take notes on your answers. You do not have to answer any question and you may stop the interview at any time.

Q1. I would like you to reflect on your perceptions of specific phone calls that have occurred recently. [They will be asked if they can recall a specific example or details from a recent communication incident. They will be asked if they have and are able to share any archival data to support the shared information. Specific types of data may be requested separately as needed.]

Q2. Can you provide additional support for this situation or any communication practices?

[The following will be used as needed for probes.]

Q3. Why do you call certain students?

Q4. Are there times when you use calling over e-mail or vice versa? Can you explain your rationale? Do you think the results differ? Please explain in as much detail as you can. [These will be asked singularly.]

Q5. Do students call you back if you have to leave a message? Do you provide multiple ways to contact you?

Q6. What are your expectations for student participation in and responses to phone calls?

Q6B. What do you think makes a student work in response to your phone calls? [Probe further as needed with regard to specific examples.]

Q7. Do you prefer to talk to the student or parent? Why?

Q8. What advice regarding communications with students would you give to a new virtual teacher? 


\section{Appendix D}

Supplemental Interview Guide-Students Needing Frequent Probes

I am going to ask you a series of questions in order to guide responses toward information about your recent communications with your teachers. You may ask me for clarification. You do not have to answer any question and you may stop the interview at any time.

Do you remember the last time you talked on the phone with your teacher?

Who called whom?

What was the purpose of the call?

Tell me about any work completed during the call or submitted after the call.

Do you regularly call your teachers? Can you explain that?

[depends on previous answer] Why? [do you or do you not...]

If you have a question with an assignment, what do you generally do?

How do you or your learning coach respond when a teacher calls and leaves a message?

If you could request that your teachers communicate with you when and how you prefer, what would that look like?

Do you think it is more helpful for a teacher to call you before an assignment is due or after you have missed it? Can you explain?

Do you prefer phone calls, e-mails, or K-mails?

Can you explain or describe your preferences for each type of communication? [This may need further probing or breaking down.]

Do you have any examples or samples of work that you submitted in response to a teacher phone call? [The follow-up to this question will depend on the student's response.]

Thank you for your time. Those are all of the questions I have for you today. Do you have any additional comments you would like to make about teacher phone calls or communication practices?

\section{Athabasca University $\mathbf{A}$}


THE INTERNATIONAL

REVIEW OF RESEARCH IN

OPEN AND DISTANCE LEARNING

\section{Connectivism and Dimensions of Individual Experience}

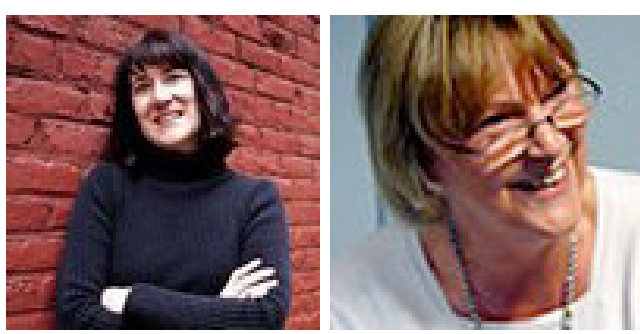

Carmen Tschofen and Jenny Mackness

\section{Abstract}

Connectivism has been offered as a new learning theory for a digital age, with four key principles for learning: autonomy, connectedness, diversity, and openness. The testing ground for this theory has been massive open online courses (MOOCs). As the number of MOOC offerings increases, interest in how people interact and develop as individual learners in these complex, diverse, and distributed environments is growing. In their work in these environments the authors have observed a growing tension between the elements of connectivity believed to be necessary for effective learning and the variety of individual perspectives both revealed and concealed during interactions with these elements. In this paper we draw on personality and self-determination theories to gain insight into the dimensions of individual experience in connective environments and to further explore the meaning of autonomy, connectedness, diversity, and openness. The authors suggest that definitions of all four principles can be expanded to recognize individual and psychological diversity within connective environments. They also suggest that such expanded definitions have implications for learners' experiences of MOOCs, recognizing that learners may vary greatly in their desire for and interpretation of connectivity, autonomy, openness, and diversity.

Keywords: Autonomy; openness; diversity; connectedness; connectivism; self-determination; massive open online course; motivation; personality theory; MOOC; identity; learner experience

\section{Introduction}

Connectivism has been offered, but has not yet been universally accepted, as a new learning theory for a digital age (Verhagen, 2006; Kop \& Hill, 2008; Bell, 2011). For the purposes of this discussion, connectivism is viewed as a viable description of learning that incorporates emergent disciplinary and interdisciplinary understandings that may not yet have been 
tested in traditional forms. It reflects the many shifts in contemporary cultural narrative including increased recognition of systems, complexity, and interrelatedness. Connectivism is based on the principle that all learning starts with a connection (Siemens, 2004). These connections occur on neural, conceptual, and social levels (Siemens, 2008), and in connectivism, learning is thought to be "the ability to construct and traverse connections" (Downes, 2007).

Learning in connectivism terms is a network phenomenon, influenced, aided, and enhanced by socialisation, technology, diversity, strength of ties, and context of occurrence. However, the influences on connectivism that we will focus on in this paper are the four key principles for learning that exist within connectivist thought: autonomy, connectedness, diversity, and openness (Downes, 2010a). Connectivism is a response to a perceived increasing need to derive and express meaning, and gain and share knowledge. This is promoted through externalisation and the recognition and interpretation of patterns, which are shaped by complex networks (both internal neural networks and external social networks) (Siemens, 2004). Connectivism attempts to situate learning in the continual expansion and creation of knowledge and posits that information and knowledge growth in this digital age exceed our ability to cope; the quantity and complexity of information available is overwhelming (Siemens, 2006).

Whilst connectivism has recently been acknowledged as "beginning with the individual," and as "leaving space for human agency" (Bell, 2011), as well as "increasing the value of the individual" (Siemens, 2011), there has been a much more intense focus on the networked and shared (or sharing) experiences that have been viewed as a key difference from other learning theories. An understanding of the individual in connectivism, while acknowledged with respect to the choice and use of technologies associated with personal learning environments and the activities of aggregating, remixing, repurposing, and sharing (Kop \& Fournier, 2010), has not been explored in any detail to this point. It is easy to see that attention to the perspective of the individual may perhaps be viewed as ultimately moot within the cumulative mass of network connections. Additionally, increased attention to the idea of "combinatorial creativity" (a term coined by blogger Maria Popova at http:// www.brainpickings.org/index.php/2011/08/01/networked-knowledge-combinatorial-creativity/), which counteracts the "lone genius" concept with a recognition of the complexity of influences on ideas and creativity (Sawyer, 2007), steers us towards a more collective understanding of learning, creation, and innovation. However the authors suggest that there is still room for - and a need for - both recognition of the accruing and beneficial nature of networked learning and attention to the unique individual as a separate self within the connectivism dialogue.

The discussion here is not intended to "roll back" cultural narrative to reassert the primacy of the individual. It does, however, attempt to understand the interplay between individuals and connectivist thought by introducing the potential perspectives brought by the individual and juxtaposing them with connectivist principles.

An important factor in our understanding is that the testing ground for connectivism and 
its principles has been in massive open online courses (MOOCs). In 2011 we have seen a surge of MOOC offerings (see Wikipedia, Massive Open Online Course for a list of MOOCs - http://en.wikipedia.org/wiki/Massive open online course). MOOCs are online courses that attract a wide diversity of participants from across the world. They are massive in the sense that they can attract literally thousands of participants. They are open in the sense that they are free and participants are expected to openly share their expertise, knowledge, understanding, and ideas, so that knowledge is not only freely distributed across the network, but also created within the network. MOOCs are courses in that they provide a structured curriculum around a given theme or topic, but learners are expected to be autonomous and manage their own learning by making their own social and conceptual connections to suit their own needs.

As the number of MOOC offerings increases, so does awareness of areas of tension as these "events" negotiate between innovative and traditional learning processes. Among those tensions that have recently come to the fore is the desire by some to define a MOOC, and subsequently what is not a "true" MOOC, evidenced by debates surrounding what is truly an "open" course, for example, or the increasingly difficult and limiting distinction between online and offline networks. (See discussions in Change MOOC - http://change.mooc.ca/.) At the same time, an interest in defining acceptable or appropriate roles for individuals within MOOCs and among connectivist participants has arisen. Siemens (2010), for example, has expressed serious reservations about "lurkers," while others have been recently concerned with the "responsibility" of MOOC conveners. In many conversations we detect a tacit conceptual conflation of connectivism and MOOCs.

It should be noted that the discussion offered here is an outgrowth of the ongoing conversations surrounding connectivism in the past several years, during which both authors have participated in varying levels with MOOCs and in applying connectivist principles in their respective environments. It also reflects an effort to gain insight into the actions (or nonactions) and subsequent frustrations evidenced by individual participants in the MOOC environments. The intent is to potentially ease the tensions suggested by the desire for definitions and roles - and the concern about what is the "right way" to "do" connectivism. The process offered here juxtaposes connectivist principles with a basic review of contemporary psychological theory and offers an expanded vocabulary and dialogue surrounding personal motivation and personal choice within connectivist learning and the "testing environment" of MOOCs.

\section{Juxtaposing Three Concepts}

To date, connectivism has been discussed principally in relation to behaviourism, cognitivism, and constructivism (Siemens, 2004; Anderson \& Dron, 2011). In this paper we explore connectivism in relation to personality theory and self-determination theory and suggest that together these three concepts offer a lens through which we can explore dimensions of individual experience in connectivism. 
Stephen Downes has identified autonomy, connectedness, diversity, and openness as the key components of connectivism conducive to (or required for) learning in networks. These descriptors are intended to apply to a network and its functioning and are viewed as positive or desirable conditions, although this was critiqued by Mackness, Mak, and Williams (2010) following their experience of the Connectivism and Connective Knowledge MOOC in 2008 (CCKo8). While recognizing that terms used in one field can have completely unrelated meanings and implications in another discipline, the overlap in language between the concept of connectivist principles and two additional concepts, personality theory and self-determination theory, seems to call for exploration.

\section{A Brief Introduction to Personality Theory}

When psychologists use the term personality, they are referring to the unique and relatively enduring set of behaviors, feelings, thoughts, and motives that characterize an individual...personality is what distinguishes us from one another and makes us unique... personality is relatively enduring, or consistent. (Feist, 2010. p.114)

One of the most widely accepted models of personality traits in contemporary human psychology is the "Big Five" (McCrae \& Costa, 1987). (For a more thorough discussion of the multiple contributors to the evolution of research in personality structures, see John \& Srivastava, 1999).

These five, very broad, spectrum-oriented traits are openness, conscientiousness, extraversion, agreeableness, and neuroticism. Ongoing research in this area also recognizes the situational or environmental factors involved in their expression, as well as the role of biology, evolution, and neuroscience in contributing further understanding of personality traits (Fiest, 2010). John and Srivastava (1999) note:

Personality traits are basic tendencies that refer to the abstract underlying potentials of the individual, whereas attitudes, roles, relationships, and goals are characteristic adaptations that reflect the interactions between basic tendencies and environmental demands accumulated over time. According to McCrae and Costa, basic tendencies remain stable across the life course whereas characteristic adaptations can undergo considerable change.

While it is clear that this is a complex realm of understanding, the simplifying terms of the Big Five allows an initial juxtaposition of personality traits with the networked learning principles, contributing to some interesting relationships. 


\section{A Brief Introduction to Self-Determination Theory}

An additional concept, self-determination theory, has also offered insight into potential relationships between networked learning and individuals within networks. (We acknowledge that this can also include nonhuman nodes, but this is not addressed here). This is not to be confused with self-directed learning, which is oriented toward academic tasks and practice. Kirwan, Lounsbury, and Gibson (2010, p. 23) characterize self-direction as
a personality construct reflecting an individual's preference to be in charge of their learning process; ability to conceptualize, plan, implement, and evaluate their academic experience; and disposition to be goal- oriented and to work independently or in group settings with little guidance.

In contrast, self-determination theory (SDT) examines human growth and initiative as a form of dynamic potential and is closely linked to understandings of psychology and motivation. It is about a 'way of being.'

SDT begins with the belief in and acceptance of innate, constructive tendencies for action and growth (not a universally accepted stance), whilst simultaneously recognizing that complex social-contextual factors affect any potential expression of "integrating" tendencies. Ryan and Deci (2002) introduce three essential components in self-determination: competence, relatedness, and autonomy. All elements, we suggest, are significantly related to the interactions of connectivist learning and connectivist principles, both in terms of gaining a broader understanding of the vocabulary and semantic nuances of terms used to explain connectivism and in understanding factors that affect how and why individuals may choose to engage with connectivist learning.

The discussion here uses the scaffold of the four connectivism principles to explore connections between connectivism, personality theory, and self-determination theory.

\section{Exploring Autonomy}

\section{Autonomy as Choice and Control}

The idea of autonomy is closely identified in educational literature with concepts of choice, control, and independence (see for example Thanasoulas, 2002 and Crome, Farrar, \& O'Connor, 2011). And yet the ability to act independently and select levels of choice and control is not an element that has offered an easy path in connectivist learning, where learners are expected to choose among connections and information, and where deliberate attempts are made to reduce external control by minimizing traditional instructional processes and power structures. In his work on adult learning in formal and semiformal e-learning courses, Dron (2007) has recognized that how autonomy is experienced "varies from person to person and context to context... Different structures will lead, inevitably, 
to different consequences and offer different benefits to different learners." (p. xvi.) He recommends that learners should be able to "choose when to choose," understanding that some learners will opt for more structure (control) or dialogue (choice). Even at this point, "The mediation of learner control requires metacognitive skills that are not universally distributed among the population." (Bouchard, 2011, p. 293).

Along these lines, there have been increasing suggestions that a potentially unfettered network environment may work best only for adults or the most experienced learners and perhaps those with a large amount of traditional education as a background. Some have expressed surprise at the "learned helplessness" of even mature or "well educated" learners, and learners themselves are often frustrated at the lack of control in connectivist environments. In research (Mackness, Mak, \& Williams, 2010) in which participants were surveyed and interviewed about their experience of participation on the massive open online course CCKo8 (Connectivism and Connective Knowledge, 2008), course participants were asked questions designed to elicit their experience of learner autonomy. These questions typically led to the following type of response:

A controlled environment would have been a great start. I liked that participants could start threads of their own but it also got out of hand a few times. It was clear the kids were in control of the classroom, which as an 'experiment' it was sort of expected to be. (Mackness, Mak, \& Williams, 2010, p. 271).

Also: "I felt like some guidance would have helped. Freedom is great, but this course was all over the place. There was no one place to follow the latest thinking on any one subject." (Mackness, Mak, \& Williams, 2010, p. 269).

\section{Psychological Autonomy and the Individual}

Concerns about how or whether learners are motivated or equipped to take advantage of the many options in connectivist environments has engendered some frustration for both learners and facilitators. Some insight may be gained by an understanding of psychological autonomy, which Dron recognizes as different from the autonomy of choice and control (2007, p. 60).

The definition of psychological autonomy offered by Ryan and Deci (2002) seems of interest: “[A]utonomy refers to being the perceived origin or source of one's own behavior. Autonomy concerns acting from interest and integrated values. When autonomous, individuals experience their behavior as an expression of the self...” (p. 8).

In contrast to the potential of connectivist learning, traditional learning environments rarely request or allow an "expression of the self," focusing, rather, on expressions desired by instructors, who have also traditionally determined the scope of choices and learner control. In this light, connectivist environments such as MOOCs may well be placing learners in two dimensions of unfamiliar autonomy, those of both "choice and control," and 
psychological autonomy.

At the same time, while seeing autonomy as an expression of the self, Ryan and Deci (2002) see no contradiction in maintaining a community orientation.

Autonomy is often confused with, or melded together with, the quite different concept of independence (which means not relying on external sources or influence)... Indeed, one can quite autonomously enact values and behaviors that others have requested or forwarded, provided that one congruently endorses them. (p. 8)

Stephen Downes has blogged about autonomy from various angles (see for example, 2010b), and, while often emphasizing a connectivist, network orientation, has also provided descriptions of autonomy that seem to "leave room for" acknowledgment of the individual.

Wherever possible, learners should be guided, and able to guide themselves, according to their own goals, purposes, objectives or values. It is a recognition that, insofar as a person shares values with other members of a community, and associates with those members, it is a sharing freely undertaken, of their own volition, based on the evidence, reason and beliefs they find appropriate.

(Downes, 2010a)

The parallels between these descriptions of autonomy suggest that both the network (or community) autonomy (Downes, 2010a) and autonomy of the self or individual (Ryan \& Deci, 2002) have room for equal focus within connectivism.

\section{Autonomy and Lurking}

Additionally relevant for connective learning is the proposal that while autonomy as choice and control offers a "menu" of externalized actions, autonomy as an expression of the self offers the basis of a rationale or understanding of the motivations involved in making those choices. Reconciling the apparent discrepancy between, for example, outwardly active participation and so-called lurking may well lie in the meshing of an understanding of these two ideas. We suggest that thinking about networked autonomy in terms of choice and control offers the active "what" of learning; thinking about autonomy in terms of self underlies the motivational "why" in accepting or engaging (or not) with those choices.

The current tensions about autonomy and the self or individual in connectivism may also be seen in contrasting two further discussions. Aviram and Assor (2010) introduce the characteristics of an autonomous individual, noting commitment to three values and the ability to realize them: self-knowledge, self-direction, self-expression (p. 118). Yet within connectivism, the modifier "self" is sometimes identified in a negative light. Siemens (2010), a primary connectivism theorist, writes of lurking: 
Being connected, without creating and contributing, is a self-focused, self-centered state.... there is never a good time to be a lurker. Lurking = taking. The concept of legitimate peripheral participation ... is actually negative. Even when we are newcomers in a network or community, we should be creating and sharing our growing understanding...

Siemens is an influential blogger and discussions in the blogosphere have indicated that this is not an uncommon view, where lurking has been referred to as 'free-riding' by a number of authors (see for example Wellman \& Gulia, 1998).

A concern with this view is that there are many extrinsic (community-oriented) and intrinsic (self-oriented) variables among the complex sociocontextual factors, which Ryan and Deci (2002) identify as important to self-determination. Similarly, as suggested here, there are different dimensions of autonomy involved in choosing to participate in obvious and visible ways. With this understanding, the interpretation of certain types of participation (or perceived nonparticipation) as selfishness and the denial of community values seems to reflect a personal worldview and may fail to acknowledge the complexity of individuals engaged in connective spaces.

\section{Exploring Connectedness/Interactivity}

The concern about lurking is also reflected in our exploration of the implications and dimensions of connectedness and interactivity as a connectivist principle. Our experiences as MOOC participants suggest that for some learners there may be a tension between being sufficiently connected to take advantage of all the Web has to offer and having enough choice in relation to 'space' for individual and independent development and personal learning.

\section{Relatedness, Agreeableness, and Neuroticism}

Recent research into personal learning environments, a primary conduit for connectivist learning, has largely discussed connectedness in connectivism in technology-based terms - a collection of hardware and software applications (Cormier, 2011). At the same time, the "sharing" emphasis in connectivism (Kop, 2011) has been linked with a tacit or even explicit expectation of mutual obligation and support, as in Siemens' quote about lurking (2010). Under the vocabulary offered in self-determination theory, we see the networked learning principles of connectedness and interactivity as having parallels in the concept of relatedness (Ryan \& Deci, 2002), which is defined as a sense of personal connectedness, caring, and belonging. These areas of "caring and belonging" take us well into an emotional realm not part of the connectivist conversation to date. One exception is Kop and Fournier's (2010) survey on self-directed learning in open networked environments which suggests that for many learners, the sociality and personal sense of connectedness - relatedness - in networked learning is as valued as the conceptual connections of connectivism. 
This is a delicate and complex area of understanding as there is both the understanding that network participation should be voluntary and not emotionally coercive, while at the same time the tools and technologies used in connective learning are designed as amplifications of human interaction as "social" media. In terms of personality theory, the trait of agreeableness, understood as the tendency to be compassionate and cooperative, may also play a factor here; in the case of digital connectivism, the ability to project agreeableness in an online environment may in part determine perceptions of connectedness, interactivity, and relatedness.

At the same time, the trait of neuroticism, in which individuals may more readily experience negative emotions, may affect perceptions of interactions within networked environments. The presence of a "troll" in the CCKo8 forums, for example, evoked varying expressions of anger and discomfort among some learners and was considered a determining factor in participation levels in that environment (Mackness, Mak, \& Williams, 2010).

\section{Identity, Extraversion, and Introversion}

Etienne Wenger (2011) has reflected that in the 21st century identity can be linked to a multitude of communities (or networks). The challenge for individuals is how to engage with and enable individual identity to be realised in these communities and networks. Wenger's work posits that the definition of identity and the development of relatedness are shifting more and more onto the shoulders of the individual person rather than being automatically acquired through familial, geographic, or other traditional structures.

The shifts in the sources of identity and thus potential relatedness in communities and networks has drawn attention to the idea of the quality of one's network and connectedness/interactivity. At the same time, the very idea of a MOOC is rooted in the idea that the potential quantity of connections, or at least connective opportunities, is a key element of learning.

The personality traits of extraversion and introversion, which affect perceptions of the quality and quantity of personal interactions, may complicate conceptualizations of both quality and quantity in connectedness and interactivity (Topi, Valacich, \& Rao, 2002). These Jungian terms reflect the spectrum along which people are drawn to and gain energy from interactions with other people or from ideas and self-reflection. It may be that these concepts are already embedded in the "layers" of connectivism, perhaps with the "social" layer accommodating varying levels of extraversion and the conceptual layer accommodating introversion. But, as noted above, personality tendencies are relatively stable, although they may be expressed differently in different environments. Thus the connectivist imperative of "sharing" and "interactivity" may excite some who are also most likely to share this excitement in an overt way, while the same processes may be a burden to others.

Studies in this area are limited and somewhat inconclusive. Topi, Valacich, and Rao (2002) conducted a small study, which showed that while extraverts found more satisfaction in both face-to-face and computer-mediated communicative environments, introverts were equally able to influence problem-solving outcomes. Jung, Lee, and Karsten (2011) found 
"significant performance differences between extravert-CMG [computer-mediated groups] and introvert-CMG regarding producing unique and diverse ideas," with extraverts performing better in moderate and high idea stimuli environments.

Additionally, the trait of extraversion has been split into two components: sociability-gregariousness and confidence-assertiveness. Feist (2010) refines Topi, Valacich, and Rao's findings, noting that highly creative individuals tend toward the second component and "are generally not sociable and outgoing, but they are independent, confident, and assertive...” (p. 121).

In terms of understanding these personality preferences in learning environments (which would include MOOCs), Puccio (1999) notes:

One warning for instructors is not to automatically assume that only those students who show extraverted tendencies are engaged in the course. Although the introvert does not show overt involvement in course content, this does not mean he or she is not engaged. To the contrary, it may be the more introverted students who are internally stimulated by the concepts presented in a course who are actually the most engaged.

\section{Privacy, Solitude, and Control}

The traits of extraversion and introversion may have implications for "social learning" as a whole since while extraverts can thrive on sociality, introverts crave solitude and often desire privacy. This raises questions about power and personal control in networked learning. Malmud Smith (1997) notes: "The essence of solitude, and all privacy, is a sense of choice and control. You control who watches and learns about you. You choose to leave and return" (p. 37).

The choice of leaving and returning seems on one hand a very viable option in networked learning, with learners variably connecting and disconnecting from networks, both digitally and socially (White \& Le Cornu, 2011). And yet, because of the pace of change and information exchange within networks, this disconnection may well sever people's tacit sense of relatedness and confuse others who seek or expect other rhythms in their connectedness and interactivity. And while much recent work has been devoted to the idea that learning and knowledge creation does not occur in isolation, reflections on privacy and solitude quickly merge into considerations of creativity, a topic not yet considered in depth in relation to connectivism. For example, Storr (1988) notes that in a search for coherence (a word quite relevant in discussions of information abundance), "creators... are able to define identity and achieve self-realization by self-reference; that is, by interacting with their own past work rather than by interacting with other people" (p. 147). This is not necessarily contradictory to some elements of connective and social learning as this "past work" may include ideas compiled from many sources. A concern arises, however, if all (valid) connectivist learning is viewed as being of transaction, of process, and is measured or evaluated largely 
through the lens of ongoing interactivity, evidenced by externalized activities such as online aggregation, posting, and "feeding forward." In this case, voluntary disconnection (temporary or otherwise) may well be viewed as leading to inadequate learning and judging others' learning processes as insufficient. (Issues surrounding involuntary disconnection are not addressed here.)

The emphasis on connection above all else is an especially critical concern as connectivism and networked learning enter the more formal education realms. Many of these call for assessment and accountability in ways that may reflect the "ghost" of educational control discussed by Doll (2002), whereby, for example, even "personal networks" are required to be displayed and evaluated.

The discussion regarding these issues here is relatively brief. The apparent paradox of simultaneously pursuing connectedness and interactivity while at the same time offering the potential to support the individual and that which is "personal" is an aspect of connective learning theory that has not been fully explored.

\section{Exploring Diversity}

The concept of diversity in education is traditionally understood in the light of measurably obvious differences among learners, especially based on gender, race, culture, socioeconomic status and perhaps aptitudes such as Gardner's "intelligences" (Gardner, 1999). Additionally, Baym (2010) notes diversity in the degrees and kinds of interactivity offered by various modes of digital communication, a point relevant to MOOCs.

In connectivism terms, Downes (2010a) shares his understanding of diversity as follows:

....the system of education and educational resources should be structured so as to maximize diversity. The intent and design of such a system should not be to in some way make everybody the same, but rather to foster creativity and diversity among its members, so that each person in a society instantiates, and represents, a unique perspective, based on personal experience and insight, constituting a valuable contribution to the whole.

In the context of this discussion, connectivism's potential ability to support diversity in a significant area of self-motivation, competence, as well as the ability to accommodate diversity on the personality trait spectrum of conscientiousness, offers a unique strength. At the same time, efforts to create structure or requirements within connective learning, which could negatively affect learner choice and autonomy, may hinder diversity. And the complex nature of connective learning, which at this time requires high levels of competence in certain skill areas, and, perhaps, high levels of conscientiousness in contributing to visible participation, means that diversity among connective learners may actually be limited from the outset. 


\section{Competence}

In terms of self-determination theory, the factor of competence is defined as feeling effective in interactions and having the opportunities to enact this effectiveness. A sense of competence is one factor which empowers individuals to further endeavors. In MOOCs, this sense of competence can be affected by many things, including language ability, overall learning and technology skill level, and the ease of user interface and connection.

Connectivism learning advocates have generally supported diversity of expression, including the choice of tools for expression, where learners may gravitate towards those where they feel most competent. However, varying expressions of areas of competence may also create tensions during interaction among learners with diverse formal and informal learning expectations. Puccio (1999), for example, notes that instructors' personal orientations have an "unconscious influence... on expectations of what constitutes productive student behavior."

In terms of connective learning, unconscious influences may also affect expectations in peer-to-peer learning and networked interactions, where individuals may advocate for forum participation over blogging, for example. In some cases these expectations may also include what has been termed a "product bias," in which learners' tangible products (expansive verbal interaction or production of text, for example) are considered a stronger contribution or more valuable to interactivity than less-documentable explorations of potential and process (Beghetto, 2010, p. 456). These issues reinforce the importance of diversity in connective learning, whereby learners may opt for favored (strengths-based) forms of expression and tools which reflect and support their sense of competence.

\section{Conscientiousness}

In considering diversity in light of visible and active MOOC participants, one speculation is that the most obviously active MOOC participants are individuals high in the psychological trait of conscientiousness, geared toward duty and achievement, perhaps in forms generally rewarded in formal learning environments. (Research by Kirwan, Lounsbury, \& Gibson, 2010 uses a similar understanding of this definition.) For example, regular attendance at MOOC sessions, consistent (public) writing, and public collegial exchanges contribute to an overall perception of active connective learning. MOOCs, which point to such conscientious activities as the most appropriate learning processes, may appeal to these outwardly attentive and active learners more than those less oriented toward these forms of achievement and interaction.

At the same time, there would seem to be ample room in MOOCs for more spontaneous behaviour, a characteristic of the other end of the conscientiousness spectrum, especially in light of the recognition of emergence, although much remains unexplored in this speculation. To date, one example of (possibly) more spontaneous behaviour was negatively perceived by some as violating community or personal boundaries: Stephen Downes' autosubscribing participants to a forum in the CCKo8 MOOC (Mak, Williams, \& Mackness, 2010). 


\section{Exploring Openness}

Connectivist environments to date have framed openness largely in the context of sharing resources, ideas and expertise, and communicating and creating new information and insights through networks. In contrast to the educational traditions of closed lectures, proprietary texts, and classroom-enclosed discussions, openness as sharing in networks offers a refreshing change in perspective and is essential as a tenet of connective learning. Downes (2010a) has described the principle of openness in connective learning as follows:

Openness - the system of education and educational resources should be structured so as to maximize openness. People should be able to freely enter and leave the system, and there ought to be a free flow of ideas and artifacts within the system. This is not to preclude the possibility of privacy, not to preclude the possibility that groups may wish to set themselves apart from the whole; openness works both ways, and one ought to be able to opt out as well as in. But it is rather to say that the structure of the system does not impede openness, and that people are not by some barrier shut out from the system as a whole.

This notably parallels our discussion of connectedness and personal control, above, with an acceptance of entering and leaving the system. This systemic and structural openness is, as noted, perhaps the most significant departure from previous learning theories. Paradoxically, the "sharing" aspects of openness may actually be supported by less personal connectedness in ways that have implications for understanding the "opting out" and "opting in" and inclination for privacy in such environments. Malmud Smith (1997) notes this rather paradoxical relationship between privacy, self-expression, and openness in terms of both sharing and reflective experience: "Whereas on first glance we might think of the wish for privacy as only a wish for aloneness, in fact one of its most important attributes is that it makes possible a deeper, more chosen openness...” (p. 8).

This perspective reinforces Downes' understanding of how privacy and groups may be set "apart," even under the idea of openness (2010a). While some may view the greatest obstacle in MOOCs as the lack of generous and "open" engagement, it is also possible that any "tyranny of participation" (Ferreday \& Hodgson, 2008) may deter those individuals who favour reflection, privacy, and solitude over connectedness and interactivity. At the same time, it is important to emphasize that the idea of privacy does not preclude the idea of sharing, but it may have implications for the pace and extent of openness in connective terms.

The concept of psychological openness infers an internal state rather than an external expression or action. In a psychological context, openness is defined as "the breadth, depth, originality and complexity of an individual's mental and experiential life" (John, Naumann, 
\& Soto, 2008, p. 120). In writing on the role of openness in self-determination, Hodgins and Knee (2002) use and expand on openness as a factor in personality and autonomy:

By "openness" we mean a readiness to perceive ongoing experience accurately, without distorting or attempting to avoid the experience, and a willingness to assimilate novel experiences into self-structures. Another way of stating this is that when individuals function autonomously, they are open to experience what is occurring in the current moment. This openness is similar to what has been called "mindfulness" in both Buddhist writings ...and empirical psychology ... It also relates to the personality dimension of openness ... and to Roger's (1961) suggestion that a fully functioning person is able to encounter experience honestly. (p. 88)

This inner state of openness offers a significantly expanded perspective from the much more externalized "sharing" definition of openness and the "no barriers" definition currently articulated in connectivism. It leaves room for the speculation, for example, that legitimate peripheral participants may be experiencing "openness" in relation to connective learning by being attentive in a mindful and non-judgmental way.

An understanding of psychological openness and its relationship to connectivist principles and process also introduces a potential connection between creativity and connective learning. The personality trait of openness to experience is linked to curiosity, exploration, creativity, and unusual ideas. These elements may be significant in gaining insight into MOOC "early adopters" and in understanding the challenges and rewards of promoting and conducting such unusual learning ventures. By the same token, learners who express discomfort in learning networked environments, calling, for example, for more structure, may be closer to the "more cautious" end of the openness spectrum, with greater preference toward the familiar, including learning conventions and traditions. Questions remain as to how connective learning can best accommodate learners throughout this spectrum.

\section{Discussion}

While elements related to the psychological diversity of learners have at least tacitly been acknowledged as a backdrop in learning, learning systems or theories have generally been limited in their ability to accommodate or be actively responsive to the highly and potentially variable complex interactions among psychologically diverse individuals. (Attempts to do so generally utilize the Myers-Briggs Type Indicator.) A potential strength of connectivism as a learning theory lies in the potential ability (and perhaps need) for (healthy) networks to accommodate the psychological diversity of participating individuals.

Sawyer (2010, p. 366) suggests that the idea of collaborative emergence best explains how 
new things are created, in which both individual and collective explanation are incorporated. We find parallels in the suggestion that attention to principles of connectivism in relation to both networks and the individual may be beneficial in the further development of connective learning.

An understanding of the complexity of social, conceptual, and biological connections along with the complexity of human needs and the diverse circumstances generating and emerging from these connections is an emerging process for connectivist understanding. Without this augmented recognition, there is the risk that connectivism will serve as another educational prescription or as a description of information and knowledge flow, rather than a theory of learning and a conduit for growth and even transformation (Mezirow, 2000), which may also be inferred in Downes' recognition of "learning to become" (2011). As Wenger (2011) notes: "Learning is not merely the acquisition of a body of knowledge, but $a$ journey of the self" (Authors' italic). (At the same time, this view itself may be a product of psychological diversity in terms of intrinsic motivation. For example, Feist (2010, p. 122) theorizes: "Scientists are probably more driven by the need to know and artists more by the need for self-expression.”)

Understanding the psychological dimensions or interpretations of connectivist principles also suggests that participation variables in testing environments such as MOOCs and distance learning courses might not in all cases be the result of the ability or inability to cope with the diverse learning environments and choice and control requirements of autonomous learning, but, rather, forms of individual self-expression. A paradox here is that acknowledging and accepting the importance of individual and psychological diversity, autonomy, connectedness, and openness may well result in some learners choosing (in appearance or actuality) very limited engagement with networked learning environments such as MOOCs.

Additionally, the exploration of self-determination theory and personality theory in connectivist and MOOC landscapes has implications for expectations of people's learning in online learning and open networks. In particular, efforts to marginalize the significance of individuals or efforts to seek conclusive or limiting definitions and roles for individuals within connectivist theory are potentially, and perhaps ironically, counterproductive to the furtherance of connectivist learning. This is potentially as applicable for MOOC conveners and connectivism facilitators as it is for MOOC "learners" (while recognizing that connectivism suggests these are not distinct roles). While there have been calls for more or different efforts on the part of MOOC facilitators (Dron, 2011), the psychological insight brought by contemporary personality theory and self-determination theory suggests that the manipulation or envisioned refinement of MOOC environments and processes may be moot, or certainly less effective than it is typically assumed to be in the promotion of learning and curriculum design. Indeed, in their exploration of self-direction and personality in college students, Kirwan, Loundsbury, and Gibson (2010) conclude with a parallel consideration: "It may be that personality traits, not academic and personal experiences, are the major determinants of college student self-direction in learning."

If the idea that learning experiences (and, by association, perhaps their facilitation) are less 
influential for learning than personality traits, there may be benefits to increased attention to the role of self-determination and personality. This also raises the question as to whether connectivism, with attention to the existing and newly proposed dimensions of autonomy, connectedness, diversity, and openness offered here, is primed to step (or remain) beyond more traditional views of how learning occurs and is best enabled. Connectivism may offer a framework in which the focus on the primarily external structures, processes, and demands of learning (which even in contemporary execution could be regarded as vestiges of behaviorism) is reduced, and factors which address and accept how learners engage and motivate the self in the development of personal potential come to the fore. It is in the context and recognition of this engagement of the self that we find connectivism is a prescient and viable framework for learning, offering great potential ...but also offering paradoxes and uncertainty during transitional times in the understanding, acceptance, and incorporation of these ideas.

As understanding of connectivism increases and as connectivism's principles are put to the test in our daily learning, we hope to see a recognition of network capabilities and possibilities intertwined with the recognition of human concerns and potential in a networked and connectivist world. 


\section{References}

Anderson, T., \& Dron, J. (2011). Three generations of distance education pedagogy. International Review of Research in Open and Distance Learning. Retrieved from http://www.irrodl.org/index.php/irrodl/article/view/89o

Aviram, A., \& Assor, A. (2010). In defense of personal autonomy as a fundamental educational aim in liberal democracies: A response to Hand. Oxford Review of Education, 36(1), p. 111-126.

Baym, N.K. (2010). Personal connections in the digital age. Digital Media and Society Series. Polity Press.

Beghetto, R.A. (2010). Creativity in the classroom. In Kaufman, J. C. \& Sternberg, R.J., The Cambridge handbook of creativity. Cambridge University Press.

Bell, F. (2011). Connectivism: Its place in theory-informed research and innovation in technology-enabled learning. The International Review of Research in Open and Distance Learning. Retrieved from: http://www.irrodl.org/index.php/irrodl/article/ view/902

Bouchard, P. (2011). Network promises and their implications. In The impact of social networks on teaching \& learning (online monograph). Revista de Universidad y Sociedad del Conocimiento (RUSC), 8(1), 288-302. University of Catalunya. Retrieved from http://rusc.uoc.edu/ojs/index.php/rusc/article/view/v8n1-bouchard/v8n1-bouchard-eng

Cormier, D. (2011) Ple diagrams. Retrieved from: http://edtechpost.wikispaces.com/ $\underline{\text { Ple+Diagrams }}$

Crome, K., Farrar, R., \& O'Connor, P. (2011). What is autonomous learning ? The role of autonomous learning in higher education. Discourse, 9(1), p.111-126. Retrieved from http://www.prs.heacademy.ac.uk/pdf.html/PrsDiscourseArticles/113

Dron, J. (2007). Control and constraint in e-learning: choosing when to choose. Idea Group Publishing. Retrieved from http://bit.ly/iP9ah9

Dron, J. (2011) And so it ends... Retrieved from https://landing.athabascau.ca/pg/blog/ $\underline{\mathrm{read} / 91481 / \mathrm{and}-\mathrm{so}-\mathrm{it}-\mathrm{ends}}$

Doll, W. E. Jr. (2002). Ghosts and the curriculum. In Doll, W. E. Jr. \& Gough, N. (Eds.) Curriculum visions. New York, Washington DC/Baltimore: Peter Lang.

Downes, S. (2005). An introduction to connective knowledge. Retrieved from http://www. downes.ca/post/33034

Downes, S. (2007). What connectivism is. Retrieved from http://halfanhour.blogspot. 
com/2007/02/what-connectivism-is.html

Downes, S. (2010a). What is democracy in education? Retrieved from http://halfanhour. blogspot.com/2010/10/what-is-democracy-in-education.html

Downes, S. (2010b). A model of autonomy. Retrieved from http://halfanhour.blogspot. com/2010/11/model-of-autonomy.html

Downes, S. (2011). Identity and learning. Retrieved from http://www.downes.ca/archive/11/09 26 news OLDaily.htm

Feist, G. J. (2010). The function of personality in creativity. In Kaufman, J. C. \& Sternberg, R.J., The Cambridge handbook of creativity. Cambridge University Press.

Ferreday, D. J., \& Hodgson, V.E. (2008). The tyranny of participation and collaborating in networked learning. 6th International Networked Learning Conference, Halkidiki, Greece.

Gardner, H. (1999). Intelligence reframed. Multiple intelligences for the 21st century. New York: Basic Books.

Hodgins, H.S., \& Knee, C.R. (2002). The integrating self and conscious experience. In Deci, R.M. \& Ryan, R.M. (Eds.), The handbook of self-determination research. The University of Rochester Press.

John, O.P., Naumann, L.P., \& Soto, C.J. (2008). Paradigm shift to the integrative Big Five trait taxonomy. In John, O.P., Robins, R.W. \& Pervin, L.A. (Eds). Personality handbook: Theory and research (p. 114-158). New York: Guilford.

John, O.P., \& Srivastava, S. (1999). The big-five trait taxonomy: History, measurement, and theoretical perspectives. Retrieved from http://pages.uoregon.edu/sanjay/ pubs/bigfive.pdf

Jung, J. H., Lee, Y., \& Karsten, R. (2011). The moderating effect of extraversion-introversion differences on groupideageneration performance.SmallGroup Research. Retrieved from http://sgr.sagepub.com/content/early/2011/og/20/1046496411422130

Kirwan, J.R., Lounsbury, J.W., \& Gibson, L.W. (2010) Self-direction in learning and personality: The big five and narrow personality traits in relation to learner self-direction. International Journal of Self-Directed Learning, 7(2), 21-34.

Kop, R. (2011). The challenges to connectivist learning on open online networks: Learning experiences during a massive open online course. International Review of Research in Open and Distance Learning. Retrieved from http://www.irrodl.org/ index.php/irrodl/article/view/882

Kop, R., \& Fournier, H. (2010). New directions to self-directed learning in open networked 
learning. International Journal of Self-Directed Learning, 7(2), p. 1-20.

Kop, R., \& Hill, A. (2008) Connectivism: Learning theory of the future or vestige of the past. International Review of Research in Open and Distance Learning. Retrieved from http://www.irrodl.org/index.php/irrodl/article/view/523/

Mackness, J., Mak, Sui, Fai, J., \& Williams, R. (2010). The ideals and reality of participating in a MOOC. In Networked Learning Conference, Aarlborg (pp. 266-274). Retrieved from http://www.lancs.ac.uk/fss/organisations/netlc/past/nlc2010/ abstracts/Mackness.html

Mak, Sui, Fai, J., Williams, R., \& Mackness, J. (2010). Blogs and forums as communication and Learning tools in a MOOC. In Networked Learning Conference, Aarlborg (p. 275-284). Retrieved from http://www.lancs.ac.uk/fss/organisations/netlc/past/ nlc2010/abstracts/Mak.html

Malmud Smith, J. (1997). Private matters: In defense of the personal life. Reading, Massachusetts: Addison Wesley

McCrae, R.R., \& Costa, P.T. (1987). Validation of the five-factor model of personality across instruments and observers. Journal of Personality and Social Psychology, 52, 8190 .

Mezirow, J. (2000). Learning as transformation. San Francisco: Jossey Bass.

Puccio, G.J. (1999). Psychological diversity: Implications for teaching and learning. Retrieved from http://www.buffalostate.edu/orgs/cbir/readingroom/html/Puccio-99.html

Ryan, R.M., \& Deci, E.L. (2002). An overview of self-determination theory: An organismicdialectical perspective. In Deci, R.M. \& Ryan, R.M. (Eds.), The handbook of selfdetermination research. The University of Rochester Press.

Sawyer, R. K. (2007). Group genius: The creative power of collaboration. New York: Basic Books.

Sawyer, R. K. (2010). Individual and group creativity. In Kaufman, J. C. \& Sternberg, R.J., The Cambridge handbook of creativity. Cambridge University Press.

Siemens, G. (2004). Connectivism. A learning theory for the digital age. Retrieved from http://www.elearnspace.org/Articles/connectivism.htm

Siemens, G. (2006). Learning theory or pastime for the self-amused? Retrieved from http:// www.elearnspace.org/Articles/connectivism self-amused.htm

Siemens, G. (2008). What is the unique idea in connectivism. Retrieved from http://www. connectivism.ca/?p=116 
Siemens, G. (2010). My personal learning network is the most awesome thing ever. Retrieved from http://www.elearnspace.org/blog/2010/12/01/my-personal-learning-network-is-the-most-awesomest-thing-ever/

Siemens, G. (2011). Moving beyond self-directed learning: Network-directed learning. Retrieved from http://www.connectivism.ca/?p=307

Storr, A. (1988). Solitude. A return to the self. New York. Free Press.

Thanasoulas, D. (2002). What is learner autonomy and how can it be fostered? Retrieved from http://www3.telus.net/linguisticsissues/learnerautonomy.html

Topi, H., Valacich, J., \& Rao, M.T. (2002). The effects of personality and media differences on the performance of dyads addressing a cognitive conflict task. Small Group Research, 33, 667. Retrieved from http://sgr.sagepub.com/content/33/6/667.short

Verhagen, P. (2006). Connectivism: A new learning theory? Retrieved from http://www.4shared. com/office/ddZv-naA/Connectivism a new learning th.html

Wellman, B., \& Gulia, M., (1998). Net surfers don't ride alone: Virtual community as community. In Kollock, P., \& Smith, M. (Eds.), Communities in cyberspace (pp. 167195). Berkley: University of California Press.

Wenger, E. (2011). Learning in and across landscapes of practice. Lancaster University, UK. Retrieved from http://www.lancs.ac.uk/celt/celtweb/ewenger

White, D.S. \& Le Cornu, A. (2011) Visitors and residents: A new typology for online engagement. First Monday, 16(9). Retrieved from http://firstmonday.org/htbin/ cgiwrap/bin/ojs/index.php/fm/article/view/3171/3049

\section{Athabasca University $\mathbf{I}$}


THE INTERNATIONAL

REVIEW OF RESEARCH IN

OPEN AND DISTANCE LEARNING

\section{Online Social Networks as Formal Learning Environments: Learner Experiences and Activities}

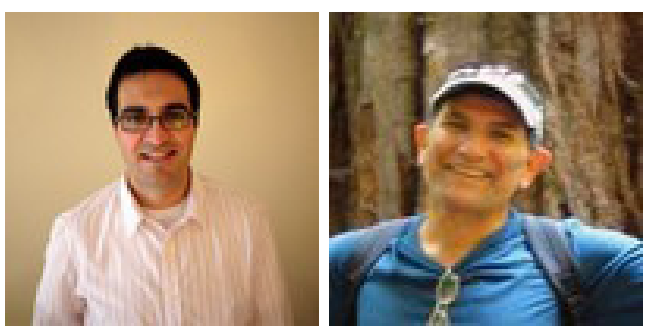

George Veletsianos and Cesar C. Navarrete University of Texas at Austin, USA

\section{Abstract}

While the potential of social networking sites to contribute to educational endeavors is highlighted by researchers and practitioners alike, empirical evidence on the use of such sites for formal online learning is scant. To fill this gap in the literature, we present a case study of learners' perspectives and experiences in an online course taught using the Elgg online social network. Findings from this study indicate that learners enjoyed and appreciated both the social learning experience afforded by the online social network and supported one another in their learning, enhancing their own and other students' experiences. Conversely, results also indicate that students limited their participation to course-related and graded activities, exhibiting little use of social networking and sharing. Additionally, learners needed support in managing the expanded amount of information available to them and devised strategies and "workarounds" to manage their time and participation.

Keywords: Online learning; learner experience; online learning environments; online social networks; social networking sites; Elgg

\section{Introduction}

Social networking sites (SNSs) have the potential to facilitate interaction, communication, and collaboration, and as a result have been prominently featured in discussions centering on the use of technology to support and amplify educational endeavors (Greenhow, Robelia, \& Hughes, 2009; Veletsianos, in press). Empirical research on their role in online education is limited, even though researchers have identified an accelerating use of social software in formal learning contexts (Schroeder, Minocha, \& Schneider, 2010). To fill this gap in the literature, we present a case study of learners' perspectives and experiences in an online course taught via an SNS. We studied SNS deployment and learner experiences in an ecological setting in order to capture both the implications of SNS use and the tensions 
that arose with the use of social networking sites in online education.

Historically, distance education (DE) has been plagued by feelings of learner isolation and alienation (Galusha, 1997), lack of participant interaction (both student-student and student-instructor), and high dropout rates (Peters, 1992). The rise of Web 2.0, social networking sites, and a general interest in student-centered pedagogies have attracted attention to the use of popular Internet tools to enhance distance education and address the aforementioned problems. For instance, Lee and McLoughlin (2010) suggest that online social networks enable learners and instructors to present themselves socially in an online environment and connect with one another while enabling individuals to engage in recurring meaningful experiences with others (Jenkins, Clinton, Purushotma, Robinson, \& Weigel, 2006; Wheeler, Yeomans, \& Wheeler, 2008). Nevertheless, prior research strongly suggests that technological innovations need to be accompanied by pedagogical enhancements for technology-rich interventions to be successful (Doering \& Veletsianos, 2008; Mishra \& Koehler, 2006; Hughes, Thomas, \& Scharber, 2006; Veletsianos, 2010). Researchers also recommend examining which course delivery format fits particular pedagogical approaches (Tallent-Runnels et al., 2006). Therefore, we purposefully chose to study a case in which a social networking site used in an online course was also accompanied by a socioconstructive pedagogical ethos. Our intention is not to examine the pedagogy independent of the technology, or vise versa. Rather, our objective is to describe and evaluate learner experiences to clarify what online education mediated by a social networking site used in conjunction with an SNS-oriented pedagogy might afford. To do so, we first present a review of the use of online social networks in higher education. Next, we present our research questions, study context, and methodology. We then discuss our findings and implications.

\section{Review of Relevant Literature}

Learners have turned to online distance learning as a reliable alternative to face-to-face education (Brady, Holcomb, \& Smith, 2010; DeSchryver, Mishra, Koehleer, \& Francis, 2009). One in four higher education students in the United States now take at least one online course during their undergraduate career (Allen \& Seaman, 2010). Distance education offerings have traditionally been organized and supported through learning management systems (LMSs) or content management systems (CMSs), such as Blackboard and Moodle, because these systems offer opportunities for organization, efficiency, and security (DeSchryver et al., 2009; Lee \& McLoughlin, 2010; West, Waddoups, \& Graham, 2006). Nevertheless, researchers have argued that these platforms have generally been used as static repositories of content, failing to provide the robust social experience found on platforms that have garnered societal interest and appeal, such as Facebook or YouTube (Brady et al., 2010; Lee \& McLoughlin, 2010; Schroeder et al., 2010; Whitworth \& Benson, 2010). Furthermore, learning and content management systems have been criticized for suppressing motivation and enthusiasm and failing to support personalization (DeSchryver et al., 2009; Naveh, Tubin, \& Pliskin, 2010), while also inhibiting broader pedagogical support with their default settings and familiar features (Lane, 2009). 
As a result, educators have begun exploring alternative platforms to provide learners with the social communication tools that allow for ease of use, pedagogical freedom, fluid online discussions, and identity management (Brady et al., 2010; Lee \& McLoughlin, 2010; Webb, 2009). Though institutions may not support a number of these platforms, popular Web 2.0 and social media tools have been appropriated in higher education, presumably because of their perceived opportunities and benefits. For example, instructors have asked students to maintain blogs and wikis hosted outside of the institution (e.g., on Wordpress.com) or have used an amalgamation of Web 2.o tools to develop unique online learning environments for their students (Conole, 2010). Online social networks have also been used in this context, and in a study conducted at a large university in the southeastern US, Ajjan and Hartshorne (2008) found that $56 \%$ of faculty believed such tools would be useful for student-to-student interaction.

The use of online social networks in educational endeavors has been supported by numerous educational technology researchers, who have highlighted the benefits of participatory technologies in formal learning contexts in K-12 (Barbour \& Plough, 2009; Greenhow et al., 2009) and higher education settings (DeSchryver et al., 2009; Veletsianos, 2011; Webb, 2009). Social networking technologies have been viewed as tools that enable the use of participatory pedagogies able to address the problems that have traditionally plagued distance education: creating a sense of presence, community-building, and learner participation in interactive discussions (Brady et al., 2010; Lee \& McLoughlin, 2010; Naveh et al., 2010). The literature suggests that using online social networks as educational platforms may support learners in forming social connections with others while they collaborate to share ideas, create products, construct identities, and receive timely feedback (Dron \& Anderson, 2009a; Greenhow, 2011; Wheeler et al., 2008). Additionally, research on informal learning within SNS contexts suggests that SNS participation fulfills important social learning functions (Greenhow \& Robelia, 2009), though Selwyn (2009, p. 170) argues the kind of learning that occurred in a study of naturally occurring Facebook interactions among undergraduates represents the "chatter of the back row of the lecture hall." On the other hand, Schroeder et al. (2010) offer a long list of potential issues that may arise when using social software in higher education. These include workload concerns for faculty and students, lack of trust in peer feedback, ownership issues with regards to public and collaborative spaces, difficulty in adapting publicly available tools, and difficulty in protecting the anonymity of students. Furthermore, Madge, Meek, Wellens, and Hooley (2009) have suggested that SNSs might be more useful for informal rather than formal learning as $91 \%$ of the undergraduates in their study never used such tools to communicate with university staff, and $43 \%$ believed that SNSs have no potential for academic work.

Indeed, there is a lack of literature examining social networking sites in higher education settings (Brady et al., 2010), and even less of that literature is focused on student experiences in online courses. The few studies that do exist, however, provide much-needed insight on the topic. Brady et al. studied one online and two hybrid graduate courses that used the Ning social network (http://www.ning.com/). After surveying the students, these researchers found that the majority of participants agreed that communication and collaboration 
were appreciably enhanced after using Ning. Results suggest that there are potential learning benefits derived from the SNS, leading these researchers to argue that the tool can potentially be used to improve learning experiences. Similar findings were reported by Wang, Woo, Quek, Yang, and Liu (in press), where the researchers found that students in two teacher education hybrid courses were satisfied with the use of the Facebook Group as an LMS, though features that were perceived to be of value to education (e.g., threaded discussions) were missing from this platform. Arnold and Paulus (2010) also integrated Ning into a blended course. In their case, Ning was used as a space to host blogs, discussion forums, and course information. Students in this study believed that social networking features of the site encouraged community-building, and the public nature of the tasks allowed for modeling and feedback. Nevertheless, student activity was generally limited to assigned tasks, even though the authors argue that further student activity might have taken place that was "invisible" to them. The authors argue that such activity (e.g., reading other students' entries but not responding) is important, and though sometimes pejoratively described as "lurking," may be a vital form of participation. Focusing specifically on online education, Dron and Anderson (2009b) studied an online undergraduate course taught via the Elgg social networking platform (which is the same platform used in this study). While their findings reveal that the learner experience was generally positive, these researchers also discovered that students were "lost in social space" and needed support and scaffolding to participate in the social network.

Our review of the literature suggests that SNSs hold promise for online education. Nevertheless, considerable gaps exist in the empirical literature, especially with regards to what the student experience is like in these environments. A contributing factor to these gaps is the scarcity of studies reporting on the use of social networks in formal education, with Arnold and Paulus (2010), Brady et al. (2010), Dron and Anderson (2009b), and Wang et al. (in press) being the exceptions at the time of writing.

\section{Research Questions}

Our goal is to identify, describe, and understand learners' experiences in an online course facilitated through a social networking platform. In particular, we pose the following research questions:

- What are student experiences in an online course taught on a social networking platform?

- How did students perceive the use of a social networking platform as the mechanism through which the online course was taught? 


\section{Study Context}

\section{The Course}

This study was conducted in the context of an optional online graduate-level course taught at a large public university in the United States. The course was part of an educational technology program, and the syllabus described the course as being focused on online education. One of the authors was the instructor of the course, and this was the first time that this specific course was offered online. The instructor had prior experience teaching online courses, often experiments with emerging technologies in his instruction, and was excited about the possibility of students having access to SNS-like functionality within a centralized space. The course ran during a six-week summer session and was composed of four weeks of instruction, one week in which students were asked to reflect on course content, and one week in which they spent their time writing a final paper.

The course had a consistent structure throughout the week. The instructor introduced a new topic every other day. On day 1, students were asked to read papers or watch/listen to resources shared by the instructor, respond to one or two self-reflective questions on their blogs, and locate and share a Web site pertinent to the readings. The last activity is referred to as the "social bookmarking activity" in the rest of this paper. On day 2, students were required to read their colleagues' reflections, post two questions/comments to two learners' blogs, and respond to all questions/comments left on their own blogs. This process continued for six days per week, and students were graded on all of these activities. The course included two additional activities: one was a critique of a research paper and the second asked participants to argue for or against a particular thesis in a debate in lieu of responding to self-reflective questions. The goal of this process was to initiate investigation of the content, while creating space for learner-centered exploration and discussion. Instructor activities to shape participation and motivate engagement included frequent commenting on student blog entries, occasional alerts directing students to particularly noteworthy comments from their colleagues, and an ethos of openness throughout the course encouraging students to suggest ways to improve it. For example, the debate activity described above was not in the original design of the course, but came about as a result of student suggestions.

\section{Elgg: The SNS Platform}

The course was taught via an Elgg environment hosted by the educational institution and closed to individuals not affiliated with the course. Elgg (http://elgg.org/) is an open source framework that enables designers to implement a variety of Web 2.0 tools such as blogs, social bookmarks, collaborative document authoring, and microblogging in a central space (Figure 1). 


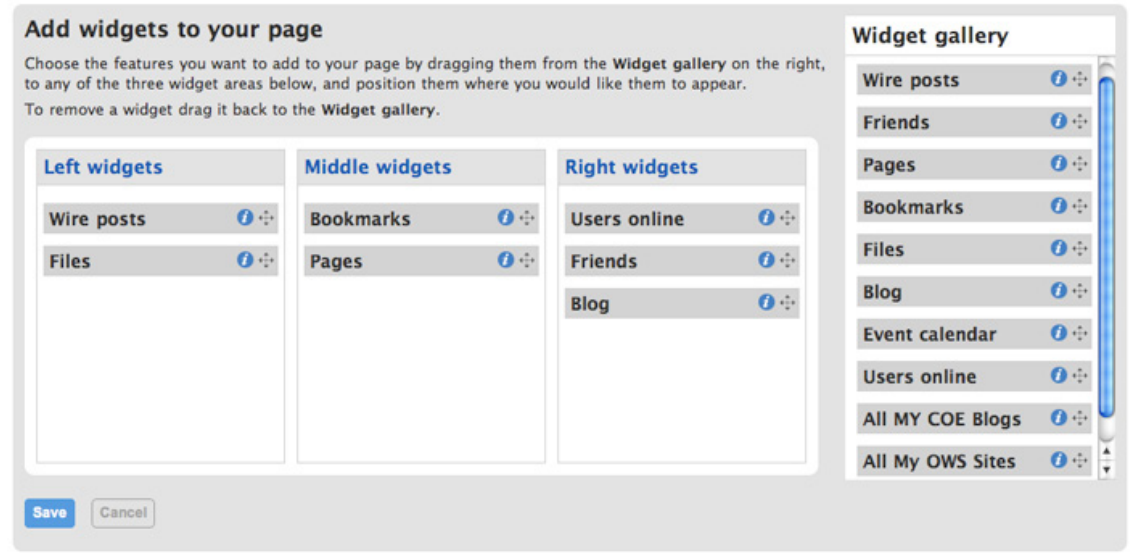

Figure 1. A selection of features available in Elgg.

Social networking functions are central to Elgg's design: students are able to create personal profiles and "friend" lists, post status updates, follow activity streams, and subscribe to be notified of other users' actions within the environment. For example, Figure 2 shows a user's profile page and Figure 3 shows a user's personal dashboard in the Elgg configuration used for this study. Once logged on, students first encountered their dashboards, which they were able to edit by adding or removing features.

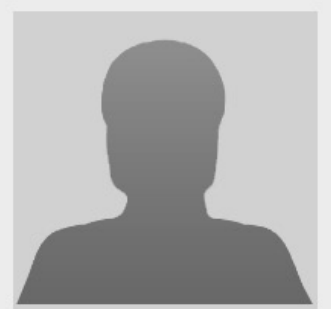

John Doe

Glad to be back, everyone!

(4 minutes ago)

Location: my city

Interests: cycling, reading, cooking

Skills: design \& development of corporate training

Contact email: sample-student@email.edu

Telephone: XXX-XXX-XXXX

Website: http://www.mywebsite.org

Friends

Friends of

About me

I am enrolled in the Educational Technology program at ABC university. This is my first online course and I am excited, but also a bit nervous. This topic is closely related to my job, and I am very interested in learning more about it. This summer, I am looking forward to enjoying a two-week Caribbean cruise with my parents and children.
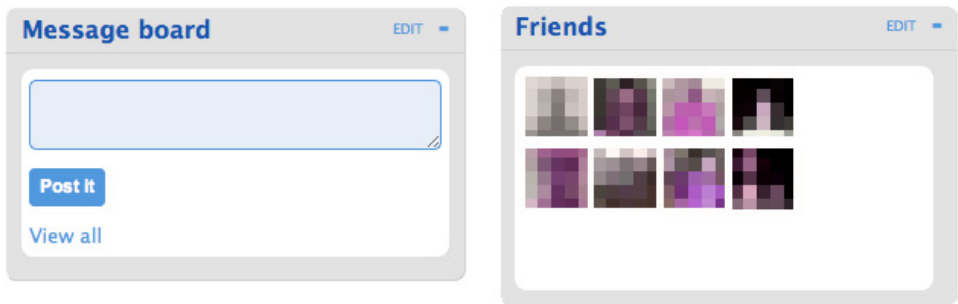

Edit page

Blog
Blog: Reflecting on my digital
footprints
John Doe 3 minutes ago

Wire posts

John Doe: Glad to be back, everyone!

Posted to the wire 4 minutes ago via Site.

More wire posts

\section{Bookmarks}

New York Times: Rise in Online Classes Flares Debate About Quality John Doe just now More

More bookmarks

Figure 2. Student profile. 

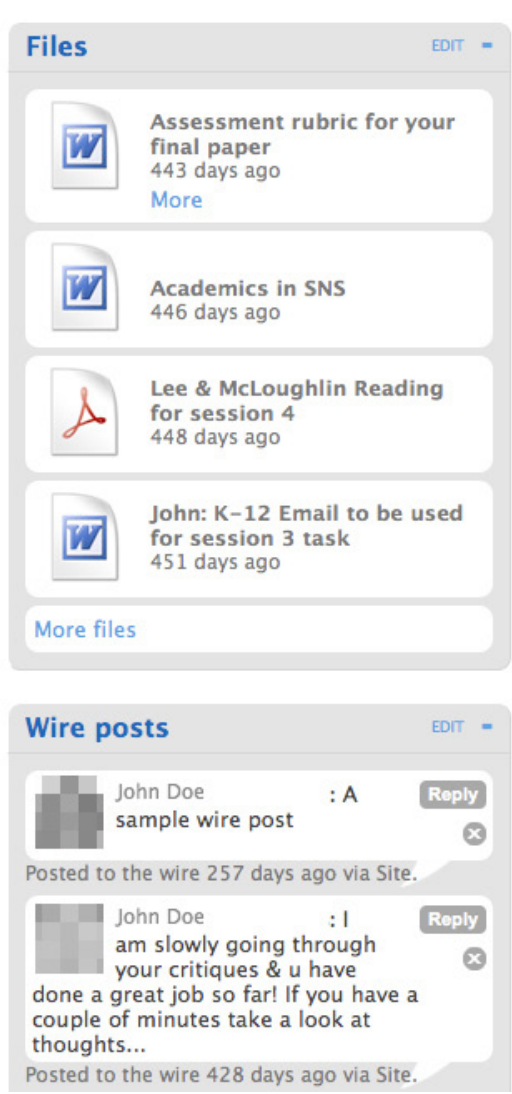
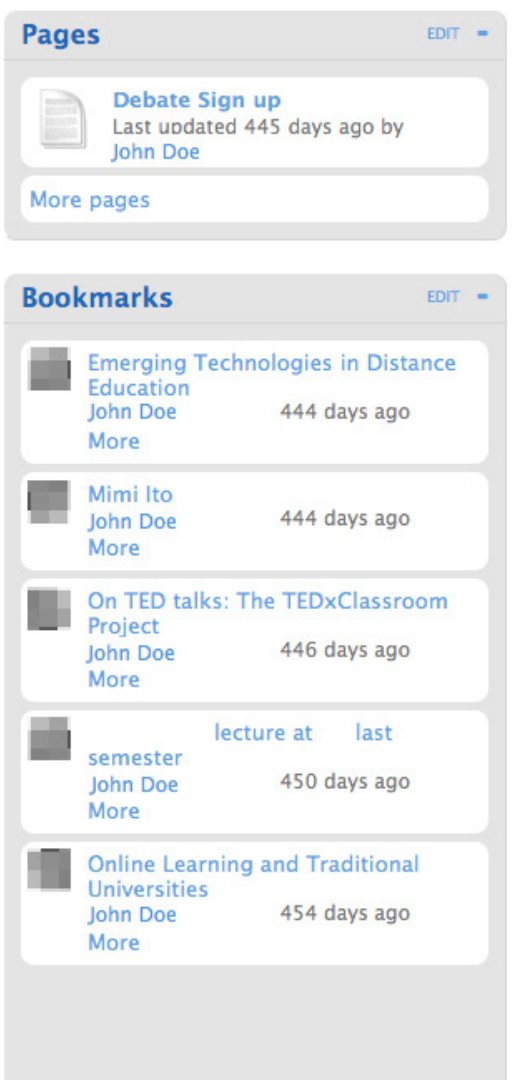
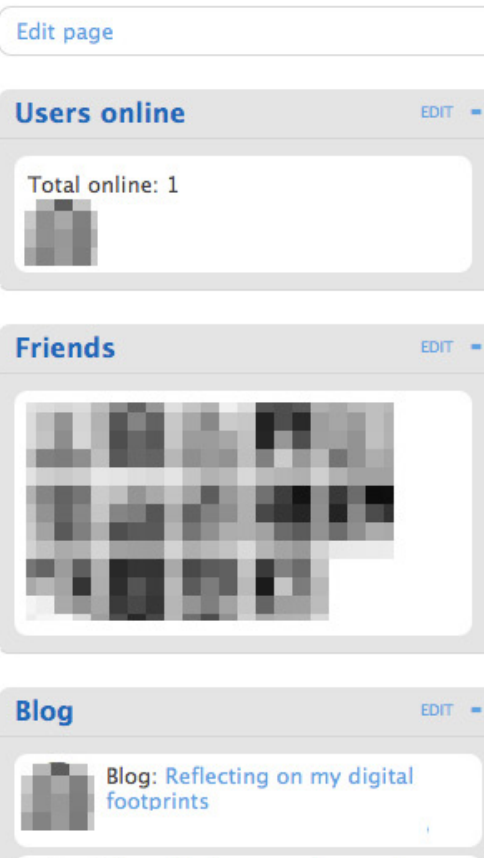

Blog: Final paper and questions

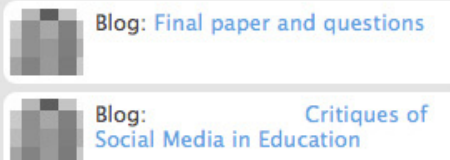

Figure 3. The original configuration of the student dashboard.

While users were able to follow other students' activities on their dashboards, they were also able to visit affordance-specific pages in order to access updates pertaining to a specific activity. For example, Figure 4 shows the page that users were able to visit in order to view everyone's bookmarks. 


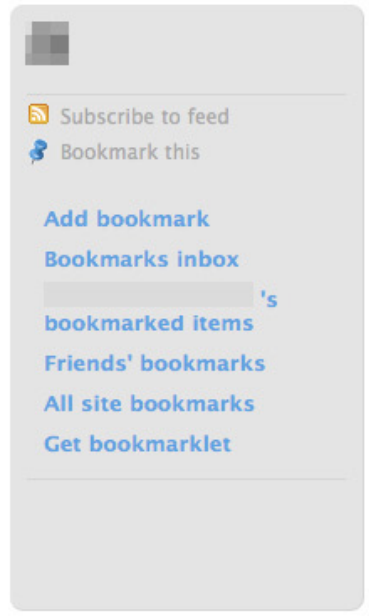

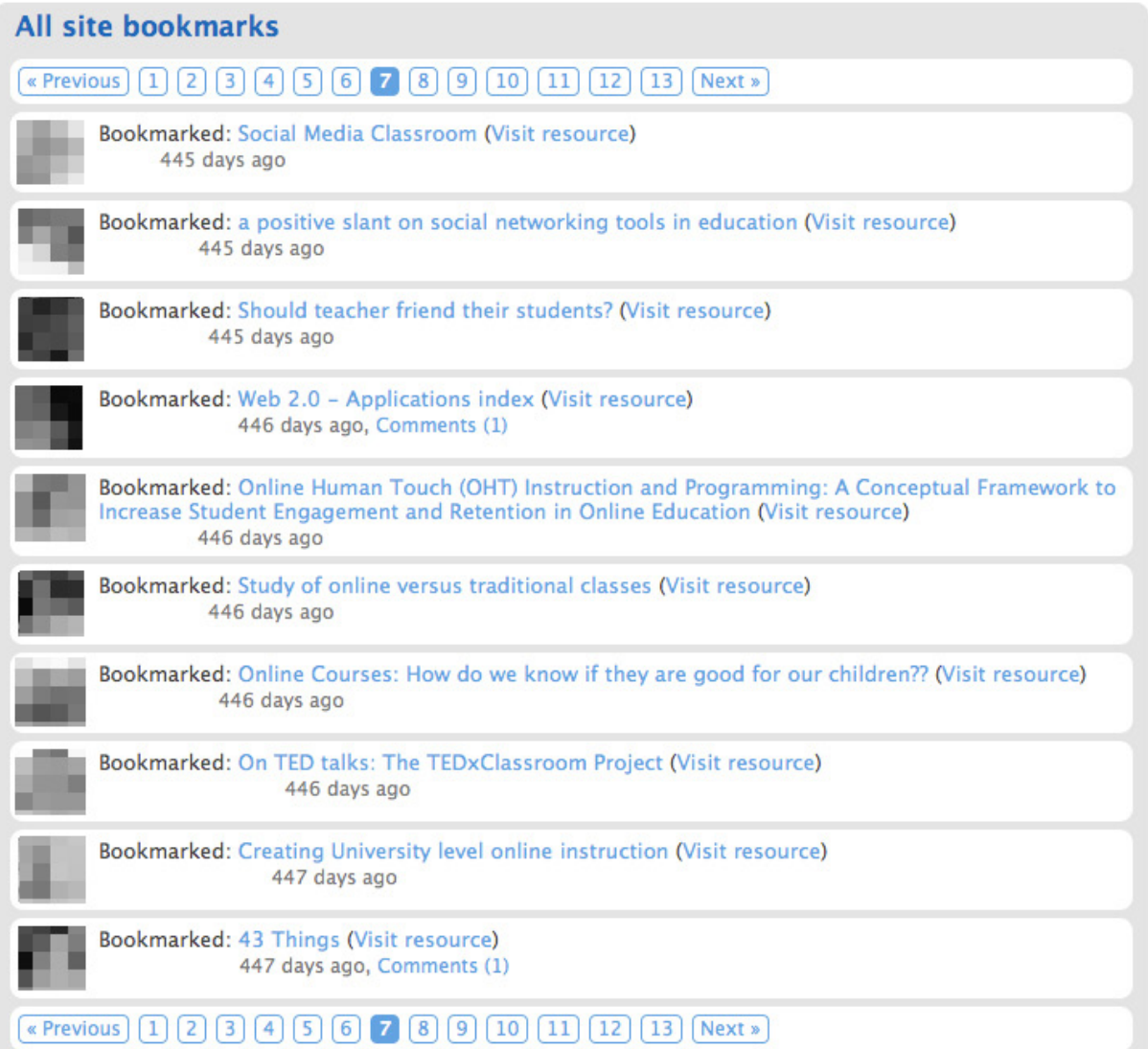

Figure 4. User bookmarks page.

We thought Elgg was uniquely positioned to function as an online social network for hosting formal educational endeavors. In addition to offering a few pragmatic affordances that appealed to us (e.g., access to a diverse array of social tools such as bookmarking, microblogging, and blogging within one location), the platform also seemed to align quite well with a socioconstructive ethos of learning. Rather than viewing learning as acquisition of a body of knowledge, we perceived it as consisting of participation within the sociocultural environment that we created. This perspective is informed by the works of Vygotsky (1962, 1978) and Lave and Wenger (1991). Social constructivism contends that learning is a social process supported through interaction, dialogue, sharing personal experiences, peer/ instructor support and scaffolding, and personal and social meaning-making. We saw Elgg as supporting and complementing socioconstructivism as the environment seemed to (a) respect participants' voices without centering on or elevating the instructor, and (b) enable individuals to have access to varied information streams in the same way that these exist in popular social networking tools.

\section{Method}

\section{Participants}

Ten out of 14 learners enrolled in this course agreed to participate in the study. Nine par- 
ticipants reported their gender ( 6 female, 3 male), and all reported their age ( $M$ 37, $S D$ 9.2) and the degree they were pursuing (five $\mathrm{PhD} / \mathrm{EdD}$ and five MA/MS). One student had received her undergraduate degree online, four students had never taken an online course, and the rest had taken three or fewer online courses. Three participants pursued a degree in educational technology, and the rest pursued a degree in other education-related specialties. All participants reported having a computer at home and were comfortable with using the Internet for learning purposes. For instance, all of them either agreed or strongly agreed with the statement, "I am able to use the Internet for personal learning," and nine out of ten completely agreed or agreed with the prompt "Using the Internet to learn about a topic that interests me on my own excites me." Nine out of ten also disagreed or strongly disagreed with the prompt "Using the Internet to learn about a topic that interests me on my own stresses me out." With regards to using social software in their personal life, eight participants reported having a Facebook account (six used it on a daily basis), three reported having uploaded a video on a video-sharing site in the past, and six reported having uploaded photos on a photo-sharing site in the past.

\section{Data Sources}

The data corpus was collected within one to two weeks after the end of the course and consisted of personal interviews (dominant data source) and survey responses (secondary data source). The interviews lasted between 45 minutes and one hour each. Both of us conducted the first interview, and the author who was not the course instructor conducted all subsequent interviews in order to reduce the possibility of respondent bias. The interviews consisted of a set of open-ended questions, and follow-up questions were used to solicit further information. Interviews were audio-recorded and transcribed verbatim. The survey was primarily used to collect demographic and educational information, and prior experiences with technology, social media, and online education. The survey also included open-ended questions that sought feedback about (a) student experiences, and (b) specific activities and attributes of the course.

\section{Data Analysis}

Methodologically, this study falls within the broad framework of the interpretive research paradigm. Under the interpretive research paradigm we employed a case study method (Yin, 2003), where the Elgg-using classroom was perceived to be the case under investigation. We used the constant comparative method (Glaser \& Strauss, 1967) to analyze interviews and survey responses, arriving at salient categories and data patterns. Both of us engaged in open coding of all the data, independently reading and analyzing it to note emerging patterns with regards to students' experiences in the online course. We then met six times to discuss identified categories, compare notes, and collaboratively analyze data in search of common themes and meanings. The patterns we discovered were compiled and reanalyzed in order to confirm and disconfirm the codes across participants. Open coding of the data resulted in 26 codes relevant to the research questions. We continued the analysis until we could not identify any new themes or coding categories and felt that the data had been completely represented by the final codes/themes (i.e., the data had been saturated). Once patterns were identified, we grouped them into themes. 


\section{Validity and Reliability}

Several triangulation methods were used to enhance the study's validity and reliability. First, we collected data from multiple sources (survey and interviews). Second, we analyzed each data source independent of other data sources. Third, we each analyzed the data independently and then met to discuss our findings. These methods enabled us to (a) examine the accuracy of the collected data, and (b) reduce the possibility of researcher bias in drawing conclusions from the data. A potential threat to the study's validity and reliability is that participants may have (consciously or unconsciously) reported on issues they believed to be valuable to the instructor due to his dual role as instructor and researcher. We sought to minimize this threat by repeatedly encouraging participants to report their perspectives as opposed to what they believed the instructor wanted to learn about.

\section{Results}

The identified themes focus on the social attributes of the online learning experience, student perceptions of the social networking platform, and student management of learningrelated processes.

\section{Social Attributes of the Student Experience}

The dominant theme that arose from the interviews concerned the social nature of the learning experience. Social interaction, combined with meaningful knowledge building, was a significant element in the course.

Interaction, communication, and social connectivity.

All students interviewed and nine out of ten students surveyed stated that they found great value in their interactions with other students and the social setting in which the course was set. When asked to reflect about their course experiences, students predominantly focused on describing their connections and interactions with others, and the value they found in peer collaboration and support. For example, $\mathrm{Bob}^{1}$ said that the social nature of the course was "as intellectually engaging as I have been involved in a while," and Joan, comparing the course to a previous learning experience, expressed a similar view, "this time ... I did the assignment but there was a whole lot more interaction afterwards and I really appreciated that." Mary also compared the experience to traditional face-to-face courses that she has taken and noted that she "really lik[ed] that connection with our classmates, it's interesting that in a traditional face-to-face course, I don't always feel as connected to my classmates, even though I'm going to be sitting right next to them, engaged in face-to-face conversation."

Learners also found their interactions with others were important in helping them make sense of the subject matter and reported that these interactions extended their learning.

$1 \quad$ All names are pseudonyms. 
Jen commented,

Some of the questions they [other students] would post made me have to think about it ... further than the paper ... and reading some of their posts, I would realize, 'Oh, I didn't think of it that way.'

According to Bob, participants' diverse experiences meant that each person had something valuable to contribute, and Nancy explained that such contributions had an impact on her: "Gary had ... a lot of experience ... and his experiences and his thoughts and his reflections really inspired me."

The ease with which participants were able to communicate was also deemed to be important to social connectivity. For example, participants pointed out the following valuable affordances: the ability to navigate efficiently through the social network, to easily reach student and instructor blogs, to effortlessly access course content, and to be notified of comments to their blogs via email. Referring to the platform, Cindy observed that she liked "having access to all the things that everyone posted," and Lucy noted that this allowed her to "ask questions more easily and ... communicate ... thoughts and ideas more easily." Significantly, Mary clarified that ongoing dialogue between students was important because simply responding to questions is "like you're just in it as a clock in, clock out kind of thing, and that's not really the realm of education."

\section{Social presence and identity.}

At the beginning of the course, students were asked to create a profile on the social networking site; share a photograph of themselves; post information on their majors and interests both in and outside of class; share summer plans that they were looking forward to; and view one another's profiles. This activity was an attempt to introduce students to one another and to the instructor, to explore common interests, and to establish social presence. Social presence has been defined by Garrison, Anderson, and Archer (2000, p. 89) as participants' ability "to project their personal characteristics into the community, thereby presenting themselves to other participants as 'real people." Students in this study discussed finding value in viewing other learners' profiles, but they also expressed concerns with regards to appropriately representing themselves online and correctly understanding other students' actions.

Bob commented that other students' profiles and interests gave him "a greater sense of connection to the course, also to my colleagues that were online," while Betty noted that the online profiles and course discussions "made me feel, oh wow, they're real people, they're not just these little icons on the screen." The connections that students formed allowed Don to contribute more to the course, as he commented,

I find that when I have ... a sense that this is ownership, within the site ... I tend to put ... more into it ... writing 
the assignment, expressing myself, clarifying my thoughts

and so on.

Other students described positive experiences they had with specific individuals. For instance, Nancy, a student from Germany, described sharing a personal story, and stated "the reason that I could have confidence to share my story was Betty ... she has German friends, she knows [the] German language too, and . . . that lowered my anxiety." Lucy reported enjoying her interactions with Gary, "who always had the coolest posts. I loved what he had to say." As the students progressed through the course, they were able to share personal experiences and identify with others as a result.

Nevertheless, negotiating their presence in the environment was also a point of tension, and about half of the students expressed concerns either with how they presented themselves or how others perceived them online. On the one hand, Betty discussed trying to find an appropriate voice with which to participate in the course. As she stated, "I'm blogging for a class, so I have to be more formal ... I don't see my voice coming out." On the other hand, both Don and Cindy struggled with creating representative portrayals of their colleagues. Don, for instance, asked "how many of those canned introductions give you an understanding of who this individual is, or what kind of experiences they've had? What kind of wealth of knowledge are they bringing to the conversation?" Cindy's experiences capture the complexities of this issue because even though she stated that "student-student interactions within this course were much better than any of the other online and hybrid courses I've taken" she still felt that "the comments on my blog posts by some students were either contrived to fulfill a grading requirement or outright argumentative." She clarifies this issue by noting that "my opinion is tentative on this issue because it was difficult to understand the [other students'] intentions for responding to my blog posts."

\section{Pedagogical considerations.}

Learners also alluded to the student-centered pedagogy used by the instructor as a positive contributor to the learning experience. Betty noted that she "realized it was just about good teaching ... following or putting together a really good curriculum for the students and just making the most of all the tools and using them as tools to support instruction." Another student stated that

The blogs were great. Just the whole back and forth that [the instructor] had us do where we actually posted [blog entries] and then we had to respond to someone else's, and then respond to everyone else that was responding to us ... the [instructor] really challenged us ... I really started getting more out of it.

Joan had similar thoughts, relating that she liked the conversations with others,

especially when people disagree with me or have different 
viewpoints because I would have to look at their viewpoint and then see which one was actually working ... I think that's what education should be about, about making people ... consider other people's opinions.

Finally, in a moment of reflection, Lucy noted that the pedagogical approach not only helped her learn the content but also improved her own teaching practices:

I feel that I learned a great deal . . . the readings and from what everyone had to say, I feel like I just kind of internalized it all. ... I've been working very closely with our technology teachers ... on different things we can do for our students that are in the middle school where I work, so I thought it was a great experience.

\section{Online Learning Mediated by a Social Networking Site}

This theme describes students' initial apprehensions with online courses in general and their subsequent excitement about the opportunities afforded by this specific online course; students' comparisons between the Elgg SNS and other platforms they used; usability problems, barriers to learning, and recommendations for enhancing the Elgg platform.

\section{From apprehension to positive learning experiences.}

Four students, all new to online courses, described the apprehension that they experienced at the start of the course. These students were concerned they would lose intimacy and discipline by being in an online course. Gary explained,

it was my first online class, I really didn't know what to expect, ... . so I was a little apprehensive, I wasn't sure if . . . my personality would fit in, I'm something of a procrastinator, so I was afraid that somehow I'd lose the discipline of a face-to-face classroom time and end up falling behind.

Mary shared similar feelings, reporting "at first, I was a little overwhelmed ... I really didn't know what was expected," and Betty found that "especially the first couple of assignments, I felt like I was completely lost.” Nevertheless, all four learners reported that these initial apprehensions were resolved once they became acquainted with the online environment and accustomed to the daily requirements, structured pace, and consistent rhythm of the course. Appreciation for the opportunities afforded by the collaborative nature of the online course quickly replaced learners' initial apprehensions. Cindy reported that the experience, "was very collaborative ... everybody was in there together and that's another really good aspect of the online environment ... there's not that one person in charge, standing at the front of the class." Additionally, Betty noted that she enjoyed the flexibility, describing herself as "a homebody" who "likes doing things on [her] own time," while Don observed that 
the online course allowed participation from geographically scattered participants:

[What] I enjoyed about this course was that there were people with diverse background[s]. For example, Bob apparently is some kind of administrator in college ... we had a student in Puerto Rico, and she wouldn't have been able to join ... we had a student, I think, in Syria.

Survey responses indicated that by the end of the course, seven participants completely agreed and three agreed with the prompt "After taking this course, I feel comfortable with the idea of taking an online course."

\section{Comparison to other platforms.}

Learners also reflected on past learning experiences and compared the social networking platform to others they experienced (most frequently this was Blackboard because it was used institution-wide). More specifically, students expressed a preference for the social networking platform over other traditional course management systems, as reflected by Don's comment, "I appreciated using Elgg over, say, using Blackboard or another CMS that I have had to use in other courses." Mary and Nancy also expressed a preference for the social network over other platforms. Mary noted that she "thought it was excellent ... we have other learning management systems. . . . But I thought it had everything right where we wanted it." Nancy identified the social interface on the SNS as superior to a variety of other platforms:

I used Blackboard, CollegeLMS ${ }^{2}$, and Moodle and Ning . .

. to me, Elgg was the newest and the most fresh thing, to me, I really liked the interface, it's kind of friendly ... For example ... I really feel formal with Blackboard ... [like] I'm facing the professor.

Gary summarized such feelings when he stated that "embedding those features, photos, links, all that, I think, contributed to learning ... in contrast to [other LMSs] where it's even more difficult to do that." The extent to which such positive perceptions are the result of the social network, however, is debatable because pedagogy and technology were inextricably intertwined, and Elgg, in this case, cannot be regarded to be independent of the pedagogy with which it was used. We will return to this point in the discussion section of the paper.

\section{Technological barriers to learning.}

Despite the positive experiences, students identified particular features of the platform as problematic in terms of usability and inhibitive to their learning experience. These barriers were the result of missing functionality that detracted from efficient and effective commu-

2 CollegeLMS is a pseudonym for the LMS designed for and used by the College of Education at the institution where this study took place. 
nication and collaboration. For instance, Don and Gary both felt a more intuitive navigation system would have been more usable. Don said that he "felt that I had to click on each person's blog post ... to read comments to the blogs, to understand what kind of conversation was happening there," while Gary suggested that "it would be nice if somehow it had a feature that would let me sort of scan all the comments instead of having to go to each person's blog individually." Lucy also asked for a better blog management structure because she found that newer blog entries suppressed older ones: "I was late on an assignment because [the instructor's] blog post got buried and I didn't see that, so that was one thing that kind of threw me off toward the end of the class." One issue that bothered all the students was Elgg's inability to inform them of responses to comments they had left on other students' blogs. For example, when students commented on Gary's blog, he received an email notification about this activity. When Gary responded to these comments, however, the students did not get a notification that he had taken this action. They wouldn't necessarily know that Gary had replied to their comments without coming back to his blog to check for responses. This problem frustrated students, contributed to time demands, and made continuous interaction difficult. One way of resolving this issue is to provide students with the option to be notified of follow-up comments on a blog entry they respond to, or, as Lucy suggests, "it would be neat to have a feature where your name was tagged or ... anytime you'd mention someone's name they are notified."

\section{Managing Information and Participation}

Learners also discussed information management and network participation as it pertained to their learning and interactions with one another, noting that they felt a need to formulate methods and strategies for dealing with time constraints and the perceived abundance of ideas and resources that were available in the course.

As the students worked through the assigned readings and activities, managing and organizing information proved to be a challenge. Betty stated that,

reading all of my classmates blogs and comments, commenting on the blogs and/or comments, reading the material for the course, trying to find and read any supplementary material, and then composing a blog is taking significantly more [time than] the course is supposed to take. I am taking two other courses, and I find that I do not have enough time to devote to all of my classes.

Numerous other students shared this feeling. Our interviews revealed that students either used technology tools to manage what they perceived to be "abundance of information," or devised personal strategies for information management. Elgg provided one such feature to manage information and participation, and one student stated,

I enjoyed that the system sent email notifications regarding the items submitted to the site . . . having 
notifications helped me manage my time better by not having to consistently remember to log into the site to find out what has been added.

Personal strategies for managing information focused on time-saving techniques. For example, Cindy would sort through the blogs to respond to the ones that dealt with topics that interested her. Taking a different track, Nancy responded primarily to individuals who had written informative and insightful entries in the past, while both Cindy and Mary described reading and scanning blog entries for relevance. For instance, Cindy stated that she "might read a little piece of this and little piece of that or skip all the way to the bottom." Bob's "workaround" for deciding on whom to interact with focused on ensuring communicating with individuals who had a different opinion: "I found that I would go to the people that either had a similar take to my own and [who I] agree with; probably more often, people [who] had a different take on it." Gary's workaround indicated that he, too, had certain individuals he preferred to interact with:

I tried to make sure I went and read at least everybody's comments, at least once during the class, um, but there were clearly certain individuals that I would go back to more often and read what they had to say.

It appears that learners' strategies for managing their time often centered around scanning or skimming other students' contributions and making selections based on their best judgment for the appropriate circumstance. Betty, for example, described feeling overwhelmed when she searched the Web to find and share pertinent information as part of the social bookmarking activity. "I wish I had more time ... [you] start finding other things and there's so much information, and there's no way to get a tiny fraction of all the information out there." She described her method of time management in this way: "I had to consciously tell myself, okay, you've been doing this for twenty minutes, stop now; go do your work for your other class." As Nancy elaborated about her time-saving strategies, "I didn't read every reflection, I had some preferences." Lucy and Mary both noted that they also had commitments outside of class and therefore had to make choices about the extent to which they engaged with course activities and their day-to-day life. For example, Mary noted,

my schedule at home is busy, so it was a matter of just getting the readings done and thinking about them and working on the posts, and so there wasn't any time in between ... for back and forth discussion, because it was just a time frame ... so I didn't have time for all of that.

\section{Discussion}

Findings from this study indicate that learners enjoyed and appreciated the social learning experience afforded by the combination of the online social network and the employed 
pedagogy. Learners supported one another in their learning and noted that they perceived their learning experience was enhanced by their interactions. Nevertheless, in contrast to claims from the existing literature on informal learning in SNSs, and in support of emerging empirical evidence from the use of online social networks in hybrid courses (Arnold \& Paulus, 2010), learners limited their public activity to course-related topics. Additionally, students did not appear to mix social and educational participation and seemed to need support in managing the expanded amount of information available to them. In order to manage their time and participation, learners devised strategies and "workarounds" to complete assigned activities and course commitments.

In this study, we found evidence that the focus of the course was on the learner and his or her interaction with his or her peers. Frequent and ongoing participation and collaboration within the context of the social network (in combination with the relatively short duration of the course) seemed to mitigate the problems traditionally facing online learners, such as isolation and lack of support, while contributing to a positive learning experience. It is unclear, however, whether the problems traditionally facing distance learners were addressed as a result of introducing the social networking platform, as a result of the instructor's pedagogical approach, or as a result of the platform offering affordances that enabled social pedagogies to be implemented. Even though prior literature has recognized that the relationship between pedagogy and technology is complex and negotiated (Veletsianos, 2010), this is further evidence of the tensions that exist between the two. While the educational technology literature indicates that technology alone does little to improve educational outcomes (e.g., Clark, 1983), we also suggest that researchers and educators should resist allowing pedagogy and familiar instructional approaches to determine how technologies are used in online learning settings. Steps that can help instructors to move in this direction are using technology as a "means to provide opportunities for personally relevant and meaningful transformation" (Veletsianos, 2011) and working to eliminate the obstacles (e.g., Internet filtering, mandated technology policies) that structure how educational technology is used and constrain its use within familiar molds.

While this study indicates that networked learning opportunities are promising and that learners cherished the opportunities for interaction presented to them, information and participation management was one of the tensions that arose in this course. On the one hand, the learners' act of devising strategies and "workarounds" to complete the activities assigned to them indicates that some were reflective, self-directed, and able to individually figure out ways to solve the problems they were facing. Nevertheless, this finding introduces two other issues:

- Some learners lacked this ability. Unfamiliarity with ways to manage their own learning points to a need for teaching network learning skills, such as the ability to find and categorize content for future retrieval and traverse networks of interest (Jenkins et al., 2006). Such skills are also transferable to learners' lives outside of formal education as they enable individuals to utilize online social networks to manage and further their lifelong learning. 
- Workarounds, while effective at enabling learners to successfully complete course requirements, can also be seen as activities that potentially undermine their exposure to diverse opinions that collaborative learning activities seek to attain. This may not be true of all workarounds (e.g., Bob sought individuals who expressed opinions that differed from his), but the risk is that information abundance, coupled with an inability to manage information, may create echo chambers in which like-minded individuals interact with one other, isolating themselves from diverse or differing opinions (Sunstein, 2002). One way to target this issue is to ask, what do the workarounds tell us about improving future courses? In response, one idea is to structure activities in such a way that students are asked to take sides and argue for opinions that they do not espouse (e.g., online debates). A second idea is to develop technological solutions. For instance, the platform could track student interactions and indicate to learners their participation patterns, alerting them when their activity (e.g., interaction with one other member) is isolating them from the group, or when textual analysis of their contribution suggests high levels of agreement with the individuals with whom they interact.

Prior research has indicated that participants in social networking sites embrace the opportunity to demonstrate various dimensions of their personality by posting images and videos that are meaningful to them (Greenhow \& Robelia, 2009). However, in this study we found minimal evidence of learner activities beyond what they were instructed to do. Learners shared information about themselves either because the instructor asked them to (e.g., they had to create a personal profile) or because it served to clarify the arguments they presented in their blog entries. One student even commented specifically to this, saying she "was disappointed that very few (only one person) responded or seemed to look at information [that she posted] that was related to the course, but not part of the assigned comments." Therefore, even though learners contributed their personal experiences and examples when answering questions or responding to one another, they did not appear to mix social and "educational" life. Indeed, the pace of the course was fast, which may have resulted in limited student control and time to explore the site's social features. Nevertheless, this is especially interesting given that numerous students alluded to the social experience they had in this course. It appears that while the technology and pedagogy enabled (and even encouraged) sharing, students used the online learning environment in a strict educational (albeit socially enhanced) manner, deviating little from the tasks and assignments, and focusing on the activities that were graded. While this observation should not be surprising, it stands in contrast to the techno-centric and pedagogy-centric perspectives often embraced within the educational technology field and highlights the need for further study of the "often compromised and constrained social realities of technology use 'on the ground” (Selwyn 2010, pp. 66). Elgg is a framework and, as such, it can become many things. Though it includes social networking features as part of its design, these were not the features used in the course. This is reminiscent of what Dron and Anderson (2009b) have called "Web 1.5," the construction of environments that lie in between the two extremes of teacher-centric LMSs and generic social software tools. Environments such as the one described here may include the sharing and read/write capabilities found on the social Web, but they are constrained by the setting in which they occur. Under such circumstances 
it would be highly unlikely for social networking to occur. To figure out how to encourage social networking within the context of formal education, one has to investigate the entire system's impediments more closely and examine not just technological and pedagogical alignment but broader contextual influences such as institutional constraints and cultures (e.g., in this study, the fast pace of the summer course may have reduced learner control, impeding the learners' abilities and motivations to explore the social tools). To reach this goal, it may be worthwhile to consider social networking as a feature rather than a destination (Anderson, 2007). Rather than viewing online social networks as locations that students visit to interact with one another, it may be more productive to evaluate which social networking features are valuable in day-to-day educational experiences, how such features are compatible with academic cultures and values, and how such features are used in realworld interventions.

\section{Conclusion}

Online learning in higher education in the US is on the rise. At the same time, social networking sites have gained wide societal interest. In this study, a social networking platform was used as a medium to teach a graduate-level online course. The study is deliberately tied to its context so as to offer a rich and holistic picture of the interactions between technologies, pedagogies, and educational setting. Results indicate the complexities of implementing social networking technologies in ecologically valid environments, highlighting the benefits and multifaceted tensions that may result when adopting such tools in online education. While this research focuses on one case with a small sample size, it offers insights and explanations that go beyond its immediate setting, corroborating emerging evidence from other case studies. These results indicate that learners (a) did not engage with one another in activities beyond what was required for course credit, (b) needed support to navigate the online social network, and (c) devised personal strategies to manage participation and online presence. Future research on the topic might delineate the reasons for and impacts of student workarounds and examine cases in which learners exhibit greater social presence on online social networks so that we can better understand this phenomenon. Finally, future research could also investigate the voice of the instructor when teaching on online social networks, which is a voice that is missing from both this paper and the relevant literature.

\section{Acknowledgments}

The authors would like to thank two anonymous reviewers for their feedback and suggestions. 


\section{References}

Ajjan, H., \& Hartshorne, R. (2008). Investigating faculty decisions to adopt Web 2.0 technologies: Theory and empirical tests. The Internet and Higher Education, 11(2), 71-80.

Allen, E., \& Seaman, J. (2010). Learning on demand. Online education in the United States, 2009. Needham: Sloan Center for Online Education. Retrieved from http://www. sloan-c.org/publications/survey/pdf/learningondemand.pdf

Anderson, C. (2007). Social networking is a feature, not a destination. [Web blog post]. Retrieved from http://www.thelongtail.com/the_long_tail/2007/o9/social-networki.html

Arnold, N., \& Paulus, T. (2010). Using a social networking site for experiential learning: Appropriating, lurking, modeling and community building. The Internet and Higher Education, 11(2), 71-80.

Barbour, M., \& Plough, C. (2009). Social networking in cyberschooling: Helping to make online learning less isolating. TechTrends, 53(4), 56-60.

Brady, K. P., Holcomb, L. B., \& Smith, B. V. (2010). The use of alternative social networking sites in higher educational settings: A case study of the e-Learning benefits of Ning in education. Journal of Interactive Online Learning, 9(2), 151-170.

Clark, R. E. (1983). Reconsidering research on learning from media. Review of Educational Research, 53(4), 445-459.

Conole, G. (2010). Facilitating new forms of discourse for learning and teaching: Harnessing the power of Web 2.o practices. Open Learning, 25(2), 141-151.

DeSchryver, M., Mishra, P., Koehleer, M., \& Francis, A. (2009). Moodle vs. Facebook: Does using Facebook for discussions in an online course enhance perceived social presence and student interaction? In I. Gibson et al. (Eds.), Proceedings of Society for Information Technology \& Teacher Education International Conference (pp. 329-336). Chesapeake, VA: AACE.

Doering, A., \& Veletsianos, G. (2008). Hybrid online education: Identifying integration models using adventure learning. Journal of Research on Technology in Education, 41(1), 101-119.

Dron, J., \& Anderson, T. (2009a). How the crowd can teach. In S. Hatzipanagos \& S. Warburton (Eds.), Handbook of research on social software and developing community ontologies (pp. 1-17). Hershey, PA: IGI Global Information Science.

Dron, J., \& Anderson, T. (2009b). Lost in social space: Information retrieval issues in Web 1.5. Journal of Digital Information, 1O(2), 1-12. 
Galusha, J. M. (1997). Barriers to learning in distance education. Interpersonal Computing \& Technology, 5(3-4), 6-14.

Garrison, R., Anderson, T., \& Archer, W. (2000). Critical inquiry in a text-based environment: Computer conferencing in higher education. The Internet and Higher Education, 2(2-3), 87-105.

Glaser, B. G., \& Strauss, A. L. (1967). The discovery of grounded theory. Chicago: Aldine Publishing.

Greenhow, C. (2011). Online social networking and learning. International Journal of Cyber Behavior, Psychology and Learning, 1(1), 36-50.

Greenhow, C., \& Robelia, B. (2009). Old communication, new literacies: Social network sites as social learning resources. Journal of Computer-mediated Communication, 14(4), 1130-1161.

Greenhow, C. G., Robelia, B., \& Hughes, J. (2009). Learning, teaching, and scholarship in a digital age Web 2.0 and classroom research: What path should we take now? Educational Researcher, 38(4), 246-259.

Hughes, J., Thomas, R., \& Scharber, C. (2006). Assessing technology integration: The RAT - Replacement, Amplification, and Transformation - framework. In C. Crawford et al. (Eds.), Proceedings of Society for Information Technology \& Teacher Education International Conference (pp. 1616-1620). Chesapeake, VA: AACE.

Jenkins, H., Clinton, K., Purushotma, R., Robinson, A. J., \& Weigel, M. (2006). Confronting the challenges of participatory culture: Media education for the 21st century. MacArthur Foundation. Retrieved from http://www.digitallearning.macfound. org/

Lane, L. (2009). Insidious pedagogy: How course management systems impact teaching. First Monday, 14(10).

Lave J. \& Wenger E. (1991) Situated learning: Legitimate peripheral participation. Cambridge University Press, Cambridge, UK.

Lee, M. J. W., \& McLoughlin, C. (2010). Beyond distance and time constraints: Applying social networking tools and Web 2.o approaches to distance learning. In G. Veletsianos (Ed.), Emerging technologies in distance education (pp. 61-87). Edmonton, AB: Athabasca University Press.

Madge, C., Meek, J., Wellens, J., \& Hooley, T. (2009). Facebook, social integration and informal learning at university: 'It is more for socialising and talking to friends about work than for actually doing work.' Learning, Media and Technology, 34(2), 141. 
Mishra, P., \& Koehler, M. (2006). Technological pedagogical content knowledge: A framework for teacher knowledge. Teachers College Record, 108(6), 1017-1054.

Naveh, G., Tubin, D., \& Pliskin, N. (2010). Student LMS use and satisfaction in academic institutions: The organizational perspective. The Internet and Higher Education, 13(3), 127-133.

Peters, O. (1992). Some observations on dropping out in distance education. Distance Education, 13(2), 234-269.

Schroeder, A., Minocha, S., \& Schneider, C. (2010). The strengths, weaknesses, opportunities and threats of using social software in higher and further education teaching and learning. Journal of Computer Assisted Learning, 26(3), 159-174.

Selwyn, N. (2009). Faceworking: Exploring students education-related use of Facebook. Learning, Media and Technology, 34(2), 157-174.

Selwyn, N. (2010). Looking beyond learning: notes towards the critical study of educational technology. Journal of Computer Assisted Learning, 26(1), 65-73.

Sunstein, C. (2002). Republic.com. Princeton, NJ: Princeton University Press.

Tallent-Runnels, M. K., Thomas, J. A., Lan, W. Y., Cooper, S., Ahern, T. C., Shaw, S. M., \& Liu, X. (2006). Teaching courses online: A review of the research. Review of Educational Research, 76(1), 93-135.

Veletsianos, G. (in press). Higher education scholars' participation and practices on Twitter. Journal of Computer Assisted Learning.

Veletsianos, G. (2011). Designing opportunities for transformation with emerging technologies. Educational Technology, 51(2), 41-46.

Veletsianos, G. (2010). A definition of emerging technologies for education. In G. Veletsianos (Ed.), Emerging technologies in distance education (pp. 3-22). Edmonton, AB: Athabasca University Press.

Vygotsky, L. S. (1962). Thought and language. Cambridge, MA: MIT Press.

Vygotsky, L. S. (1978). Mind in society. Cambridge, MA: Harvard University Press.

Wang, Q. Y., Woo, H. L., Quek, C. L., Yang, Y. Q., \& Liu, M. (in press). Using the Facebook group as a learning management system: An exploratory study. British Journal of Educational Technology.

Webb, E. (2009). Engaging students with engaging tools. Educause Quarterly, 32(4), 1-7.

West, R., Waddoups, G., \& Graham, C. (2006). Understanding the experiences of instruc- 
tors as they adopt a course management system. Educational Technology Research and Development, 55(1), 1-26.

Wheeler, S., Yeomans, P., \& Wheeler, D. (2008). The good, the bad and the wiki: Evaluating student-generated content for collaborative learning. British Journal of Educational Technology, 39(6), 987-995.

Whitworth, A., \& Benson, A. (2010). Learning, design, and emergence: Two cases of Moodle in distance education. In G. Veletsianos (Ed.), Emerging technologies in distance education (pp. 195-213). Edmonton, AB: Athabasca University Press.

Yin, R. (2003). Case study research: Design and methods (3rd ed.). Thousand Oaks, CA: Sage.

\section{Athabasca University $\mathbf{A}$}

(c) (i) 
THE INTERNATIONAL

REVIEW OF RESEARCH IN

OPEN AND DISTANCE LEARNING

\section{Rapport in Distance Education}
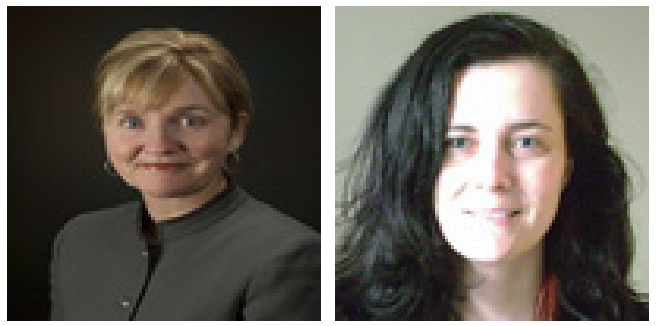

Elizabeth Murphy and María A. Rodríguez-Manzanares Memorial University, Canada

\section{Abstract}

Rapport has been recognized as important in learning in general but little is known about its importance in distance education (DE). The study we report on in this paper provides insights into the importance of rapport in $\mathrm{DE}$ as well as challenges to and indicators of rapport-building in DE. The study relied on interviews with 42 Canadian high-school DE teachers. Findings revealed that rapport is necessary in DE because of the absence of faceto-face communication. Challenges to building rapport relate to the geographic dispersion of students, the asynchronous nature of DE, teacher workload, limits of the software, teachers and students not seeing the need for rapport, and DE traditions. We identified six categories of rapport-building in DE as follows: Recognizing the person/individual; Supporting and monitoring; Availability, accessibility, and responsiveness; Non text-based interactions; Tone of interactions; Non-academic conversation/interactions. We break the categories into subcategories and provide indicators for each one. The indicators might also be used in contexts of DE teacher professional development as a springboard for discussion, or, more prescriptively, as guides to DE teacher behaviour. A follow-up study using a more fine-grained focus on specific indicators might provide insights into specific rapport-related behaviours.

Keywords: Distance education; online learning; rapport; teachers' beliefs; high school education

\section{Rapport in Distance Education}

Benson, Cohen, and Buskist (2005) found that in classes where teachers established rapport students were more likely to attend class, pay attention, and enjoy the subject matter. Frisby and Martin (2010) found that instructor rapport emerged as a significant predictor of cognitive and affective learning. Granitz, Koernig, and Harich (2009) linked rapport with 
enhanced learning, attention, motivation, attendance, and involvement for students. For faculty, they linked rapport with more rewarding teaching and higher ratings/evaluations. Not surprisingly, given these outcomes, the authors concluded that "one of the key traits of a master teacher is the ability to foster student rapport” (p. 52).

Rapport, defined as harmonious interactions between teachers and students (Bernieri, 1998) or a relationship with mutual understanding and satisfactory communication (Carey, Hamilton, \& Shanklin, 1986), is identified as important in the literature. However, that literature is primarily concerned with learning in face-to-face contexts. What about rapport in a context of distance education (DE)? Is rapport-building important or even possible in DE? In a Canadian study of high-school DE, Murphy and Rodríguez-Manzanares (2008a) found that the absence of "body language and visual presence as mediators requires eteachers [DE teachers] to find new ways of interacting and building rapport” (p. 1061). The authors contrasted the spontaneous, informal, daily interactions in the physical classroom with the situation in the DE classroom. In the former setting, teachers can easily build rapport. In the latter, the authors argued, "rapport building must be premeditated, consciously promoted and can only be achieved with more work" (p. 1068).

In spite of its importance and compared to other classroom variables, little is known about rapport. Studies conducted on the construct have not necessarily focused on educational contexts (e.g., Gremler \& Gwinner, 2000; Macintosh, 2009a, 2009b). Not surprisingly, it remains, therefore, a "relatively new variable to be considered in the educational setting" (Frisby \& Martin, 2010, p.160). In a context of DE, even less is known about the construct, its importance, how it might be built, and what it might look like. The psychology literature includes some attempts to identify indicators or evidence of rapport; however, these attempts have all been in contexts of face-to-face interactions (e.g., Bernieri, Gillis, Davis, \& Grahe, 1996; Miles, Nind, \& Macrae, 2009). In this paper, we report on a study that probed teachers' beliefs about rapport in a context of DE. Specifically, we report on its importance, challenges to rapport-building, and indicators of rapport in DE. We begin by examining how rapport has been conceptualized in the literature.

\section{Rapport in the Literature}

Rapport is a dyadic phenomenon (Altman, 1990), experienced only in interaction between individuals, and not a personality trait (Tickle-Degnen \& Rosenthal, 1990). It is therefore a mutual phenomenon characterized by mutual attentiveness (Tickle-Dengen \& Rosenthal, 1990), mutual respect (Kyriacou, 2009), mutual openness (Granitz et al., 2009), mutual attention (Hall, Roter, Blanch, \& Frankel, 2009), and mutual understanding (Carey et al., 1988). The mutual attention, however, must be positive or harmonious in nature.

Tickle-Dengen and Rosenthal (1990) argue that rapport would not be present when the attentiveness is negative. Therefore, rapport involves harmonious understanding (Kyriacou, 2009), harmonious interactions (Bernieri, 1998), and harmonious relations (Gremler \& Gwinner, 2000; Spencer-Oatey, 2000). It involves being "on the same wave length" (Berni- 
eri, 1988) or clicking (Tickle-Dengen \& Rosenthal, 1990).

Coordination is another element in rapport. According to Tickle-Dengen and Rosenthal (1990), coordination refers to balance and regularity in the mutual attentiveness; however, the coordinated movements of individuals on a crosswalk do not imply rapport. "Smooth and efficient interactional coordination" (p. 288) occurs when individuals know one another and are able to adopt one another's perspective. In a study of rapport between medical students and patients, Hall et al. (2009) defined rapport as "a relationship that was pleasant and engaging, a high degree of liking or positive affect, mutual attention, harmonious relation, easy/smooth communication, and/or symmetry and synchrony in the interaction" (p. 324).

Figure 1 presents the elements of rapport as articulated in our summary of the literature.

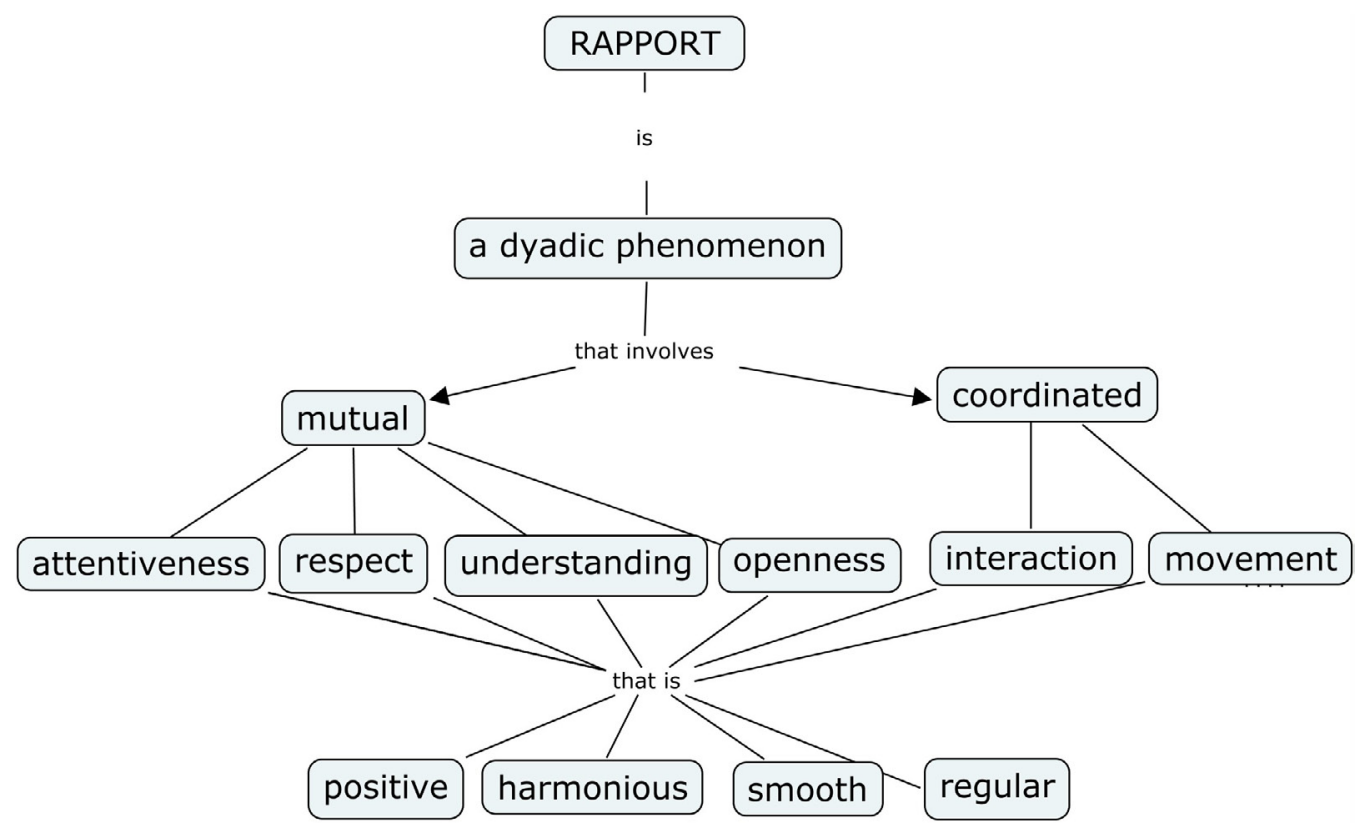

Figure 1. The elements of rapport.

\section{Indicators of Rapport}

The next step after defining rapport and identifying its elements is to identify how it might manifest itself or be operationalized in terms of behaviours such as coordinated movements or interactional synchrony (Bernieri, 1988), matched body language (Marks, 1994), matched voice tone and gestures (Nickels, Everett, \& Klein, 1983), behavioural and posture sharing, mimicry or mirroring (Gillis, Bernieri, \& Wooten, 1995; Granitz et al., 2009; Lakin \& Chartrand, 2003; Shapiro, 1989). Tickle-Dengen and Rosenthal (1990) paid particular attention to nonverbal behaviour as a key element in creating rapport. They referred to spatial configurations and "bodily postures" as attentiveness correlates of rapport and behaviours such as smiling and head nodding as positivity correlates, while the coordination correlates would be behaviours such as "postural mirroring and interactional synchrony" (p. 290). 
Kyriacou (2009) discussed rapport from the perspective of classroom effectiveness, arguing that effective classrooms are task-oriented but are also characterized by "mutual respect and rapport" (p. 115). Rapport involves care for the students' progress and mutual respect for students as learners and as individuals. Indicators of mutual respect include tailoring learning to students' needs; monitoring progress and giving help patiently and constructively; giving praise; and "dealing with lack of progress in a concerned manner" (p. 116). Respect through treating students as individuals (independent of school) contributes to good rapport. Social conversation and remarks such as "Anyone go to the match on Saturday?" (p. 117) are also indicators of rapport.

Granitz et al. (2009) identified three categories of what they referred to as "antecedents of rapport." These are: approach, personality, and homophily. The category of approach includes being available to answer questions; providing guidance, feedback, support, help and praise for good work; accessibility, responsiveness, and openness (e.g., providing a home telephone number). It includes mutual openness and disclosure, understanding the student as a person, and recognizing differences between teachers and students. The category of approach also involves creation of trust through fulfillment of contracts and promises and through consistent and predictable behaviours; respect and courtesy; not psychologically threatening students by talking down to them; listening; paying attention; showing patience; and taking time with students. This latter element of rapport also includes showing interest in student success and helping and encouraging them to succeed. In addition, it involves being honest and transparent, showing students one's human side, admitting faults and mistakes, exerting an effort, and expecting effort from students.

Personality factors related to rapport include caring, bonding, showing concern and empathy, and avoiding favouritism. Rapport includes creating a positive, friendly, cooperative environment, using humour, and understanding students' needs. Homophily relates to sharing values, attitudes, social style, beliefs, and behavioural mimicry. It involves engaging in self-disclosure and posture sharing or similarity in movement (Granitz et al., 2009).

\section{Indicators of Rapport in Distance Education}

The previous section identified indicators of rapport in general and in education in particular. This section focuses specifically on identifying indicators of rapport in a context of DE. There has been limited attention in the literature thus far pertaining to the types of behaviours that might be indicative of rapport in that context. Stock (2010) considered rapport in a context of staff-patron interactions in a reference library. He noted that in an online context because of the absence of voice and nonverbal behaviour, paying attention to factors such as "the length of the patron's sentence and level of formality and writing a response in approximately the same style" can help build rapport (pp. 48-49). He also argued that in cases where the phone is used voice plays an important role in building rapport especially when aspects such as tempo and volume are matched.

Jones, Warren, and Robertson (2009) studied rapport in a context of online text-based communication in a $3 \mathrm{D}$ online learning environment (OLE). Rapport elements in messages were indicated by the following: reporting on or requesting information on personal infor- 
mation, ideas, opinions, and emotions. Thanking, complaining, apologizing, or engaging in personal discussions were also considered as indicators of rapport. The authors concluded that the earlier weeks in a course represent a critical period for the type of student interaction that will lead to rapport. In particular, face-to face meetings early in the course help develop a critical communication mass that positively supports the development of rapport. The visual nature of a 3D OLE (with hand gestures, facial expressions) supports more naturalistic communication similar to that of face-to-face interactions.

In a study of 15 high-school DE teachers, Murphy and Rodríguez-Manzanares (2008a, $2008 \mathrm{~b}$ ) found that because of a lack of visual cues and physical presence in this form of learning teachers compensated by deliberate rapport-building. Teachers described their compensatory strategies such as having students' photographs and keeping track of information related to their preferences and extracurricular activities. Other strategies included providing constant and immediate feedback, sharing personal information, engaging in non-course related, off-task chat, getting to know students socially, ensuring that communication is comfortable, making personal contacts, and using technologies such as instant messaging with which students are comfortable.

\section{Summary of Rapport Indicators}

In Table 1, we synthesize and categorize the indicators of rapport as articulated in the literature in general and in the DE literature specifically. We have grouped like indicators and provided labels in italics. 
Table 1

Summary of Rapport Indicators in the Literature

Disclosure, honesty and respect

Being open, honest, and transparent

Showing students one's human side

Admitting faults and mistakes

Talking freely

Engaging in self-disclosure

Thanking, apologizing

Sharing personal information

Creating trust through fulfillment of contracts and promises

Not psychologically threatening students by talking down to them

Showing consistent and predictable behaviours
Supporting and monitoring

Showing care for and monitoring students progress

Tailoring learning to students' needs

Providing guidance, feedback, support, help

Giving praise for good work

Giving help patiently and constructively

Dealing with lack of progress in a concerned manner

Showing patience with students

Exerting and expecting effort from students

Listening and paying attention

Showing interest in student success

Helping and encouraging them to succeed

Creating a positive, friendly, cooperative environment

\section{Recognizing the person/individual}

Understanding the student as a person

Recognizing differences

Avoiding favouritism

Reporting on or requesting personal information, ideas, opinions, and emotions

Engaging in personal discussions

Keeping track of students' photos and information related to their preferences and extra-curricular activities

Making personal contacts
Sharing, mirroring, mimicking, matching

Being "on the same wave length"

Adopting each other's perspective

Behavioural and postural sharing, mirroring, and mimicry

Writing a response in the same style

Matching body language, gestures, voice tempo, and volume

Smiling and head nodding

Sharing values, attitudes, social style, beliefs 
Interacting socially

Engaging in social conversation

Engaging in non-course related, off-task chat

Getting to know students socially

Using humour
Availability, accessibility, and responsiveness

Being available to answer questions

Being accessible

Being responsive

Providing constant and immediate feedback
Caring and bonding

Being caring

Bonding

Showing concern

Showing empathy and an understanding of students' needs

\section{Communicating effectively}

Ensuring that communication is comfortable, easy/smooth

Using technologies such as instant messaging with which students are comfortable

\section{Method}

The previous section of this paper focused on indicators of rapport in the literature. The limited attention in the literature to indicators of rapport specifically for DE provided the motivation for this study. In addition, our purpose was to identify why rapport was important in DE and what challenges might be associated with rapport-building in DE. To achieve these three objectives, we interviewed 42 Canadian high-school teachers. It was beyond the scope of the study to observe rapport in DE (i.e., to identify how these 42 teachers actually engage in rapport-building in their courses). Our focus was on teachers' beliefs or personal theories (Fox, 1983; Siedentop, 1991) related to rapport in DE.

\section{Recruitment of Participants and Ethics Procedures}

The first step in recruitment of participants involved identifying organizations delivering DE high-school courses in Canada. Different models of the provision of high-school DE exist in different regions. For this reason, we identified a variety of organizations such as school districts and virtual schools. For each organization, we identified a contact person or persons in order to request permission to recruit teachers for the study. These organizations included, for example, virtual school principals as well as individuals working for provincial departments of education or school districts. For the organizations that replied to our call for participation, we then proceeded to contact individual teachers by sending them a consent form and a letter inviting them to participate in the study. 


\section{Participants}

Forty-two DE teachers who returned consent forms were included in the study. They worked in 14 organizations located in the provinces of British Columbia, Alberta, Saskatchewan, Manitoba, Ontario, Quebec, New Brunswick, and Nova Scotia. The number of teachers affiliated with any one of the 14 organizations ranged from one to six. All the teachers worked for a single organization, except for one who taught for two organizations. While 19 teachers reported to a principal either in their online school or in the school where they taught their face-to-face classes, one teacher reported to the principals of the schools in which the students were registered for face-to-face classes. One teacher was working both as a principal and a teacher. The remaining 21 teachers reported directly to a coordinator of DE for an area greater than a single school. For seven of these teachers, the coordinator worked for the school board, while six reported to an individual employed by the provincial Department or Ministry of Education. Eight teachers stated that they reported to one or more individuals employed by different institutions at a variety of levels.

\section{Data Collection}

We conducted individual one-hour, audio-taped telephone interviews over a two-month period. Interviews were semistructured (Patton, 2002). The advantage of semistructured interviews is that they allow the researcher "to respond to the situation at hand, to the emerging worldview of the respondent, and to new ideas on the topic" (Merriam, 2009, p. 90). We used probing to gain further insight into participants' beliefs about rapport in their DE courses. As King and Horrocks (2010) observed, stronger probing may be needed in telephone than in face-to-face interviews. In the absence of visual cues, probing allows the researcher to resolve ambiguities in communication in qualitative telephone interview studies. In addition, probing can be useful when conducting telephone interviews because participants might need to be "encourage[d] to open up if their responses are becoming too 'factual' in tone" (p. 83).

We asked three questions to the teachers:

1. Is building rapport important in $\mathrm{DE}$ ?

2. What are the challenges related to promoting rapport in DE?

3. In what ways do you build rapport between yourself and students in DE?

\section{Data Analysis}

We began by transcribing the interviews. We then gathered the interview segments on rapport and unitized them (Miles \& Huberman, 1994) by breaking the text of the transcripts down into units of meaning, containing one identifiable idea (Aviv, 2001). Rather than looking, for example, at "a word, a sentence, or a section" (Marshall, 1981, p. 396), the focus was on searching for logical units or "chunks of meaning" (p. 396) coming out of the data. We labelled each segment of text that formed a unit of meaning. Analysis proceeded 
by identifying thematically similar units across the data (Lee \& Fielding, 2004). The regularities identified revealed patterns that we sorted into categories (Patton, 2002).

\section{Findings}

We present the findings in three sets. The first set consists of responses to the first question, which asked teachers if it was important to build rapport in DE. The second set groups responses to the question about challenges related to building rapport in DE. The third set of findings related to rapport-building between teachers and students. Based on our analysis of the interview transcripts, we grouped approaches to rapport-building into six categories. We broke the categories into subcategories and provided indicators for each.

\section{The Importance of Rapport in Distance Education}

Teachers emphasized that rapport is necessary because in DE there isn't face-to-face communication. It is important to "establish some sort of personal connection;" otherwise, it is like teaching "a bunch of little computers." Getting to know students individually is important and that includes knowing "how they think, how they work, what their personalities are, what they can handle, what they can't handle.”

Having an idea of a given student's situation is important because, for example, "a student might be... a single parent, who has a young child, and that gives us a better understanding of why they are delaying in providing some answers." Another might have a parent who is terminally ill. The student could have an emotional disorder. Rapport is required "because we [teachers] have to treat each individual student in a different manner." As well, "the more contact that you have with the student and the more familiar you are with them, the more they contact you regularly, the greater the chance of their success."

\section{Challenges to Rapport-Building in Distance Education}

Some teachers noted that building rapport with DE students can be more challenging, especially when students are scattered across the province or when they are not together at the same time, or working on their assignments outside of office hours. As one teacher commented: "I can't say that I've really... established a rapport among students."

Rapport can be difficult to establish, not only because of the distances created by geography, but also because of the way the courses are designed and the limits of the software: "For example, Moodle doesn't have a built-in synchronous tool. It's essentially an asynchronous tool." The workload may also present obstacles to a teacher's engagement in rapport, as the following remark illustrates: “... we have some students who could keep you on the phone for an hour at a time, but, unfortunately you have to attend to more than one student, so... I try to limit [discussion] to academic questions." In other cases, teachers may not see the need for or value of rapport: "Building rapport in a social sense is not something that's happening right now, nor would I say it is something that is really essential to having the students benefit in an educational sense from the course." 
Compared to the face-to-face student who is "there partly by obligation," the DE student is there by his or her "own free will." As a result, some DE students "don't want to have any interactions. They're just getting through it because they have to get through it." Some DE students may not want to be contacted. "They just want to get in, get this course done, and get out." One teacher described his own challenges with trying to build rapport:

There are literally children that [sic] send in emails with just attachments; they don't give any email responses, they don't write comments, they don't write questions. And I send back to them things like: received and read, great job, great work, and I make comments... and I receive no response. I have no sense of them as people.... it's their decision to decide whether they want to contribute to the other side of this kind of banter... if they don't, that's fine. I would feel really awkward sending an email to a kid who was being very business-like saying "Hey, let's chat! How do you feel?”

Another teacher cautioned about how in an online environment, attempts to build rapport might backfire:

...you have to be very careful what you say: you might be trying to make a joke with a student, but if you don't know their sense of humour, they don't see it as a joke ... because you don't know what kind of day they're having or what kind of situation they're in.

Other obstacles to rapport-building relate to traditions of DE. In the following comment, one of the participants explained how past practices with $\mathrm{DE}$ in his province may inhibit attempts to build rapport:

...the people who took distance education in the olden days did so without any contact with the teacher. They received their lessons in the mail, and they completed them, and they mailed them back... there was no chatter at all with the teacher. And so that perception is still out there, and some students who take online courses believe that they're not supposed to contact the teacher, even though we... keep telling them, 'Now, please, phone whenever you have a question or need assistance or anything like that.'

In spite of these challenges related to rapport-building in DE, teachers nonetheless identified numerous indicators of rapport-building in this context. These are described in the next section. 


\section{Indicators of Rapport in Distance Education}

Our analysis of the transcript of interviews with the 42 teachers revealed six categories of rapport-building as follows: Recognizing the person/individual; Supporting and monitoring; Availability, accessibility, and responsiveness; Non text-based interactions; Tone of interactions; Non-academic conversation/interactions. We broke the categories into subcategories and provided indicators for each. The indicators use as much as possible the actual words of interviewees. We summarized the categories and subcategories in Table 2.

Table 2

Summary of Categories and Subcategories

Categories Subcategories

Recognizing the person/individual

Eliciting personal information

Expressing personality

Acknowledging the person

Supporting and monitoring

Supporting and monitoring

Praising

Providing feedback

Availability, accessibility, and responsiveness $\quad$ Being available

Responding quickly

Non text-based interactions

Hearing each other

Seeing each other

Interacting in real-time, face-to-face

Tone of interactions

Being friendly

Being humorous

Being respectful and honest

Non-academic conversation/interactions

Conversing socially 
The indicators of rapport included in the category of Recognizing the person/individual focus on the individual or person, beyond the academic setting. The indicators relate to eliciting and acknowledging aspects of students' personality, interests, hobbies, pastimes, and future plans. They also include teachers' disclosure of personal information. We summarize the subcategories and their indicators in Table 3.

Table 3

Category: Recognizing the Person/Individual

Subcategory Indicator

Eliciting personal information
Setting up profiles or homepages at the beginning of the course where students post pictures of themselves and answers to questions related to personal interests, such as the type of music they like.

Using chat to learn the attitudes, temperaments, and likes and dislikes of students.

Encouraging students to write about their personal interests.

Finding out at the beginning of the year students' interests and likes, then asking questions about them later, e.g., "Hey, how did your volleyball game go?"

At the very beginning of the course, using a 10-question assignment that elicits information from the student.

Finding out some personal information early on so that you can build on that as you go through the course.

Getting students to tell a little bit about themselves, what brought them to online learning, what their interests, hobbies and pastimes are, and what they plan to do after graduation, etc.

Having students use a course café to introduce themselves and their interests, and why they are taking the given course.

Getting to know who students are, chatting about what their future ambitions are, and what they are planning on doing after graduation. 

Expressing person- Having students choose the colours and the fonts to represent their personali- ality ties.

Letting the teacher's personality come through as much as possible.

Having students and teachers post discussion messages about themselves.

Having teachers create their own profile page.

Teachers disclosing certain amounts of personal information about themselves, such as interests and hobbies, so that students feel like they know them a little bit.

Personalizing the welcome pages to the courses.

Acknowledging the Noticing personal things about students.

person

Engaging students at a personal level outside the course.

Using chat to establish some sort of relationship outside of the academic setting and getting to know a bit more about students personally.

Sending personalized emails and comments specific to a student in order to acknowledge the person.

Making connections, so that each time students contact the teacher, the teacher can look them up in the file and say, "Oh, yeah, this is that student," so they are able to continue the relationship.

Unlike the previous category, which focuses on personal attention, the category Supporting and monitoring relates more specifically to the academic aspects of the teacher's interactions with students. The category groups indicators that refer to the teacher's efforts to ensure that students remain on track and on task. The category also includes attention to the affective component of learning in terms of reducing or preventing students' frustration or discouragement. We summarize this category in Table 4. 
Table 4

Category: Supporting and Monitoring

Subcategory Indicator

Supporting and

Posting emails that say, "If you're having trouble, come and talk to me."

monitoring

Sending students a hard copy letter to welcome them to the course.

Sending emails to students regarding information so they know that the teacher is there trying to help them get through.

Asking students to submit a document explaining any special circumstances that the virtual school should be aware of.

Trying to read messages as if they were spoken, and then writing, phoning, or chatting with students to know that they are surviving and are not getting too frustrated.

Sending weekly emails to students just to make sure they are on track and are not discouraged with the course.

Sending information to schools and ccing the students, so they can see that the teacher is really looking out for them and making sure they are on task and getting work done.

Offering help to improve submissions.

Being willing to give students as much help as they need. 
Providing feedback Providing regular feedback from the teacher everyday in terms of how well students are meeting the outcomes of the lesson.

Returning a lesson with comments.

Not marking an assignment if a student had a problem on it, but returning it and saying, "You really had trouble with that assignment. How about you meet me on chat and we'll talk about it and you can re-submit it?"

Emailing students to provide positive reinforcement, encouragement, or feedback or to invite questions.

The category Availability, accessibility, and responsiveness in Table 5 groups indicators that reference the ongoing, easy, and immediate accessibility of the teacher to answer questions, welcome students, or address needs.

Table 5

Category: Availability, Accessibility, and Responsiveness

Subcategory Indicator

Being available

Talking on a daily basis.

Having constant messaging going on.

Being accessible, offering chats and office hours, and making kids know that they can email you at any time.

Building the feeling that students are welcome to email at any time.

Being available to provide help to students.

Making it as easy as possible for students to get in contact and stay in contact.

Being there to answer students' questions.

Responding quickly Responding as soon as possible when students ask a question or want something.

Addressing students' needs in a timely fashion. 
Table 6 groups the indicators for the category Non text-based interactions. This category references the tools used by teachers to contact students. In particular, it emphasizes realtime interactions such as those provided through phone and video. This category also includes interactions that occur in person such as in face-to-face visits by teachers.

Table 6

Category: Non Text-based Interactions

Subcategory Indicator

Hearing each other Letting students hear your voice.

Making initial telephone calls to touch base and help develop a relationship.

Phoning new students.

Phoning the student and introducing oneself.

Calling students and talking.

Using phone contact first because, in the voice, we hear friendliness and antagonism.

Seeing each other Using webcams to see each other.

Providing an opportunity for students to see a picture of you, to hear your voice on video.

Having weekly meetings using real-time, web conferencing to see others' expressions. 
Interacting in real- Inviting students to come to specific sessions such as a provincial exam prepatime, face-to-face ration session.

Holding a ski trip.

Holding a picnic.

Holding an open house in the virtual school and inviting other students to come, and having games and pizza for them.

Going out to the schools and meeting the students.

Table 7 presents the indicators related to the category Tone of interactions. This category suggests that rapport, at least in part, is a function of the tone of the communication. The tone might communicate humour and respect and it may be light, honest, friendly, and warm.

Table 7

Category: Tone of Interactions

\begin{tabular}{ll}
\hline Subcategory $\quad$ Indicator \\
\hline
\end{tabular}

Being friendly Exchanging pleasantries.

Being as positive as possible.

Teacher revealing to students that he or she is pretty easy-going.

Having a more jovial relationship.

Building a relationship with that student, so it doesn't feel as cold.

Addressing students' needs in a friendly fashion.

Being approachable and friendly. 
Being humorous

Teachers revealing to students their sense of humour.

Joking with the students as much as possible.

Having a sense of humour.

Being respectful and honest
Treating students with respect and showing that they are important to you.

Respecting the commitment that students are making.

Showing students respect in the chat room.

Conveying to students respect for making such a big commitment.

Treating students like adults.

Admitting mistakes.

Table 8 groups indicators related to the category of Non-academic conversation/interactions between students and teachers. This category highlights the social nature of rapport and emphasizes the affective components of caring and empathy. Unlike the category presented in Table 4 (Supporting and monitoring), it emphasizes monitoring and supporting students personally, as opposed to solely academically.

Table 8

Category: Non-academic Conversation/Interactions

Subcategory Indicator

Conversing socially Initiating small talk.

Communicating with students on a social level.

Seeking ways to have conversations with students.

Talking about off-topic issues.

Part of the teacher's message should not be business-related, but should be, "Hope you're having a good week. Grad's coming up: did you get your dress?"

Sending students emails that would be more in the sense of banter. 
Showing care and concern
Answering students when they ask questions and asking them about other things, like "Are you having a good week this week?"

Asking "How was your weekend? How are you feeling today?"

If students have had a personal problem, checking up with them later on to make sure that everything is ok.

Text messaging students to ask them how their day is going.

Saying good morning to them, and asking them how their day is going.

Talking to students about things that are important in their life.

Asking students how they are doing.

Showing care, that you are on the student's side, and that the student is not just another number.

Not downplaying students' feelings.

\section{Discussion}

In addition to identifying indicators of rapport, the previous section identified the importance of rapport as well as challenges associated with rapport-building in DE. Teachers presented two different types of beliefs or personal theories concerning rapport. One emphasized its importance given the online context as a mechanism that compensates for the anonymity resulting from lack of face-to-face interactions. The other downplayed its importance and highlighted limitations related not only to time, software, and traditions of DE, but to preferences on the part of students.

Teachers' beliefs about the importance of rapport may have been limited by our first question, which simply asked whether rapport was important in DE. If we had provided teachers with a list of indicators of rapport from the literature and asked them to identify which were important, all the teachers might have selected some of the indicators. This is because a number of the indicators, although associated with rapport in this context, are indicative simply of effective teaching in general. These indicators might relate to giving praise (Kyriacou, 2009), showing respect for students (Delaney, Johnson, Johnson, \& Treslan, 2010; Granitz et al., 2009), creating a positive atmosphere (Granitz et al., 2009), using humour, providing timely feedback, or being accessible and communicative (Delaney et al., 2010).

Rapport, as noted already, has been described as a dyadic phenomenon experienced only in 
interaction between individuals. Tickle-Degnen and Rosenthal (1990) emphasized the notion of mutual coordination as an element in rapport such as adopting the other's perspective or posture sharing and mimicry. We identified three indicators of rapport which reflect this mutual interaction and which we grouped in the category Recognizing the person/ individual. However, our findings focus more on teachers' role in rapport-building and, in that regard, the dyadic, mutual character of the construct is downplayed in favour of teachers' conscious efforts to engage in rapport behaviours directed toward the student. Those efforts do not reference any expectations of or requirements for the student to reciprocate. For example, one teacher described promoting rapport by asking students about their personal interests. Another focused on letting the teacher's personality come through as much as possible.

The literature on rapport has come largely from contexts of psychology (e.g., Bernieri et al., 1996; Tickle-Degnen \& Rosenthal, 1990), the medical and counselling field (e.g., Barnett, 2001; Gaglio, Nelson, \& King, 2006; Hall et al., 2009), and marketing (e.g., DeWitt \& Brady, 2003; DeWitt \& Liu, 2002; Gremler \& Gwinner, 2000; Macintosh, 2009a, 2009b). It is possible that, in those contexts, rapport might be defined more as a mutual phenomenon. In a context of DE however, it may be that rapport-building is a task of the teacher. Teachers linked respect with rapport and referred to the importance of showing students respect for their commitment and treating them like adults. Kyriacou (2009) and Granitz et al. (2009) also identified respect as an indicator of rapport, although they described it as a mutual phenomenon. Also, the question we asked teachers about rapport-building did not focus on its mutual dyadic nature.

The nonverbal behaviours associated with rapport in the literature such as smiling and head-nodding or postural mimicry might be possible in a context of DE where video or webcams are used. As noted in the study by Stock (2010), mimicry can even be achieved in a text-based context through behaviours as mirroring sentence length. In our study, teachers did not refer to any types of mirroring. They did, however, refer to adapting or tailoring their behaviours to the students such as finding out their interests and then asking questions about them later. We may assume, therefore, that text-based mirroring and mimicry is an appropriate rapport-building behaviour in DE.

In terms of comparisons with the literature on rapport, teachers referenced many of the indicators that we identified in the literature. One notable exception would be those indicators grouped in the category Recognizing the person/individual as well as the indicator Avoiding favouritism. In a DE environment where interactions may be more one on one, favouritism may not be an issue. Teachers did not refer specifically to thanking students or apologizing to them, except for the one indicator that referred to admitting mistakes. Other indicators identified in the literature but not referenced by teachers include: Showing consistent and predictable behaviours and Creating trust through fulfilment of contracts and promises. Although teachers did not refer to Creating a positive, friendly, cooperative environment, the category of Tone of interactions groups similar indicators. 
Teachers identified indicators of rapport that we had not noted in the literature. We grouped one set of these indicators in the category Non text-based interactions. Some are specific to DE such as Setting up profiles or homepages. Other indicators referred to the use of specific tools such as chat, course café, email, video, webcam, and telephone. Teachers also provided more specific indicators than those we identified in the literature. For that reason, we included categories and subcategories as well as indicators. We might have referred to our subcategories as indicators and to our indicators as examples.

\section{Conclusion}

The findings presented in this paper are limited to teachers' beliefs. Beliefs of students enrolled in DE would not only have provided some triangulation but, as well, further insights into how important rapport, or some elements of it, might be in DE. The findings should also be interpreted in a context of virtual schooling (i.e., a high-school as opposed to a postsecondary context). An adolescent's needs for rapport might be different from those of postsecondary adults learning online. The scope of our questions limited the types of responses. A follow-up study using a more fine-grained focus on specific indicators might provide insights into specific rapport-related behaviours. The objective of the study was not to identify the types of rapport-building behaviours in which teachers are presently engaging. That type of focus might be taken in a follow-up study using interviews and online observations. Likewise, follow-up studies could explore the role of other factors that might influence either negatively or positively rapport-building in DE. These might include, for example, culture and language.

In spite of the limitations, this study highlights an element of DE about which little has been written. It provides indicators of rapport that might be used by DE teachers in their own teaching. The indicators might also be used in contexts of $\mathrm{DE}$ teacher professional development as a springboard for discussion or, more prescriptively, as guides to online teacher behaviour. They might be presented to teachers in survey format. Alternatively, the indicators might be used to measure rapport in the transcripts of online discussions or email correspondence. Finally, in terms of research, our study raises questions such as the following: Which indicators of rapport are most important in DE? What are the obstacles to building rapport in $\mathrm{DE}$ ?

\section{Acknowledgements}

The study reported on in this paper was made possible by a grant from the Social Sciences and Humanities Research Council of Canada (SSHRC). Thank you to research assistants Kate Scarth, for her assistance with coding, Charlie O'Keefe and Janine Murphy, for recruitment of research participants, and Ying Zhang, for help with locating literature on rapport and with the reference list. 


\section{References}

Altman, I. (1990). Conceptualizing “rapport.” Psychological Inquiry, 1(4), 294-323.

Aviv, R. (2001). Educational performance of ALN via content analysis. Journal of Asynchronous Learning Networks, 4(2), 53-72. Retrieved from http://www.aln.org/ publications/jaln/v4n2/pdf/v4n2 aviv.pdf

Barnett, P. B. (2001). Rapport and the hospitalist. American Journal of Medicine, 111(9), 31-35.

Benson, T. A., Cohen, A. L., \& Buskist, W. (2005). Rapport: Its relation to student attitudes and behaviors toward teachers and classes. Teaching of Psychology, 32, 236-238.

Bernieri, F. J. (1988). Coordinated movement and rapport in teacher student interaction. Journal of Nonverbal Behavior, 12(2), 120-138.

Bernieri, F. J., Gillis, J. S., Davis, J. M., \& Grahe, J. E. (1996). Dyad rapport and the accuracy of its judgment across situations: A lens model analysis. Journal of Personality and Social Psychology, 71(1), 110-129. doi: 10.1037/0022-3514.71.1.110

Carey, J. C., Hamilton, D. L., \& Shanklin, G. (1986). Development of an instrument to measure rapport between college teachers. Journal of College Student Personnel, 27(3), 269-273.

Delaney, J., Johnson, A., Johnson. T., \& Treslan, D. (2010). Students' Perceptions of Effective Teaching in Higher Education. Retrieved from http://www.uwex.edu/disted/ conference/Resource library/handouts/28251 10H.pdf

DeWitt, T., \& Brady, M. K. (2003). Rethinking service recovery strategies: The effect of rapport on consumer responses to service failure. Journal of Service Research, 6(2), 193-207.

DeWitt, T., \& Liu, Y. (2002). The customer orientation-loyalty model: The role of emotional contagion and rapport in the service encounter. In W. J. Kehoe \& J. H. Lindgren Jr. (Eds.), 2002 American Marketing Association Summer Educators' Conference proceedings: Enhancing knowledge development in marketing (p. 321). Chicago, IL: American Marketing Association.

Fox, D. (1983). Personal theories of teaching. Studies in Higher Education, 8(2), 151-163.

Frisby, B. N., \& Martin, M. M. (2010). Instructor-student and student-student rapport in the classroom. Communication Education, 59(2), 146-164. doi:10.1080/03634520903564362

Gaglio, B., Nelson, C. C., \& King, D. (2006). The role of rapport: Lessons learned from conducting research in a primary care setting. Qualitative Health Research, 16(5), 
723-734.

Gillis, J., Bernieri, F. \& Wooten, E. (1995). The effects of stimulus medium and feedback on the judgment of rapport. Organizational Behavior and Human Decision Processes, 63, 33-46.

Granitz, N. A., Koernig, S. K., \& Harich, K. R. (2009). Now it's personal: Antecedents and outcomes of rapport between Business faculty and their students. Journal of Marketing Education, 31(1), 52-65. doi: 10.1177/0273475308326408

Gremler, D. D., \& Gwinner, K. P. (2000). Customer-employee rapport in services relationships. Journal of Services Research, 3(1), 82-104.

Hall, J. A., Roter, D. L., Blanch, D. C., \& Frankel, R. M. (2009). Observer-rated rapport in interactions between medical students and standardized patients. Patient Education and Counseling, 76(3), 323-327. doi: 10.1016/j.pec.2009.05.009

Jones, J., Warren, S., \& Robertson, M. (2009). Increasing student discourse to support rapport building in web and blended courses using a $3 \mathrm{~d}$ online learning environment. Journal of Interactive Learning Research, 20(3), 269-294.

King, N., \& Horrocks, C. (2010). Interviews in qualitative research. London: Sage.

Kyriacou, C. (2009). Effective teaching in schools: Theory and practice ( $3^{\text {rd }}$ ed.). London: Nelson Thornes Publishers.

Lakin, J. L., \& Chartrand, T. L. (2003). Using nonconscious behavioural mimicry to create affiliation and rapport. Psychological Science, 14(4), 334-339.

Lee, R. M., \& Fielding, N. G. (2004). Tools for qualitative data analysis. In M. A. Hardy \& A. Bryman (Eds.), Handbook of data analysis (pp. 529-546). London: Sage.

Macintosh, G. (2009a). Examining the antecedents of trust and rapport in services: Discovering new interrelationships. Journal of Retailing and Consumer Services, 16(4), 298-305. doi:10.1016/j.jretconser.2009.02.001

Macintosh,G.(2009b).Theroleofrapportinprofessionalservices:Antecedentsandoutcomes. Journal of Services Marketing, 23(2), 71-79. doi:10.1108/08876040910946332

Marks, R. B. (1994), Personal selling: An interactive approach. Boston, MA: Allyn \& Bacon.

Marshall, J. (1981). Making sense as a personal process. In P. Reason \& J. Rowan (Eds.), Human inquiry: A sourcebook of new paradigm research (pp. 395-399). Chichester: John Wiley \& Sons.

Merriam, S. B. (2009). Qualitative research: A guide to design and implementation. San 
Francisco, CA: Jossey-Bass.

Miles, M. \& Huberman, A. M. (1994). Qualitative data analysis: An expanded sourcebook. Thousand Oaks, CA: Sage.

Miles, L. K., Nind, L. K., \& Macrae, C. N. (2009). The rhythm of rapport: Interpersonal synchrony and social perception. Journal of Experimental Social Psychology, 45(3), 585-589. doi:10.1016/j.jesp.2009.02.002

Murphy, E., \& Rodríguez-Manzanares, M. A. (2008a). Contradictions between the virtual and physical high-school classroom: A third-generation Activity Theory perspective. British Journal of Educational Technology, 39(6), 1061-1072. doi: 10.1111/j.1467-8535.2007.00776.x

Murphy, E., \& Rodríguez-Manzanares, M. (2008b). Revisiting Transactional Distance Theory in a context of web-based high-school distance education. Journal of Distance Education, 22(2), 1-14. Retrieved from http://www.sfu.ca/ ada27/JDE/MarkPDFs/Volo5/Murphy.pdf

Nickels, W. G., Everett, R. F., \& Klein, R. (1983). Rapport-building for salespeople: A neurolinguistic approach. Journal of Personal Selling and Sales Management, 3(2), 1-7.

Patton, M. Q. (2002). Qualitative research and evaluation methods ( $3^{\text {rd }}$ ed.). Thousand Oaks, CA: Sage.

Shapiro, S. (1989). Building proper rapport enhances guest relations. Restaurants and Institutions, 99, 22.

Siedentop, D. (1991). The mountain yet to be climbed. Paper presented at 1991 AIESEP NAPEHE World Congress, Atlanta.

Spencer-Oatey, H. (2000). Culturally speaking: Managing rapport through talk across cultures. London: Continuum.

Stock, M. (2010). The three R's: Rapport, relationship, and reference. The Reference Librarian, 51, 45-52. doi:10.1080/02763870903361995

Tickle-Degnan, L., \& Rosenthal, R. (1990). The nature of rapport and its nonverbal correlates. Psychological Inquiry, 1(4), 285-293.

Athabasca University 
THE INTERNATIONAL

REVIEW OF RESEARCH IN

OPEN AND DISTANCE LEARNING

\section{The Implications of the Local Context in Global Online Education}
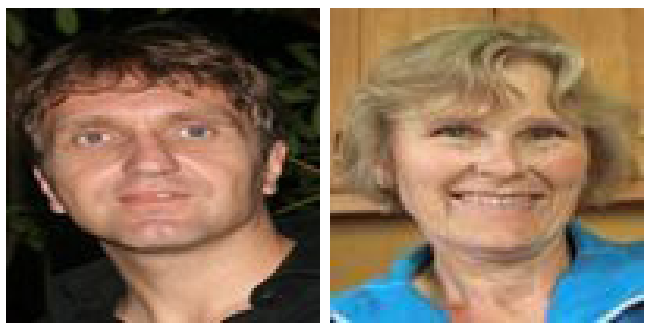

Ståle Angen Rye and Anne Marie Støkken

University of Agder, Norway

\section{Abstract}

This paper investigates how features in students' everyday life influence their participation in online global collaboration, and it suggests that students' local context should be recognised as a significant part of their educational space. In this exploratory case study of students engaged in a global online master's programme, the discussion is organised under three main headings: the social, material, and cultural dimensions of students' daily life. The paper shows how the influence of the students' local context typically creates a situation whereby the online learning space is characterised by inequality. This recognition should be taken into account when providers of online education design courses and make provision for student support. In this way, the inequalities can be seen as a resource for learning rather than as a problem.

Keywords: Internet; global education; everyday life; student role; virtual collaboration; distance education

\section{Introduction}

Recent developments in communication technology have enabled new forms of Internetsupported flexible education. The Internet infrastructure, as well as access to it, is now spreading to people and places that were previously largely excluded from the global network of information and knowledge. Accordingly, the range of online education has increased and new groups of potential students have been reached (Tiffin \& Rajasingham, 2003). We may now claim to see the contours of the "global village" described half a century ago by McLuhan (1962) or at least a global classroom where students from different places in the world can take part in the global production and acquiring of knowledge (Bates \& de los Santos, 1997). 
However, some writers, such as Kirkwood (2001), question the appropriateness of the global distance education offered to culturally heterogeneous learners. One concern is that students from developing countries are hindered in their participation in global education due to the weak local technological infrastructure (see also Evans, 1995; Perraton, 2000; Rumble, 2001). With reference to Massey's (1994) concept of "power geometry," Kirkwood also expresses reservations about the cultural bias such students often encounter when accessing global networks. He follows Castells' $(1996$; 2001) notion of the network society as being geographically organised so that information flows out from nodes in the network to the periphery. This implies that in terms of globalisation, including global education, we may act together, but the individuals' resources available for action vary widely.

This issue is explored further in this paper through an investigation of the ways in which online students rely on the resources available in their daily environment when collaborating with other students through digital networks and how these resources help constitute global collaboration. This approach is grounded in the recent recognition that students' daily environments are important for helping to determine how well students perform and participate in various forms of flexible education. How the local life of students interacts with their global interconnectedness has not yet been widely researched, although these relationships are increasingly characteristic of online higher education. In this paper, we will discuss these issues through an exploratory case study of an online master's programme in development management, in the course of which 24 students from Europe and Africa, mostly in their early twenties, collaborated using the Internet.

We will first briefly discuss what the research literature says about the importance of local context in distance education and how the students' local contexts relate to the global flow of higher education.

The Importance of the Local Context in Online Distance Education

Recent research literature includes discussion about how various conditions in the students' daily environment may enable or constrain students' participation in different forms of spatially distributed education, such as online, flexible, and distance education. The social relations and obligations in students' daily life are perceived as relevant to student participation in distributed education. Researchers have concluded that family, work situations, and leisure activities are all important in affecting how students perform in terms of the institutional goals associated with their education (Bhalalusesa, 2001; Grepperud, Rønning, \& Støkken, 2005; Kember, 1999; Taplin \& Jegede, 2001). This indicates that to be a student concerns much more than the individual's connections to an educational institution and to external learning resources. It is also important to consider how relation to the education system interacts with features in the student's daily social world. In various ways, the student's close associations will blend with the distant connections; the place of study, in the words of Massey (2005), becomes a place of throwntogetherness, where the local and the global meet.

A second consideration in the literature concerns materiality and the role of the technology 
present in the distributed students' daily environments (Kirkwood, 1991; 2001; Rye, 2007; 2008; Rye \& Zubaidah, 2008). Although it is obvious that Internet access is necessary for participation in online education, precisely how the social organisation of technology influences student participation in various forms of distributed education has not been extensively researched. Online education is not only about having access to the Internet, but also about how connection to the Internet is embedded in social relations in the students' daily life (Rye, 2007). As Beer (2005) observes, digital technologies are now deeply rooted in people's everyday life. It may thus be said that the use of the Internet in online education is not only a matter of digitalisation of education but also a digitalisation of everyday life. Beer (2009) takes this a step further by suggesting that the material feature of Web 2.0, which constitutes the backbone of online collaboration and participation, shapes our lives in a way which we only partly understand. He suggests that we should be aware of the new forms of power that interact in individuals' daily life through their participation in an apparently democratic and equal environment. Beer's argument indicates that power in global online education is as much about hegemonic power exercised through participation as it is about who is being excluded or included.

Handling diversity in cultural backgrounds to create a successful online learning environment is another issue discussed in the literature (Bates, 1999; Bates \& de los Santos, 1997; Little, Titarenko, \& Bergelson, 2005; Rasmussen, 2006; Williams et al., 2001). A focus in this literature has been on how to facilitate collaboration despite language barriers and across a variety of educational cultures. A significant finding of this research is that one consequence of bringing together students with a range of different cultural backgrounds is that they will gain useful experiences, beyond those gained from the formal curriculum. However, despite the potential benefits of multicultural online learning environments, Parrish and Linder-VanBerschot (2010) warn that cultural diversity brings with it implicit potential difficulties as the learning environment is likely to be culturally biased. Sadykova and Dautermann (2009) take this argument further, suggesting that although international online education is usually framed formally within a partner model between two or more specific cultures, the collaboration is typically not equal. They maintain that international online open and distance higher education entails a real potential for educational and cultural imperialism.

Regarding the role of the local context in global online education, it is also interesting to note, as suggested by Marginson (2006; 2008), that higher education is a global competitive field of education institutions with different and hierarchically ordered status. In this field, there is a flow of education from developed countries, particularly the USA, the UK, and Australia, to the developing world. In conventional education, this flow implies students travelling from developing countries to Europe, North America, and Australia. In online education, students retain their location. Ideas and learning resources, however, flow through digital networks from north to south. The result - following Bourdieu (1984; 1998), who understands education as a source of cultural capital - is a digital flow of power and domination where people and places in developing countries may become dominated by external powers. 
This approach to global online education reflects that of Castells (1996; 2009), who claims there has been a shift from "space of place" to the "space of flow"; the flow does not exist independently from place, or the local. As Massey (2005) says, most struggles around globalisation are inevitably local. Similarly, she argues that the local will never be only local, but that it is constituted through a set of interconnections that create a temporary constellation of being together, or what she calls throwntogetherness. This throwntogetherness will always demand negotiations, which will influence how places are related to other places, and thereby how the global is constituted.

In summary, the above discussion shows that students' local context has importance for their participation in online learning and for the educational outcome. At the same time, the local context of the students' daily life should be considered part of the educational space as it is constituted through the students' educational participation. This implies that when students meet online, their collaboration is at least partly a product of where they come from and how their study activities are embedded in their daily life. As also noted by Scarino, Crichton, and Woods (2007), international collaborative programmes will in some ways always have to confront a variety of social, political, and economic realities. Similarly, the students, in their daily lives, must negotiate with social and material connections to distant places. In the rest of this paper, we will discuss this from the perspective of students' experiences gained during their participation in an international, cross-cultural, distancelearning master's programme in development management.

\section{A Global Online Master's Programme in Development Management}

The master's programme discussed in this paper originated from a United Nations meeting on sustainable development held in Johannesburg in 2002, when an agreement was made to establish the Global Virtual University (GVU) as a branch of the United Nations University (UNU). The main actors in addition to UNU were the University of Agder (UiA, formerly Agder University College) in Norway and GRID-Arendal, a branch of the United Nations Development Programme (UNDP).

The first task of the GVU was to establish a set of master's programmes within the field of sustainable development. This Master's in Development Management (DM) became in 2005 the first programme offered. It was developed by UiA in cooperation with several other universities in countries in the global South. Altogether, 28 students from five countries were initially accepted to enrol in the programme: 14 from the North (Norway) and 14 from the South (Tanzania, Uganda, Ethiopia, and Ghana).The academics directly responsible for delivering the instruction were mainly drawn from the Norwegian university, with only one exception. Academics from developing countries were involved in course development and in face-to-face sessions with the students.

Although this programme was basically an online course, the structure can be considered a hybrid between conventional higher education and new alternative forms of flexible learning as several of the students, particularly the Norwegian students, regularly used a university campus as a place for study. It was intended that all the students should be offered 
study facilities on campus at one of the participating universities. However, in reality, campuses were not used much as the formal agreement with partner universities was not clearly communicated to most of the African students, while some of the Norwegian students lived too far from the UiA campus. Regardless of their place of study, all the students received their learning materials and instructions via the Internet.

The main instruction tool was a learning management system (LMS) facilitating file distribution, synchronous and asynchronous communication, and online group collaboration among the students, which was a core element of the programme. Almost every week one or more group assignments had to be completed by teams of students from different countries. The students also met face to face on two occasions: in Kristiansand, Norway, at the start of the programme, and a year later in Pretoria, South Africa. All the academic staff members were from UiA, except for two of the tutors responsible for handling the daily activities relating to the LMS and one with course responsibility. English, which was a second language for all the students and most of the staff, was used for instruction and communication.

The authors of this article have followed the development of this programme from the start because they are affiliated to the Norwegian university that took the initial initiative to this programme. The authors were, however, not directly involved in the development and implementation of the programme, apart from giving feedback from the research reported in this article, which was externally funded. The next section presents further methodological consideration regarding this research.

\section{The Current Study}

The data discussed in this paper is mainly drawn from semistructured qualitative interviews and observations of 14 students during their fourth semester of registration in the master's programme. The students were selected with reference to the principle of maximum variation (Patton, 2002). We looked for variations in gender, family obligations, and geographic locations. Four of the students interviewed lived in Ghana, four in Uganda, and six in Norway. The interviews were accompanied by an interview guide that focused on the students' experiences and their reflections on being students in a global programme. The students were asked to explain how they organised their study activities in the place where they lived or studied and how they viewed and organised their online activities. We also asked the students about what they considered the main challenges associated with participating in the programme and their expectations about the outcomes of participation in the programme. We also offered students an open-ended opportunity to comment about how they had experienced their participation in the programme. The students were all interviewed face to face at a location close to where they conducted their daily study activities. Each interview typically lasted for about an hour. Further elaboration of issues raised in the interview typically occurred in more informal ways when the researchers observed and explored the student's daily study environment. During data collection, the researchers took extensive interview notes as well as field notes. 
Another source of data was an online survey sent to all students just before they finished their programme of study. The questionnaire consisted of 26 items, covering six themes: background information, work situation, family situation, study situation, motivation for studying, and the use of information and communication technology. The questions were formulated to elicit factual answers as in "Have you studied previously in a foreign country?” Responses were organised through ticking answers at one of four levels of intensity, such as "very often," "sometimes," "seldom," or "not at all." The questionnaire ended with an open question, asking the students to give any extra information which they felt might be relevant to the questions they had answered. The LMS was used as the forum for distributing the questionnaire. In total, 20 of the 24 students responded. The survey also asked the students about how the study activities were embedded in their daily life and environment. The cross-cultural dimension was emphasised. The survey sample was limited in number, so its size did not allow any statistical analyses. The survey data are only used descriptively in this paper. However, the data made it possible to map the students' characteristics and their experiences.

When analysing the data, we used the qualitative interviews and observation as a primary source for meaningful categorisation, following the basic principles of grounded theory (Glaser \& Strauss, 1965). The survey data were used to highlight what we found in the qualitative data. It should be emphasised that we do not intend to use the survey data for any kind of generalisations. We do, however, hope that the discussion in this paper might identify valuable information and considerations to be taken into account when developing and running similar programmes.

\section{The Students' Global Collaboration}

The students in the Master's Programme in Development Management took part in an education programme that in many ways was global in its reach. After joining the programme, they continued to perform their existing roles in life; most of them continued living at the same place as before. However, becoming a student in the DM programme changed their life dramatically in some ways, especially for the African students, as will be shown later. In this section, we will discuss the students' participation in the DM programme in terms of three dimensions developed through analyses of the interviews and observation, which appeared significant for the students' participation in global online collaboration. These are the social, the material, and the cultural dimensions.

\section{The social dimension: Negotiation with family.}

The interviews indicated that most of the students had initially believed that as they were participating in a type of online distance education programme, it would be relatively easy to be a student, without it affecting their daily life too much. This preconception was described by a male Norwegian student:

My impression [before I started on the DM programme] was that distant education was an easy, low-status way of studying, for housewives. But in reality, this study is 
much more demanding than any other programme. The workload in the beginning was enormous, and it all felt a bit wild.

In the excerpt above, we see how after the first face-to-face meeting, this student revised his views about what it was like to be a student participating in the DM programme. All the other students interviewed, wherever they came from, expressed similar views. On their return home from the first face-to-face session, they began, in various ways, to reorganise their daily life so that they could continue to participate in the programme. This situation initially appeared similar for Norwegian and African students. All the students interviewed expressed that they felt overwhelmed at first. For the Africans, however, the situation was more critical because they felt the pressure more acutely in several respects, as will be discussed later.

The coursework was, however, not the only pressure the students encountered. After returning from the first face-to-face seminar, several of them started negotiations with members of their family regarding their daily tasks and social obligations. Such characteristics of flexible students have also been documented in other research (Bhalalusesa, 2001; Grepperud et al., 2005). The role of the student in the family appears to be very important to the students in the DM programme. Like many other students engaged in flexible learning, they had to find time for study activities and to negotiate their various family obligations (Kember 1999; Støkken et.al., 2007). This was despite the fact that the students were relatively young - most of them were aged between 20 and 30. For example, one of the female Norwegian students explained in the interview how she had adjusted her daily study routines to fit better with her partner's working hours. One of the African students reported that she had to leave her daughter with a close relative whenever she had to travel to the campus. She mostly went to the campus when her husband had a week off work and was able to stay at home. When her husband was working, she usually stayed at home and studied while simultaneously taking care of their child.

Although family was important to most of the students, the African students appeared to have wider family networks and more frequent interactions. This was, on the one hand, a potential resource when they were organising their daily routines so they could participate in online collaboration. On the other hand, it left them with obligations that made participation difficult. Interestingly, the survey data indicate that the African students' social life changed most after they embarked on the master's programme. They reported having lost friends, but they were also the ones who most frequently said they had made new friends through the study activities. When the students were asked "To what degree have your studies led to changes in your social life?" eight of the nine African students reported that their social life had changed to a high or very high extent, whereas only three of the Norwegians made that response.

From the interviews, it is apparent that differences in the students' relations with their families are largely associated with the difference between Norway and African countries regarding the position of education in society and the status of being a student. For most 
Africans, higher education is difficult to access; it makes a significant difference if one has a master's degree, both in terms of work opportunities and social status. This may indicate that the student role and its expected outcome constitute a resource in negotiations with family members and relatives for time to study and to participate in online collaboration. This is also seen in the survey data. When the students were asked "Why did you embark on this education?" seven of eight African students indicated that they "agree" or "very much agree" to the statement "To increase my wages." For the Norwegians the number was much smaller; three agreed the same way. The spread of responses to the statement "To obtain a higher degree of appreciation and recognition" was similar.

Several of the African students described how support received from their family was entirely to be expected as the programme was of great importance for the family as a whole. To be a student was thus a family project. Making an effort and some sacrifices so that a student could receive a degree would probably be well rewarded for everyone involved. In contrast, none of the Norwegian students described the master's degree as particularly special, but rather as just one of many possibilities in their individual career planning.

\section{The material dimension: Accessing the Internet.}

During the course of their study, some students experienced financial problems due to loss of employment or failure of their own small business. These problems particularly afflicted the African students. For these students, money was important not only for daily living but also for access to the Internet. As one of the female African students explained when asked about the most important challenges that confronted her as a student in the master's programme,

Access to the Internet. I mean, that is not easy in this city and it means everything for my study. If there is a day when I'm not online I lose a lot, and there is even more that I have to do when I'm online again. [I'm] often spending much time and money looking for a good place to study [on the Internet.]

The survey revealed that there were three main access points for using the Internet: home, campus, and Internet cafes. The only free solution, the campus, was used "sometimes" or "often" for accessing the Internet by 17 of the 19 students who responded on this question. However, several students explained in the interviews that their right of access to the facilities of the local university was unconfirmed or that they lived too far from campus for it to be useful. Consequently, home Internet connections or Internet cafés were commonly used alternatives, both of which cost money. It was necessary to cover these expenses if the students were to continue their studies; hence, they needed some kind of financial support. The Norwegian students said in the interviews that they were able to take advantage of financial support from the Norwegian educational loan fund, which also enabled them to buy their own computer. In contrast, the African students explained that they were not entitled to receive support from this institution; they were dependent on a monthly scholarship pro- 
vided by UiA through support from the Norwegian Aid Agency (NORAD). In addition, each of the African students was entitled to borrow a laptop for use during their period of study.

However, using laptops for Internet-based collaboration with students in other places was not easy for most of the African students. Large parts of Africa have a generally weak technological infrastructure; what is taken for granted in most European countries may prove a great challenge in many areas of Africa. For instance, the instability of the electricity supply was frequently demonstrated during our observations of the African students' environment. In the interviews, the African students frequently mentioned this as a major challenge that created serious problems for them as the study programme required much online study time. When the power supply was down, so too were the servers, and the students had to start searching for an Internet connection at a place that still had electricity or that was supplied by a generator. In Kampala, for example, the solution was often an Internet café in the city as the campus there was poorly equipped with generators.

In contrast, for the Norwegian students interviewed, the material and financial problems involved in using communications technology were not considered a major issue. They had good access to broadband connections at home or on campus; the Internet provision and electricity system were stable and reliable. The Norwegian students explained that their main problem regarding technical issues was that in their joint projects their progress was constrained by their African partners' difficulties and delays associated with IT connectivity. This could have been a serious problem because the course activities were tightly scheduled and a delay by a student in one place easily created problems for students in other places. The network of students as a whole depended on each of its members to complete the tasks assigned by the educators. When the server was down in Kampala, the students lost contact, which in turn also affected fellow students in other African countries and in Norway.

The quality of infrastructure was also reflected in differences between African and Norwegian students regarding previous experience and skills in using the technology. This was evident from the data in the survey where only one of the African students reported they had "much experience" in the use of computers and the Internet before their enrolment in the programme. This is also evident in the interviews. Although the survey showed that only a few of the Norwegian students had experience of online learning programmes, they had all in some way or other used the Internet in their previous education. The Norwegian students also confirmed that they were familiar with the use of the LMS; some of them had experience of a system identical to the one used in the DM programme. The University of Agder appeared to be aware of the potential differences in computer literacy: at the first face-to-face meeting, much time was spent ensuring that all of the students knew enough about using the LMS to be able to participate in online course work. Several of the African students said in their interview that this introduction, before the start of online collaboration, had been essential in enabling them to participate in the online discussions. Still, several of them also expressed that they would have liked the session to have been longer and more detailed. 


\section{The cultural dimension: The meaning of education.}

Collaboration in the DM programme proved a challenge to the students because of cultural differences within the group. During the first introduction in Norway, the students confronted for the first time the cultural differences that would later accompany them throughout the programme to a greater or lesser extent. One of the African male students described his experiences of the first face-to-face session as follows:

It was remarkable to see how the Norwegian students criticised the Norwegian professors and addressed them by their first names. In [my country] we are accustomed to it being more important to reproduce what the professors say, and not to criticize them. We show them respect.

The above excerpt illustrates how the African students had observed, with some surprise, how the Norwegian students communicated with the academic staff and their fellow students in a very direct and critical way. From the African students' point of view this was, as several of them remarked in their interview, somewhat impolite behaviour, which was a new experience for them to witness within an academic setting. They were uncertain about how to handle such situations. At home, as indicated by the student quoted above, they were accustomed to showing respect to their professors, and they did not see it as their right to question them.

This respect for authority, the students told us, in many ways characterised their previous educational experiences and the expectations placed upon them as students in their home country. Several of the African students explained that they were used to repetition and reproduction of knowledge delivered in lectures and in written materials. Rather than taking their previous experience online, they had to revise their understanding of what it meant to be a student. Some said in the interviews that this was not easy as respect for authority is a deep-rooted value in most African societies. Thus, the first months of global online collaboration was for many of the African students characterised by observation and by wondering about how they might be able to function as a real member of the online community. In the words of one of the male African students:

To begin with, I only read [on the Internet forum] and did not understand how I could become part of it. ... I sneaked around and only took a peek at what the others [the Norwegians] did. But then I received a communication from one of the supervisors who both encouraged and required me to participate. I tried, and received a positive response from [one of the professors]. This was an important turning point. I understood then that I too had something to contribute. 
Like this student, several other African students only accessed the Internet when it was absolutely necessary to maintain their status as students. It took them time to release themselves from their previous student role. This somewhat difficult start may, ironically, explain why the African students interviewed declared themselves more satisfied with the experience of participation than did the Norwegians. A difficult start meant that they eventually had a good feeling of progress. Similarly, the African students were more likely to feel that they had developed as students. Although all of the students who answered the survey responded that they agreed to the utterance "I have become a more clever student," eight of the nine African students said that they "very much agree" with the statement while only two of the Norwegians did.

At the beginning of the programme, the Norwegians students behaved as they were accustomed to do, namely to be direct and critical, both in relation to the staff and toward their fellow students. Still, to some extent this was also a new way of studying for the Norwegian students. In the interviews they said that the volume of the workload and the expectation of regular delivery of assignments were new experiences. However, they were familiar with the basic elements of the programme and could readily understand the lecturers' expectations. In a way, they just had to do more of what they had done in their earlier educational practice, and they had already been socialised into the academic tradition in which the master's program was embedded.

When it came to interaction with their fellow students from Africa, the Norwegian students were more uncertain. They experienced that the African students were more reserved and that it was not easy to engage in academic discussions with them. The lack of response from fellow students left them feeling frustrated. This 'problem,' however, seemed to be at least partly resolved during the course of the programme. The Norwegian students changed their way of communication, becoming less direct and critical, at least regarding their peers, while the African students learned some of the new academic codes and became more confident, gradually becoming active members of the online community. Both groups had to adjust to their role as students in an online classroom.

\section{Concluding Discussion}

Anderson (2006) concludes that students' relations with other students as well as with their instructors are critical for their participation in online group discussions. At the same time, he emphasises that each of these actors have their own histories, culture, and structures located outside the online activities. He also argues that the wider social context confronting the different individual parties has to be kept in mind when we attempt to understand what is going on in online forums. The present paper supports this argument by showing how local arrangements were crucial for the outcome of the students' participation in the DM programme. Following Merriam (2001), the students we interviewed described the global online education programme as a system containing several local learning environments that were interconnected. From each location, the students brought with them constraints and opportunities into the global arena, which according to Castells $(1996 ; 2009)$ can be 
considered a social network distributed in space rather than a virtual reality.

It should, however, be noted that the assets and experiences that different students bring into the network are not equal, and the resources for negotiating with others regarding the time and space for performing and developing their student role are not the same (Anderson, 2006). In the DM programme the African students had fewer material resources available to them, compared to the Norwegians. Differences in educational experiences before their participation in the global online programme also favoured the Norwegian students as the programme was grounded in an educational culture typically found in most Western countries, including Norway.

To some extent, the African students were also more constrained by social relations in daily life because they had more social obligations than the Norwegian students did. However, these relations also represented resources that supported their participation in the global network, for example by taking over some of the caring duties that the students had before they became students. Nevertheless, altogether the African students experienced multiple constraints affecting their participation in the programme, due to technical problems, financial problems, and unfamiliar academic conventions. This was especially visible in the beginning of the programme. In contrast, the Norwegians largely continued in their normal role as Norwegian students. An important factor in enabling the African students to continue their studies, despite the problems they experienced, appears to have been the possibility of mobilising local social resources, together with their willingness to struggle to maintain their position as students. To some extent, the African students' high level of motivation seems to have compensated for the lack of resources.

This high motivation appears to be associated with the opportunity to participate in an educational programme different to the educational culture with which they were familiar. The changes in the manner of communication between the students in the group illustrate this point. For the Norwegian students, the adjustment in the way of communicating with the African students was mainly a practical issue that never threatened their basic conception of being a student. It was necessary for collaboration within a system that they already knew. Experience gained from cross-cultural collaboration was considered an additional benefit of the course. For the African students, on the other hand, the change in communication was experienced as a totally new way of understanding education, which was related to a main motivation for being a student in such a programme. They were eager to adapt to the new educational culture and saw this as a key outcome of participation in the programme.

It should, however, be noticed that for the African students, in the process of transforming high motivation into online participation, the role of the educators appears to have been of great importance. For instance, they had resources available for empowering the students by making available the technology necessary for them to become members of the online student network. Kirkwood (2001) suggests that e-education will always be most beneficial for those who are already well equipped with educational resources. In this instance, the Norwegian students expressed that they appreciated the DM programme, but not to the same extent as most of the African students. To some extent, the experiences from the DM 
programme support the proposition that those who can bring the most resources with them into an online cross-cultural learning environment are those who will gain most from the process, at least regarding the formal curriculum. The African students may, however, have a greater benefit from the study if a broader definition of benefit is applied.

As the students' participation depends on resources accessible in their daily surroundings as well as local arrangements, it may be claimed that global online education largely reflects the localities where students and educators live their daily lives, have experiences, and acquire history. This form of education enables distant people and places to interact. However, rather than creating a new space of equality, the differences between local contexts, and the inequalities between participants, are exposed in such an online environment. Even if educators have limited opportunity to influence the student's daily context, our experience is that educators can make significant contributions towards making this environment function as a good learning environment. However, this requires skilful handling of the differences in resources so that students participating in an international programme can benefit. A first and very important step in this direction is to recognise that global online collaboration typically reflects inequality rather than being a space of equal collaboration.

The next step is to determine how to address this inequality. Students' comments in the current study indicate that educators should not necessarily seek to remove unequal preconditions by adjusting the educational structure and culture, making them more closely resemble what is familiar to students from developing countries. If this happens, the students from developing countries may miss one of the main learning outcomes of their participation. Rather, the educators should support students from developing countries when they collaborate in global networks. This might be done by paying extra attention to the process of learning and adapting to the dominant language for global collaboration, as well as by providing practical and material support for accessing the digital networks. If this happens, students from developing countries are given access to important resources that will enable them to compete at an international level. However, there is also a real danger of putting students from developing countries into a role as subordinates in a colonial system, in which they effectively lose out, because they will always be the ones who have to adapt. 


\section{References}

Anderson, B. (2006). Writing power into online discussion. Computers and Composition, $23,108-124$.

Bates, A. W. (1999). Cultural and ethical issues in international distance education. Paper at the Engaging Partnership-Collaboration and partnership in Distance Education UBC/CREAD Conference.

Bates, A. W., \& de los Santos, J.G.E. (1997). Crossing boundaries: Making global education a reality. Journal of Distance Education, 11(1), 49-66.

Beer, B. (2005). Sooner or later we will melt together: Framing the digital in the everyday. First Monday, 10(8).

Beer, D. (2009). Power through the algoritm? Particatory web culture and the technological unconscious. New Media and Society, 11(6), 985-1002.

Bhalalusesa, E. (2001). Supporting women distance learners in Tanzania. Open Learning, $16(2), 155^{-168 .}$

Bourdieu, P. (1984). Distinction: A social critique of the judgment of taste. London: Routledge \& Kegan Paul.

Bourdieu, P. (1998). On television and journalism. London: Pluto Press.

Castells, M. (1996). The rise of the network society. Cambridge, MA: Blackwell.

Castells, M. (2001). The Internet galaxy reflections on the Internet, business, and society. Oxford: Oxford University Press.

Castells, M (2009). Communication power. Oxford: Oxford University Press.

Evans, T. (1995). Globalisation, post-Fordism and open and distance education. Distance Education, 16(2), 256-269.

Grepperud, G., Rønning, W. M., \& Støkken, A. M. (2005). Adult student life and learning. Lifelong Learning in Europe, 9(1), 12-17.

Kember, D. (1999). Integrating part-time study with family, work and social obligations. Studies in Higher Education, 24(1), 109-124.

Kirkwood, A. (1991). Access to computing for home-based students. Studies in Higher Education, 16(2), 199-208.

Kirkwood, A. (2001). Shanty towns around the global village? Reducing distance, but widening gaps with ICT. Education, Communication \& Information, 1(2), 213-228. 
Little, C. B., Titarenko, L., \& Bergelson, M. (2005). Creating a successful international distance learning classroom. Teaching Sociology, 33, 355-370.

Marginson, S. (2006). Dynamics of national and global competition in higher education. Higher Education, 52(1), 1-39.

Marginson, S. (2008). Global field and global imagining: Bourdieu and worldwide higher education. British Journal of Sociology of Education, 29(3), 303-315.

Massey, D. (1994). Space, place and gender. Cambridge: Polity Press.

Massey, (2005). For space. London: Sage Publications.

Merriam, S. B. (2001). Andragogy and self-directed learning: Pillars of adult learning theory. In S. B. Merriam (Ed.), The new update on adult learning theory (pp. 3-14). San Francisco: Jossey-Bass.

McLuhan, M. (1962). The Gutenberg galaxy. Toronto: University of Toronto Press.

Parrish, P., \& Linder-VanBerschot (2010). Cultural dimensions of learning: Addressing the challenges of multicultural instruction. International Review of Research in Open and Distance Learning, 11(2).

Perraton, H. (2000). Open and distance learning in the developing world. London: Routledge.

Rasmussen, K. L. (2006). It's a new world: Multicultralism in a virtual environment. Distance Education, 27(2), 256-278.

Rumble, G. (2001). Just how relevant is e-education to global educational needs? Open Learning, 16(3), 223-232.

Rye, S. A. (2007). Flexibility, technology, and the day life practices of distance students living beyond the digital mainstream. Geoforum, 38, 1028-1039.

Rye, S. A. (2008). Dimension of flexibility: Students, communication technology and distributed education. Seminar.net Media Technology and Life Long Learning, 4(1).

Rye, S.A., \& I. Zubaidah. (2008): Distance education and the complexity of accessing the Internet. Open Learning, 23(2), 95-102.

Sadykova, G., \& J. Dautermann (2009). Crossing cultures and borders in international online distance higher education. Journal of Asynchronous Networks, 13(2), 89-114.

Scarino, A., Crichton, J., \& Woods, M. (2007). The role of language and culture in open learning in international collaborative programs. Open Learning, 22(3), 219-233. 
Støkken, A. M., Lorentsen, A., Niemann, K., \& Sorensen, L. (2007). Husholdet - en arena for samspill og forhandling. In V. M. Rønning (Ed.), Den usynlige student (pp. 81 - 101). Trondheim: Tapir.

Taplin, M., \& Jegede, O. (2001). Gender differences in factors influencing achievement of distance education students. Open Learning, 16(2), 133-154.

Tiffin, J., \& Rajasingham, L. (2003). The global virtual university. London: Routledge Falmer.

Williams, S. W., Watkins, K., Daley, B., Courtenay, B., Davis, M., \& Dymock, D. (2001). Facilitating cross-cultural online discussion groups: Implications for practice. Distance Education, 22(1), 151-167.

\section{Athabasca University $\mathbf{\Omega}$}

(2) (1) 
THE INTERNATIONAL

REVIEW OF RESEARCH IN

OPEN AND DISTANCE LEARNING

\section{Challenges of Virtual and Open Distance Science Teacher Education in Zimbabwe}
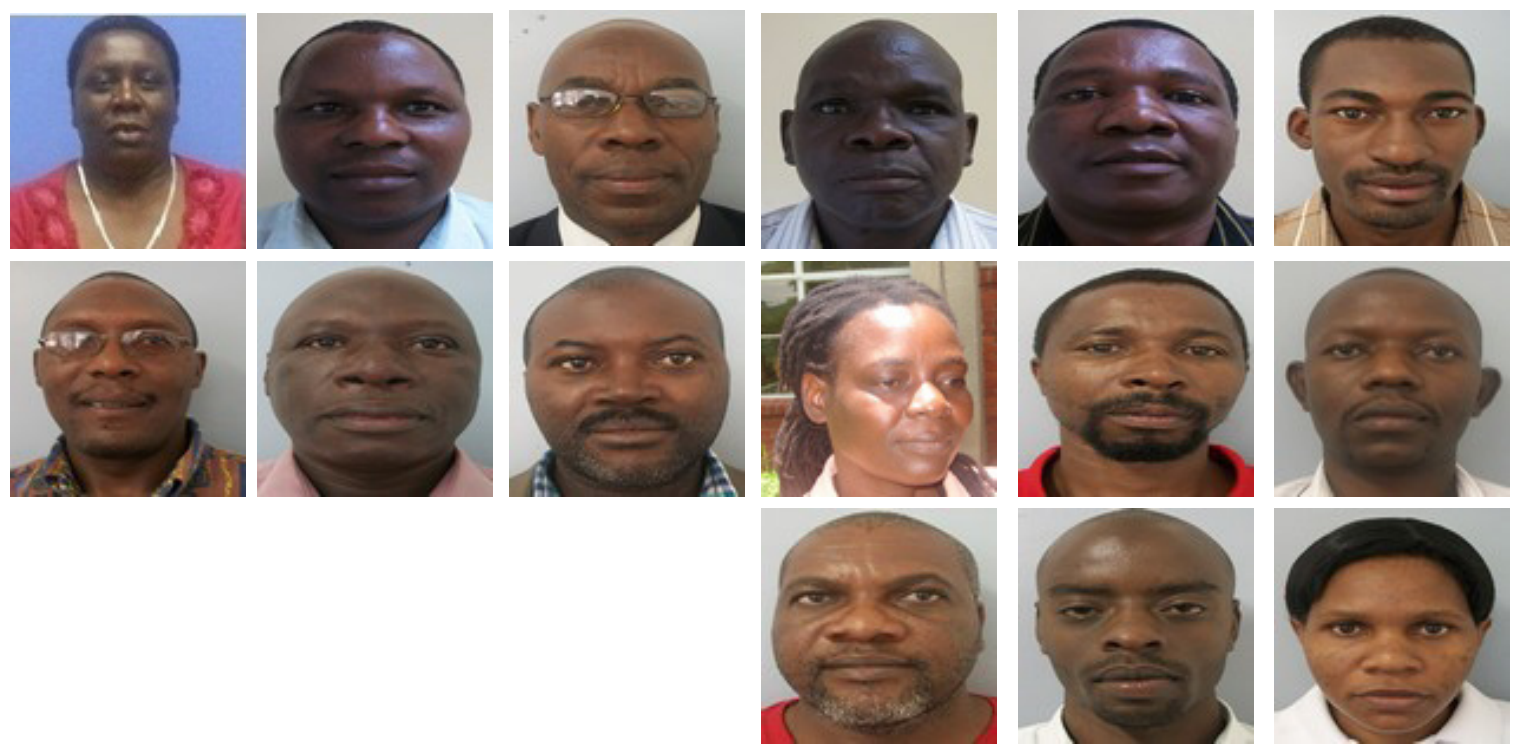

Vongai Mpofu, Tendai Samukange, Lovemore M Kusure, Tinoidzwa M Zinyandu, Clever Denhere, Nyakotyo Huggins, Chingombe Wiseman, Shakespear Ndlovu, Renias Chiveya, Monica Matavire, Leckson Mukavhi, Isaac Gwizangwe, Elliot Magombe, Munyaradzi Magomelo, and Fungai Sithole Bindura University of Science Education (BUSE), Zimbabwe

\section{Abstract}

This paper reports on a study of the implementation of science teacher education through virtual and open distance learning in the Mashonaland Central Province, Zimbabwe. The study provides insight into challenges faced by students and lecturers on inception of the program at four centres. Data was collected from completed evaluation survey forms of forty-two lecturers who were directly involved at the launch of the program and in-depth interviews. Qualitative data analysis revealed that the programme faces potential threat from centre-, institution-, lecturer-, and student-related factors. These include limited resources, large classes, inadequate expertise in open and distance education, inappropriate science teacher education qualifications, implementer conflict of interest in program participation, students' low self-esteem, lack of awareness of quality parameters of delivery systems among staff, and lack of standard criteria to measure the quality of services. The paper recommends that issues raised be addressed in order to produce quality teachers.

Keywords: Open distance learning; lecturer; science education; virtual learning 


\section{Background}

The Millennium Development Goal (MDG) of Education for All (EFA) is clear testimony that education is recognized as a key development concern. However, the realisation of the EFA goal is threatened by several challenges faced by the education sectors across the globe. One of the major challenges facing the education sector is the severe shortage of science teachers, particularly in developing countries. UNESCO (2007) estimated that between 15 and 35 million new teachers are required globally by 2015; 25\% of this global teacher demand is needed in Africa. This high teacher demand has been created mainly by HIV/AIDs attrition and out-of profession teacher migration (UNESCO, 2008).

In Zimbabwe, the economic meltdown of the past decade has triggered one of the worst episodes of technical skills drainage (Chetsanga, 2001; Nyathi, 2010). Science teachers mainly have migrated to other countries in great numbers in search of better working conditions. This has exacerbated the major obstacle in science education in Africa and particularly Zimbabwe in an era when it has been recognized that teacher education lies at the heart of all development (Teferra \& Skauge, n.d., cited in Thakrar, Zinn, \& Wolfenden, 2009). The need to train large numbers of science teachers in Zimbabwe has never been more critical than now. In Zimbabwe this challenge is amplified by the significant numbers of untrained science teachers currently deployed in schools as relief teachers. These relief teachers need access to professional training opportunities urgently.

Bindura University of Science Education (BUSE) is the sole institution in Zimbabwe whose name carries the mandate of science education. It was established as Bindura University College of Science Education (BUCSE) in 1996 to replace the then just ended ZimbabweCuba science teacher training programme. Since then, the University enjoyed a steady increase in the science student teacher enrolment up to 2003. Thereafter, the science student teacher enrolment went down drastically to unsustainable levels by 2009. This scenario has threatened the University's fulfilment of its mandate. Upon recognising that the large numbers of trained science teachers the nation currently needs cannot be achieved through traditional conventional training, BUSE launched an institutionally born intervention project named Virtual and Open Distance Learning (VODL) in Mashonaland Central Province. This national programme was initially started in August 2010 at four centres covering five districts of Mashonaland Central Province.

The VODL programme goal is to train postsecondary school students and Certificate/Diploma in Education holders to attain diplomas or degrees in Science Education. The students recruited in the VODL programme include practicing science teachers (relief and nongraduate) and nonpractising people with prerequisite qualifications who had no access to university education. Deterrents to university teacher education include high entry requirements and high cost of education in an era when Zimbabwe has undergone difficult economic times for more than a decade. The project has been initiated at a time when every nation is in pursuit of EFA (Thakrar et. al, 2009), making it quite significant. The VODL programme is guided by the assumptions of taking university education to the doorstep of the student at an affordable cost and factoring in the bridging aspect to students who meet 
the minimum entry requirements for our degree programmes but without ordinary-level mathematics.

\section{Statement of the Problem}

VODL is a research and development based project designed to meet the high demand of science teachers in Zimbabwe by extending access to science teacher education. Although there have been previous studies on distance education in Zimbabwe and other nations, the unique focus of the VODL project on science teachers calls for empirical evidence that explores the perceptions of students and lecturers of the programme. The study is guided by the following three questions:

1. What are the challenges of the VODL project?

2. What are the sources of these challenges?

3. How can these challenges be overcome?

\section{Significance of the Problem}

The findings of the study are important to BUSE as the proprietor of the programme, in view of Kirk and Dembélé's (2007) caution that short-term responses to teacher shortages can ensure that every classroom has a teacher but raise concerns about their impact on the quality of teaching and learning. Therefore, the study sought to inform programme stakeholders on challenges to expect and enable empirically informed decisions on implementation strategies. Furthermore, the study would enrich the existing theory and knowledge base on distance learning, and in particular contribute towards the literature base on open and distance science teacher education in Zimbabwe and the world at large.

\section{Research Methodology}

\section{Context of Study}

The study was conducted in August 2010 at the four centres during the three-week residential session of the programme launch. The period was university vacation and school holiday. Three of the centres are high schools established as district VODL centres. The other centre is a youth training institution. As a BUSE initiative, the programmes and courses offered are under the auspices of the Faculty of Science Education (FSE). Centre coordinators are responsible for centre administration and report to the programme coordinator. Teaching services were offered by lecturers from the FSE and the Faculty of Agriculture and Environment Science (FAES) at BUSE. A cohort of 1,296 students pioneered in the programme. During semester one of block one (S1B1) the students attended a three-week learner support residential session. The balance of the semester was to be covered in the next school holiday block referred to as S1B2 in December 2010. During the residential session, students attended lectures and consulted their lecturers from Monday to Saturday. 
Students did assignments and in-class tests which contribute to their coursework. At the end of residential session they received assignments to work on during school time.

\section{Research Design}

A mixed methodology research paradigm was adopted in this study for complementary purposes (Gay \& Airasian, 2000) and to capture the different facets of the study (Sandelowski, 2000).

\section{Participants}

All 42 lecturers who were involved in the teaching of the residential session participated in this study.

\section{Data Collection}

Paper and pencil survey, interviews, and document analysis were the different methods triangulated in the collection of data. This was done in line with Creswell's (2007) contention that triangulation is important because the methods in data collection complement each other in such a way that overlapping and different facets of the phenomena under study emerge. This ensures high probability of the trustworthiness of the findings.

A total of 42 participants completed self-designed and administered survey forms in the third week of the residential session. The survey instrument consisted of semistructured questions. The participants were asked to complete the survey and their feedback was guaranteed confidentiality.

Open-ended interviews with six identified key informants were conducted. The open nature of the interviews allowed probing and assessment of the participants' views and feelings. The duration for the interviews was between 20 to 30 minutes. Interview discussions were tape-recorded to capture the audio discussions. These allowed the researcher to gain indepth meanings from the nonverbal cues which were captured by means of field notes.

Documents analysed included the University Act, programme regulations, programme minutes, supervision reports, centre reports, teaching timetable, and lecturers' and students' records.

\section{Data Analysis and Presentation}

The data from the survey was analysed using Statistical Package for Social Sciences SPSS version 17. Interviews were transcribed and the resultant data was content analysed to describe and interpret their meaning and then organized into emerging themes (Walliman \& Buckler, 2008). All data from the documents, interviewees, and survey respondents were compared, integrated, and pooled together to address the research questions. The findings are presented in a descriptive form supported by some descriptive statistics and direct extracts from field notes and interview transcripts. The data is presented in the form of tables, charts, and graphs. 


\section{Findings}

The findings of this study revealed the following challenges: centre-, institution-, staff- and student-related.

\section{Centre Challenges}

The greater parts of Mashonaland Central Province are rural areas. Three of the VODL centres were connected to electricity, but the power was not always available 24 hours per day, due to power outages. The centres had electric generators but the centre budgets could not sustain the expensive diesel fuel to power the machines throughout the working day. The fourth centre had a vandalised electrical grid. However, this centre was able to run its generator for the three-week residential session daily. The problem of electricity created problems of integration of ICT tools (e-mail, fax, Internet, television, radio, etc.) into the VODL programme. The basic communication infrastructure to enable VODL to make use of these technologies is not in place at the centres.

The residential session centres currently lack enough laboratory space to cope with the demand of practical subject training. Only one centre (25\%) has physics, chemistry, computer science, and biology laboratories. These laboratories have a carrying capacity of $15-25$ students per session. Though the buildings are in place, they lack equipment, apparatus, and consumables for practicals. Limited electricity supply meant that teaching and learning was done without the support of ICT most of the time. Poor physical infrastructure and limited resources promoted the use of traditional teaching approaches. No practical work was conducted in all courses, except a practical component for computer science at one centre during the first residential session, divorcing theory from practice. The first residential session promoted procedural learning rather than conceptual learning. Other resources which were in short supply included reading material, stationery, and furniture.

The challenge of resource limitation was summed up by one of the interviewees who lamented that,

We were excited about the programme. However, our first residential session had lots of things need to be taken into consideration for the program to be a success. These include lack of resources for practical work, limited teaching resources like stationery, reading material for students and furniture. Imagine, some of the classrooms we used as lecture rooms did not even have boards to write on. Library facilities had limited text books and some of them irrelevant. I had no preparation time as I was loaded during the day and no electricity for lighting at night.

\section{Institution Challenges}

The majority (93.3\%) of lecturers cited that too many courses were offered during S1B1. Di- 
ploma students were enrolled in the following options: Biology, Geography and Agriculture (BGA), Mathematics, Physics and Computer Science (MPCs) and then Chemistry, Physics and Biology (CPB). All students registered for education courses which included educational foundations (Philosophy, Sociology, and Psychology) and Communications. Teaching practice referred to at this institution as Applied Science Education (ASE) was to be introduced. Candidates without an ordinary level mathematics pass were offered a bridging course. This translated to a diploma student doing a total of nine courses without a bridging course and ten courses if a mathematics bridging course was included (six courses per combination, namely three education courses and one ordinary-level mathematics bridging course).

All participants (100.0\%) concurred that this residential session was short, packed with a congested timetable which ran from 7:00 a.m. to 5:30 p.m. from Monday through Saturday. There was a half hour and a one hour tea and lunch break per day. The major challenge for the lecturers was overload with some teaching six hours per day for six days a week. The centres were paired to enable the teaching of same courses at two centres for oneand-a-half weeks per centre and exchange thereafter. For example, for diploma courses in chemistry at two paired centres, General Chemistry was taught at one centre, whilst at the centre paired to it, Laboratory Techniques was being taught. This caused comprehension problems for the students who started with a higher level course. On average $35 \%$ of the theory course content was covered during the $\mathrm{S} 1 \mathrm{~B} 1$ residential session as reported by the majority $(67.7 \%)$ of the lecturers. No planning for practical work was done as reflected by the absence of practical work slots on the timetable and as a result no practical work was done.

The VODL curriculum (courses on offer) was adopted from the conventional programmes and courses. This means that the curriculum was not adapted to the needs of the programme.

One interviewee offered the following reflection:

The departmental individualistic approach to teaching made it difficult for students to understand abstract things, especially considering their background. However, this can easily be overcome if we harmonize courses where possible. Those that communicate (courses that are related) should be combined at the same time. In some cases Diploma courses we offered are conventional undergraduate courses.

The implication is that students were challenged by cognitive overload which refers to "mental blackout" as a result of learning new, varied, and complex content, which challenges conceptual understanding of the material presented (Tyler-Smith, 2006). Furthermore, students had very little time to access library services during the day. During the night students had no time to access the library due to power outages. 


\section{Staff Challenges}

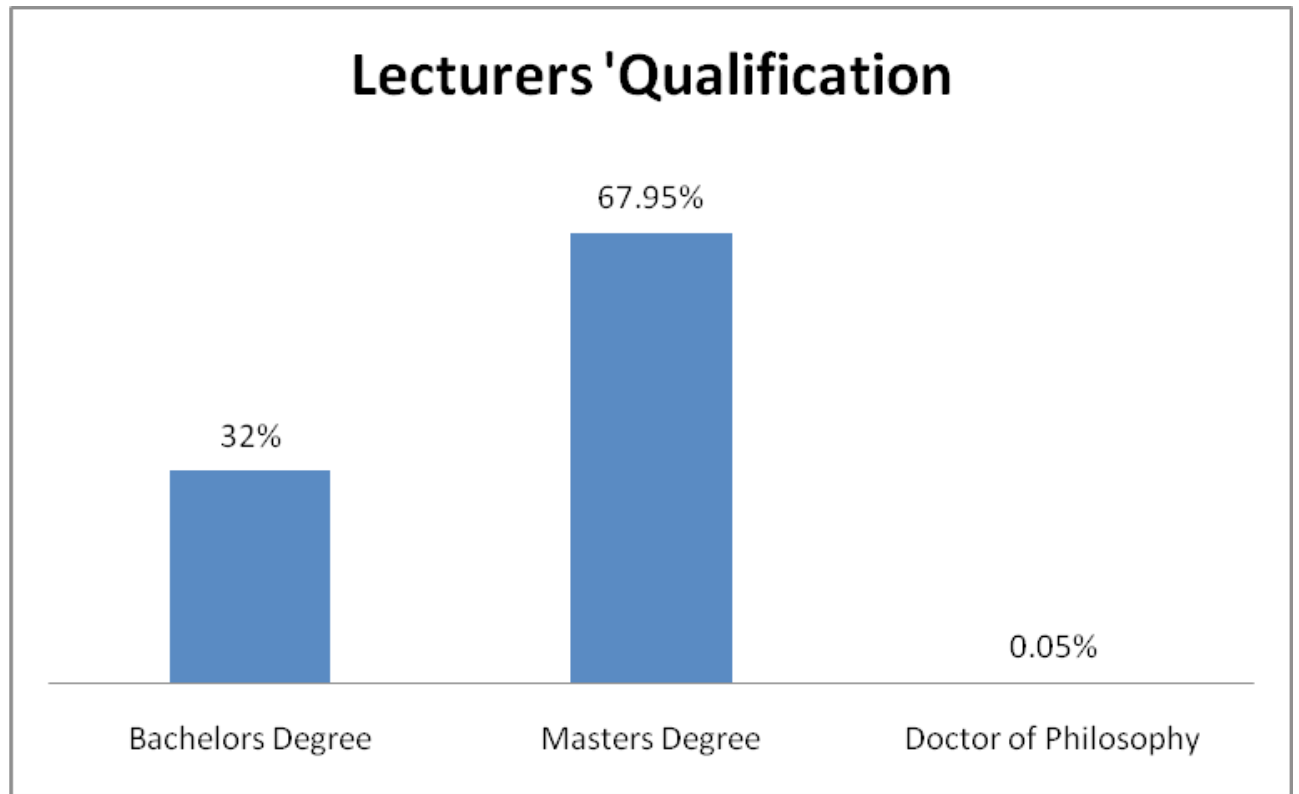

Figure 1. Showing lecturers' qualifications.

The majority (90.0\%) of lecturers who participated in the S1B1 are BUSE FSE employees, whilst the remaining proportion was engaged on a part-time basis. Approximately, $32 \%$ of the first residential session lecturers are first-degree holders in pursuit of master's degree qualifications, about $67.95 \%$ have master's degrees, and a significantly smaller number (0.05\%) are $\mathrm{PhD}$ holders.

\section{Evaluation of Teaching Areas}

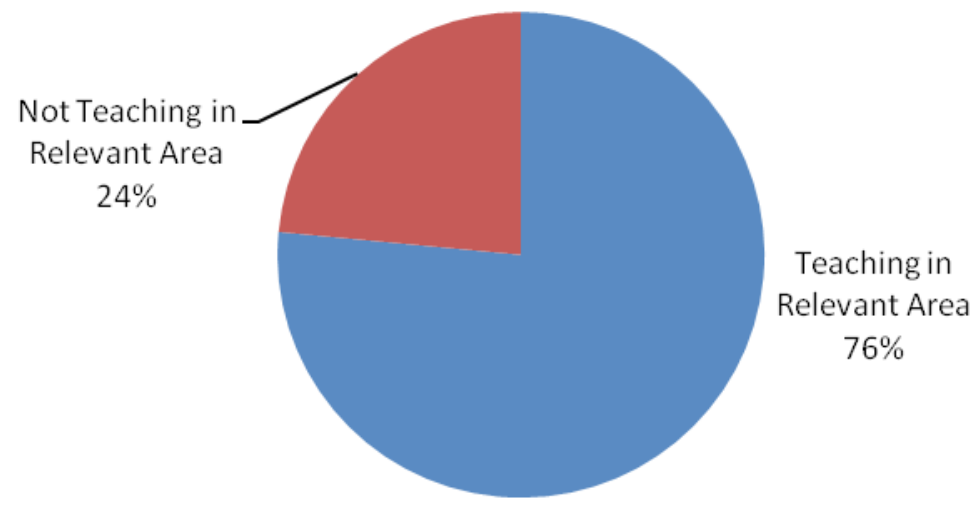

Figure 2. Showing an evaluation of teaching areas. 
Quite a significant proportion of lecturers (23.5\%) was teaching in areas not quite relevant to their area of specialisation. In addition, all the lecturers (100.0\%) have a full load of conventional teaching. The foresaid leads to underperformance of duties as a result of time constraints and course knowledge limitations.

Thirty-two percent of lecturers have not been trained as science educators. This insufficiency was reflected in the lack of quality instruction as reported by one interviewee:

Some lecturers had content depth and coverage problems especially to teaching diploma students. Some of the students have already said gejo ngaridzike (meaning teaching content should be adjusted to match the students' learning styles and the study level).

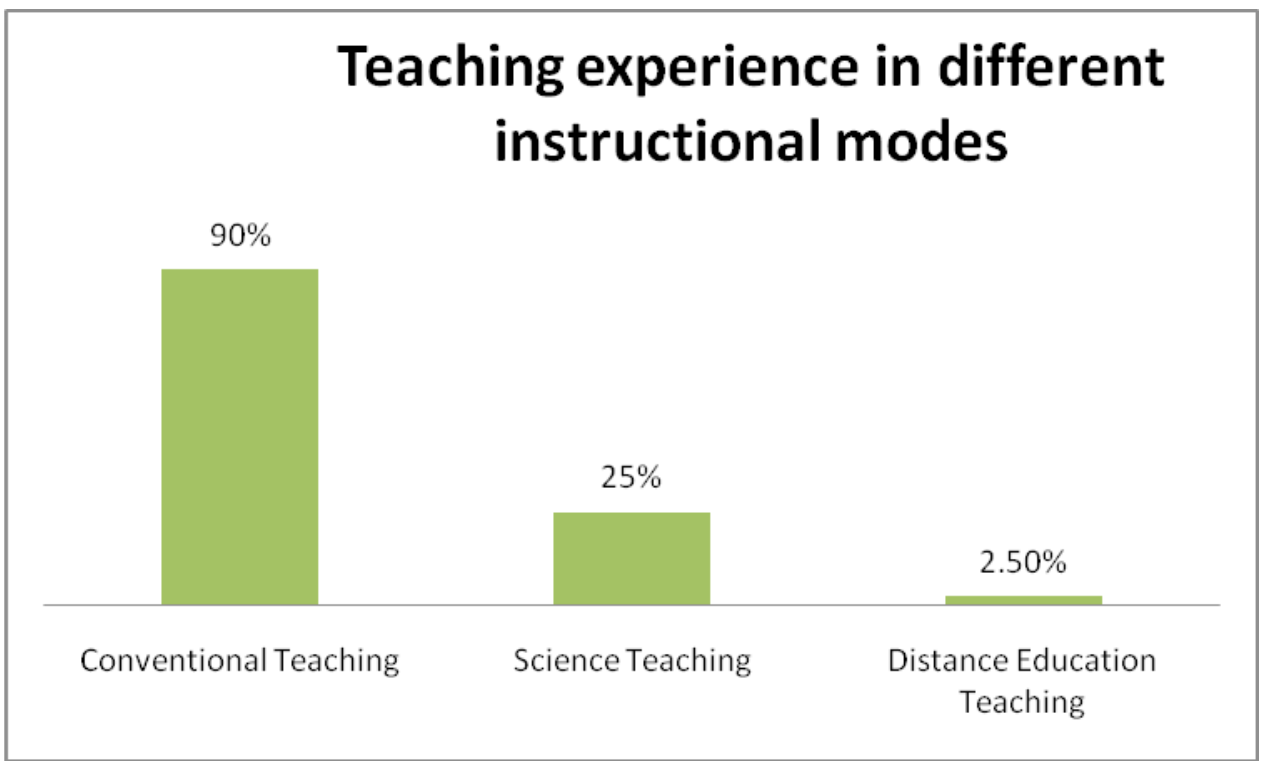

Figure 3. Showing the teaching experience of the lecturers in different instructional modes.

Most of the lecturers (90.0\%) have 1-3 years university conventional teaching and 97.5\% have no experience in distance education. Seventy-five percent of those who lectured educational foundation courses have no science-related background. Insufficient university conventional teaching experience, limited pedagogical knowledge, and limited science qualification promoted the use of traditional classroom practices which are not appropriate for quality learning in the programme. This may create frustrations in students and eventually lead them to drop out.

The nation's current economic situation and its effects on most Zimbabweans have made the cost of living very high. University lecturers in Zimbabwe earn far below their counterparts in Southern African Development Community nations' universities. The regional salary levels which are notably above the average regional poverty datum level motivate them or raise their professional dedication. It is likely that most of the lecturers have joined 
lectureship in order to get better pay. More so, the participation in the VODL programme, for the majority, was dysfunctionally construed as an opportunity to make money. One of the interviewees is quoted as saying,

The lecturers were excited, especially with the idea of getting an extra allowance. U-um it's really just disappointing that some of them were not content with the allowance. They sold notes to the students. I don't know what is wrong. Why could they not bear with the economic situation of the VODL students?

The other challenge associated with the aforementioned drawback is the absence of programme quality assurance benchmarks and systems.

\section{Student Challenges}

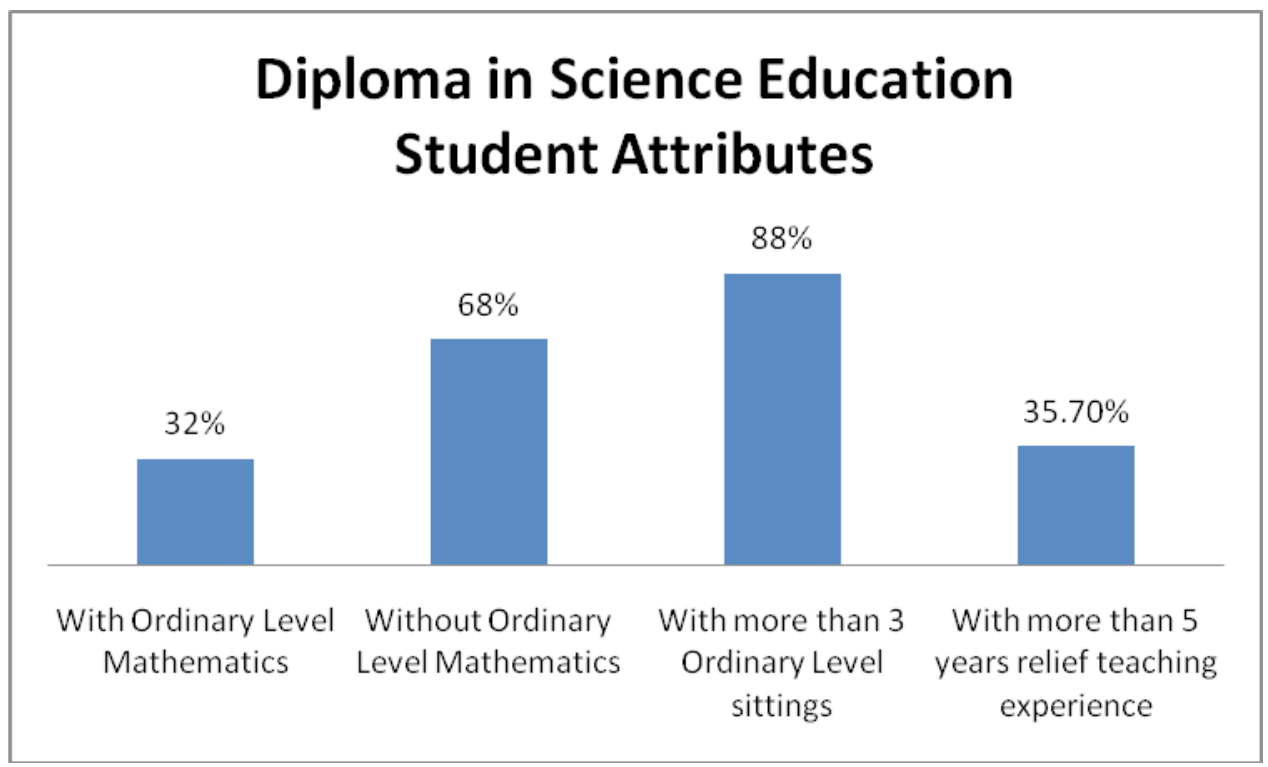

Figure 4. Showing Diploma in Science Education students' attributes.

The majority (76.5\%) of the students are enrolled in the Diploma in Science Education (DipScED) VODL programme. The educational background of DipScED students is a minimum of five O-level passes including a science subject and English language. Sixty-eight percent of these students do not have a pass in O-level mathematics and are doing it as a bridging course. Most (88 \%) of the DipScED students have more than three O-level sittings. Such an educational background results in feelings of low self-efficacy, stress, and cognitive overload, especially where complex and diversified content is presented within a short space of time. Such effects are worse in learners at advanced ages, which ranged from 23 - 54 years with several of them having a primary-level relief teaching experience; $35.7 \%$ had above five years of relief teaching experience. This observation is substantiated by what one of the interviewees said: 
The background of most students contributed much to lapses and time wastage. Their academic level and stamina required caused us to go down to low levels and then take them up gradually. But this was impossible considering the amount of content we needed to cover during the residential session.

The Bachelor of Science in Education (BScEd) students (23.5\%) have better O-level results and higher qualifications, with either two subjects at Advanced Level or a certificate/ diploma in secondary or primary education, than the DipScED students. However, such a diversified background is problematic to instruction taking cognisance of the weak pedagogical content knowledge of the lecturers.

Over $75.0 \%$ of the students enrolled in the first VODL cohort are contract teachers on relief teaching in primary and secondary schools. The remaining proportion of the students was unemployed or employed in nonteaching jobs and a variety of unskilled jobs. Their main purpose for enrolling in the programme was conveyed in one of the interviews:

You see relief teaching is a source of income for those who have not done so well at O-level. They consider it as a last resort as the Ministry is in high demand of teachers. This programme to them guarantees continuous employment as they do not have to queue for it on termly basis.

The preceding expression evidences a high probability that these students, especially the DipScED ones, have turned to the programme and teaching in particular for the employment opportunities and the regular income it offers at the present moment rather than for professional reasons. The drawback associated with such a scenario is the resulting poor attitudes, including lack of commitment, resourcefulness, self-discipline, and selfmanagement, among others, which may cause students to drop out when the going gets tough.

Other student-related problems include financial costs of study, disruption of family life, lack of stakeholder support, and rural operating environment.

\section{Discussion, Implications, and Recommendations}

Problems encountered during the $\mathrm{S} 1 \mathrm{~B} 1$ residential session were many and varied. There are several ways of categorising these challenges. One way adopted in this study is the categorising of the challenges into centre-, institution-, staff- and student- related. Whilst the residential session is meant to provide student-lecturer face-to-face interactive opportunities, which are lacking in most distance education programmes, it becomes imperative that the centres' physical infrastructures, equipment, and furniture be supportive to the intensive learning. Institutional support helps to alleviate distance learners insecurities 
related to centre context (Knapper, 1988). The literature is rich with the problems of attrition associated with distance learning. Whilst numerous studies cite myriad and complex reasons for attrition, Simonson et al., (2000) refer to Garland's ethnographic study finding that a poor learning environment and a lack of time are the major determinant to high attrition rate. The current resource statuses of residential session centres are likely to depress the enrolled students and cause attrition as well as deter prospective program students. Though the programme has the potential to sustain itself, at this infant stage it requires substantial funding to inject it with the highly needed resources. The management needs to appraise all the critical stakeholders and partner with them in the programme in order to build a strong resource base. The virtual component of the programme calls for intensified efforts to integrate ICT in learning.

The resource-constricted conventional curriculum adapted to the VODL programme presents a number of study mode incompatibility problems The conventional content curriculum demands, limited resources, lecturers' limited pedagogical content knowledge, and short residential session, among others, orient lesson delivery towards traditional teaching instruction. A research study by Sikwibele and Mungoo (2009) concurs with the foresaid concern that lecturers who are trained for conventional instruction at primary, secondary, or tertiary educational settings lack distant education teaching experience and use pedagogy that borrows heavily from traditional classroom practices. Traditional teaching approaches promote rote learning and develop cognitive overload and resistance in students. According to Rubanju (2008), use of traditional teaching strategies defeats the purpose of context-based learning. In view of the foregoing discussion, all those involved in the VODL teacher education programme should be equipped with skills and knowledge of productive distance education teaching. The institutions have to provide frameworks for VODL operations to curb unethical practices. Restructuring of the ways in which teaching and learning are delivered and regular curriculum review to suit the nature of the programme becomes fundamental for its goal to be realised.

Generally, distance learners, more often than not, have insecurities about learning grounded in personal, residential session, centre, and institutional factors (Knapper, 1988). The centre, institution-, and staff-related VODL programme challenges revealed in this study added pressure on the student. Such pressure often results in dropouts (Sweet, 1986). According to Campbel (1992) as cited by Nyondo (n.d.), age, maturity, and learning styles impact the learning process of the distant student. In this regard Yusuf (2006) emphasises proper selection of learners with desirable characteristics for distance learning programmes. Therefore, overcoming distance learning pressure is heavily dependent on individual characteristics. The characterisation of the VODL students presented in this study reflects that they need a lot of economic, social, and resource support if they are to withstand the programme pressure. It becomes imperative that these students be attached to study mentors to offer them guidance, time management techniques, and initiatives to encourage them to progress (Huang, 2000, cited by Yusuf, 2006).

The success of the programme heavily lies with issues of monitoring and evaluation (ME) of the programme for quality assurance. Valid and reliable ME performance frameworks 
should be in place, known, and well understood by all programme stakeholders and then rigorously applied in the implementation of the VODL programme. This will not only ensure a quality product but market the programme for possible expansion beyond Zimbabwean boarders.

\section{Conclusion}

The VODL programme has incredible potential to supply secondary schools in Zimbabwe and beyond with the much needed large numbers of science educators. The complementary aspects of student-lecturer face-to-face interaction during residential sessions and learner independence and responsibility in between residential sessions make this particular programme innovative to science teacher education. These unique features provide a basis for the development of theoretical models for quantity and quality science educator demanddriven programmes. The programme also provides an effective step towards democratisation of science education. Further, it is a basis for providing science teacher education through lifelong learning opportunities. If successfully implemented, this VODL mode of science teacher education programme has unique features that other nations may incorporate in their science educator programmes as a way of addressing the science educator shortage. This is in line with the recommendation made by Osborn and Dillion (2004). However, the University, residential session, institution, lecturer, and student challenges highlighted in this study have serious repercussions on the quality of the programme and need to be addressed. The VODL programme goals will be achieved if proper steps to address the challenges revealed in this study are taken. The steps to be taken may include the following: setting up induction, orientation, and in-service programmes for lecturers; recruitment of full-time course coordinators with relevant experience and expertise; provision of weekend sessions for both academic and nonacademic dialogues to cater for students' learning needs. Finally, there is a need to put into place research-driven curriculum modification to enhance the quality of the programme. 


\section{References}

Kirk, J., \& Dembélé, M. (2007). More and better teachers needed: Achieving quality education for all. Id21 Insights, 6. Retrieved from http://www.id21.org/insights/insights-edo6/insights edn 6.pdf

Knapper, C. (1988). Lifelong learning and distance education. American Journal of Distance Education, 2(1), 63-72.

Nyondo, C., (not dated). Socioeconomic factors affecting distance learning in Papua New Guinea.

Rubanju, A. C. G. (2008). Quality challenges in higher education institutions in Uganda. Institute for Educational Research, University of Oslo. Retrieved from http://www. uv.uio.no/studentliv/isne/assets/docs/Unit\%201\%20paper\%20assignment.doc

Sikwibele, A.L., \& Mungoo,J.K. (2009). Distance learning and teacher education in Botswana: Opportunities and challenges. International Review of Research and Open Distance Learning, 10(4).

Sweet, R. (1986). Student drop-out in distance education: An application of Tinto's model. Distance Education, 7, 201-213.

Thakrar, J. Zinn, D., \& Wolfenden, F., (2009). Harnessing open educational resources to the challenges of teacher education in Sub-Saharan Africa. International Review of Research in Open and Distance Learning, 10(4). Retrieved from http://www. irrodl.org/index.php/irrodl/article/view/705

Tyler-Smith, K. (2006). Early attrition among first-time e-learners: A review of factors that contribute to drop-out, withdrawal and noncompletion rates of adult learners undertaking e-learning programmes. Journal of Online Learning and Teaching, 2(2). Retrieved from http://jolt.merlot.org/Vol2 No2 TylerSmith.htm

Yusuf, M. O., (2006). Problems and prospects of open and distance education in Nigeria. Turkish Online Journal of Distance Education, 7(1).

\section{Athabasca University $\mathbf{1}$}

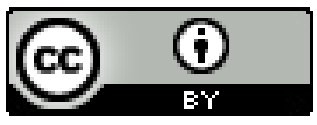


THE INTERNATIONAL

REVIEW OF RESEARCH IN

OPEN AND DISTANCE LEARNING

\section{Learning Management System Migration: An Analysis of Stakeholder Perspectives}

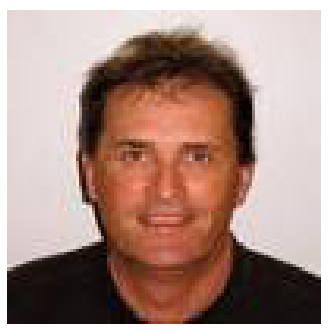

Thomas G Ryan, Mary Toye, Kyle Charron, and Gavin Park Nipissing University, Canada

\section{Abstract}

In this mixed methods study the authors describe the institution-level perceptions of stakeholders transitioning to a new learning management system (LMS). We address issues related to change, the institution's administration of the transition process, problems encountered, and realized learning via online survey data collection, analysis, and interpretation. We further detail results of a faculty survey, which sought to illuminate the LMS transition experience. The summation includes suggestions for institutions as they prepare for, and move through, foreseeable LMS change and transition.

\section{Introduction}

Emerging "in the mid-1990s. . Management systems have evolved from somewhat basic collections of disparate applications into intricate, integrated enterprise systems" (Leslie, 2003, p. 1). Alias and Zainuddin (2005) defined a learning management system (LMS) as "a software application or Web-based technology used to plan, implement, and assess a specific learning process" (p. 28). Mohawk College (2009) suggested an "L.M.S. can be broadly described as a web-accessible platform for the 'anytime' delivery, tracking and management of education and training. L.M.Ss are essentially software running on dedicated hardware" (p. 5). Some LMSs are now over twenty years old, and much has changed since the first LMS arrived on the distance education scene in the mid 1990 .

Over a period of 20 years a great deal of change and research has unfolded in all areas of distance education. Turner (2011) completed a meta-analysis of 695 studies, concluding that distance education research fits "into three main categories: (1) macro level research focusing on distance education systems and theories; (2) meso level research focusing on management, technology, and organization; and (3) micro level research focusing on teaching and learning in distance education" (p. 4). Our objective herein was to add to the macro 
and meso level by examining online instructor perceptions of our institution-level change of a learning management system (WebCT/Blackboard CE to Blackboard Learn version). To do this we undertook a research design and review of literature that would not only meet our needs but also frame our study.

Within the mixed methods research study, objectives included addressing issues pertaining to when, and why, such LMS transitions might occur, the dynamics of making the changes, this institution's management of the transition process, problems encountered, and lessons learned. This research built an informed awareness and overview of faculty by learning about their teaching background, years of experience, and LMS change experiences via survey and interview modes. Our research did not comment on micro-level issues by directly addressing teaching and learning; however, our focus was clearly directed towards our LMS as it changed and impacted technical staff and online instructors.

We reviewed several pertinent studies to learn what top features were supported by some LMSs and, in doing so, we became aware of the features and limitations within LMSs in general. Authors such as Colace, de Santo, and Vento (2003) completed evaluations, assessing 15 commercial LMSs, revealing two central aspects: online training services and course management attributes. Concurrently, Leslie (2003) concluded, "as a result of reviewing 45 CMS on 41 features, the researchers at Edutools were able to form a picture of some of the common and not so common features of these systems" (p. 6), which were listed as follows.

Table 1

Top 15 Features Supported across Products

\begin{tabular}{|l|c|c|}
\hline Feature name & $\begin{array}{c}\text { \# Products supporting fea- } \\
\text { tures }\end{array}$ & $\begin{array}{c}\text { Percentage of total (45) } \\
\text { products }\end{array}$ \\
\hline Discussion forums & 41 & $91.11 \%$ \\
\hline Registration integration & 41 & $91.11 \%$ \\
\hline Internal email & 39 & $86.67 \%$ \\
\hline Authentication & 38 & $84.44 \%$ \\
\hline Real-time chat & 34 & $75 \cdot 56 \%$ \\
\hline Orientation/help & 34 & $75 \cdot 56 \%$ \\
\hline Groupwork & 34 & $75 \cdot 56 \%$ \\
\hline Self-assessment & 34 & $75.56 \%$ \\
\hline Course authorization & 34 & $75 \cdot 56 \%$ \\
\hline Automated testing and scoring & 34 & $75.56 \%$ \\
\hline File exchange & 33 & $73.33 \%$ \\
\hline Calendar/progress review & 33 & $73.33 \%$ \\
\hline Instructor helpdesk & 33 & $73 \cdot 33 \%$ \\
\hline Searching within course & 31 & $68.89 \%$ \\
\hline Student tracking & 31 & $68.89 \%$ \\
\hline Mean \# of products supporting a feature 29, Standard Deviation 8.72 & \\
\hline (Lesie, 2003, & & \\
\hline
\end{tabular}

(Leslie, 2003, p. 6) 
By looking at what had been the top features of past LMSs we were able to develop an informed and useful perspective and understanding. We discussed past research and decided that while these LMS features seemed adequate, innovation since 2003 has resulted in many more features being offered, hence the need to upgrade and transition as the LMSs evolve. We concluded, as others have, that "an effective LMS must support active engagement, meaningful connections between segments of the course, easy communication, and formative feedback on work that is presented in class discussions or through other venues" (Rubin, Fernandes, Avgerinos, \& Moore, 2009, p. 82). When some of these features are lacking or not as current as they should be, migration and transitioning can be expected, which can impact all stakeholders as the adjustment and change ensues. By focussing solely on the LMS we do not discount the importance of the instructor, who uses this LMS as a tool, or the background behaviour of the instructor, which can dictate the positive or negative outcomes associated with learning online, transitioning, and migration.

Stakeholders often include users, faculty, staff, and administration (Jafari, McGee, \& Carmean, 2006). These people may use terms such as best practices, which are bantered about and have deep roots in LMS research (Whitmyer, 2000). It could be that the reason for a change was related to basic system performance issues, such as increased demands on current LMSs, thus the need to move forward every few years, transitioning at what seems to users as a rapid pace (Jafari et al., 2006). Few researchers, and even fewer studies, have considered the turbulence, upset, and adjustments required when a LMS is upgraded from something that may be viewed as wanting or antiquated, by some, to one that is viewed as current. This transitioning sends various stakeholders into problem-solving mode as the unfamiliarity of the new LMS, and changes required, transfer stakeholders from the known into the unknown.

Smart and Meyer (2005) investigated faculty perceptions of LMS change and discovered "faculty, who would need to restore course content, that did not convert intact and accurately-will face increased workloads and frustration, should an institution choose to change from one LMS to another" (p. 69). Smart and Meyer also found that people "... are legitimately concerned about the time and effort needed to make the transition a success for their courses and students" (p. 70). Concern and research findings proved to be the impetus for us to look at our transitioning. Change is one of the top ten information technology (IT) issues (Allison, et al., 2008), and change management (Fullan, 2002) has made the list of institutional IT concerns for the first time in many institutions. Yet, behind any change are the stakeholders as the transitioning process is not just a hardware concern. Hulley and Dier (2005) discovered that leaders who are facilitating change need highly refined emotional intelligence skills in order to know how, and when, to press on, change direction, or back off (p. 21). Change management is about "developing a process for handling IT changes that are made on a regular basis (e.g., patches, upgrades, replacements) and that can be very disruptive if there is no change management process in place" (p.40). This change can occur simply as part of the product's evolving sophistication or when "institutions want a centralized system to assure uniformity of appearances and, if possible, to manage many other aspects of the course and overall administration" (Marsh, McFadden, \& Price, 1999). 
Whether to move to a new version or to a new product is not the issue because change is inherent in the use of technology (Finkelstein \& Pittinsky, 2003; Sclater, 2008). Indeed we "are still at the 'Model T' stage of LMS use" (Morgan, 2003, p. 12).

\section{Purpose}

In this exploratory mixed methods study we interviewed technical staff and surveyed instructors online who experienced the institution-level change of a learning management system (WebCT/Blackboard CE to Blackboard Learn version). We addressed issues pertaining to when, and why, such LMS transitions might occur, the dynamics of making the changes, this institution's management of the transition process, problems encountered, and lessons learned. This research was to serve as an awareness-building overview of the situation facing faculty and as a signal for institutions considering or planning this type of change. This study was an attempt to share the lessons learned at the authors' institution, which can be a starting point; some may suggest it is all about managing change effectively.

\section{Background: CMS and Change}

The use of a learning management system at our university has been evolving since the late 1990s. During this period we used distance education teleconferencing for courses in education and the arts and sciences. In the later part of the 1990's we recognized the potential of the software, and the campus's information technology people began an investigation of various applications (WebCT). Understanding that the choice should be faculty driven, we convened a faculty committee who reviewed leading products. After a lengthy review, the committee made its recommendation. The University negotiated a contract, developed a training program, and hosted and supported the system. Although initial faculty use was minimal, a slow but steady period of growth followed as more faculty began to use the software each semester for a variety of blended, teleconference, and online courses. This process was to be repeated in the late 1990 s and again in 2005 (WebCT).

In 2010, we repeated this process and after much discussion a new LMS was introduced to our campus, and faculty using the old LMS were given a semester to make the transition/ migration. Naturally, some faculty were unhappy about this change because users had devoted a good deal of time and effort learning the original LMS (Blackboard CE). They now needed to learn about a new LMS (Blackboard Learn) platform that was quite different from the one with which they were already familiar. This experience provided the campus with an important lesson on the changing dynamics of LMSs, and campus support staff was determined to manage the use and transition process to the best of their ability. We believe our system was akin to the one displayed in Figure 1, as follows. 


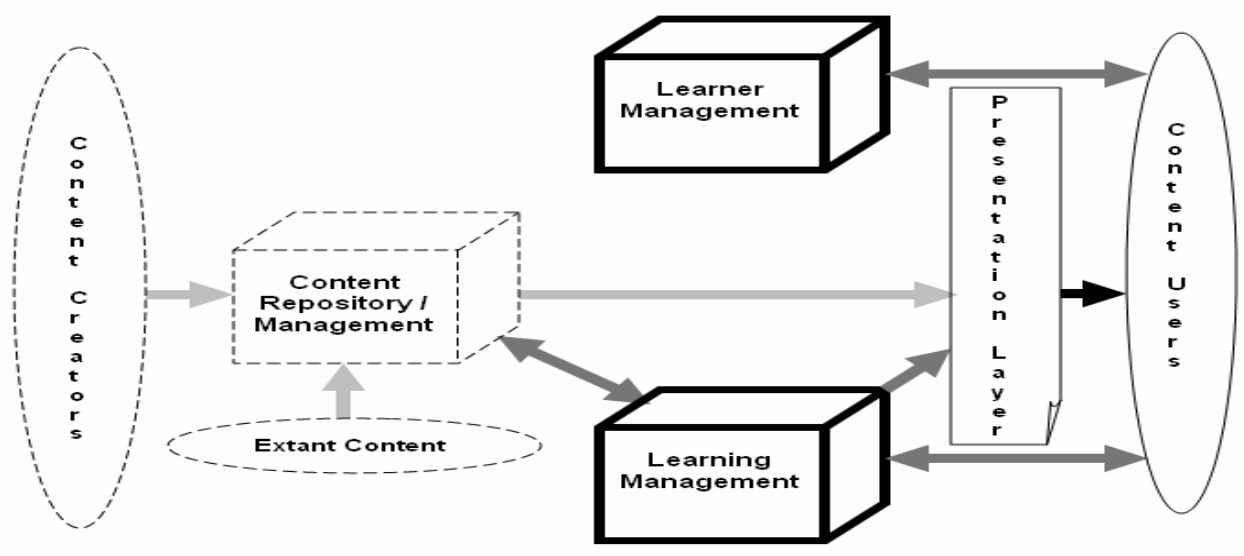

Figure 1. LMS Components (Irlbeck \& Mowat, 2005, p. 6).

\section{Method}

In January of 2010, academic and technology staff met to discuss issues and concerns related to the transition to the new CMS (Blackboard Learn from Blackboard CE). We met several times to record our thoughts on the course of action. During this month we also developed an ethics application and gained final approval, in May of 2010, for our study tentatively entitled, The Blackboard Jungle Research Panel. We located a survey tool online and requested permission to adapt it from Dr. Clayton at Middle Tennessee State University. Permission was received and our panel began adapting and piloting the 22 item survey, with a completed tool in place for June 2010 (Appendix). We decided to use kwiksurveys (http://www.kwiksurveys.com/) as this service was offered for no charge, and we could use it for several months to complete our work. We were able to send online invitations to all instructors, track responses, quantify, and examine (descriptive statistics) in table format (Microsoft Excel) via kwiksurveys. We also displayed results in a summative manner that facilitated analysis and interpretation as the survey data was filtered into easily read charts and tables, which are listed in the Results section.

Our discussion group transcripts were analyzed, and evidence was realized for this mixed methods study. To be clear, we understood "mixed methods designs evolved from the notion of triangulating the information from different data sources" (Tashakkori \& Teddlie, 2003, p. x). Hence, we collected interview, survey data, and anecdotal evidence via personal communications (email, voice mail, and face-to-face). Within the survey, there were opportunities for empirical (short answer) and long responses, which both enhanced the data and allowed for triangulation (Denzin, 1989). Admittedly, our study does not contain thick descriptions usually found within qualitative studies, yet "it does meet the minimum criteria spelled out in our definition. Therefore, we consider it an example of mixed methods research" (Creswell \& Plano-Clark, 2006, p. 11-12). 


\section{Results}

We concluded our online survey after three weeks with 51 respondents $(N=51)$. Analysis of demographic information allowed us to better understand the voices within the feedback which revealed our sample contained 21 males $(44 \% n=22)$ and 27 females $(56 \% n=$ 29). This sample of 51 was comprised of three new instructors who had not taught online previously and 16 participants, who had between one and five years of experience teaching online. We also determined that 23 participants had between five and ten years of online teaching experience. Even at this point, we concluded that the sample was mostly female and had online teaching experience at the university level. As for previous teaching experience at a level other than university, we found that 19 respondents had no previous experience outside the university. Five had between one and five years experience outside the university, and four had between five and 10 years of experience. Interestingly, 17 had over 10 years of experience outside of the university; hence, we deduced that our sample was largely an experienced group before they began teaching online.

The representative faculties and divisions broke down as follows: Arts \& Science, 14 (29\%), Education, 10 (21\%), Applied and Professional Schools, 16 (31\%), Distance (In-Service/AQ, $\mathrm{ABQ}), 8$ (16\%), Distance, (CCE) 3 (6\%). This breakdown resulted in a total of 51 participatory instructors. Note: Rounding of numbers resulted in totals over $100 \%$.

Our first item on our survey asked, To what extent did you use Blackboard CE (formerly WebCT) in your teaching?

Table 2

Responses to the Question about the Previous Use of Blackboard CE (formerly WebCT) to Teach

\begin{tabular}{|c|c|c|c|c|}
\hline Never & Seldom & Sometimes & Often & Very Often \\
\hline $22 \%(n=11)$ & $4 \%(n=2)$ & $12 \%(n=6)$ & $20 \%(n=10)$ & $44 \%(n=$ \\
$22)$
\end{tabular}

These responses led us to conclude that most had used the former LMS and only a minority were new users. Our next item on our survey asked, To what extent did you use Blackboard Learn in your teaching? 
Table 3

Responses to the Question about the Use of Blackboard Learn to Teach

\begin{tabular}{|c|c|c|c|c|}
\hline Never & Seldom & Sometimes & Often & Very Often \\
\hline $14 \%(n=7)$ & $4 \%(n=2)$ & $14 \%(n=7)$ & $18 \%(n=9)$ & $51 \%(n=26)$ \\
\hline
\end{tabular}

We found that our instructors were experienced, and most had used the Blackboard Learn platform very often prior to this survey (51\%). In fact when we asked, do you teach any fully online distance education courses? 27 respondents (53\%) told us they did and slightly less 24 (47\%) signalled that they had not. Of the $51 \%$ who had taught online we asked, how many course do you teach each year?

Table 4

Responses to the Question about Teaching Fully Online Distance Education Courses

\begin{tabular}{|c|c|c|c|c|}
\hline None & One Course & Two Courses & Three Courses & $\begin{array}{c}\text { Four } \\
\text { Courses }\end{array}$ \\
\hline $25 \%(n=13)$ & $8 \%(n=4)$ & $6 \%(n=3)$ & $6 \%(n=3)$ & $5 \%(n=3)$ \\
\hline
\end{tabular}

We found out that half of our instructors teach at least one course online and many teach more than one course per year.

We also asked, do you teach any hybrid/blended courses (using Blackboard features to supplement your face-to-face instruction)? Of our 51 respondents 23 (45\%) said yes, and 28 (55\%) said no, they did not teach any hybrid/blended courses using Blackboard features to supplement the face-to-face instruction.

\section{Training}

We asked if they had attended any Blackboard training, workshops, or demonstrations? Participants signalled that 19 (37\%) had, and a majority of 32 (63\%) indicated they had not attended any Blackboard training, workshops, or demonstrations. Specifically, 13 attended a workshop, one attended two workshops, and one attended three workshops. Following this question was an item that asked, have you consulted (in person, by e-mail, or by phone) with a technologist for Blackboard instruction? A majority of 48 (94\%) did consult (in person, by e-mail, or by phone) with a technologist.

\section{Transition}

We asked our sample if they believed they were well-informed about what they needed to 
do to transition courses from WebCT to Blackboard Learn.

Table 5

Responses to the Question about Being Well-Informed about How to Transition Courses

\begin{tabular}{|c|c|c|c|c|}
\hline Strongly Disagree & Disagree & Neither & Agree & $\begin{array}{c}\text { Strongly } \\
\text { Agree }\end{array}$ \\
\hline $9 \%(n=5)$ & $22 \%(n=11)$ & $38 \%(n=19)$ & $22 \%(n=11)$ & $9 \%(n=5)$ \\
\hline
\end{tabular}

Most of the sample (36) indicated that they did know if they were well informed or not, yet only a little over $20 \%$ suggested they were well informed, and the same signalled they thought they were not well informed. When we asked about the state of change, most indicated they were not frustrated with having to learn a new learning management system (CMS/LMS).

Table 6

Responses to the Question about Frustration Level about Having to Learn a New LMS

\begin{tabular}{|c|c|c|c|c|}
\hline Strongly Disagree & Disagree & Neither & Agree & $\begin{array}{c}\text { Strongly } \\
\text { Agree }\end{array}$ \\
\hline $13 \%(n=7)$ & $20 \%(n=10)$ & $36 \%(n=18)$ & $22 \%(n=11)$ & $9 \%(n=5)$ \\
\hline
\end{tabular}

Given the lack of concern while transitioning there also appeared to be an understanding of why Nipissing University moved to a new version of Blackboard (Learn).

Table 7

Responses to the Question about Understanding why the University was Moving to a New $L M S$

\begin{tabular}{|c|c|c|c|c|}
\hline Strongly Disagree & Disagree & Neither & Agree & $\begin{array}{c}\text { Strongly } \\
\text { Agree }\end{array}$ \\
\hline $9 \%(n=5)$ & $20 \%(n=10)$ & $33 \%(n=17)$ & $28 \%(n=14)$ & $11 \%(n=6)$ \\
\hline
\end{tabular}

Only $29 \%$ indicated they did not understand (strongly disagree + disagree) why Nipissing University moved to a new version of Blackboard. Overall the transition was 'smooth' for a majority of respondents (26). Keeping on a positive note we asked, what do you think 
were the most positive aspects of the transition to Blackboard Learn? Several respondents indicated, "It wasn't too difficult" and a few suggested, "I didn't really notice that there was a transition". One commented on "the functionality - The ability to embed video (YouTube/ other)" and many others noted how support staff were helpful, supportive and effective. In sum, many told us, "It provides a lot more options for discussion boards.".

Turning to the negative aspects of the transition we asked, what do you think were the most negative aspects of the transition to Blackboard Learn? One mentioned how "saving content from old system = migration issues" was a negative, and another instructor explained:

Discussion folder creation and maintenance is less intuitive in terms of labels, actions, modifications. There are so many choices (settings/permissions) in creating folders that it is more difficult to do it correctly, at least at first attempts. The interface seems relatively large and clunky (big icons - perhaps these can be resized?) Have not used it for a fully online course yet, but will be doing so in May so I hope it works well.

\section{Support}

With the transition we asked if the Nipissing support staff was very helpful in showing instructors how to use the newer version of Blackboard.

Table 8

Responses to the Question about the Helpfulness of Support Staff during the Transition Process

\begin{tabular}{|c|c|c|c|c|}
\hline Strongly Disagree & Disagree & Neither & Agree & $\begin{array}{c}\text { Strongly } \\
\text { Agree }\end{array}$ \\
\hline $11 \%(n=6)$ & $13 \%(n=7)$ & $15 \%(n=8)$ & $37 \%(n=19)$ & $\begin{array}{c}24 \%(n= \\
12)\end{array}$ \\
\hline
\end{tabular}

Of course we had to ask how they viewed the change as it unfolded; therefore, we put forward this unique statement: I would have preferred NOT to have learned how to use Blackboard Learn. As respondents indicated, they actually preferred learning how to use the new LMS. 
Table 9

Responses to the Question about Preferring Not to Have Learned How to Use Blackboard Learn

\begin{tabular}{|c|c|c|c|c|}
\hline Strongly Disagree & Disagree & Neither & Agree & $\begin{array}{c}\text { Strongly } \\
\text { Agree }\end{array}$ \\
\hline $37 \%(n=19)$ & $35 \%(n=18)$ & $22 \%(n=11)$ & $02 \%(n=1)$ & $\begin{array}{c}04 \%(n \\
=2)\end{array}$ \\
\hline
\end{tabular}

On another item concerning help and support over $65 \%$ of instructors indicated that support was good, while another $15 \%$ agreed help was neither good nor wanting. Only a minority of $20 \%$ (10) suggested the help was not up to the expected standard.

\section{Technical}

We wanted to know about some of the technical aspects so we asked, which browser program(s) do you usually use? A majority indicated they used Internet Explorer (26) or $46 \%$, followed by Firefox (17) or 30\%, then Safari (10) or 18\%, and lastly Google Chrome at (4) or $7 \%$. We wondered why the percentages added up to over 100 and decided that it was possible for instructors to use more than one browser to service online teaching. We looked deeper into browsers by asking, did you encounter any specific problems using Blackboard Learn with your usual choice of browser? Sixty-five percent (30) indicated no and $35 \%$ (16) signalled yes that they had problems with their browser. Participants were given an opportunity to provide short answers to further detail answers, and in the area of technical issues, one respondent suggested, they had "Java runtime errors as my version is newer than Blackboards. Google Chrome has issues ... I needed to use Firefox". Another commented, "Slower navigation overall - more frequent time-outs - extremely unreliable formatting control on posted messages - inability to attach multiple files to a posted message." Several commented on the pace of the LMS which was simply described as "slow." Some instructors recalled posting issues, such as the post not appearing for some students; however, this was linked to settings, such as moderation, and permissions, which was really within the domain of the instructor.

\section{Discussion}

\section{Problems and Positives}

As the transition was undertaken during September of 2010, we surveyed online to ascertain the types of success and problems encountered and to discover other issues. We also realized qualitative data within our interview transcripts, emails, and anecdotal evidence. Problems encountered during the transition fell into two categories (themes): technical and 
faculty issues. Given the many barriers that faculty typically encounter when working with instructional technologies (Brinthaupt, Clayton, \& Draude, 2009), it was not a surprise that there were several faculty-related behavioural and technical issues that emerged during the transition process. One administrative issue noted was the lack of compensation for the time required to convert courses from one LMS (form) to another. The university management decided at the beginning of the transition process that compensation was not available. This decision was upsetting for many, yet it was one instructors moved past as a matter of necessity to meet looming course start-date deadlines.

As well, many instructors suggested they had little time to revisit and redesign course materials, and some lacked an understanding of new instructional deadlines during the migration. These new timelines were attributed to additional time required by technical staff to act; and admittedly, for some faculty, making the transition in a timely fashion was a low-interest task. Faculty did not anticipate the time required to make their conversion and, as such, were frustrated when limited time remained. Time can be less an issue, we believe, if mandatory faculty training is established and available on a continual process (Nkonge \& Gueldenzoph, 2006). The type of training offered in our study included Blackboard orientation, workshops, and/or demonstrations. A minority of respondents $37 \%$ ( $n$ $=19$ ) did indeed make use of the opportunities to learn, however a large majority, $63 \%$ ( $n$ = 32) made no attempt to attend any Blackboard training, workshops, or demonstrations; this was something that was puzzling since, in doing so, problems and frustrations could be lessened, we believed.

Teaching online is, in many ways, best understood as "pedagogy empowered by digital technology" (Nichols, 2008), and this perception may illuminate a reason why only a minority of instructors (13 / 25\%) did attend a workshop, and just one participant attended two workshops; another participant attended three workshops. Of the several workshops available it was noteworthy to discover that only a few of our online instructors deemed this necessary. Perhaps this indicated decreased anxiety concerning change since we did have a majority of experienced instructors. However, most of our sample did make contact with a technologist for Blackboard instruction $(94 \%, n=48)$ in person, by e-mail, or by phone, which seemed to be a sign that perhaps the most convenient manner in which to remedy issues was that which seemed to fit the individual need of the instructor, whether it be in person, by e-mail, or by phone. Tallent-Runnels et al. (2006) reviewed several studies and concluded that all instructors and students need training and support within a LMS transition. For instructors, to not avail themselves of the offered training seems to be asking for frustration down the road.

Within our interviews some of the evidence gleaned by the transition team referred to new technical recommendations, the identification of "best practices," and the need for an increased emphasis on communication. Another realization was the need to focus less on administrative concerns and more on the instruction and learning area, within the LMS and the milieu in which it was to be utilized (Tallent-Runnels et al., 2006). Instructors further commented, "Tech support was freely available which helped allay my apprehensions," and we understood this as an indication of a level of confidence in the technical staff. On the 
technical side, the differences in the way certain learning resources converted to the new system led some instructors to conclude, "Marking tools are amazing," and "simply that it is a very easy program to use, very user friendly." The positive comments indicated a measure of satisfaction, yet training and encouragement remained a key feature for all for staff and faculty as they moved forward creating new curricula and standards within the newer LMS (Blackboard Learn). With more features and opportunities all stakeholders could widen the definition of "best practices" for online courses. Rubin et al. (2009) has stressed, "In teaching fully online courses, it is important that basic communication tasks be made simple for faculty and students, and automatic where feasible." Our communication was a prevailing factor leading some instructors to conclude, "I was truly thankful that I had tech support that was patient and accessible at all times when I first started. Thank you!" The migration was a positive move as one instructor suggested the new Blackboard Learn system has "more advanced features that allow us to better manage learning." There is however much criticism in the literature of all LMSs, and the fact that we used Blackboard forced us to consider that "Blackboard has limited tools to enable grouping across different kinds of tools (e.g., Discussion, and Assignments). This means that the elements needed for the week's work are spread across several pages, and require multiple clicks to access the materials ...” (Rubin et al., 2009, p. 83). Because our instructors may have only used Blackboard versions in previous years there was modest concern that, "other LMSs allow all learning elements and tools to be placed contiguously in a hierarchy or outline structure that visually represents the grouping" (Rubin et al.). What was clear was that we migrated successfully, and what was done has produced mostly positive results as students learn and faculty continue to instruct online.

\section{Conclusions and Recommendations}

This research was to serve as an awareness-building overview of the situation facing faculty and as a guide for institutions considering this type of change. As management systems continue to evolve, both instructors and site administration will need to adapt, change, and respond to the needs as they surface. LMSs can enhance access to educational opportunities while providing learning materials for students throughout a broad geographical area (Abrami et al., 2006). With the surfacing of innovative technologies, revisions to current systems, and changing needs and abilities of instructors, future LMS transitions are predictable. Each institution "must adapt, using technologies and models of understanding, in this case to reconcile teaching, research, IT, a changing environment, financial accountability and managerial models" (Wise \& Quealy, 2006, p. 4). By taking a prudent, informed approach to moving faculty forward and helping them make the change, we have begun to generate an enhanced understanding of this migration.

The data herein suggest there is much more to do; for instance, some faculty did not appear to adequately comprehend the need for migration to a new LMS. Perhaps these are people who do not like change, and any disruption would be viewed as unnecessary. As well, our survey data did not suggest that those who attended training sessions were less frustrated. Nonetheless research has indicated, and we believe, training should always be 
offered, whether mandatory or not.

As for recommendations, we realized two types: those from the survey (via the instructors) and our own. Our instructors suggested the following:

- Make available tutorial sessions that are face-to-face (not an online self workshop).

- Involve the instructors and implement their suggestions. We should have more control over content and updating information.

- More support, more training, and more student training.

- Ensure (hardware) servers work ALL the time.

- Roll out well in advance of September with pilot testing of changes.

- Ask instructors for input concerning what is needed; specifically, what did not work with the old version and what did work well with the old version.

- Continue to offer easy-to-access technology support and continue to hire staff to meet growing demands and growth.

Our own recommendations developed in a reflective manner as we reviewed our data and collectively decided what our next steps would be. We did this to continue to monitor, respond to, and change the system in a professional and strategic manner that infused the professional development of our team. Hence, for continued growth we decided to do the following:

- Continue to survey instructors each semester (pre/post).

- Survey students as an exit or entry item to create a 360 loop of information.

- Survey IT staff to gain insight and align this with student and instructor surveys.

- Provide an online suggestion box for $24 / 7$ input.

- Form a University-wide steering committee.

- Provide training for instructors through a centre for flexible teaching and learning. 


\section{References}

Abrami, P.C., Bernard, R.M., Wade, A., Schmid, R.F., Borokhovski, E., \& Rana Tamim, R.(2006). A review of e-learning in Canada: A rough sketch of the evidence, gaps and promising directions. Canadian Journal of Learning and Technology, 32(3). Retrieved from http://www.cjlt.ca/index.php/cjlt/article/view/27/25.

Alias, N. A., \& Zainuddin, A. M. (2005). Innovation for better teaching and learning: Adopting the learning management system. Malaysian Online Journal of Instructional Technology, 2(2), p.27-40.

Allison, D.H., P.B. DeBlois, \& the EDUCAUSE Current Issues Committee. (May/June 2008). Top 10 IT issues 2008. EDUCAUSE Review, 37-61.

Brinthaupt, T. M., Clayton, M. A., \& Draude, B. J. (2009). Barriers to and strategies for faculty integration of IT. In P. Rogers, G. Berg, J. Boettcher, C. Howard, L. Justice, \& K Schenk (Eds.), Encyclopedia of distance learning ( ${ }^{\text {nd }}$ ed. pp. 138-145). Hershey, PA: IGI Global.

Creswell, J. W., \& Plano-Clark, V.L. (2006). Designing and conducting mixed methods of research. Thousand Oaks, CA: SAGE Publications.

Colace, F., De Santo, M., \& Vento, M. (2005). Personalized learning path based on metadata standards. International Journal on E-Learning, 4(3), 317-335. Norfolk, VA: AACE. Retrieved from http://www.editlib.org/p/4820.

Denzin, N. K. (1989). The research act: A theoretical introduction to sociological methods. Englewood Cliffs, NJ: Prentice Hall.

Finkelstein, J., \& Pittinsky, M. (2003). The evolving role of course management systems providers in the transformation of education: An interview with Blackboard's Matthew Pittinsky. The Technology Source. Retrieved from http://technologysource. org/article/evolving role of course management system providers in transformation of education/

Fullan, M. (2002). Change forces with a vengeance. London: Routledge-Falmer.

Hulley, W., \& Dier, L. (2005). Harbours of hope: The planning for school and student success process. Bloomington: National Educational Service.

Jafari, A., McGee, P., \& Carmean. C. (Jul/Aug 2006). Managing courses defining learning: What faculty, students, and administrators want. EDUCAUSE Review, 41(4), pp. 50-52, 13 pp.

Leslie, S. (2003). Important characteristics of course management systems: Findings from the Edutools.info project. Retrieved from http://www.island.net/ leslies/blog/ stories/2003/06/13/importantCharacteristicsOfCmsFindingsFromEdutools.html 
Marsh, G. E., A. C. McFadden., \& B. J. Price. (Fall 1999). An overview of online educational delivery applications. Online Journal of Distance Learning Administration, II( II). Retrieved from http://www.westga.edu/!distance/marsh23.html .

Mohawk College. (January 2009). Final report of the LMS project. Retrieved from http:// lmsreview.mohawkcollege.ca/docs/LMSreviewFinalReport ModifiedBrief.pdf

Morgan, G. (May 2003). Faculty use of course management systems. ECAR Key Findings. EDUCAUSE Center for Applied Research, 2. Retrieved from http://net.educause. edu/ir/library/pdf/ecar_so/ers/ers0302/ekfo302.pdf.

Nichols, M. (2008). E-Learning in context. Retrieved from http://akoaotearoa.ac.nz/sites/ default/files/ng/group-661/n877-1---e-learning-in-context.pdf

Nkonge, B., \& Gueldenzoph, L. E. (2006). Best practices in online education: Implications for policy and practice. Business Education Digest, 15, 42-53.

Rubin, B., Fernandes, R., Avgerinos, M.D., \& Moore, J. (January 2009). The effect of learning management systems on student and faculty outcomes. The Internet and Higher Education , 13(1-2), 82-83.

Sclater, N. (June 2008). Web 2.0, personal learning environments and the future of learning management systems. EDUCAUSE Center for Applied Research, Volume 20o8, 13. Retrieved from http://connect.educause.edu/Library/ECAR/Web20PersonalLearningEnvi/46952.

Smart, K. A., \& K. A. Meyer. (2005). Changing course management systems: Lessons learned. EDUCAUSE Quarterly, 2, 68-70.

Tashakkori, A., \& Teddlie, C. (Eds.). (2003). Handbook on mixed methods in the behavioral and social sciences. Thousand Oaks, CA: Sage Publications.

Tallent-Runnels, M.K., Thomas, J.A., William Y. Lan, W. Y., Cooper, S. Ahern, T.C., Shana \& Shaw, S.M. (2006). Teaching courses online: A review of the research. Review of Educational Research, 76, 93-135. doi: 10.3102/00346543076001093.

Turner, S.A. (2011). A self-study of technological transition: Instructional impacts of shifting a distance course delivery system. The Journal of Educators Online, 8(2), 1-24.

Whitmyer, C. (2000). Comparative features analysis of learning course management software. University of the Future, LLC.

Wise, L., \& Quealy, J. (2006). LMS governance project. Retrieved from University of Melbourne, Information Services Web site: http://www.infodiv.unimelb.edu.au/ telars/talmet/melbmonash/media/LMSGovernanceFin alReport.pdf 


\section{Appendix}

We need some information about your familiarity with Blackboard CE and Learn and your use of Blackboard in your courses.

1. To what extent did you use Blackboard CE (formerly webCT) in your teaching? (Please circle the appropriate number.)

$\begin{array}{ccccc}1 & 2 & 3 & 4 & 5 \\ \text { Never } & \text { Seldom } & \text { Sometimes } & \text { Often } & \text { Very Often }\end{array}$

2. To what extent have you used Blackboard Learn in your teaching?

$\begin{array}{ccccc}1 & 2 & 3 & 4 & 5 \\ \text { Never } & \text { Seldom } & \text { Sometimes } & \text { Often } & \text { Very Often }\end{array}$

3. Doyou teach any fully online distance education courses? How many

$\begin{array}{rr}1 & 2 \\ \text { Yes } & \text { No }\end{array}$

4. Do you teach any hybrid/blended courses (that use Blackboard features to supplement your face-to-face instruction)?

$\begin{array}{rr}1 & 2 \\ \text { Yes } & \text { No }\end{array}$

5. Have you attended any Blackboard training workshop or demonstrations?

12

If yes \#_ Yes $\quad$ No

6. Please indicate your gender (with an "X"): female male

7. Please indicate the number of years you have taught at the University level: years other

8. Please indicate your faculty: Arts \& Science Education. Professional Schools

CCE In-Service Education (ABQ,AQ 
For the remainder of the survey, please rate each of the items using the following response scale. Be sure to write in a number for each item.

$\begin{array}{rrrrr} & 2 & 3 & 4 & 5 \\ \text { strongly } & \text { disagree } & \text { neither agree } & \text { agree } & \text { strongly } \\ \text { disagree } & & \text { nor disagree } & \text { agree }\end{array}$

1. I was well-informed about what I needed to do to transition my courses from WebCT to Blackboard Learn.

. I was frustrated with having to learn a new course management system.

3. I understand why Nipissing University moved to a new course management system.

4. The Nipissing support was very helpful in showing me how to use Blackboard.

5. I would have preferred not to have learned how to use Blackboard Learn.

6. The amount of time given for the transition to Blackboard was appropriate.

7. When I needed help in learning Blackboard, I was able to obtain that help quickly.

8. Overall, my transition to using Blackboard was a smooth one.

The remaining questions are open-ended. Please provide as much detail as you wish for these items.

1. What do you think were the most positive aspects of the transition to Blackboard Learn?

2. What do you think were the most negative aspects of the transition to Blackboard Learn?

3. Do you have any recommendations for how Nipissing should manage the transition to a new course management system in the future?

Thank you for your help! As mentioned earlier, we intend to take your feedback very seriously as we change and evolve. 


\section{Athabasca University $\mathbf{a}$}

(c) (i) 
THE INTERNATIONAL

REVIEW OF RESEARCH IN

OPEN AND DISTANCE LEARNING

\section{Motivating Factors that Affect Enrolment and Student Performance in an ODL Engineering Program}
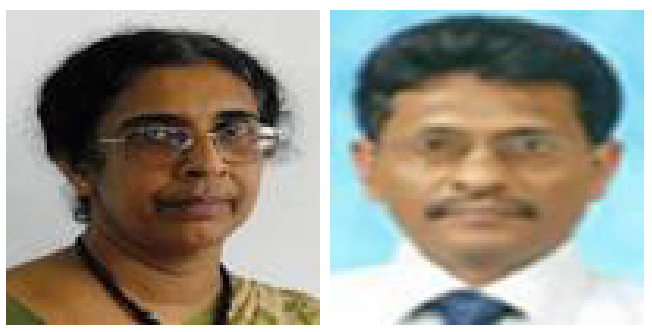

P.R. Dadigamuwa and SAMANS Senanayake The Open University of Sri Lanka

\section{Abstract}

The present study was carried out to determine the motivating factors for enrolling in an engineering study programme in open and distance learning (ODL) and the factors that affect the students' performance. The study was conducted with two convenient samples of students following distance learning courses in engineering technology, conducted by the Open University of Sri Lanka and leading to the award of diploma or degree in Engineering Technology. One sample consisted of students who failed to qualify for sitting the year-end examination and the other consisted of successful students.

The study showed that many students opt to follow the programme without knowing the relevance of the study programme for them. Most of the students (53\%) had taken the courses believing that they could obtain a recognized degree. The students with secondary education qualifications in the mathematics stream were found to be successful, provided that they had selected the ODL programmes with an understanding of the nature of the ODL system, the percentages being 61 with 4 passes, 75 with 3 passes, and 20 with 2 passes at the General Certificate in Education (Advanced Level) examination.

All successful students were of the opinion that the course delivery methods should be improved, especially face-to-face teaching, laboratory classes, and assignments.

Keywords: Distance learning; engineering; performance; motivating factors; Sri Lanka

\section{Introduction}

At present, higher education in Sri Lanka is faced with a problem of providing educational opportunities for those who do not gain admission to conventional national universities. The chance of securing a place in one of the study programmes offered by these universities 
is very low as more and more students compete to enter the universities through a tough competition at the G.C.E. (A/L) qualifying examination, whilst the available vacancies are not expanding in pace with the demand. In 2010 only $17.2 \%$ of the eligible students were admitted to national conventional universities. This is a common problem faced by many developing countries. As such, many educational institutions, including conventional universities, are taking initiatives to offer study programmes through open and distance learning (ODL) methods in parallel with on-campus programmes.

The Open University of Sri Lanka (OUSL) is the only recognized national institution in the country to offer ODL programmes. From its inception, the OUSL has offered study programmes for employed students. However, at present, ODL in Sri Lanka seems to be a viable and effective method of providing higher educational opportunities for everybody who desires to study while being employed, especially in a situation where the traditional universities are not in a position to cope with increasing demand. The high flexibility in course choice and the unrestricted completion time are making ODL more acceptable and popular among the students. However, as ODL programmes heavily rely on self-study, the students who choose ODL courses need to be well aware of the course delivery method and should be prepared to study with self-motivation.

Usually the number of students dropping out in a distance learning programme is significantly higher than that of a conventional study programme. As several factors affect the students' performance and subsequent dropout, continuous studies need to be carried out to find the root causes for poor performance in view of increasing the number of successful students. The main concern is for the causes for dropping out due to the nature of the present ODL practices, which the students find difficult to cope with and thus perform poorly.

Various researchers have carried out studies to develop models for predicting which students will likely drop out of ODL programmes. These models have limitations, especially when applied to different contexts and situations depending upon the political, economic, and social environment. Woodley suggested that rather than pursuing a general model, researchers need to conduct experiments to determine meaningful remedial actions for retention of students.

\section{Rationale for the Study}

The Faculty of Engineering Technology of the OUSL has been offering distance education courses in engineering for 20 years, being the pioneering institute in the world to offer engineering study programmes in distance mode. The student dropout rate has been high in the early years of the study programmes, which is more or less 50\% from year 1 to year 2 . Teachers, without proper study, attribute this high dropout rate to various factors such as nonpreparedness for self-study, lack of aptitude to the engineering discipline, lack of support on the part of faculty, and improper selection of courses at the beginning.

This study attempted to establish the exact reasons for the high dropout rate at early stages of the engineering technology programmes offered by the Faculty of Engineering Technology of the OUSL while determining the motivation factors for enrolment in the engineering 
study programme.

\section{Study Programme and Student Profile}

The study programme in Technology (Engineering) consists of courses from six academic levels and from different categories. Levels 1 and 2 are foundation levels. The course categories included in the present curriculum are Engineering, Mathematics, Engineering Projects, Management, General, Industrial Training, Computer Literacy, and English Language. The curriculum consists of core courses, which vary according to the field of specialisation, and other courses to be chosen from a list of courses to meet the credit requirements for an award as determined by the faculty.

The students who have passed G. C. E. (A/L) in the mathematics stream can omit courses at levels 1 and 2, and those who have higher qualifications may receive further exemptions from relevant courses. In an academic year, a student can register for up to 45 credits of courses (equivalent to 1,125 notional hours of study). Students need to collect 115 credits to receive the Diploma in Technology; whereas, 205 credits are necessary for the Degree. The total number of credits obtained is subjected to certain conditions so that a given minimum should be obtained from different categories of courses and levels.

The printed course materials prepared by the staff are the main and sometimes only instructional material for the courses. At registration the students are given the first set of course materials with relevant take-home assignments. The remaining course materials with assignments are issued to the students after three months, on the payment of the second instalment of course fees. There are a minimum of nine hours and maximum of 18 hours of scheduled face-to-face teaching sessions each of three-hour duration per course.

The students are assessed on a continuous basis by various assessment tools that differ according to the nature of the course. The most dominant assessment methods used at present are assignments (mostly in the form of tutorials), continuous assessment tests (CATs), laboratory work, student presentations and mini-projects. The eligibility to sit the final examination in respect of each course is based on the performance in continuous assessments. These assessments also provide an opportunity for the students to keep motivated and guide themselves towards achieving acceptable faculty standards. An overall continuous assessment mark (OCAM) is computed in respect of each course by combining the marks obtained by the students for various continuous assessment components administered throughout the academic year.

\section{Methodology}

The students who registered for the Technology (Engineering) programme of study at the OUSL that leads to the award of a Diploma in Technology and a Bachelor of Technology (Engineering) were the experimental group selected for the study.

Two convenient samples of students aged below 30 years were selected for the study. The number of students in each sample was 40. One sample consisted of those who did not ob- 
tain eligibility to sit the year-end examinations in any one of the courses offered. The other group consisted of successful students in obtaining eligibility to sit the year-end examination in all the courses. A well-structured questionnaire together with discussions was used to collect information. The areas covered were student profile, reflecting such factors as age, prequalifications, gender and employment, feedback on course delivery, factors that motivated the students to enrol in the programme, and awareness of the ODL programmes at the time of enrolment.

\section{Results}

\section{Motivating Factors for the Selection of ODL Programmes}

\section{Programme recognition.}

Most of the students indicated that recognition and flexibility were the reasons for selecting the programme: $42 \%$ from among the successful students indicated recognition as the main reason for selection of the programme, of which $34 \%$ had four passes in the G.C.E. (A/L) examination. For unsuccessful students, this was $53 \%$, of which $31 \%$ had 4 passes in the G. C. E. (A/L) examination. This indicates that even a fair number of "good" students who selected the engineering study programmes because of mere recognition have failed in ODL. So the general understanding that the students with passes in the G.C.E. (A/L) can cope better in ODL than others is questionable. More importantly, students should have good reasons as well as knowledge of ODL together with the necessary background subject knowledge to succeed in the ODL programme in engineering.

The acceptance of the OUSL-ODL engineering programme in terms of recognition and flexibility is a positive and encouraging factor to the faculty. However, enrolment of students in the programme after considering recognition only is problematic. 


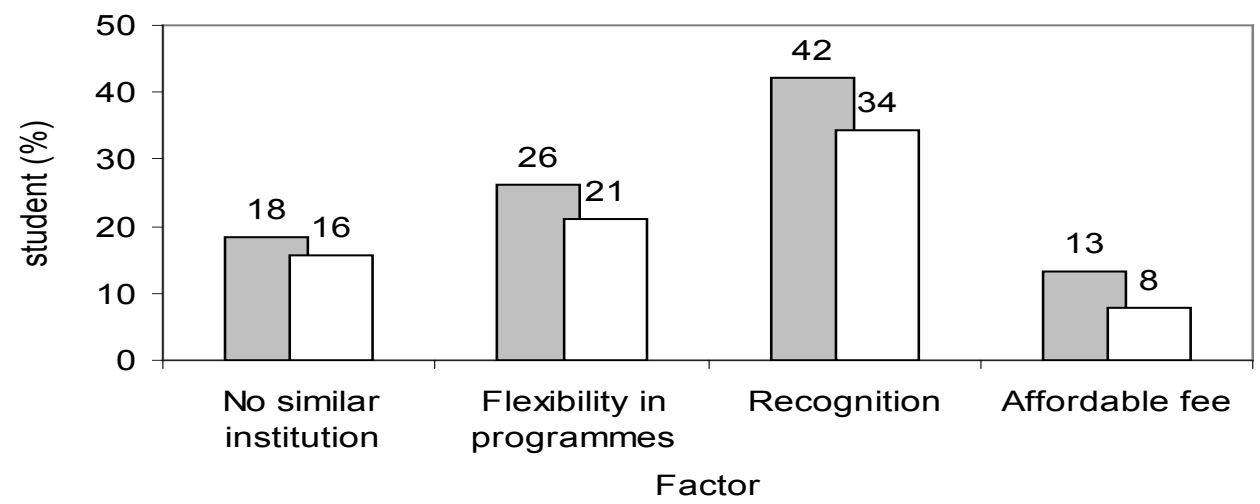

\% student $\square$ Students with 4 passes at GCE (A/L) examination

Figure 1. Factors affecting the enrolment (successful students).

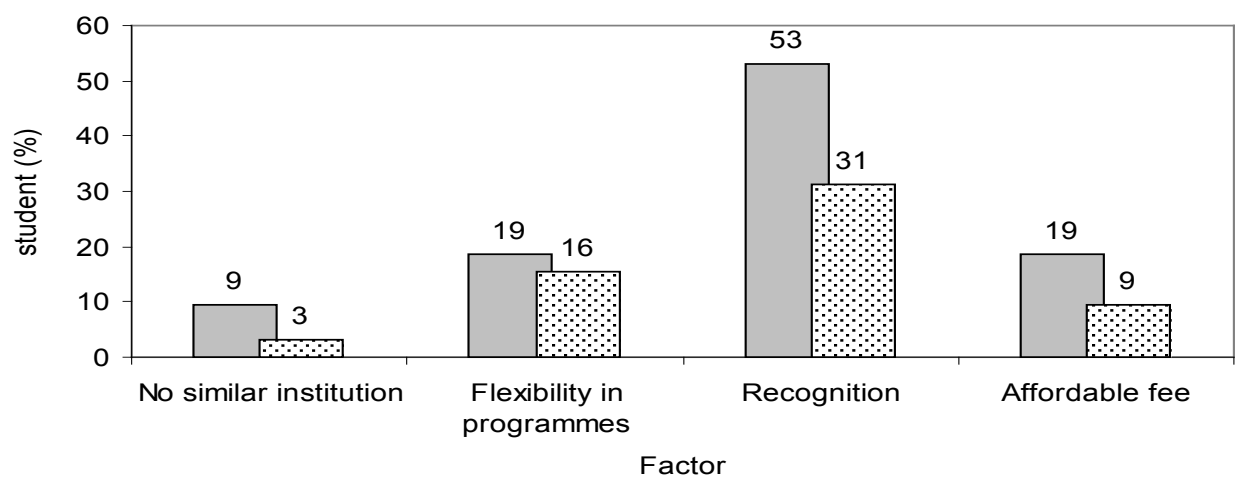

$\square \%$ student $\quad$ S Students with 4 passes at GCE (A/L) examination

Figure 2. Factors affecting enrolment (unsuccessful students).

The students normally consider recognition of a qualification as a key factor in order to secure high-demand employment. In the case of employed students who pursue higher studies for career prospects, the relevance of such programmes plays a major role rather than mere recognition. Enrolling in the ODL programmes because of recognition only, without having proper knowledge of the nature of the study methods, causes difficulties for the teachers and the students themselves. Accompanying high rates of failure, as a consequence, will unfavourably impact on the institution as well as on ODL in general. The faculty in this environment is clever enough to look to students' competence and implement alternative methods of course delivery without deviating much from the distance-learning concept. As many school leavers are joining ODL programmes and they are not familiar with self-learning, in many instances they demand more face-to-face teaching as practised in conventional degree programmes, which can never be met with the limited space and teachers available. But faculty should consider providing them with enhanced student sup- 
port possibly as discussion sessions and web-based interactive learning.

\section{Flexibility in study programmes.}

Flexibility was indicated as the second motivating factor to enrol in the OUSL-ODL engineering programme: $26 \%$ for successful students and $19 \%$ for unsuccessful students. The flexibility in course selection and the time duration for completion are usually welcomed by students as this provides them with room to follow other courses and to be employed.

Flexibility is an essential feature in any ODL programme, especially for the benefit of employed students. The flexibility in time period for completion is needed as these programmes are open for all types of students with different ages, incomes, family engagements, and previous knowledge. Diverse requirements by industry demand a wide range of courses and flexibility in the selection.

\section{Affordable fee structure.}

Affordable course fee was the third most influential factor for enrolment (13\%) for successful students; whereas, for unsuccessful students this was rated the same as flexibility in course selection (19\%). The study proved that students are prepared to pay for courses that are recognized and could be followed without interrupting their other commitments. Another reason for placing course fee in third place could be that flexibility allows students to earn money while studying.

Course fee depends on the total cost incurred in the development and delivery of courses and the government subsidy. Developing open and distance learning programmes involves high expenditures as it is a long process of designing, developing, testing, and implementing. In spite of its initial cost, ODL is considered to be cost effective because a large number of students can benefit, making the cost per student low. The cost incurred in the development process and the recurrent cost, which includes direct costs of print, audio, video etc, is recovered from the course fees. Though the course fees in ODL courses are less than that of a conventional programme, this amount too is sometimes not affordable to the students in developing countries like Sri Lanka. Therefore, a part of the ODL expenditure has to be borne by the government as distance education immensely contributes to the national educational needs of the nation, which in turn contribute in a productive manner to the national, economic, and social development of the country. In recognition of this fact fees charged for ODL programmes in Sri Lanka have been kept to a minimum. Usually the students pay only one third of the actual cost. This is much less than the private sector conventional-type study programmes. This is one reason that a large section of the population chooses distance learning programmes, giving less attention to the real nature of the system in which students' commitment, self-motivation, and relevance are very important but are ignored.

\section{Nonexistence of similar institutions.}

Eighteen percent and 9\% from successful and unsuccessful students respectively indicated 
that the deciding factor was the nonavailability of similar institutions offering study programmes in engineering.

The OUSL, being the only recognized institution in Sri Lanka to offer ODL programmes, at present, has the great advantage of attracting good students because of its recognition by the students as a government institution. However, it is also clear that if there were other avenues for students to turn for their higher studies, the OUSL would lose many students. Under these circumstances the University will have to critically consider the factors influencing students' failure, without blaming the unqualified students who are being enrolled, which is a perception of a significant number of staff members.

\section{Performance Based on Level of Secondary Education}

The students' performance at the G. C. E. (A/L) examination in the mathematics stream was examined with the successful studying in the ODL programme. In this study the number of students gaining eligibility (EL) or noneligibility (NE) is related to the number of passes the students obtained at their G.C.E. (A/L) examination.

In the sample selected, $77 \%$ of students had 4 passes in the G.C.E. (A/L) examination, of which $61 \%$ were successful. Eighty percent of the students were unsuccessful from among those who had only 2 passes. This is a clear indication that the students with good performance in secondary education can cope better in ODL than poorer performing students. It is unsurprising that those who have made a commitment and are prepared to face challenges in the highly competitive G.C.E. (A/L) examination can proceed without any difficulty in ODL programmes as well.

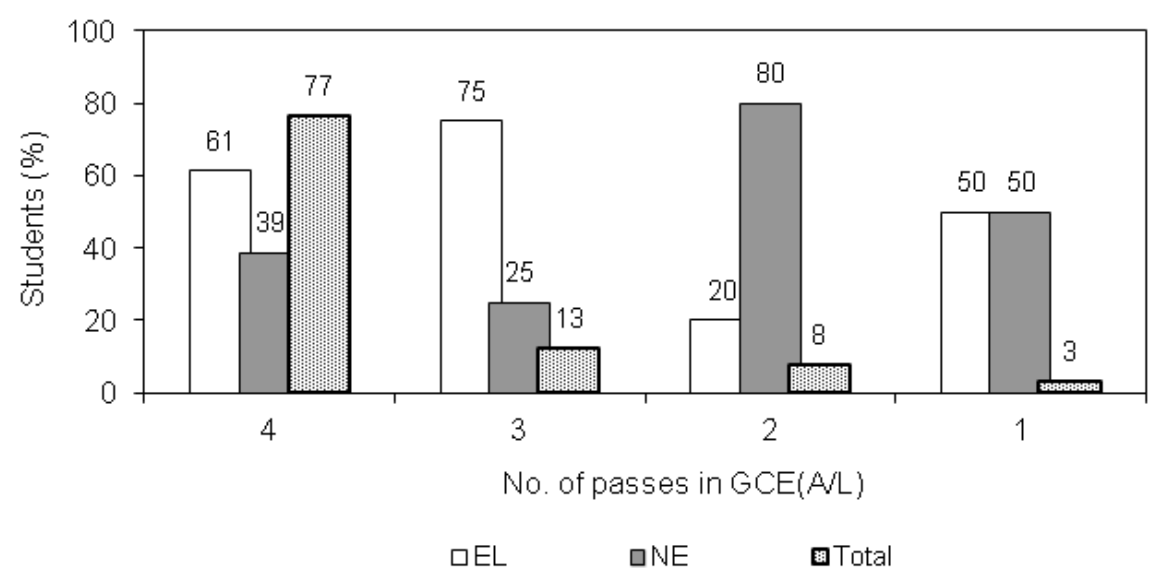

Figure 3. Performance of students according to passes in G.C.E. (A/L) examination.

Young students with successful secondary education do better in distance education programmes and therefore it is the responsibility of the faculty to recognize their commitment and capabilities and remove unnecessary constraints imposed on credits per year and inappropriate course prerequisites. This type of restructuring in ODL programmes is needed for the benefit of the students who are not employed and have performed well in secondary 
education and are joining the ODL programmes not as a second choice but as their first choice because of specific advantages of the ODL programmes. At the same time, the opportunity opened for employed students should remain as a second chance for them to study towards recognized degrees and secure employment prospects.

\section{Awareness of Students of ODL Programmes at OUSL}

Most students were aware of the main features of the study method adopted in ODL. Only $41 \%$ of students knew about the continuous assessment methods and the programme duration at the time of enrolment.

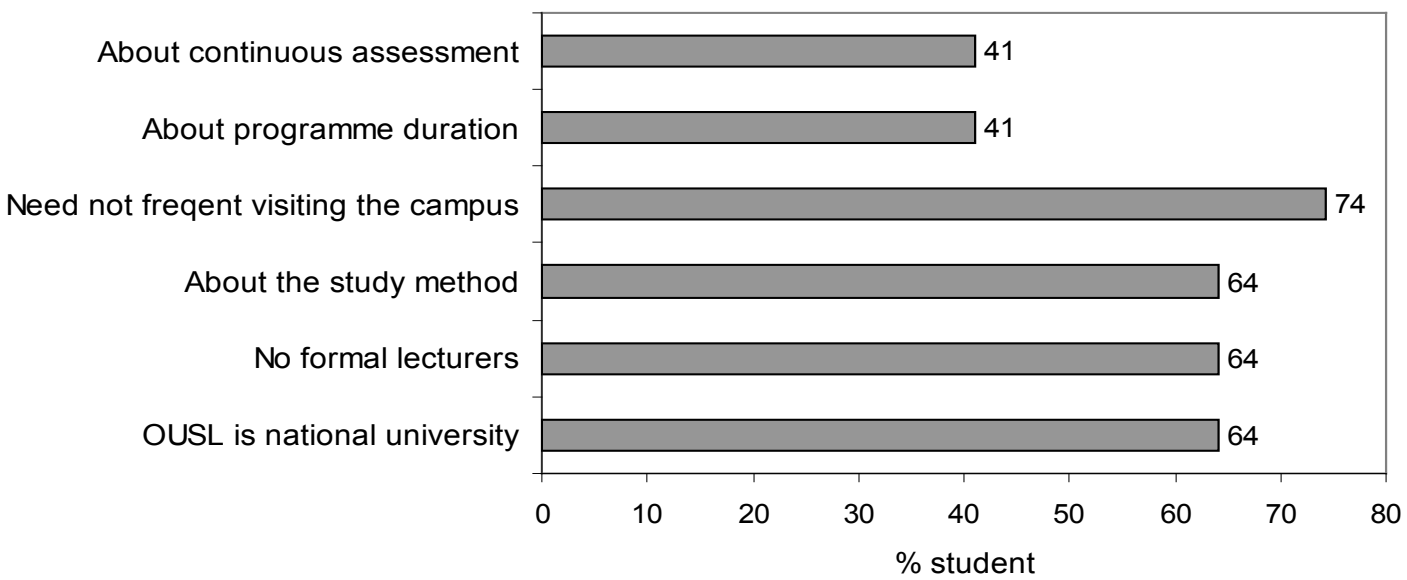

Figure 4. Awareness of the students about the ODL programmes.

\section{Students' Feedback on Course Delivery}

The students questioned on different aspects of course delivery responded quite consistently, giving their overall attitude towards the ODL as well as shortcomings of the delivery system. Course delivery in ODL includes providing instructional materials as well as guiding students by various means such as assignments, classroom tests, group projects, personal tutoring, and feedback. The main medium for bridging the gap between the teacher and the student in this programme of study is printed materials. The students were critical of the language, subject content, depth of subject matter, and readability of the print. 


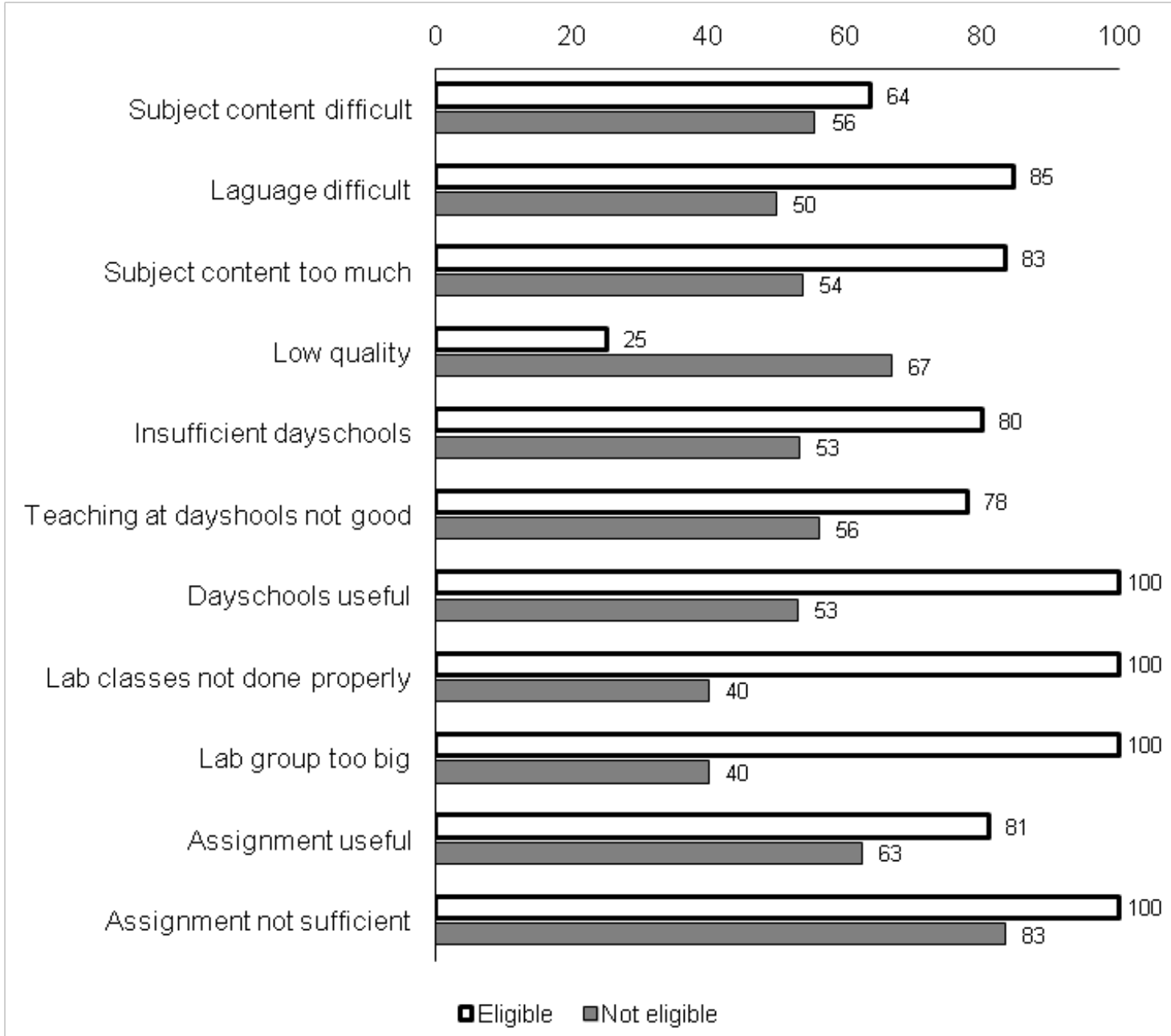

Figure 5. Students' response to different aspects in distance teaching.

Most successful students were not satisfied with many aspects of the course delivery and associated activities. They were particularly concerned about difficult subject content, too much subject content, language difficulty, insufficient day classes, and large lab groups. More importantly, all successful students indicated that the day schools were useful, but $78 \%$ said teaching at the day schools was not good. A serious concern was that all the successful students responded negatively to lab classes, indicating that lab classes were not properly done and class sizes were too large. With regard to assignments, all successful students were of the view that the number of assignments was not sufficient; 81\% said assignments were useful. Generally, the students responded negatively to course delivery aspects, indicating difficult subject content (64\%), language difficulty (85\%), and too much subject content (83\%).

\section{Discussion and Conclusions}

The study revealed that many students had chosen the ODL programme in engineering because of the recognition of the OUSL awards (53\%). This is not surprising given the present situation in the country. When choosing a study programme, everyone's deciding factor 
is directed towards finding a job which requires a recognized qualification. Many students who have no mathematical background at the secondary education level opt to enroll for technology programmes especially computer technology with the opinion that Engineering or Technology qualifications are in high demand in the job market.

A majority of students with good G. C. E. (A/L) examinations was successful in obtaining eligibility to sit the year-end examinations. The students having good G. C. E. (A/L) but who failed in ODL courses had selected the programme possibly based on incorrect reasons. While accepting that the G.C.E (A/L) qualified students can do better in the ODL engineering programme, they should be made aware of the ODL system before enrolling. At the same time, other students should be taught engineering foundation courses with more face-to-face teaching and gradually shifted to the complete ODL methods.

The least influential factors in selecting the ODL engineering programme were the nonexistence of similar institutions offering programmes suited to their needs and the course fees. This is a positive aspect of OUSL study programmes.

With regard to key features of course delivery, the faculty should rectify the shortcomings of face-to-face teaching sessions, lab classes, continuous assessment tests, and course materials. The faculty is responsible for providing necessary course materials and course guidance according to a well-defined timetable to make sure that the students follow the courses in a fruitful manner. It is also the duty of the staff to support the students to solve problems related to programme administration. In this sense distance teaching needs more responsibility on the part of academics than conventional teaching.

Therefore in an ODL system everything needs to be planned beforehand, and anticipated difficulties should be identified in advance. Although the successfulness of an ODL programme is heavily dependent on the student approach and commitment, the responsibility of the academic staff cannot be diluted.

The students need to have a number of characteristics, such as tolerance for ambiguity, a need for autonomy, and an ability to be flexible, in order to be successful in ODL. Further, they need to be focussed, strong time managers, and capable of working independently with group members. Many distance learners are different from traditional undergraduates because they are already in professions. They have well-defined goals and are more motivated. However, many students undertaking ODL programmes are not meeting these requirements, and naturally the programmes designed for mature experienced students do not suit them.

Students' erroneous perception of ODL was one of the reasons for unsuccessfulness in distance learning. Some less important factors lead students to select study programmes in distance learning without careful thought given to their readiness to adjust to the system. This will result in failure in courses. The fact that the study programmes in distance learning need more student commitment, self-motivation, good time management, and group learning skills are usually undermined, and factors like recognition of the awards, flex- 
ibility, and comparatively low fees play a great role in attracting more students, especially when there are very few avenues for higher studies. 


\section{References}

Ashby, A. (2004). Monitoring student retention in the Open University: Detritions, measurement, interpretation and action. Open Learning, 19(1), 65-78.

Barat, I.F., Lalita, S. Kumar, \& Kannan, S. (2006). A survey of a study on the reasons responsible for student dropout from the Bachelor of Science Programme at Indira Gandhi National Open University. International Review of Research in Open and Distance Learning, 3(1).Retrieved from http://www.irrodl.org/index.php/irrodl/ article/view/291/755

Barefoot, B. O. (2004). Higher education revolving door: Confronting the problem of student dropout in US colleges and university, Open Learning, 19(1), 9-18.

Brown, K.M. (1996). The role of internal and external factors in the discontinuation of off campus students. Distance education, 17(1), 44-71.

Dibiase, D. (2000). Is distance education a Faustian bargain? Journal of Geography in Higher Education, 24(1), 130-136.

Powel, R. (1991). Success and persistence at two open universities. Center for Distance Education: Athabasca University.

Threlkeld, R. \& Brezoska, K (1994). Research in distance education. In Willis, B., Distance education strategies and tools. Englewood Cliffs: Educational Technology Publications.

Woodley, A. (2004). Conceptualizing student dropout in part-time distance education: anthologizing the normal? Open Learning, 19(1), 47-64.

\section{Athabasca University $\mathbf{a}$}


THE INTERNATIONAL

REVIEW OF RESEARCH IN

OPEN AND DISTANCE LEARNING

\section{Article Review - Social Presence within the Community of Inquiry Framework}

Author: David Annand (2011). International Review of Research in Open and Distance Learning, 12(5).

Reviewer: D.R. Garrison, University of Calgary, Canada

At the outset, I want to thank David Annand (2011) for his interest in the community of inquiry (CoI) theoretical framework. We welcome all constructive efforts to address its validity and give direction to future study. Moreover, Annand is quite right to address the validity and function of the social presence (SP) construct. I have stated previously "there is much to understand with regard to the construct itself and its relationship to the other presences" (Garrison, 2011, p.35). While there is need of research into this construct, I do not agree with Annand that the CoI framework "does not adequately inform the development of online education theory and practice” (p. 40), and, specifically, that the influence of social presence (SP) is overstated. I argue that much work remains in refining and understanding SP within the CoI framework but that it is an essential construct in a collaborative constructive approach to learning.

Perhaps not surprisingly, I do not agree with David's analysis and interpretation of the studies he has raised. The core problem I wish to focus on here is that we have two very different perspectives. I believe David's critique goes off-track at the outset by not recognizing the paradigmatic assumptions of the CoI framework and the educational purposes and contexts to which it is intended to address. For example, David states that "careful reading" of the research indicates "that students do not attach much value to the group-based influences of social presence" (p. 41). This is certainly true when the learning activities are focused largely on information transmission. In such contexts there is little reason or incentive to engage in collaborative inquiry.

It would seem to me that this critique appears to be coming largely from a distance education perspective, which is very different from the online learning perspective that is the gen- 
esis of the CoI framework (Garrison, 2011; Guri-Rosenblit \& Gros, 2011). The differences in pedagogical perspectives (generations) and the usefulness of the CoI framework in understanding these differences has been rigorously made by Anderson and Dron (2011). The reality is that the CoI theoretical framework with its collaborative constructivist perspective is essentially incompatible with traditional distance education approaches that value independence and autonomy over collaborative discourse in purposeful communities of inquiry (Garrison, 2009). In short, the explanatory value of a CoI approach depends on the educational purpose and context. In this regard, it is important not to conflate two distinct educational paradigms.

The intent of this space does not permit a full defense of a collaborative constructivist approach, a counter-interpretation of selected studies, or a discussion of studies that do confirm the important mediating function of SP in a CoI (this is explored in some detail in Garrison, 2011). However, the literature around critical thinking does provide the evidence that it is very difficult to achieve deep understanding without discourse. While this may be accomplished through Socratic dialogue or in a one-to-one tutorial with a qualified instructor, it is totally impractical in most educational contexts (especially scalable distance education). The CoI theoretical framework is a commitment to personal reflection and critical discourse (both are inherent to the CoI framework and the cognitive presence construct). Discounting SP is to discount the importance of critical discourse in a connected, knowledge-based society. It is also difficult to see how one gains metacognitive awareness and ability without sustained discourse and feedback (Akyol \& Garrison, 2011). This may well be one of the great weaknesses of independent study and didactic approaches.

The CoI is a generic theoretical framework that must be viewed as a means to study collaborative constructivist educational transactions - be they in online, blended, or faceto-face environments. The validation of this framework would also suggest that it can be used as a rubric to test for functioning communities of inquiry. The bottom line is that it is misleading and counter-productive to critique a framework from an incompatible paradigmatic perspective that is not congruent with a context or for a purpose for which it was not intended. Analogically we would never consider mapping a basketball framework onto tennis. While both are sporting events, their assumptions and activities are distinct. The same could be said of the assumptions and activities of independent and collaborative approaches to educational experiences. Both may be considered educational, but they are two very different games.

Certainly I have a different interpretation of most of the studies cited by Annand. I think one of the main problems with CoI research is the tendency to consider every online/blended learning environment is a true community of inquiry design when, in fact, there is little teaching, cognitive, or social presence (students are reliant on independent activities and tests). Most practical applications are imperfect designs and we should expect some ambiguity. Regardless, theoretically and practically there is much evidence for the mediating function of social presence in the studies cited by Annand as well as others not cited. Notwithstanding this, the categories of SP are open to refinement but are not necessarily compatible with independent (or informal) learning activities and should not be critiqued 
from this perspective. In terms of refinement, I have offered a revised definition of SP "as the ability of participants to identify with the group or course of study, communicate purposefully in a trusting environment, and develop personal and affective relationships progressively by way of projecting their individual personalities" (Garrison, 2011, p. 34). The intent of this revised construct was to show the development of SP as well as clarify its interdependence with cognitive and teaching presence.

However, much work remains to refine this and the other presences to understand collaborative constructivist approaches to educational transactions. In this regard, let me add one final point about future CoI studies. That is, empirical validation of the CoI framework is not antithetical to a collaborative constructivist approach as Annand seems to suggest when he states that "the CoI framework has evolved from a description of the learning process in a social constructivist paradigm to an empirically testable construct within an objectivist paradigm" (p. 49). The rationale for this statement escapes me.

In summary, I believe the CoI framework has mistakenly gotten caught in the middle of a higher order philosophical and methodological conflict. This critique seems to be more of an argument for independent study (an objectivist paradigm) and against a collaborative, cohort-based approach (a constructivist paradigm) than it is a valid critique of the CoI theoretical framework. This is a fundamental understanding essential in refining the CoI theoretical framework as we move forward.

\section{References}

Akyol, Z., \& Garrison, D. R. (2011). Assessing metacognition in an online community of inquiry. Internet \& Higher Education, 14(3), 183-190.

Anderson, T, \& Dron, J. (2011). Three generations of distance education pedagogy. International Review of Research in Open and Distance Learning, 12(3), 80-97. Retrieved from http://www.irrodl.org/index.php/irrodl/article/view/890/1663

Annand, D. (2011). Social presence within the community of inquiry framework. International Review of Research in Open and Distance Learning, 12(5), 38-54. Retrieved from http://www.irrodl.org/index.php/irrodl/article/view/924/1855

Garrison, D. R. (2009). Implications of online learning for the conceptual development and practice of distance education. Journal of Distance Education, 23(2), 93-104.

Garrison, D. R. (2011). E-Learning in the 21st century: A framework for research and practice (2nd ed.). London: Routledge/Taylor and Francis.

Guri-Rosenblit, S. \& Gros, B. (2011). E-Learning: Confusing terminology, research gaps and inherent challenges. Journal of Distance Education, 25(1). Retrieved from http:// www.jofde.ca/index.php/jde/article/view/729 
Athabasca University $\mathbf{I}$

(c) $\underset{\mathrm{EY}}{\mathrm{C}}$ 